\title{
A Regional Guidebook for Applying the Hydrogeomorphic Approach to Assessing Wetland Functions of Prairie Potholes
}

Michael C. Gilbert, P. Michael Whited, Ellis J. Clairain, Jr., May 2006 and R. Daniel Smith
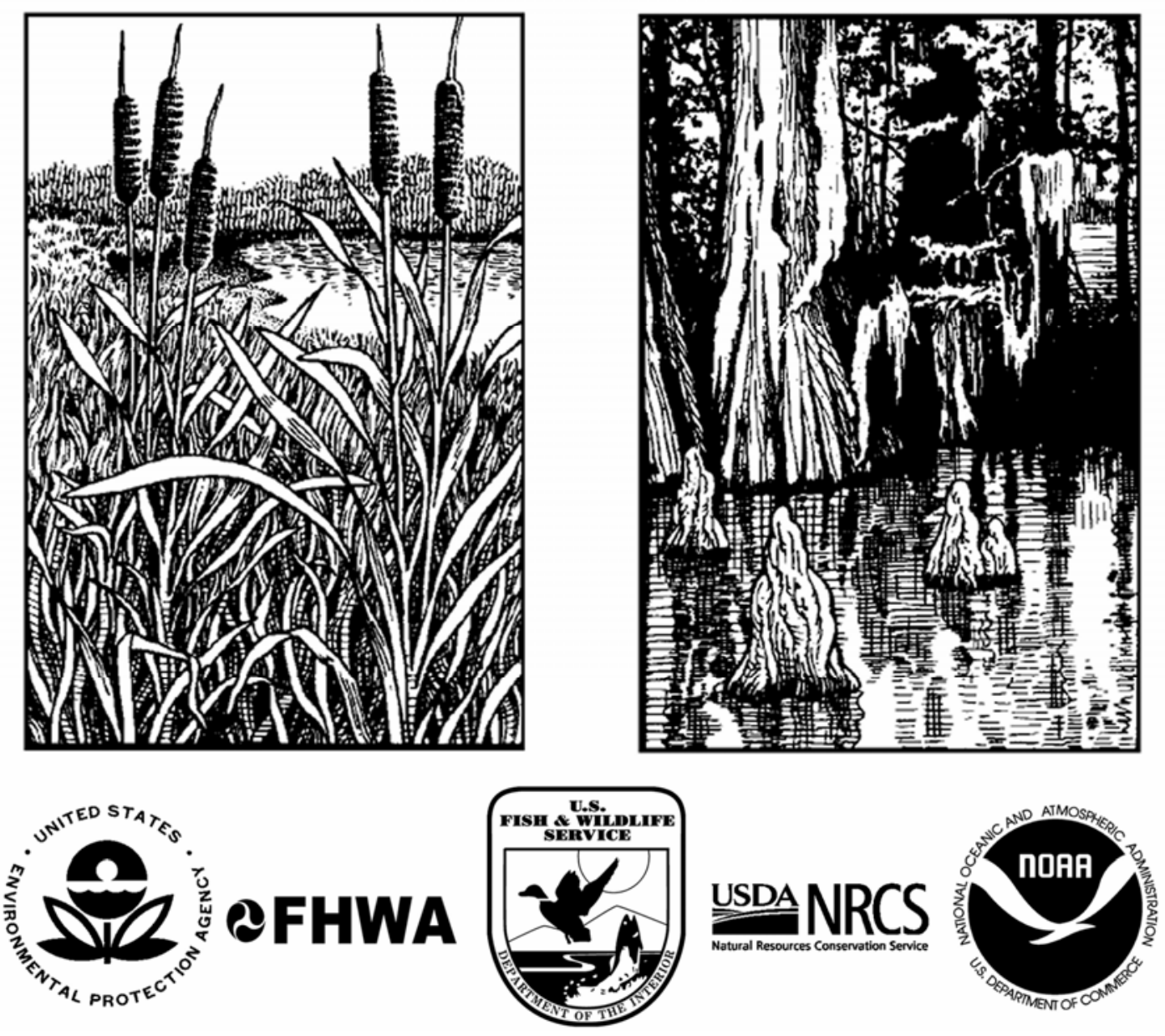


\title{
A Regional Guidebook for Applying the Hydrogeomorphic Approach to Assessing Wetland Functions of Prairie Potholes
}

\author{
Michael C. Gilbert \\ U.S. Army Engineer District, Omaha \\ 106 S. 15th Street \\ Omaha, NE 68102 \\ P. Michael Whited \\ National Resource Conservation Service \\ U.S. Department of Agriculture \\ 52 Boyden Road \\ Holden, MA 01520 \\ Ellis J. Clairain, Jr., and R. Daniel Smith \\ Environmental Laboratory \\ U.S. Army Engineer Research and Development Center \\ 3909 Halls Ferry Road \\ Vicksburg, MS 39180-6199
}

Final report

Approved for public release; distribution is unlimited 


\begin{abstract}
The Hydrogeomorphic (HGM) Approach is a method for developing functional indices and the protocols used to apply these indices to the assessment of wetland functions at a site-specific scale. The HGM Approach was initially designed to be used in the context of the Clean Water Act, Section 404 Regulatory Program, permit review to analyze project alternatives, minimize impacts, assess unavoidable impacts, determine mitigation requirements, and monitor the success of compensatory mitigation. However, a variety of other potential uses have been identified, including the determination of minimal effects under the Food Security Act, design of wetland restoration projects, and management of wetlands.

This report uses the HGM Approach to develop a Regional Guidebook to (a) characterize ponded, herbaceous marshes of the glaciated Prairie Pothole Region, (b) provide the rationale used to select functions of the ponded, herbaceous depressional marsh subclass, (c) provide the rationale used to select model variables and metrics, (d) provide the rationale used to develop assessment models, (e) provide data from reference wetlands and document its use in calibrating model variables and assessment models, and (f) outline the necessary protocols for applying the functional indices to the assessment of wetland functions.
\end{abstract}

DISCLAIMER: The contents of this report are not to be used for advertising, publication, or promotional purposes. Citation of trade names does not constitute an official endorsement or approval of the use of such commercial products. All product names and trademarks cited are the property of their respective owners. The findings of this report are not to be construed as an official Department of the Army position unless so designated by other authorized documents. 


\section{Assessing Wetland Functions}

\section{A Regional Guidebook for Applying the Hydrogeomorphic Approach to Assessing Wetland Functions of Prairie Potholes (ERDC/EL TR-06-5)}

ISSUE: Section 404 of the Clean Water Act directs the U.S. Army Corps of Engineers to administer a regulatory program for permitting the discharge of dredged or fill material in "waters of the United States." As part of the permit review process, the impact of discharging dredged or fill material on wetland functions must be assessed. On 16 August 1996, a National Action Plan to Implement the Hydrogeomorphic Approach (NAP) for developing Regional Guidebooks to assess wetland functions was published. This report is one of a series of Regional Guidebooks that will be published in accordance with the National Action Plan.

RESEARCH OBJECTIVE: The objective of this research was to develop a Regional Guidebook for applying the Hydrogeomorphic Approach to depressional wetlands in the Prairie Pothole Region in a planning and ecosystem restoration context.

SUMMARY: The Hydrogeomorphic (HGM) Approach is a collection of concepts and methods for developing functional indices and subsequently using them to assess the capacity of a wetland to perform functions relative to similar wetlands in a region. The Approach was initially designed to be used in the context of the Clean Water Act Section 404 Regulatory Program permit review sequence to consider alternatives, minimize impacts, assess unavoidable project impacts, determine mitigation requirements, and monitor the success of mitigation projects. However, a variety of other potential applications for the Approach have been identified, including determining minimal effects under the Food Security Act, designing mitigation projects, and managing wetlands.

AVAILABILITY OF REPORT: The report is available at the following Web sites: http://www.wes.army.mil/el/wetlands/wlpubs.html or http://libweb.wes.army.mil/index.htm. The report is also available on Interlibrary Loan Service from the U.S. Army Engineer Research and Development Center (ERDC) http://libweb.wes. army.mil/lib/library.htm

About the Authors: Michael C. Gilbert is a Wetland Ecologist in the Omaha District; P. Michael Whited is a Soil Scientist in the Natural Resources Conservation Service; Dr. Ellis J. Clairain, Jr., is a Research Biologist, and R. Daniel Smith is a Research Ecologist in the Environmental Laboratory, U.S. Army Engineer Research and Development Center (ERDC).

Points of Contact are Mr. Gilbert at (402) 221-3057, email Michael.C.Gilbert@us.army.mil, and Mr. Glenn G. Rhett, Ecosystem Management and Restoration Research Program Manager, ERDC, (601) 634-3717, e-mail Glenn.G.Rhett@erdc.usace.army.mil. 


\section{Contents}

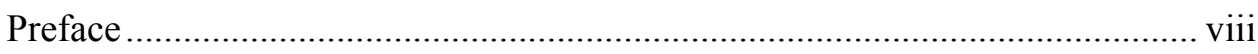

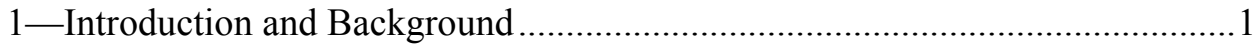

2-Overview of the Hydrogeomorphic Approach ..............................................4

Development and Application Phases .......................................................

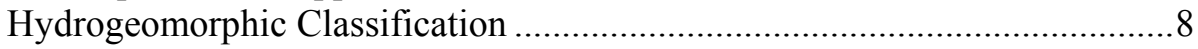

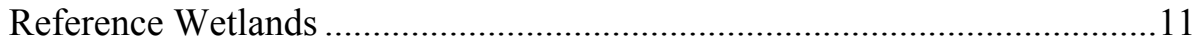

Assessment Models and Functional Indices ................................................12

Assessment Protocol ..................................................................................... 13

3 - Characterization of the Temporary and Seasonally Ponded Prairie

Pothole Wetland Ecosystems ........................................................................ 14

Regional Wetland Subclass and Reference Domain....................................14

Description of the Regional Subclass .......................................................15

Landscape setting: physiographic divisions ..........................................15

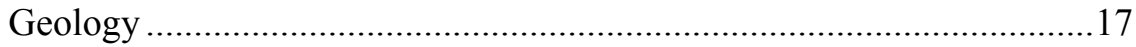

Glacial landforms included in the regional subclass ..............................18

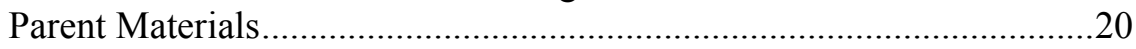

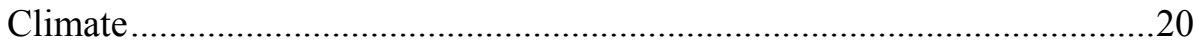

Cyclic Processes and the Reference Standard Cycle ...................................22

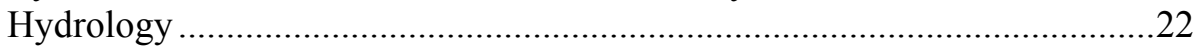

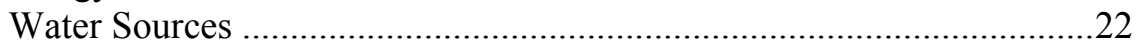

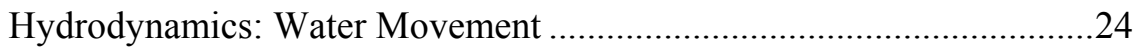

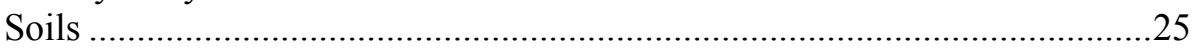

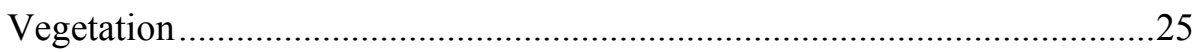

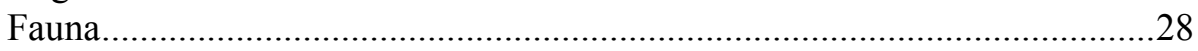

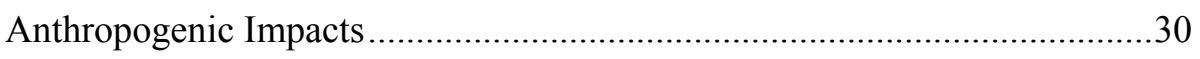

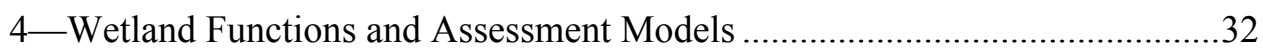

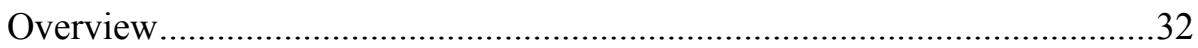

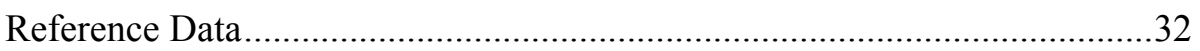

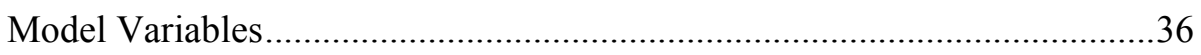

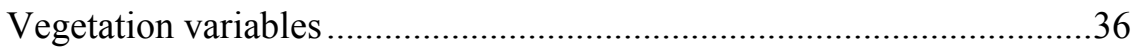

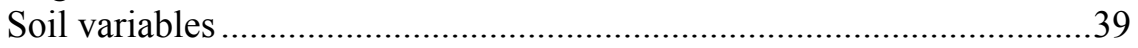

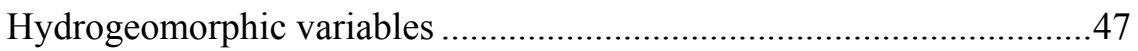

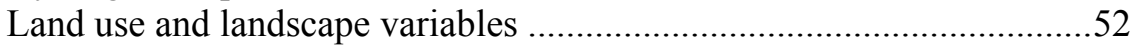

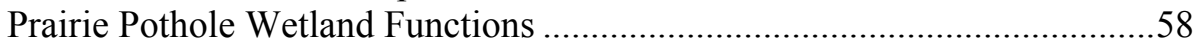

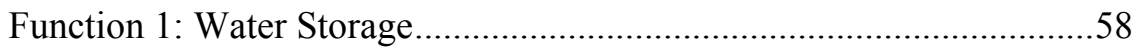




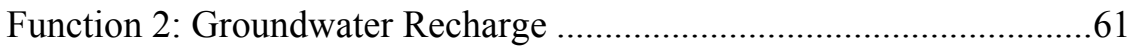

Function 3: Retain Particulates................................................................63

Function 4: Remove, Convert, and Sequester Dissolved Substances......66

Function 5: Plant Community Resilience and Carbon Cycling...............69

Function 6: Provide Faunal Habitat.......................................................73

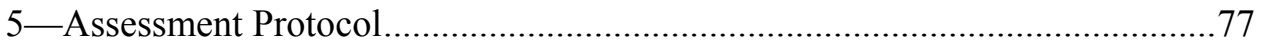

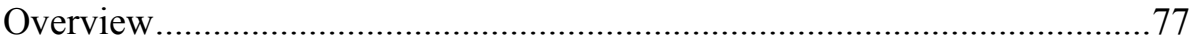

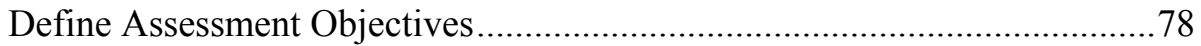

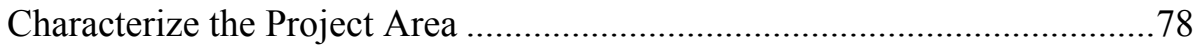

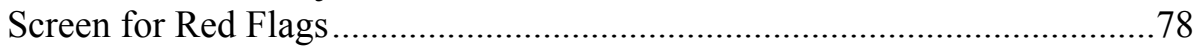

Define the Wetland Assessment Area..............................................................80

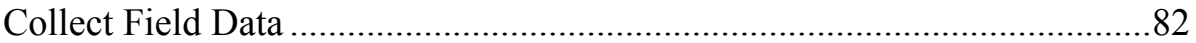

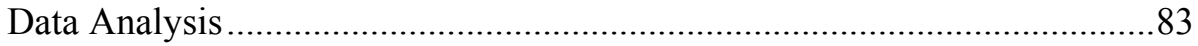

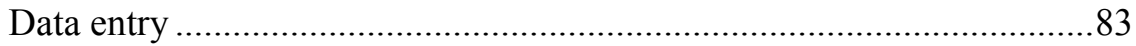

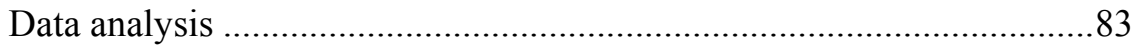

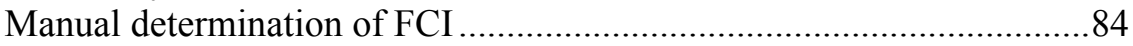

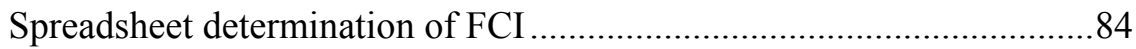

Apply the Results of the Assessment ........................................................8

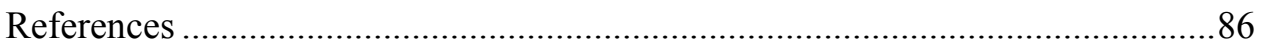

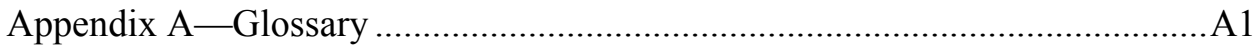

Appendix B - Summary of Functions, Variables and Spreadsheets .................. B1

Appendix B-1: Summary of Functions for Prairie Pothole Depressional

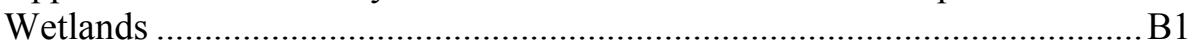

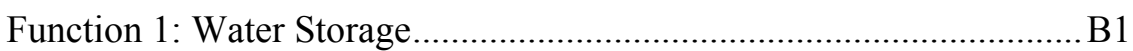

Function 2: Groundwater Recharge .................................................. B2

Function 3: Retain Particulates............................................................. B3

Function 4: Remove, Convert, and Sequester Dissolved Substances.....B3

Function 5: Plant Community Resilience and Carbon Cycling.............. B4

Function 6: Provide Faunal Habitat...................................................... B5

Appendix B-2: Summary of Model Variables ........................................... B7

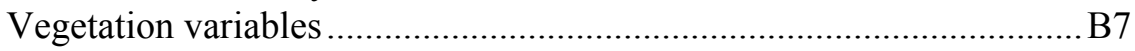

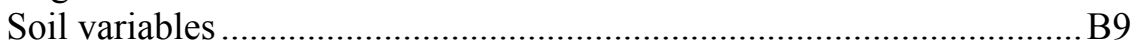

Hydrogeomorphic variables ........................................................ B14

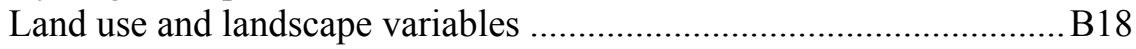

Appendix B-3: Functional Capacity Index Spreadsheets and Calculator

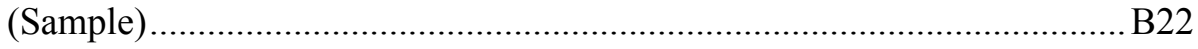

Appendix C - Reference Data and Supporting Documentation........................... 1

Appendix C-1: Reference Site Locations ……............................................. 1

Appendix C-2: Plant Species Records from Reference Data Collection ....... 5

Appendix C-3: Alternate Methods for Calculation of $V_{V E G C O M P} \ldots \ldots \ldots \ldots \ldots . . . . . . . .14$

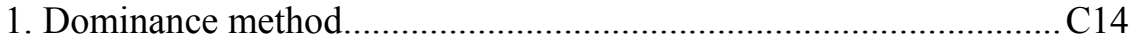

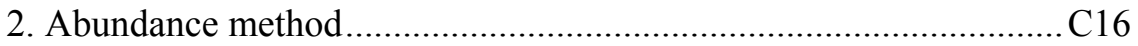

Appendix C-4: Recharge Ratings for Soil Mapping Units ......................... 17

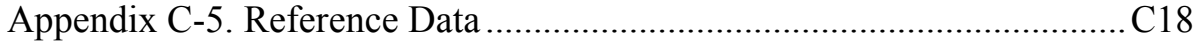

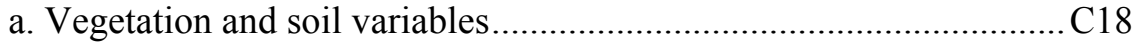

b. Hydrogeomorphic, land use and landscape variables......................... 22 


\section{List of Figures}

Figure 1. Schematic of development and application phases of the

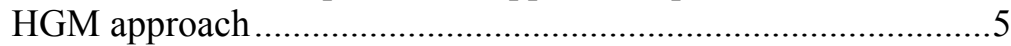

Figure 2. The Prairie Pothole Region of North America ............................16

Figure 3. Aerial oblique of the Missouri Coteau, North Dakota illustrating non-integrated surface drainage

Figure 4. Aerial oblique of prairie pothole wetlands in an agricultural landscape matrix, Glaciated Plains, North Dakota

Figure 5. Water level changes during the ice-free season over a 6year period in a seasonal basin wetland in North Dakota

Figure 6. Generalized Stewart and Kantrud (1971) wetland classes and vegetation zones discussed in this Guidebook .26

Figure 7. Generalized plan view of vegetation zones in relation to the catchment 35

Figure 8. Landscape assessment area associated with a reference site in Stutsman County, North Dakota 35

Figure 9. Relationship between the continuity of grassland adjacent to the wetland and the variable subindex .37

Figure 10. Relationship between the grassland width perpendicular to the assessment wetland and the variable subindex..................38

Figure 11. Relationship between the FQI and the variable subindex ..........40

Figure 12. Relationship between the B horizon depth and the variable sub-index for Western and Eastern Prairie Potholes

Figure 13. Relationship between the Soil Quality Index and the variable subindex

Figure 14. Relationship of the Soil Quality Index to soil organic carbon

Figure 15. Relationship of the Soil Quality Index to Soil Bulk Density .....

Figure 16. Relationship between the mean percent organic carbon and the variable subindex

Figure 17. Relationship between the ratio of the constructed outlet elevation to the natural outlet elevation and the variable subindex

Figure 18. Relationship between the shoreline irregularity index and the variable sub-index. 
Figure 19. Relationship between the ratio of catchment area to wetland area and the variable subindex

Figure 20. Relationship between the curve number and the variable subindex

Figure 21. Example of inter-wetland distance measurements for

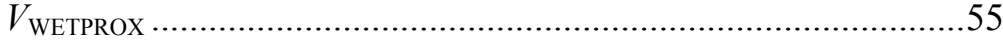

Figure 22. Relationship between the mean inter-wetland distance and the variable subindex

Figure 23. Relationship between wetland area in the LAA and the variable subindex 56

Figure 24. Relationship between the number of basins in the LAA and the variable subindex

Figure 25. Relationship between the length of linear features in the LAA and the variable subindex..............................................58

Figure 26. A single WAA within a project area .......................................... 80

Figure 27. Spatially separated WAA from the same regional wetland project area .81

Figure 28. Spatially separated WAAs from different regional wetland subclasses within a project area .81

Figure 29. WAA defined based on differences in site specific characteristics .82

Figure 30. Sample spreadsheet for data entry and FCI calculations.............85

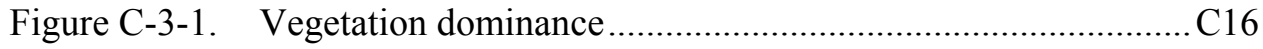

Figure C-3-2. Vegetation composition.......................................................... 17

\section{List of Tables}

Table 1. Contributors to the Regional Guidebook ……............................

Table 2. Hydrogeomorphic Wetland Classes ........................................... 9

Table 3. Potential Regional Wetland Subclasses in Relation to Classification Criteria............................................................ 11

Table 4. Reference Wetland Terms and Definitions ................................12

Table 5. Prairie Pothole Region Climatic Data ........................................21

Table 6. $\quad$ Stewart and Kantrud (1971) Classification

Corresponding to the Prairie Pothole HGM Depressional

Subclass Described in This Regional Guidebook .....................27

Table 7. Estimated Wetland Losses for States Within the Prairie Pothole Region .31 
Table 8. Information Collected at Reference Sites by Scale and

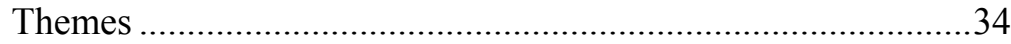

Table 9. Qualitative Method to Determine Soil Recharge

Potential............................................................................ 41

Table 10. Soil Characteristics Evaluated in Determination of the Physical Soil Quality Index .....................................................43

Table 11. $\quad V_{\text {SUBOUt }}$ Categorical Variable ..................................................50

Table 12. $\quad V_{\text {SOURCE }}$ Categorical Variable .................................................51

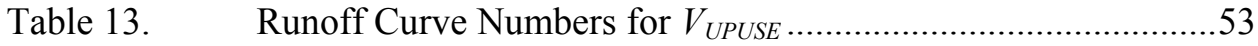

Table 14. Red Flag Features and Respective Program/Agency

Authority .79 


\section{Preface}

This report was prepared by Michael C. Gilbert, Regulatory Program, U.S. Army Engineer District, Omaha; P. Michael Whited, Wetland Science Institute, National Resource Conservation Service (NRCS); Dr. Ellis J. Clairain, Jr., and R. Daniel Smith, Environmental Laboratory (EL), U.S. Army Engineer Research and Development Center, Vicksburg, MS.

Funding was provided by the U.S. Department of Agriculture - National Resource Conservation Service, U.S. Army Engineer Research and Development Center, and the U.S. Army Engineer District, Omaha.

This report further develops the HGM procedure for prairie potholes originally articulated in the initial draft 1997 "Guidebook for the Hydrogeomorphic Assessment of Temporary and Seasonal Prairie Pothole Wetlands." The significant involvement of Dr. Lyndon Lee, Dr. Mark Brinson, Dr. Wade Nutter, and Dr. Dennis Whigham is appreciated.

The authors wish to acknowledge the efforts of the following people for assistance with developing the classification, characterizing the regional subclasses, conducting field sampling, and reviewing drafts of the Regional Guidebook: Dave Dewald, (NRCS), Bismarck, ND, Paul Rodrigue, (NRCS), Starkville, MS, Mark Anderson, Roy Boschee, Rod O'Clair, Norm Prochnow, and Hal Weiser, (NRCS), Jamestown, ND, Bill Bicknell, U.S. Fish and Wildlife Service (USFWS), Bismarck, ND, and Dr. Robert Gleason, Dr. Ned Euliss, and Deb Buhl of the U.S. Geological Survey-Northern Prairie Science Center (USGSNPSC), Jamestown, ND.

Catherine Juhas, Laura Banker, Karen Lawrence, and Brad Quayle, U.S. Army Engineer District, Omaha, assisted with the collection and analysis of reference wetland data.

The authors thank the members of the original Jamestown, ND, workshop held on June 19-21, 1995. These members include: Sandra Byrd (NRCS); Dr. Lewis Cowardin, Dr. Ned Euliss, Jr., Dr. Glenn Guntenspergen, Harold Kantrud (USGS-NPSC); Dr. Daniel Hubbard, South Dakota State University (SDSU), Northern Prairie Science Center (NPSC); Dr. Janet Keogh (NPSC); Dennis Magee (Normandeau Associates); Dr. Jimmie Richardson, North Dakota State University; Dr. Loren Smith (Texas Tech. University); Dr. George Swanson and Dr. Arnold van der Valk (Iowa State University); Dr. Milton Weller and James Winters (Corps of Engineers). 
The authors also thank Billy Teels, Alan Browder, and James Lowe of NRCS. They supported the project, developed scopes of work, and performed the contracting throughout the journey. Laura Mazanti initiated the project; her enthusiasm was contagious.

This work took place under the general supervision of Dr. Billy Teels, Director, NRCS Wetland Science Institute, and Dr. Russell F. Theriot, Program Manager, Environmental Laboratory, Characterization and Restoration of Wetlands Research Program, U.S. Army Engineer Research and Development Center, Vicksburg, MS.

Commander and Executive Director of ERDC was COL James R. Rowan. Director was Dr. James R. Houston. 


\section{Introduction and Background}

The Hydrogeomorphic (HGM) Approach is a collection of concepts and methods used collectively to develop functional indices and apply them to the assessment of wetlands. The HGM approach was initially intended to be used in the context of the Clean Water Act, Section 404 Regulatory Program permit review, to analyze project alternatives, minimize impacts, assess unavoidable project impacts, determine mitigation requirements, and monitor the success of compensatory mitigation. However, a variety of other potential applications for the approach have been identified, including determining minimal effects under the Food Security Act, designing mitigation projects, providing wetland restoration design standards, and aiding in wetlands management.

In the HGM Approach, the functional indices and assessment protocols used to assess a specific type of wetland in a specific geographic region are published in a document called a Regional Guidebook. Guidelines for developing Regional Guidebooks were published in the National Action Plan (National Interagency Implementation Team 1996) developed cooperatively by the U.S. Army Corps of Engineers (COE), U.S. Environmental Protection Agency (USEPA), Natural Resources Conservation Service (NRCS), Federal Highways Administration (FHWA), and U.S. Fish and Wildlife Service (USFWS). The Action Plan, available online at $h t t p: / / w w w . e p a . g o v / O W O W / w e t l a n d s / s c i e n c e / h g m . h t m l$ outlines a strategy for developing Regional Guidebooks throughout the United States, provides guidelines and an explicit set of tasks required to develop a Regional Guidebook under the HGM Approach, and solicits the cooperation and participation of Federal, state, and local agencies, academia, and the private sector.

In the context of the current set of Federal rules, regulations, and policies, the Natural Resources Conservation Service (NRCS) has the mandate to assist and cooperate with Federal, state and local agencies to restore and maintain the physical, chemical, and biological integrity of the Nation's waters. NRCS responsibilities are especially important in the agricultural environments of our Nation. In working to achieve the statutory and policy goals set before it, NRCS often has the need to assess past, present, or potential impacts to wetlands that are associated with agricultural operations. The scope and direction of NRCS activities and responsibilities on agricultural lands are described, in part, in the Food Security Act of 1985, as amended by the Food, Agriculture, Conservation and Trade Act of 1990, the 1993 President's Federal Wetland Plan, 1996 Farm Bill, 
Federal Agricultural Improvement and Reform Act of 1996, 2002 Farm Bill, The Farm Security and Rural Investment Act of 2002, and the third edition of the National Food Security Act Manual (NFSAM). For example, the current versions of the NFSAM require that NRCS assess wetland functions as part of the minimal effect procedures. Assessment of wetland functions is also a key step during NRCS analyses of wetland mitigation plans, and as a part of NRCS evaluation of restoration efforts in degraded wetlands. This Guidebook provides an additional tool for NRCS, COE, and others to conserve, restore, and manage prairie pothole wetlands.

The objectives of this Regional Guidebook are to:

a. Characterize temporary and seasonal prairie pothole wetland ecosystems based on the factors that influence wetland function, including the hydrogeomorphic classification factors identified by Brinson (1993).

$b$. Present the rationale used to select functions for this subclass of depressional regional wetlands.

c. Present the rationale used to select assessment variables and metrics.

d. Present the rationale used to develop assessment models.

$e$. Provide data from reference wetlands and document their use in the calibrating of assessment models.

$f$. Describe the protocols for the assessment of wetland functions in temporary and seasonal prairie pothole wetland ecosystems throughout the Prairie Pothole Region (PPR).

The document is organized in the following manner. Chapter 1 provides the background, objectives, and organization of the document. Chapter 2 provides a brief overview of the components and application of the HGM Approach. Chapter 3 characterizes the temporary and seasonal prairie pothole wetland sub-class in the PPR included in this guidebook. Chapter 4 discusses the variables used in the assessment models, wetland functions, and functional indices. The discussion includes:

a. Definition, description, and measurement techniques of model variables and variable sub-index graphs or condition categories.

$b$. Definition of the function and a quantitative, independent measure of the function for validation.

c. Rationale for choosing the function.

d. Description of the wetland ecosystem and landscape characteristics that influence the function.

e. Brief description of variables used to represent these characteristics in the assessment model.

$f$. Functional Capacity Index (FCI) model and a discussion of how model variables were combined to derive the functional index.

Chapter 5 outlines the steps and protocols that are necessary to conduct an assessment, including field forms and other information. Appendix A is a 
glossary of terms, Appendix B provides spreadsheets for analyzing the data collected during the assessment, and Appendix $\mathrm{C}$ provides the information necessary to access the reference wetland data and spatial information collected during the project. Although it is possible to begin the assessment process immediately using the information in Chapter 5, we advise that potential users first familiarize themselves with the information in Chapters 2-4. 


\section{Overview of the Hydrogeomorphic Approach}

\section{Development and Application Phases}

The Hydrogeomorphic Approach (HGMA) to Wetland Functional Assessment is a collection of concepts and methods that are used to develop and apply functional indices to the assessment of wetlands (Smith et al. 1995). The HGMA includes four integral components: 1) HGM classification, 2) reference wetlands, 3 ) assessment variables and assessment models from which functional indices are derived, and 4) application protocols. The four components of the HGMA are integrated into a regional, subclass-specific guidebook, like this document.

In the Development Phase of the HGMA, research scientists and regulatory managers work cooperatively to select a list of functions and indicators of function that will best represent the functional range of variation among wetlands of the subclass and region. Data are gathered by an Assessment Team (A-Team) from an array of wetlands that represent that range of variation; the A-Team then establishes a data set of Reference Wetlands. The assessment models and data are combined, along with field protocols and methods for analysis, to formulate the Regional Guidebook. The end-users then employ the Regional Guidebook during the Application Phase to conduct HGM functional assessments on project wetlands. Each of these components of the HGMA is discussed briefly below. More extensive discussions of these topics can be found in Brinson (1993, 1995a, 1995b), Brinson et al. (1995, 1998), Hauer and Smith (1998), Smith et al. (1995), Smith (2001), Smith and Wakeley (2001), and Wakeley and Smith (2001).

The task of the A-Team is to develop and integrate the classification, reference wetland, assessment variables, models, and application protocol components of the HGM Approach into a Regional Guidebook (Figure 1). In developing a Regional Guidebook, the team completes the tasks outlined in the National Action Plan (National Interagency Implementation Team 1996). These tasks include: 


\section{Hydrogeomorphic Approach}

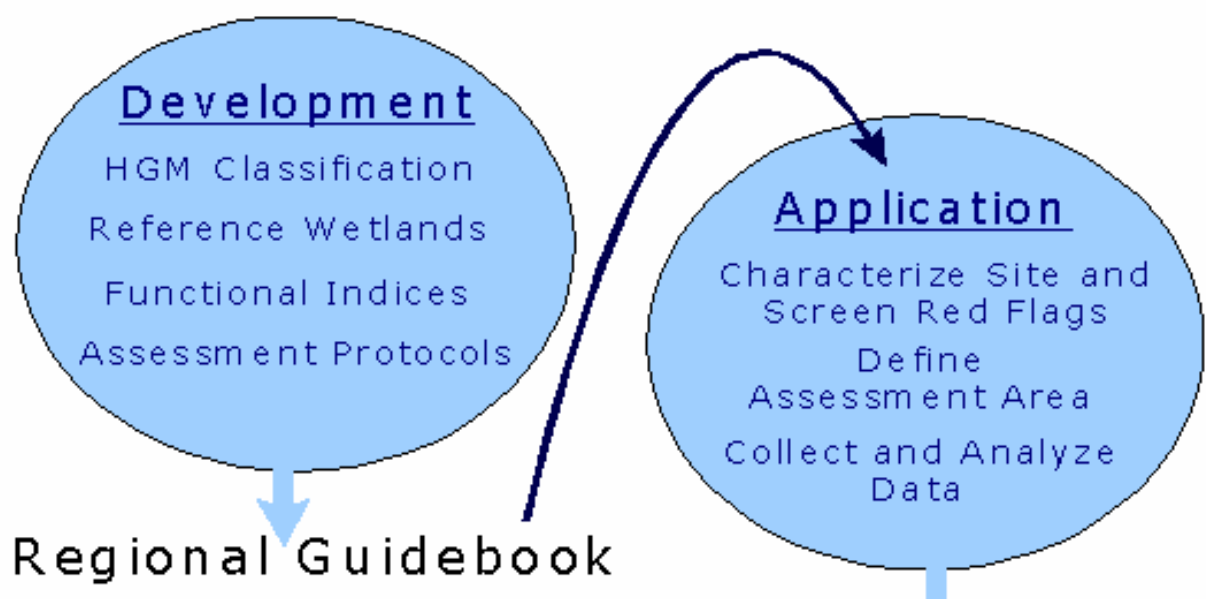

Functional Indices

Figure 1. Schematic of development and application phases of the HGM approach

Task 1: Organize the A-Team.

A. Identify team members.

B. Train team in the HGM Approach.

Task 2: Select and Characterize Regional Wetland Subclass.

A. Identify and prioritize regional wetland subclasses.

B. Select regional wetland subclass and define reference domain.

C. Initiate literature review.

D. Develop preliminary characterization of regional wetland subclass.

E. Identify and define wetland functions.

Task 3: Select Assessment Variables and Metrics and Construct Conceptual Assessment Models.

A. Review existing assessment models.

B. Identify assessment variables and metrics.

C. Define initial relationship between assessment variables and functional capacity.

D. Construct conceptual assessment models for deriving functional capacity indices.

E. Complete Precalibrated Draft Regional Guidebook (PDRG).

Task 4: Conduct Peer Review of PDRG.

A. Distribute PDRG to peer reviewers.

B. Conduct interdisciplinary, interagency workshop of PDRG.

C. Revise PDRG to reflect peer review recommendations.

D. Distribute revised PDRG to peer reviewers for comment.

E. Incorporate final comments from peer reviewers on revisions into the PDRG. 
Task 5: Identify and Collect Data From Reference Wetlands.

A. Identify reference wetland field sites.

B. Collect data from reference wetland field sites.

C. Analyze reference wetland data.

Task 6: Calibrate and Field Test Assessment Models.

A. Calibrate assessment variables using reference wetland data.

B. Verify and validate (optional) assessment models.

C. Field test assessment models for repeatability and accuracy.

D. Revise PDRG based on calibration, verification, validation (optional), and field testing results into a Calibrated Draft Regional Guidebook (CDRG).

Task 7: Conduct Peer Review and Field Test of CDRG.

A. Distribute CDRG to peer reviewers.

B. Field test CDRG.

C. Revise CDRG to reflect peer review and field test recommendations.

D. Distribute CDRG to peer reviewers for final comment on revisions.

E. Incorporate peer reviewers' final comments on revisions.

F. Publish Operational Draft Regional Guidebook (ODRG).

Task 8: Technology Transfer.

A. Train end users in the use of the ODRG.

B. Provide continuing technical assistance to end users of the ODRG.

This Guidebook has been developed by NRCS and the USACE as one component of the National Action Plan and in response to NRCS and USACE needs for a consistent and scientifically based procedure for assessment of functions of wetlands in the Prairie Pothole Region. Specifically, this guidebook addresses functions of the temporary and seasonal wetlands in the prairie pothole region (PPR) of the Midwest and the Northern Plains. Throughout the development and completion of this Guidebook, six teams of wetland experts were integrally involved. Members of the teams are shown below in Table 1.

Initial development of this Guidebook began at a workshop on 19-21 June 1995 in Jamestown, North Dakota. Attendees to the workshop included hydrologists, biogeochemists, soil scientists, wildlife biologists, and plant ecologists, with extensive knowledge of prairie pothole wetlands, from the public, private, and academic sectors. Based on the results of the workshop, a regional wetland subclass was defined and characterized, a reference domain was defined, wetland functions were selected, model variables were identified, and conceptual assessment models were developed. Subsequently, fieldwork was conducted to collect data from reference wetlands in 1996 and 1997. These data were used to revise and calibrate the conceptual assessment models. A draft version of the Regional Guidebook was then subjected to several rounds of peer review and revised into the Operational Draft Guidebook (Lee et al. 1997). 


\begin{tabular}{|c|c|}
\hline \multicolumn{2}{|c|}{$\begin{array}{l}\text { Table } 1 \\
\text { Contributors to the Regional Guidebook }\end{array}$} \\
\hline Team & Team Members and Affiliation \\
\hline $\begin{array}{l}\text { Guidebook } \\
\text { Authors }\end{array}$ & $\begin{array}{l}\text { Michael Whited (NRCS, Wetland Science Institute), Michael Gilbert (Corps of } \\
\text { Engineers, Omaha District), Ellis J. Clairain, and R. Daniel Smith (Corps of Engi- } \\
\text { neers, Waterways Experiment Station) }\end{array}$ \\
\hline $\begin{array}{l}\text { NWSTC } \\
\text { National Team }\end{array}$ & $\begin{array}{l}\text { Mark Brinson (East Carolina University), Garrett Hollands (Fugro/Ensr), Lyndon } \\
\text { C. Lee (L.C. Lee \& Associates, Inc.), Wade Nutter (University of Georgia), Dennis } \\
\text { Whigham (Consulting Wetland Scientist), William Kleindl, and Mark Cable Rains } \\
\text { (L.C. Lee \& Associates, Inc.) }\end{array}$ \\
\hline $\begin{array}{l}\text { Northern Prairie } \\
\text { A-Team }\end{array}$ & $\begin{array}{l}\text { Bill Bicknell (USFWS), Dave Dewald (NRCS), Hal Weiser (NRCS), Michael } \\
\text { Whited (NRCS, A Team Leader), and the following Corps of Engineers, Omaha } \\
\text { District personnel: Michael Gilbert, Brad Qualyle, Cathy Juhas, Laura Banker, } \\
\text { and Karen Lawrence }\end{array}$ \\
\hline $\begin{array}{l}\text { NRCS Prairie } \\
\text { Pothole Team }\end{array}$ & Mark Anderson, Roy Boschee, Rod O'Clair, and Norm Prochnow \\
\hline $\begin{array}{l}\text { USGS Northern } \\
\text { Prairie Science } \\
\text { Center }\end{array}$ & $\begin{array}{l}\text { Ned H. Euliss, Robert Gleason, Wes Newton, and Deb Buhl; Soil Lab Analysis by } \\
\text { Alan Olness (ARS, Morris, MN) and Jimmie Richardson (NDSU, Fargo, ND) }\end{array}$ \\
\hline $\begin{array}{l}\text { Regional } \\
\text { Experts }\end{array}$ & $\begin{array}{l}\text { James LaBaugh (USGS), Daniel Hubbard (SDSU), Mike Anderson (NRCS), } \\
\text { Sandra Byrd (NRCS), Harold Kantrud (NPSC), Dennis Magee (Normandeau } \\
\text { Assoc.), Arnold van der Valk (University of lowa), Laura Mazanti (NRCS), James } \\
\text { Richardson (NDSU), George Swanson, Lew Cowardin, Ned H. Euliss Jr. (USGS), } \\
\text { Loren Smith (Texas Tech Univ.), Milton Weller (Texas A \& M Univ.) }\end{array}$ \\
\hline
\end{tabular}

The Operational Draft Guidebook (Lee et al. 1997) provided the framework for further reference data collection throughout the PPR in 1998 and 1999. The data were collected by two teams: one from the U.S. Geological Survey Northern Prairie Wildlife Research Center under the direction of Ned Euliss and Robert Gleason, and another consisting primarily of NRCS Northern Plains Wetland Specialists with assistance from state and local offices of the NRCS, COE, and USFWS personnel (NRCS Jamestown Team). The USGS team focused on collecting data from seasonally inundated natural (reference standard) and restored wetlands throughout the region, and the NRCS team focused on collecting reference data from agriculturally impacted wetlands in the region. These reference data were then combined to form a reference data set of 180 prairie potholes throughout the reference domain.

During the Application Phase of the HGM Approach, the assessment variables, models, and protocols are used to assess wetland functions. This involves two steps. The first is to apply the assessment protocols outlined in the Regional Guidebook to complete the following tasks:

a. Define assessment objectives.

b. Characterize the project site.

c. Screen for red flags.

d. Define the Wetland Assessment Area.

e. Collect field data.

f. Analyze field data. 
The second step involves applying the results of the assessment at various decision-making points in the permit review sequence, such as alternatives analysis, minimization, assessment of unavoidable impacts, determination of compensatory mitigation, design and monitoring of mitigation, comparison of wetland management alternatives or results, determination of restoration potential, or identification of acquisition or mitigation sites.

\section{Hydrogeomorphic Classification}

Wetland ecosystems share a number of characteristics, including relatively long periods of inundation or saturation, hydrophytic vegetation, and hydric soils. Despite these common features, wetlands exist under a wide range of climatic, geologic, and physiographic situations and exhibit a wide variety of physical, chemical, and biological characteristics (Ferren et al. 1996a; Cowardin et al. 1979; Mitsch and Gosselink 1993). This variability presents a challenge to the development of assessment methods that are both accurate, in the sense that the method detects significant change in function, and practical, in the sense that the method can be carried out in the relatively short time that is generally available for conducting assessments. "Generic" wetland assessment methods, designed to assess multiple types of wetlands, lack the level of detail necessary to detect significant changes in function. Consequently, one way to achieve an appropriate level of resolution rapidly is to employ an approach that focuses on a subset of wetlands, thereby reducing the level of variability exhibited by the wetlands being considered (Smith et al. 1995).

The HGM Classification (Brinson 1993) was developed specifically to accomplish this task. It identifies groups of wetlands that function similarly using three criteria that fundamentally influence how wetlands function. These criteria are geomorphic setting, water source, and hydrodynamics. Geomorphic setting refers to the landform in which the wetland occurs, its geologic evolution, and its topographic position in the landscape. Water source refers to the primary source of the water entering the wetland. The three primary water sources are precipitation, overbank surface flow, or groundwater. Hydrodynamics refers to the level of energy and the direction that water takes as it moves into and through the wetland.

On the basis of these three classification criteria, any number of "functional" wetland groups can be identified at different spatial or temporal scales. For example, at a broad continental scale, Brinson (1993) identified five hydrogeomorphic wetland classes. These were later expanded to the seven classes described in Table 2 (after Smith et al. 1995). 


\begin{tabular}{|c|c|}
\hline \multicolumn{2}{|c|}{$\begin{array}{l}\text { Table } 2 \\
\text { Hydrogeomorphic Wetland Classes }\end{array}$} \\
\hline HGM Wetland Class & Definition \\
\hline Depression & $\begin{array}{l}\text { Depression wetlands occur in topographic depressions (i.e., closed elevation contours) that allow the accu- } \\
\text { mulation of surface water. Depression wetlands may have any combination of inlets and outlets or lack } \\
\text { them completely. Potential water sources are precipitation, overland flow, streams, or groundwater and } \\
\text { interflow from adjacent uplands. The predominant direction of flow is from the higher elevations toward the } \\
\text { center of the depression. The predominant hydrodynamics are vertical fluctuations that range from diurnal } \\
\text { to seasonal. Depression wetlands may lose water through evapotranspiration, intermittent or perennial } \\
\text { outlets, or recharge to groundwater. Prairie potholes, playa lakes, and cypress domes are common exam- } \\
\text { ples of depression wetlands. }\end{array}$ \\
\hline Tidal Fringe & $\begin{array}{l}\text { Tidal fringe wetlands occur along coasts and estuaries and are under the influence of sea level. They inter- } \\
\text { grade landward with riverine wetlands, where tidal current diminishes and river flow becomes the dominant } \\
\text { water source. Additional water sources may be groundwater discharge and precipitation. The interface } \\
\text { between the tidal fringe and riverine classes is where bidirectional flows from tides dominate over unidirec- } \\
\text { tional ones controlled by floodplain slope of riverine wetlands. Because tidal fringe wetlands are frequently } \\
\text { flooded and water table elevations are controlled mainly by sea surface elevation, tidal fringe wetlands } \\
\text { seldom dry for significant periods. Tidal fringe wetlands lose water by tidal exchange, by overland flow to } \\
\text { tidal creek channels, and by evapotranspiration. Organic matter normally accumulates in higher elevation } \\
\text { marsh areas where flooding is less frequent and the wetlands are isolated from shoreline wave erosion by } \\
\text { intervening areas of low marsh. Spartina alterniflora salt marshes are a common example of tidal fringe } \\
\text { wetlands. }\end{array}$ \\
\hline Lacustrine Fringe & $\begin{array}{l}\text { Lacustrine fringe wetlands are adjacent to lakes where the water elevation of the lake maintains the water } \\
\text { table in the wetland. In some cases, these wetlands consist of a floating mat attached to land. Additional } \\
\text { sources of water are precipitation and groundwater discharge, the latter dominating where lacustrine fringe } \\
\text { wetlands intergrade with uplands or slope wetlands. Surface water flow is bidirectional, usually controlled } \\
\text { by water level fluctuations resulting from wind or seiche. Lacustrine wetlands lose water by flow returning } \\
\text { to the lake after flooding and evapotranspiration. Organic matter may accumulate in areas sufficiently pro- } \\
\text { tected from shoreline wave erosion. Unimpounded marshes bordering the Great Lakes are an example of } \\
\text { lacustrine fringe wetlands. }\end{array}$ \\
\hline Slope & $\begin{array}{l}\text { Slope wetlands are found in association with the discharge of groundwater to the land surface or sites with } \\
\text { saturated overland flow with no channel formation. They normally occur on sloping land ranging from slight } \\
\text { to steep. The predominant source of water is groundwater or interflow discharging at the land surface. } \\
\text { Precipitation is often a secondary contributing source of water. Hydrodynamics are dominated by } \\
\text { downslope unidirectional water flow. Slope wetlands can occur in nearly flat landscapes if groundwater } \\
\text { discharge is a dominant source to the wetland surface. Slope wetlands lose water primarily by saturated } \\
\text { subsurface flows, surface flows, and evapotranspiration. Slope wetlands may develop channels, but the } \\
\text { channels serve only to convey water away from the slope wetland. Slope wetlands are distinguished from } \\
\text { depression wetlands by the lack of a closed topographic depression and the predominance of the ground- } \\
\text { water/interflow water source. Fens are a common example of slope wetlands }\end{array}$ \\
\hline Mineral Soil Flats & $\begin{array}{l}\text { Mineral soil flats are most common on interfluves, extensive relic lake bottoms, or large alluvial terraces } \\
\text { where the main source of water is precipitation. They receive virtually no groundwater discharge, which } \\
\text { distinguishes them from depressions and slopes. Dominant hydrodynamics are vertical fluctuations. Min- } \\
\text { eral soil flats lose water by evapotranspiration, overland flow, and seepage to underlying groundwater. } \\
\text { They are distinguished from flat non-wetland areas by their poor vertical drainage due to impermeable } \\
\text { layers (e.g., hardpans), slow lateral drainage, and low hydraulic gradients. Mineral soil flats that accumu- } \\
\text { late peat can eventually become organic soil flats. They typically occur in relatively humid climates. Pine } \\
\text { flatwoods with hydric soils are an example of mineral soil flat wetlands. }\end{array}$ \\
\hline Organic Soil Flats & $\begin{array}{l}\text { Organic soil flats, or extensive peatlands, differ from mineral soil flats in part because their elevation and } \\
\text { topography are controlled by vertical accretion of organic matter. They occur commonly on flat interfluves, } \\
\text { but may also be located where depressions have become filled with peat to form a relatively large, flat } \\
\text { surface. Water source is dominated by precipitation, while water loss is by overland flow and seepage to } \\
\text { underlying groundwater. They occur in relatively humid climates. Raised bogs share many of these } \\
\text { characteristics but may be considered a separate class because of their convex upward form and distinct } \\
\text { edaphic conditions for plants. Portions of the Everglades and northern Minnesota peatlands are examples } \\
\text { of organic soil flat wetlands. }\end{array}$ \\
\hline
\end{tabular}




\begin{tabular}{||l|l||}
\hline \hline Table 2 (Concluded) \\
\hline \hline HGM Wetland Class & Definition \\
\hline \hline Riverine & $\begin{array}{l}\text { Riverine wetlands occur in floodplains and riparian corridors in association with stream channels. Dominant } \\
\text { water sources are overbank flow or backwater from the channel or subsurface hydraulic connections } \\
\text { between the stream channel and wetlands. Additional sources may be interflow, overland flow from adja- } \\
\text { cent uplands, tributary inflow, and precipitation. When overbank flow occurs, surface flows down the flood- } \\
\text { plain may dominate hydrodynamics. In headwaters, riverine wetlands often intergrade with slope, depres- } \\
\text { sional, poorly drained flat wetlands, or uplands as the channel (bed) and bank disappear. Perennial flow is } \\
\text { not required. Riverine wetlands lose surface water via the return of floodwater to the channel after flooding } \\
\text { and through surface flow to the channel during rainfall events. They lose subsurface water by discharge to } \\
\text { the channel, movement to deeper groundwater (for losing streams), and evapotranspiration. Peat may } \\
\text { accumulate in off-channel depressions (oxbows) that have become isolated from riverine processes and } \\
\text { subjected to long periods of saturation from groundwater sources. Bottomland hardwoods on floodplains } \\
\text { are an example of riverine wetlands. }\end{array}$ \\
\hline
\end{tabular}

In most cases, the level of variability encompassed by a continental scale hydrogeomorphic class is too great for developing assessment models that can be rapidly applied, while being sensitive enough to detect changes in function at an appropriate level of resolution. For example, at a continental scale, the depression class includes wetlands as diverse as vernal pools in California (Zedler 1987), prairie potholes in the Midwest and Great Plains (Kantrud et al. 1989; Hubbard 1988), playa lakes in the High Plains of Texas (Bolen et al. 1989), kettles in New England (Golet and Larson 1974), and cypress domes in Florida (Kurz and Wagner 1953; Ewel and Odum 1984).

To reduce both inter- and intra-regional variability, the three classification criteria are applied at a smaller regional geographic scale to identify regional wetland subclasses. In many parts of the country, existing wetland classifications can serve as a starting point for identifying regional wetland subclasses (e.g., Ferren et al. 1996a, 1996b; Wharton et al. 1982; Golet and Larson 1974; Stewart and Kantrud 1971). Regional wetland subclasses, like the continental scale wetland classes, are distinguished on the basis of geomorphic setting, water source, and hydrodynamics. In addition, certain ecosystem or landscape characteristics may also be useful for distinguishing regional subclasses in particular areas. For example, regional depression subclasses might be based on water source (i.e., groundwater versus surface water), or the degree of connection between the wetland and other surface waters (i.e., the flow of surface water in or out of the depression through defined channels). In the estuarine fringe class, subclasses could be based on salinity gradients. Regional slope subclasses might be based on the degree of slope, soil type (e.g., mineral or organic), the chemical composition of the source water, or other factors. Regional riverine subclasses could be based on water source, position in the watershed, stream order, watershed size, channel gradient, or floodplain width. Examples of potential regional subclasses are shown in Table 3 (after Smith et al. 1995; Rheinhardt et al. 1997). Regional Guidebooks include a thorough characterization of the regional wetland subclass in terms of its geomorphic setting, water sources, hydrodynamics, vegetation, soil, and other features that were taken into consideration during the classification process. 


\begin{tabular}{|c|c|c|c|c|}
\hline \multicolumn{5}{|c|}{$\begin{array}{l}\text { Table } 3 \\
\text { Potential Regional Wetland Subclasses in Relation to Classification Criteria }\end{array}$} \\
\hline \multicolumn{3}{|c|}{ Classification Criteria } & \multicolumn{2}{|c|}{ Potential Regional Wetland Subclasses } \\
\hline $\begin{array}{l}\text { Geomorphic } \\
\text { Setting }\end{array}$ & \begin{tabular}{|l} 
Dominant Water \\
Source
\end{tabular} & \begin{tabular}{|l|} 
Dominant \\
Hydrodynamics
\end{tabular} & Eastern United States & \begin{tabular}{|l|} 
Western United \\
States/Alaska
\end{tabular} \\
\hline Depression & $\begin{array}{l}\text { Groundwater or } \\
\text { interflow }\end{array}$ & Vertical & $\begin{array}{l}\text { Prairie pothole marshes, Carolina } \\
\text { bays }\end{array}$ & California vernal pools \\
\hline $\begin{array}{l}\text { Fringe } \\
\text { (tidal) }\end{array}$ & Ocean & \begin{tabular}{|l|} 
Bidirectional, \\
horizontal \\
\end{tabular} & $\begin{array}{l}\text { Chesapeake Bay and Gulf of } \\
\text { Mexico tidal marshes }\end{array}$ & $\begin{array}{l}\text { San Francisco Bay } \\
\text { marshes }\end{array}$ \\
\hline $\begin{array}{l}\text { Fringe } \\
\text { (lacustrine) }\end{array}$ & Lake & \begin{tabular}{|l} 
Bidirectional, \\
horizontal
\end{tabular} & Great Lakes marshes & Flathead Lake marshes \\
\hline Slope & Groundwater & $\begin{array}{l}\text { Unidirectional, } \\
\text { horizontal }\end{array}$ & Fens & Avalanche chutes \\
\hline $\begin{array}{l}\begin{array}{l}\text { Flat } \\
\text { (mineral soil) }\end{array} \\
\end{array}$ & Precipitation & Vertical & Wet pine flatwoods & Large playas \\
\hline $\begin{array}{l}\text { Flat } \\
\text { (organic soil) }\end{array}$ & Precipitation & Vertical & Peat bogs; portions of Everglades & $\begin{array}{l}\text { Peatlands over } \\
\text { permafrost }\end{array}$ \\
\hline Riverine & $\begin{array}{l}\text { Overbank flow from } \\
\text { channels }\end{array}$ & $\begin{array}{l}\text { Unidirectional, } \\
\text { horizontal }\end{array}$ & Bottomland hardwood forests & Riparian wetlands \\
\hline
\end{tabular}

\section{Reference Wetlands}

Reference wetlands are the sites selected to represent the range of variability found in a regional wetland subclass as a result of natural processes and disturbance (e.g., succession, fire, erosion, and sedimentation) as well as anthropogenic alterations. The HGM approach uses reference wetlands for several purposes. First, they provide a tangible, physical representation of wetland ecosystems that can be observed and measured. Second, they establish the range and variability of conditions exhibited by the Regional Wetland Subclass in the reference domain (i.e., the geographic area represented by the reference wetland). Finally, they provide the data necessary for calibrating assessment model variables and functional indices.

The reference domain is the geographic area occupied by the reference wetlands (Smith et al. 1995). Ideally, the geographic extent of the reference domain will mirror the geographic area encompassed by the regional wetland subclass; however, this is not always possible owing to time and resource constraints.

The HGM approach uses reference wetlands for several purposes. First, they establish a basis for defining what constitutes a characteristic and sustainable level of function across the suite of functions selected. Second, they establish the range and variability of conditions exhibited by assessment variables and provide the data necessary for calibrating variables and models. Finally, they provide a tangible, physical representation of wetland ecosystems that can be observed and measured repeatedly.

Reference standard wetlands are the subset of reference wetlands that achieve the highest, sustainable level of functioning across the suite of functions. Generally, they are the least altered wetland sites in the least altered landscapes. By definition, all model variable subindices and functional capacity indices (FCI) are 
set to 1.0, based on the range of conditions found in reference standard wetlands (Smith et al. 1995). Table 4 outlines the terms used by the HGM approach in the context of reference wetlands.

\begin{tabular}{|l|l||}
\hline \multicolumn{2}{||l||}{\begin{tabular}{l||} 
Table 4 \\
Reference Wetland Terms and Definitions
\end{tabular}} \\
\hline \hline Term & Definition \\
\hline \hline Reference Domain & $\begin{array}{l}\text { The geographic area from which reference wetlands representing the } \\
\text { regional wetland subclass are selected (Smith et al. 1995). }\end{array}$ \\
\hline Reference Wetlands & $\begin{array}{l}\text { A group of wetlands that encompass the known range of variability in the } \\
\text { regional wetland subclass resulting from natural processes and human } \\
\text { alteration. }\end{array}$ \\
\hline $\begin{array}{l}\text { Reference Standard } \\
\text { Wetlands }\end{array}$ & $\begin{array}{l}\text { The subset of reference wetlands that perform a representative suite of } \\
\text { functions at a level that is both sustainable and characteristic of the least } \\
\text { human altered wetland sites in the least human altered landscapes. By } \\
\text { definition, the functional capacity index for all functions in a reference } \\
\text { standard wetland is 1.0. }\end{array}$ \\
\hline $\begin{array}{l}\text { Reference Standard } \\
\text { Wetland Variable } \\
\text { Condition }\end{array}$ & $\begin{array}{l}\text { The range of conditions exhibited by assessment variables in reference } \\
\text { standard wetlands. By definition, reference standard conditions receive a } \\
\text { variable subindex score of 1.0. }\end{array}$ \\
\hline $\begin{array}{l}\text { Site Potential (Mitigation } \\
\text { project context) }\end{array}$ & $\begin{array}{l}\text { The highest level of function possible, given local constraints of distur- } \\
\text { bance history, land use, or other factors. Site potential may be less than } \\
\text { or equal to the levels of function in reference standard wetlands of the } \\
\text { regional wetland subclass. }\end{array}$ \\
\hline $\begin{array}{l}\text { Project Target (Mitiga- } \\
\text { tion project context) }\end{array}$ & $\begin{array}{l}\text { The level of function identified or negotiated for a restoration or creation } \\
\text { project. }\end{array}$ \\
\hline $\begin{array}{l}\text { Project Standards (Miti- } \\
\text { gation project context) }\end{array}$ & $\begin{array}{l}\text { Performance criteria or specifications used to guide the restoration or } \\
\text { creation activities toward the project target. Project standards should } \\
\text { specify reasonable contingency measures if the project target is not } \\
\text { being achieved. }\end{array}$ \\
\hline \hline
\end{tabular}

\section{Assessment Models and Functional Indices}

In the HGMA assessment, models are simple representations of functions performed by wetland ecosystems that are constructed and calibrated by the assessment team during the development phase. Assessment models define the relationship among one or more characteristics or processes of the wetland ecosystem and the surrounding landscape, and the functional capacity of a wetland ecosystem. Functional capacity is the ability of a wetland to perform a specific function relative to the ability of reference standard wetlands to perform the same function. Assessment models result in a Functional Capacity Index (FCI) ranging from 0.0 to 1.0 . The FCI is a measure of the functional capacity of a wetland relative to reference standard wetlands in the reference domain. Wetlands with an FCI of 1.0 perform the assessed function at a level that is characteristic of reference standard wetlands. A lower FCI indicates that the wetland being assessed is performing a function at a level that is below that characteristic of reference standard wetlands.

Assessment model variables are ecological quantities that consist of five components (Schneider 1994). These include: 1) a name, 2) a symbol, 3) a metric and a procedure for measurement, 4) metric value (i.e., the numbers, categories, or numerical estimates that are generated by applying the procedural statement 
(Leibowitz and Hyman 1997)), and 5) units on the appropriate measurement scale. Assessment model variables represent the characteristics of the wetland ecosystem and surrounding landscape that influence the functional capacity of the wetland ecosystem. Model variables can occur in various conditions that correspond to the range of conditions exhibited by reference wetlands in a reference domain. For example, vegetation species composition can be more or less diverse, ponding can be more or less frequent, and soils can be more or less permeable. Model variables are assigned a sub-index ranging from $0.0-1.0$ based on the relationship between that variable condition and functional capacity of sampled wetland ecosystems. When the condition of a variable is similar to a reference standard defined for a reference domain, it is assigned an index of 1.0. As the variable metric value deflects in either direction from the reference standard condition, it is assigned a progressively lower value, based upon a defined relationship between metric values and functional capacity.

In addition to defining the relationship among variables and the relationship between variables and functional capacity, variables are combined in an aggregation equation to produce a functional capacity index (FCI) in the assessment model. The FCI is a measure of the functional capacity of a wetland relative to reference standards in the reference domain, and ranges from 0.0-1.0. The FCI decreases as conditions deviate from reference standards. A wetland ecosystem with an FCI of 0.1 performs the function at a minimal, essentially unmeasurable, level, but retains the potential for recovery. A wetland with a FCI 0.0 does not perform the function, and does not have the potential for recovery, in a practical sense, because the change is essentially permanent.

\section{Assessment Protocol}

The final component of the HGM approach is the assessment steps and protocols. The assessment protocol is a defined set of tasks, along with specific instructions, that allows the end user to assess the functions of a particular wetland area using the assessment variables, models, and functional indices in the Regional Guidebook. The first task is characterizing the wetland ecosystem and the surrounding landscape, describing the proposed project and its potential impacts, and identifying the wetland area or areas to be assessed. The second task is collecting the data for assessment variables to run the functional models. The final task is calculating functional indices in the context of regulatory, planning, or management programs (Smith et al. 1995). 


\section{Characterization of the Temporary and Seasonally Ponded Prairie Pothole Wetland Ecosystems}

\section{Regional Wetland Subclass and Reference Domain}

This Regional Guidebook is designed to assess the functions of depressional, palustrine, herbaceous, temporarily and seasonally ponded wetlands formed in glacial till. The geographic area of interest is commonly referred to as the Prairie Pothole Region (PPR).

The PPR is large and contains waters and wetlands of numerous hydrogeomorphic subclasses. The A-Team was seeking an HGM guidebook that would best serve their needs in a diverse landscape with a variety of anthropogenic disturbances. Prior to collecting, analyzing, and synthesizing data, and developing the draft regional model, the National, Technical, and Agency teams, as well as the A-Team, defined priority wetland subclasses. The most common wetland subclass, which also receives the most pressure for conversion, is small depressional wetlands with temporary and seasonal hydroperiods. About 79 percent of prairie pothole wetlands are less than 0.4 hectare (ha) in size and about 66 percent are less than 0.2 ha in size (Dahl 1990). Most of these are in the regional subclass for which this guidebook is intended. These more temporary types of wetlands are important for waterfowl feeding and courtship, as well as functions such as groundwater recharge and flood storage, and are considered to be under-protected (Hubbard 1988).

Temporary and seasonal wetlands, for the purposes of this guidebook, are classified by the system devised by Stewart and Kantrud (1971). They classify wetland basins in the northern prairie on the basis of the vegetation found in their central or deepest zone. Therefore, temporary and seasonal wetlands in prairie depressional systems are a function of the water depth and duration (van der Valk 1981). The dominant hydrologic inputs to temporary and seasonal prairie pothole wetlands are surface runoff of snowmelt and early spring rains that do not 
infiltrate into the frozen upland soils. The dominant hydrologic output is evapotranspiration; a secondary output is downward seepage (i.e., groundwater recharge). The dominant hydrodynamics are vertical. The complete descriptor of this subclass is: prairie potholes, low permeability substrate, temporary and seasonal hydroperiods, depressions.

There are two important distinctions for use of this guidebook. First, this subclass does not include wetlands developed in coarse textured (i.e., sandy) parent materials (such as glacial outwash) because these wetlands are in a different hydrogeologic setting. Second, this subclass does not include larger wetlands with semi-permanent (or wetter) hydrologic regimes. These wetlands are more likely to be areas of groundwater flow-through or discharge, provide distinct habitat functions, commonly have more saline tolerant plant communities, and have different basin morphometry and structure.

\section{Description of the Regional Subclass}

\section{Landscape setting: physiographic divisions}

Boundaries of the region have not been precisely defined, but most authors have used or modified the bounds established by Mann (1974) as illustrated in Figure 2. The PPR in the U.S. includes parts of extreme northern Montana, much of eastern South and North Dakota, western Minnesota and the glaciated Des Moines lobe of north central Iowa.

Galatowitsch and van der Valk (1994) subdivided the PPR into northern and southern regions. Their geographic division is generally analogous to the change between areas where small grain crops are dominant (northern) and areas where row crops (corn, soybeans) are grown (southern). The southern PPR is in Land Resource Region M and the northern PPR is in Land Resource Region F (United States Department of Agriculture 1981). The southern PPR is warmer and wetter than the northern PPR and the division between northern and southern approximates the boundary between the tall-grass prairie and the mixed-grass prairie. Geomorphologists have traditionally divided the northern grasslands into two large areas called the Great Plains and Central Lowland (Fenneman 1931). The more arid Great Plains support native grassland that is shorter than that in the moister Central Lowland to the east. The reference domain for this guidebook includes portions of both these areas.

The Great Plains portion of the Prairie Pothole Region contains a single physiographic division, the Missouri Coteau. This division is approximately $52,000 \mathrm{~km}^{2}$ in area. The Missouri Coteau extends from northeastern Montana through North and South Dakota to the Nebraska border. Generally, it runs parallel to and east of the Missouri River. It consists of hummocky topographythus, the Canadian French coteau, meaning "little hill." The Coteau is characterized by non-integrated drainage (meaning that ponds and sloughs are not connected to one another and no streams flow through the area). In these areas the glacial deposits are thick, and large-scale glacial stagnation processes predominated, resulting in a hilly, irregular surface with numerous wetlands and lakes. 


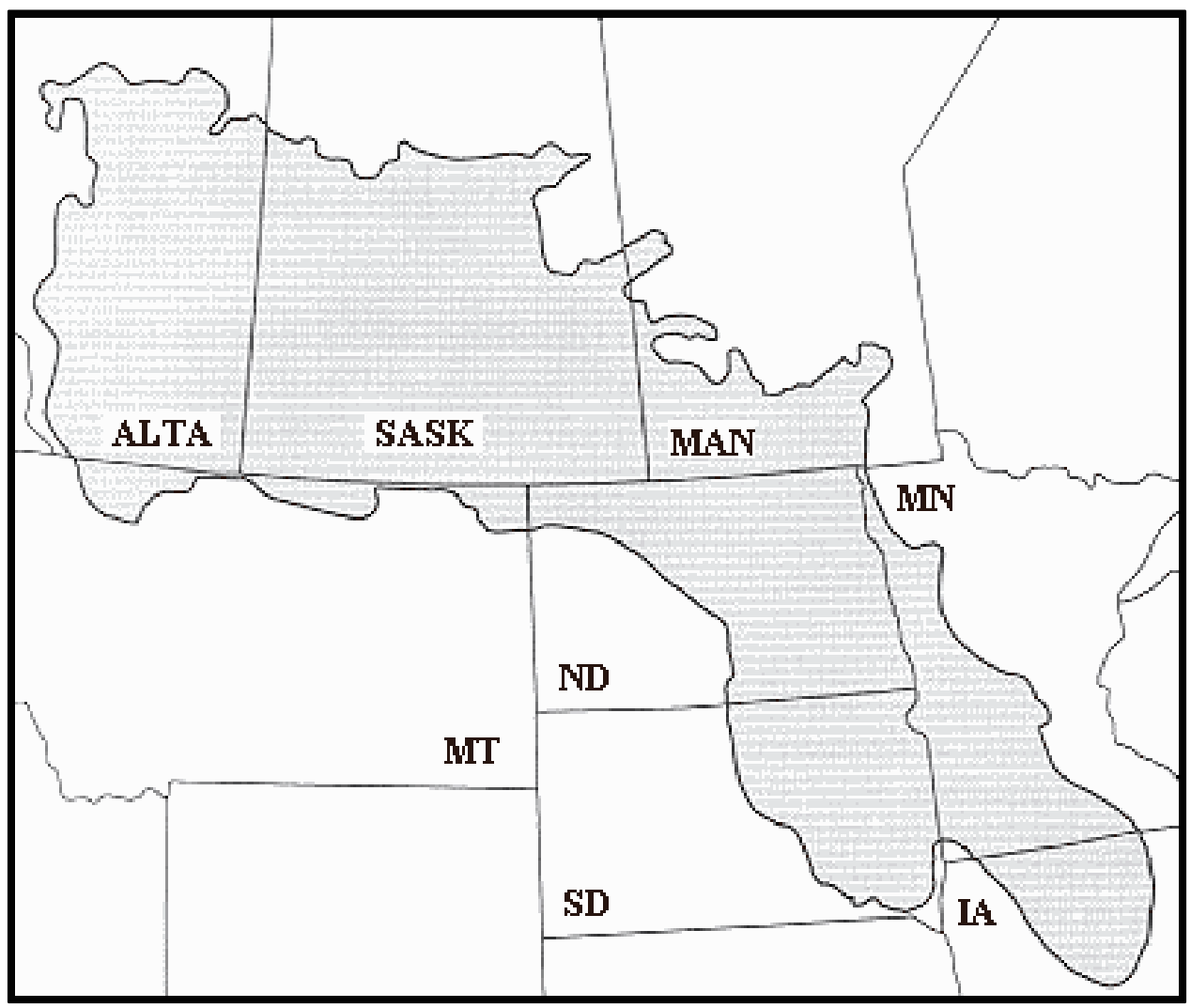

Figure 2. The Prairie Pothole Region of North America (after Mann 1974)

A gently sloping scarp, about $100 \mathrm{~m}$ high and mostly covered by glacial deposits (referred to collectively as drift), separates the Coteau du Missouri from the lower, nearly flat, drift-covered plains of the Central Lowland to the east. This escarpment, which is called the Missouri escarpment, is virtually continuous across the State of North Dakota southward into South Dakota. The base of the Missouri escarpment is the eastern boundary of the Great Plains in these northern states.

By far the largest number and area of basin wetlands in the PPR occur in the Central Lowland. Most of this land mass drains either to Hudson's Bay (North Dakota) or the Gulf of Mexico (Iowa, Minnesota, and South Dakota). Within the Central Lowland lie six major physiographic regions. These are, in decreasing order of area, the Glaciated Plains $\left(921,000 \mathrm{~km}^{2}\right)$, Prairie Coteau $\left(15,200 \mathrm{~km}^{2}\right)$, Dakota Lake Plain $\left(5700 \mathrm{~km}^{2}\right)$, Souris Lake Plain $\left(3600 \mathrm{~km}^{2}\right)$, Devil's Lake Plain $\left(1400 \mathrm{~km}^{2}\right)$, and Turtle Mountains $\left(1200 \mathrm{~km}^{2}\right)$. Reference wetlands from the Glaciated Plains, Missouri Coteau, and the Prairie Coteau are included in this guidebook.

It is important to recognize the various physiographic divisions to adequately capture the diversity of the PPR. For this guidebook, the reference domain will be discussed in the context of the major physiographic regions of the Glaciated Plains, Prairie Coteau, and the Missouri Coteau. 


\section{Geology}

Glaciation events during the Pleistocene Epoch were the dominant forces that shaped the landscape of the PPR (Winter 1989). About 7 million years ago, the subtropical climate of what is now the PPR began to change to a continental climate of cool winters and warm summers (Bluemle 1991). During the Pleistocene Epoch that followed, a succession of great ice sheets inched southward from Canada and covered most of Minnesota, the Dakotas, northern Montana and Iowa. These huge glaciers transported vast quantities of rock and soil. Large amounts of local silty and clayey bedrock outcrops were also pulverized and added to the mixture, forming glacial drift or "till" that was deposited as sediment across most of the area glaciated. The most recent episode of glaciation, the Late Wisconsin (approximately 20-25,000 years before present) is responsible for development of most of the present day landscape of the PPR. When the glaciers retreated, a landscape dotted with numerous small, saucer-like depressions was exposed. These depressions, caused by the uneven deposition of glacial till, the scouring action of glaciers, and the melting of large, buried ice blocks, are known today as prairie potholes.

The retreat of the glaciers marked the beginning of the Holocene Epoch about 10,000 years ago, as winters became cold and summers became hot (Bluemle 1991). The spruce-aspen forests of what are now the northern plains were succeeded by grasslands, and since that time, warm, dry periods have alternated with cool, wet periods (McAndrews et al. 1967). Some additional basins were formed during the Holocene from wind-worked sand dunes, but nearly all of the depressional wetlands in the PPR were formed as a direct result of glaciation or the melting of glacial ice. The area of depressional topography formed by a variety of geological processes makes up the PPR, which, until the advent of European man, was an approximately $715,000-\mathrm{km}^{2}$ grassland-wetland complex that stretched from north-central Iowa to central Alberta. Glacial till was unevenly deposited throughout the PPR. Large moraines accumulated along the terminal ends of glaciers and formed ridges of low, rolling hills in a northwest to southeast orientation, such as the Missouri Coteau and the Prairie Coteau. In these areas the glacial deposits are thick, and large-scale glacial stagnation processes predominated, resulting in a hilly, "knob-and-kettle" irregular surface with numerous wetlands and lakes (Figure 3).

The landscape of the Coteaus formed because glaciers were forced to advance up a steep escarpment before they flowed onto the uplands. As glaciers advanced over the escarpment, sediment from the base of the glacier was forced up to the surface. When the climate moderated and the glaciers stagnated, sediment melting out of the ice accumulated at the surface, insulating the ice so that it took several thousand years to melt completely. As it melted, sediment slumped and slid forming the hummocky topography. Prairie potholes are most numerous where large-scale glacial stagnation processes dominated. This type of topography tends to have basins with steeper sides and more wetlands with semipermanent water regimes. 


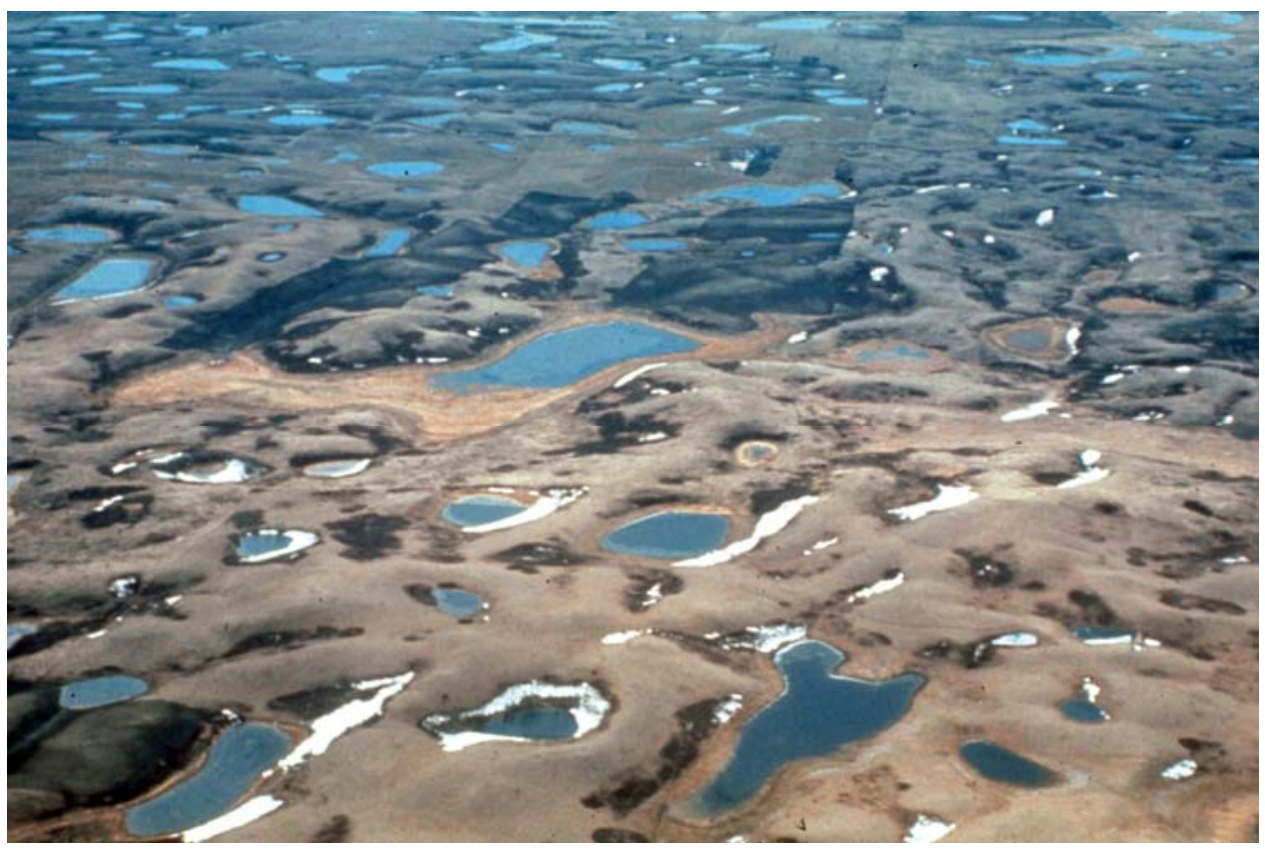

Figure 3. Aerial oblique of the Missouri Coteau, North Dakota illustrating nonintegrated surface drainage (source: U.S. Fish and Wildlife Service)

Where glaciers retreated quickly, large, gently rolling areas of glaciated plains were formed, and extremely flat lake beds developed where glaciers dammed meltwater. The Glaciated Plains is a rolling, glaciated landscape also known as the drift prairie. Much of the region is very gently sloping; in some places, the ice shoved and thrust large masses of rock and sediment, forming icethrust hills near the ice margin. In still other areas, loose accumulations of rock and sediment piled up at the edge of a glacier, resulting in areas of especially hilly land called end moraine. This landscape tends to have more numerous, but shallower, basins than the areas where glacial stagnation processes occurred. Most wetlands on the Glaciated Plains have temporary or seasonal water regimes and are more susceptible to modification (Figure 4).

Drainage patterns in these glaciated landscapes range from non-integrated patterns, where no streams flow through the areas (Missouri Coteau and Prairie Coteau), to land where poorly developed stream systems have developed (Glaciated Plains), to areas on the Des Moines Lobe where "linked depression systems" (Galatowitsch and van der Valk 1994) are the norm.

\section{Glacial landforms included in the regional subclass}

Within these physiographic divisions are a variety of glacial or postglacial landforms. Those landforms that contain relatively numerous wetland basins are as follows: 


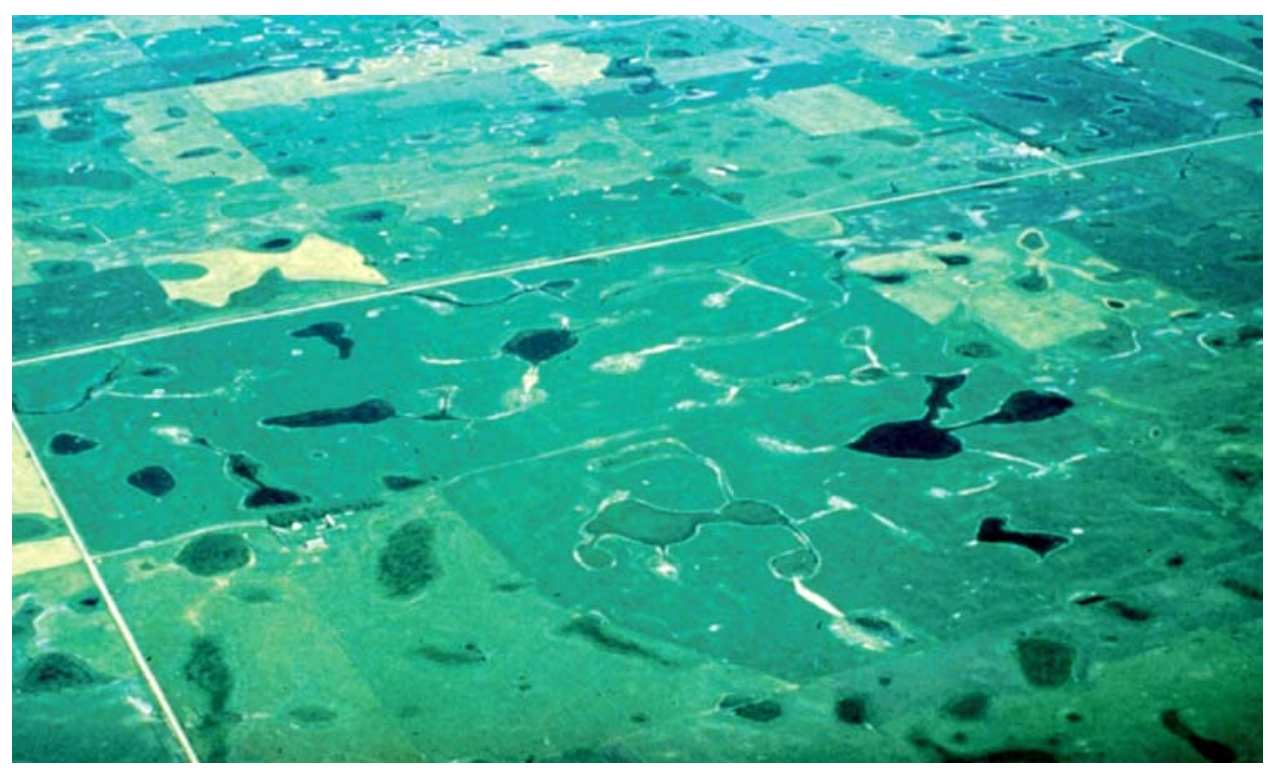

Figure 4. Aerial oblique of prairie pothole wetlands in an agricultural landscape matrix, Glaciated Plains, North Dakota (photo source: U.S. Fish and Wildlife Service)

- Ground moraine: This is the predominant glacial landform of the Glaciated Plains and can be recognized by a gently rolling landscape with numerous shallow, saucer-shaped depressions, but few hills or deep, cup-shaped depressions (Bluemle 1991). This landform occurs where moderate amounts of glacial till were deposited at the base of a moving glacier and by collapse from within the glacier when it finally melted. Most of the Glaciated Plains in eastern North and South Dakota, Minnesota, and Iowa are ground moraine.

- Washboard moraine: This form appears as small areas of irregularly spaced ridges of material thought to have been carried upward through the ice along shear planes parallel to the edge of the glacier (Bluemle 1991). Small basins are numerous in washboard moraine. This landform is mostly associated with ground moraine in the Glaciated Plains.

- Thrust moraine: This is perhaps the most spectacular glacial landform, as it is the result of large-scale glacial shearing that moved blocks of land up to 20 $\mathrm{km}$ in area for short distances (Bluemle 1991). The "hole" left by these blocks commonly resulted in a large lake, whereas the hilly blocks often contain numerous small but relatively deep basins. Devils Lake and Sulley's Hill in North Dakota are classic examples of thrust moraine topography. Most thrust moraine is found in the Glaciated Plains.

- Terminal moraine: This form resulted when glacial till was deposited at the edge of a glacier while the ice margin was melting back at about the same rate as the ice was moving forward (Bluemle 1991). Till is a general term for the mixture of materials ranging in size from clay particles to boulders of many tons that were pushed forward by and carried on top of advancing glaciers. Terminal moraines are most common in the Glaciated Plains, but also occur in the Missouri and Prairie Coteaus. These moraines are commonly $2-15 \mathrm{~km}$ wide and 
5-90 km long. Basins in terminal moraine are highly variable in size, depth, and density. The Bemis end moraine in Iowa is the southern boundary of the PPR (Harr et al. 1990).

- Dead-ice moraine: This form is responsible for some of the most rugged glacial topography in the PPR, being produced when glaciers advanced over steep escarpments. Shearing action carried material into and on top of the glacier (Bluemle 1991). This insulated the underlying ice, which took several thousand years to melt and collapse. When the overlying materials slumped and slid, thousands of basins of all shapes and sizes were formed. Dead-ice moraine is the most common landform in the Missouri Coteau and the Prairie Coteau. Smaller amounts of dead-ice moraine occur in the Glaciated Plains.

- Ice-walled and elevated lake plains: These features were formed when small lakes on areas of insulated glacial ice in the coteaus were flooded. As the ice melted, the sediment that had been deposited in the lakes slumped into irregular landforms. These small lake plains today are elevated above the surrounding land. These small, elevated lake plains are included in the reference domain; larger lake plains (e.g., Red River Valley, Lake Souris) are not included.

\section{Parent Materials}

The PPR is an extensive Wisconsin-aged glacial terrain that has a mantle of fine-textured glacial till draped over sedimentary rocks of Mesozoic and Cenozoic age (Bluemle 1991). The tills in the PPR are finer textured than most tills throughout the U.S. This characteristic of glacial till in the prairie region has a significant impact on the surface and groundwater hydrology of the region (Winter 1989). Typically, tills of the PPR contain substantial amounts of calcareous minerals that buffer the soil at slightly alkaline (Richardson et al. 1994.) Most of the tills are loams and clay loams; the term often used to describe the typical till is calcareous clay-loam till (Bluemle 1991). Thin lacustrine sediments are occasionally superimposed on the glacial terrain. The lacustrine sediments that are included in this guidebook are finer textured off-shore sediments that are silt loams to silty clays. The small depressional wetlands on these lacustrine areas commonly occur as elevated or "perched" lake plains (Bluemle 1991). Wetlands occurring in large areas of lacustrine materials such as the Red River Valley (Lake Agassiz), Dakota Lake Plain, and Lake Souris are beyond the scope of this guidebook.

\section{Climate}

The PPR is in the mid-continent of North America and is subject to the climatic extremes of this region (Winter 1989). Temperatures can exceed $40^{\circ} \mathrm{C}$ in summer and $-40^{\circ} \mathrm{C}$ in winter. Isolated summer thunderstorms may bring several centimeters of rain in localized areas while leaving adjacent habitats entirely dry. Also, winds of 50 to $60 \mathrm{~km} / \mathrm{hr}$ can quickly dry wetlands during the summer.

Besides the normal seasonal climatic extremes, the semiarid western PPR also undergoes long periods of drought followed by long periods of abundant 
rainfall. These wet/dry cycles can persist for 10 to 20 years (Duvick and Blasing 1981; Karl and Koscielny 1982; Karl and Riebsame 1984; Diaz 1983, 1986). During periods of severe drought, most wetlands go dry during summer, and most of the temporary and many of the seasonal wetlands remain completely dry throughout the drought years. Exposure of mud flats upon dewatering is necessary for the germination of many emergent macrophytes, and it facilitates the oxidation of organic sediments and nutrient releases that maintain high productivity. When abundant precipitation returns, wetlands fill with water and much of the emergent vegetation is drowned. Changes in water permanence and hydroperiod by normal seasonal drawdown and long inter-annual wet/dry cycles has a profound influence on all PPR biota, but is most easily observed in the hydrophytic community (van der Valk and Davis 1978a).

The PPR has a north-to-south and a west-to-east precipitation gradient, with areas to the north and west receiving less precipitation than those to the south and east. However, even in the wetter southeastern portion of the region, wetlands have a negative water balance. Evaporation exceeds precipitation by about $60 \mathrm{~cm}$ in northeastern Montana and by $10 \mathrm{~cm}$ in Iowa (Winter 1989). Depression focused recharge occurs in the small prairie pothole wetlands because of this precipitation deficit.

The PPR has a climate characterized by relatively short, moderately hot summers and relatively long, cold winters because these states lie in the middle of a large continent at middle latitudes. Temperature and precipitation data for several locations in the PPR are summarized for a 30-year period (1961-1990) in Table 5.

\begin{tabular}{|c|c|c|c|c|}
\hline \multicolumn{5}{|c|}{$\begin{array}{l}\text { Table } 5 \\
\text { Prairie Pothole Region Climatic Data }\end{array}$} \\
\hline Location & \begin{tabular}{|l} 
Temp. \\
Avg. Daily Min. \\
(Degrees C)
\end{tabular} & \begin{tabular}{|l} 
Temp. \\
Avg. Daily Max. \\
(Degrees C) \\
\end{tabular} & $\begin{array}{l}\text { Temp. } \\
\text { Avg. Annual } \\
\text { (Degrees C) }\end{array}$ & $\begin{array}{l}\text { Precipitation } \\
\text { Avg. Annual } \\
\text { (cm) }\end{array}$ \\
\hline $\begin{array}{l}\text { Medicine Lake, } \\
\text { MT }\end{array}$ & -19 (Jan.) & 30 (July) & "5.7 & "33.7 \\
\hline Brookings, SD & -18 (Jan.) & 28 (July) & 5.7 & 57.8 \\
\hline St. James, MN & -15.5 (Jan.) & 29.5 (July) & 7.7 & 68.4 \\
\hline Fort Dodge, IA & -14 (Jan.) & 30 (July) & 8.7 & 86.2 \\
\hline
\end{tabular}

Temperatures form roughly south-to-north gradients in the Prairie Pothole Region. Normal annual temperature ranges from about $4.4^{\circ} \mathrm{C}$ in northern North Dakota to about $9^{\circ} \mathrm{C}$ in central Iowa. Soils usually freeze to depths of $0.9-1.8 \mathrm{~m}$ in the northern PPR and 0.5-0.9 $\mathrm{m}$ in the southern PPR (adapted from Winter 1989).

Hare and Hay (1974) have attributed the relatively small amount of precipitation in the Canadian prairies to the weakness of atmospheric disturbances and their associated uplift. Air masses move eastward from the Rocky Mountains and fall steadily toward lower elevations in the northern prairies. The rate of fall is sufficient to reduce cyclonic action appreciably, thus reducing the effectiveness of the mechanism that causes precipitation. This phenomenon also reduces 
precipitation in the PPR of the Dakotas and Montana. The southern part of the region has more precipitation because it receives more moisture-laden air masses from the Gulf of Mexico.

Average annual precipitation in the region ranges from about $34 \mathrm{~cm}$ in northeastern Montana, $58 \mathrm{~cm}$ in eastern South Dakota to $86 \mathrm{~cm}$ in north central Iowa. Larger amounts of spring and summer precipitation in the southeastern part of the region account for most of this difference. About 70 percent of the annual precipitation falls as rain during spring and summer, with June the wettest month. Distinctly dry years, having less than 75 percent of normal precipitation, occur with 10 percent frequency in northwestern North Dakota, but only 4 percent in central Iowa. There is a large gradient across the Prairie Pothole Region in the length of the relatively dry season, that is, when weekly normals of less than $1.27 \mathrm{~cm}$ of precipitation can be expected. In northwestern North Dakota, this season averages 8-10 months, whereas in central Iowa, this season lasts only 2-5 months. Normal annual water loss by runoff and evaporation is $0.36 \mathrm{~m}$ in northwestern North Dakota and $0.56 \mathrm{~m}$ in southeastern South Dakota; the rest enters the ground.

\section{Cyclic Processes and the Reference Standard Cycle}

Regional climate variability leads to both inter- and intra-annual fluctuations of seasonal mean temperature, humidity and precipitation. Average annual precipitation for Bismarck is about $46 \mathrm{~cm}, 75$ percent of which falls during the growing season of April though September. The principal water sources for prairie wetlands in this regional subclass are runoff from snowmelt and precipitation, while the principal water loss is via evapotranspiration (Shjeflo 1968). So, although the majority of the precipitation falls during the growing season, the rate of regional evapotranspiration leads to an overall drawdown of the wetland water depths. It is important to note that a site can be a reference standard site as long as it is on the natural cycle. In other words, hydrologic conditions described above are within the range of the reference standard conditions because cyclic processes characterize the subclass. For instance, although the hydrologic conditions may be in a drawdown period and the associated characteristics (e.g., vegetation species composition) have responded accordingly, the overall functions of the wetland have not changed. This guidebook is written for these overall wetland functions.

\section{Hydrology}

\section{Water Sources}

Hydrologic regimes are dictated by climate and geology that establish the environment for hydrologic processes (Winter 1989). Atmospheric water, surface water, and groundwater interact with basin topographic setting and the hydraulic characteristics of glacial tills to establish wetland hydrologic functions. The Northern Prairie of North America has a continental climate characterized by 
cold winters, hot summers, and extreme variations in both temperature and precipitation (Winter 1989). Precipitation varies from semi-arid in the west to subhumid in the east. Yearly variations in both temperature and precipitation extremes are common. Broad seasonal fluctuations in precipitation are nested within multi-year cycles, resulting in drought and pluvial wet cycles as the norm.

Yearly percentage of snow cover is an expression of climate that directly influences wetland hydrology because snow cover and frozen ground act to delay groundwater recharge and strongly influence runoff and infiltration dynamics. In the northern PPR, the ground is frozen and snow covers the surface between 30 and 50 percent of the time (Arndt and Richardson 1988). Temporary and seasonal wetlands of the Northern Prairie typically receive a large portion of their water volume as surface runoff during spring snowmelt (Hubbard and Linder 1986), when frozen ground minimizes infiltration (Malo 1975), and low temperatures and dormant plant communities minimize evapotranspiration losses (Shjeflo 1968; Lissey 1971; Sloan 1972). Shjeflo (1968) determined that snow accounts for at most 25 percent of total yearly precipitation, yet it accounts for at least 50 percent of the water that reaches the wetland. Overland flow from highintensity thunderstorms (Lissey 1971) accounts for the major portion of the remaining hydrologic input.

Because surface runoff is the major hydrologic input to these wetlands, they need a relatively large catchment area as a water source. Arndt and Richardson (1988) determined that seasonal recharge wetlands have catchment area to wetland surface area ratios that range from approximately 6 to 10 . The seasonal flow through wetlands in their study had ratios of less than 6 , indicating a groundwater component of the water budget. In the northern PPR, wetlands that are usually dry by midsummer recharge shallow groundwater aquifers (Richardson et al. 1991). This is the long-term dominant process; however, it is important to note that flow can reverse both seasonally and yearly, depending upon climatic cycles, presence of phreatophytes, and proximity to more permanent wetlands.

Another important measure of climate that directly relates to wetlands and integrates the effects of temperature and precipitation is the difference between precipitation and evapotranspiration. The PPR is generally characterized by a moisture deficit, whereas the eastern glaciated regions have moisture excess. In the northern PPR, potential yearly evapotranspiration generally exceeds mean yearly precipitation (Winter 1989). This sub-humid to semi-arid climate results in surface-groundwater interactions that are depression focused (Lissey 1971). The alternate drought and wet (pluvial) periods produce decade-long cycles of water table fluctuations. The temporary and seasonal wetlands that are the focus of this Guidebook commonly go through draw-down stages where surface ponding is rare or absent for several years.

Many seasonal wetlands (especially those in the eastern part of the PPR) have a component of groundwater discharge as part of their hydrologic budget. These areas can be characterized by the presence of slightly saline tolerant plant communities, calcareous soils, and smaller size catchments. The correlation of plant communities, soil morphology, hydroperiod, and hydrologic function is well documented in the literature (Arndt and Richardson 1988; Bigler 1981; Fulton et al. 1986; Hubbard et al. 1987; Miller et al. 1985; Sloan 1970). 
The principal hydrologic function of these wetlands is that of surface water storage because of their location as the lowest point in closed watersheds.

Groundwater recharge is a secondary hydrologic function for many wetlands of this subclass because the dominant source of water is relatively fresh water from surface runoff and direct precipitation, the climatic setting resulting in depression focused groundwater interactions, and the fine textured substrates. The cumulative total of these small wetlands has a tremendous effect on the overall groundwater flow net of the PPR.

\section{Hydrodynamics: Water Movement}

Temporary and seasonal potholes exhibit extreme vertical fluctuations of water levels. In pluvial cycles they commonly fill above the wetland boundary and can overflow onto adjacent landscapes and down slope to other depressions (Leibowitz and Vining 2003). As illustrated in Figure 5, these wetlands exhibit both long- and short-term fluctuations in ponding depth. The absence or presence (and elevation of) outlets is important and may result in some functions during wet cycles that are more commonly associated with wetlands on open landscapes.

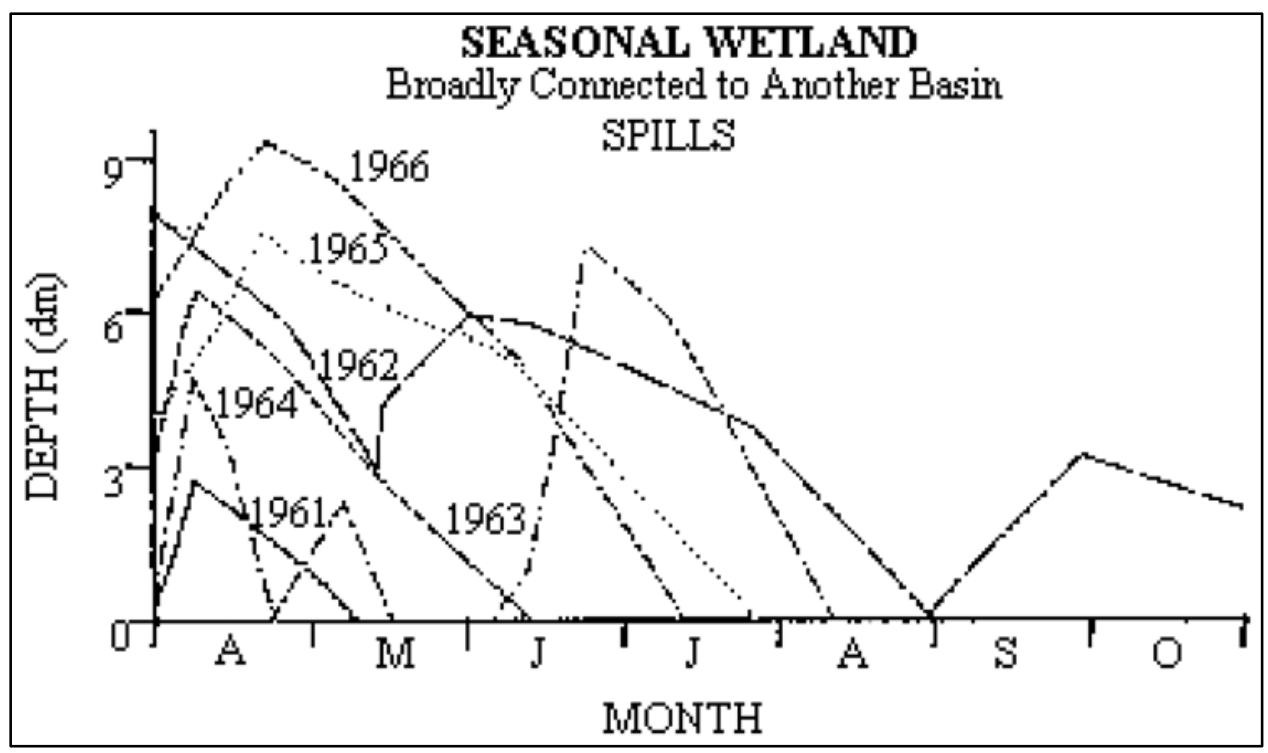

Figure 5. Water level changes during the ice-free season over a 6-year period in a seasonal basin wetland in North Dakota (adapted from Kantrud et al. 1989)

The PPR landscape is characterized by a mosaic of ponds varying in depth at a single point in time, thus contributing to diverse habitats. This is a result of the elevation or lack of surface outlets to these wetlands. Floodwaters can be detained permanently or attenuated by these small depressions (Hubbard and Linder 1986). The hydrodynamics contribute to groundwater recharge, maintenance of salt balance in the landscape, maintenance of anaerobic conditions, and fluctuations between anaerobic and aerobic conditions. The retention of surface waters in these depressions results in an aquatic-moist habitat in an otherwise sub-humid to semi-arid landscape. These conditions directly influence biogeochemical functions. 


\section{Soils}

Most soils of the reference system have formed in calcareous loamy glacial till. The wetland basins have soils formed in glacial till that often have a surface of post-Pleistocene local alluvium or colluvium (slopewash) from the surrounding uplands. This subclass also includes small depressional wetlands formed in clayey till and clayey lacustrine sediments. Most temporary and seasonal wetlands in the PPR are ponded with fresh water and have leached soil profiles consistent with their hydrologic function (Richardson et al. 1994). Temporary wetlands in the PPR are characterized by wet-meadow (Stewart and Kantrud 1971) or sedge-meadow (Galatowitsch and van der Valk 1994) vegetation. The soils in temporary wetlands vary throughout the region with Argialbolls (e.g., Tonka, Tetonka series) dominating in Montana, North Dakota, and South Dakota (i.e., northern PPR) and Endoaquolls dominating in Minnesota and Iowa. Seasonal wetlands are characterized by shallow-marsh vegetation in the basin center surrounded by a wet-meadow zone. The soils in seasonal wetlands of the northern PPR are commonly Argiaquolls (e.g., Parnell, Worthing series) or noncalcareous, fine-textured Cumulic Endoaquolls in the center. These soils grade to Argialbolls and fine-loamy Endoaquolls in the wet meadow zone and often have a rim of Calciaquolls (e.g., Vallers).

Some seasonal wetlands have a component of groundwater discharge as part of their hydrologic budget. These areas can be identified by the presence of slightly saline tolerant plant communities, calcareous soils, and slightly lower catchment area to wetland surface area ratios (Arndt and Richardson 1988).

Freeland and Richardson (1996) evaluated prairie wetland soil properties as indicators of sedimentation as it affects wetland condition. They propose that soil phosphorous (Olsen et al. 1954) in the 0- to 15-cm depth is the best indicator of wetland condition. They also recommend that organic matter content and soil texture analysis be included in future wetland condition studies. Galatowitsch and van der Valk (1996) sampled restored (less than 5 years since re-flooding) and natural prairie wetlands in north-central Iowa. They found that the restorations had only $1 / 3$ to $2 / 3$ as much organic carbon as the natural wetlands. Another project found that soils in native (i.e., reference standard) prairie pothole wetlands had as much as 1.5 percent (i.e., $1 / 3$ ) more organic carbon than restored wetlands with a cultivation history (Olness et al. 2002).

\section{Vegetation}

Major themes of the phytosociological literature for the PPR consist of zonation patterns, wetland classification, vegetation dynamics, relationships between environment and plants, and impacts of anthropogenic disturbance. All of the preceding themes are interrelated and must be viewed in concert. The reader is referred to Stewart and Kantrud (1972), Kantrud et al. (1989a), Kantrud et al. (1989b), and van der Valk (2000) for in-depth syntheses of the prairie pothole plant ecological literature. 
Specifically, factors influencing species composition and distribution along the gradient (zonation) in Prairie Pothole wetlands include hydrologic regime, salinity of water, edaphic complex, plant competition, $\mathrm{pH}$, nutrient status, and the seed banks (Dix and Smeins 1967; Walker and Coupland 1968; Walker and Wehrhahn 1971; Dirshl and Coupland 1972; Stewart and Kantrud 1972; Millar 1973; van der Valk and Davis 1978a). Zonation in prairie depressional systems is a function of the water depth and duration (van der Valk 1981). Characteristic life forms and species assemblages dominate each zone. Life forms are commonly accepted as indicators of hydroperiod (Kantrud et al. 1989b). The complexity of zonation typically increases with the length of time a wetland holds water during the growing season, and species richness generally decreases with increasing water permanence (Kantrud et al. 1989a).

Observations on vegetation zonation and plant-environmental relationships have formed the basis of wetland classification for the PPR. Stewart and Kantrud (1971) developed a classification specifically for the glaciated prairie region that was designed to classify entire basins. Classes of interest for this Guidebook are Class II, temporary ponds, and Class III, seasonal ponds and lakes. Next in this classification scheme are subclasses defined by water chemistry, ranging from fresh to moderately brackish. Following the sub-class designation, basins are further described by the central zone. Vegetation zones applicable to this Guidebook, in order of increasing degree of water permanency, are the low prairie, wet meadow, and shallow marsh (see Figure 6).

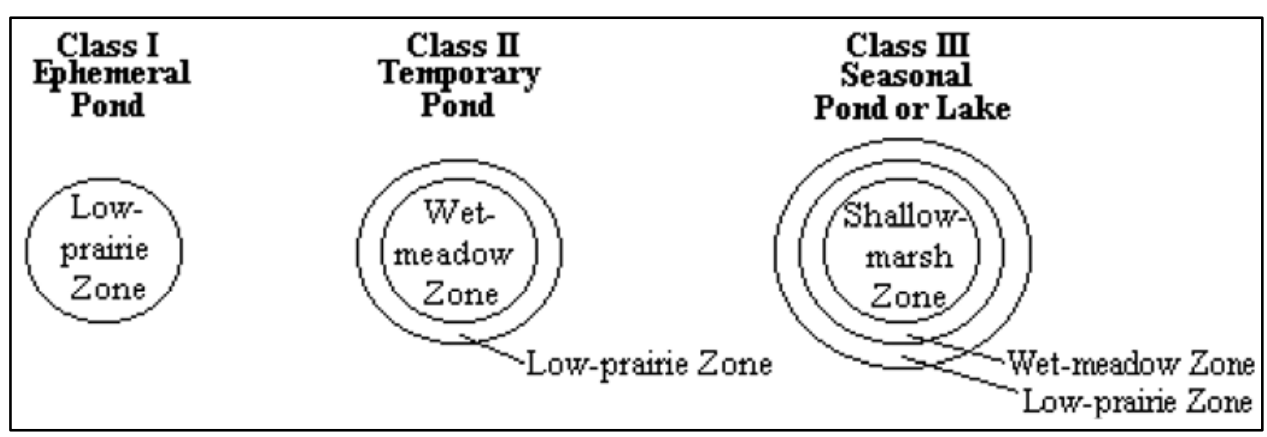

Figure 6. Generalized Stewart and Kantrud (1971) wetland classes and vegetation zones discussed in this Guidebook

Within zones, "phases" were assigned to describe variation from a "normal emergent" condition to species assemblages attributable to wet phases, drawdown conditions, water chemistry, or effects of cultivation. Floristic composition of these phases, in terms of primary and secondary species, is provided as an additional characterization. Ephemeral Ponds, Class I, are also contained in the Stewart and Kantrud (1971) classification but are not considered "jurisdictional" wetlands according to Federal wetland delineation protocol (Environmental Laboratory 1987) nor considered wetlands under the Cowardin et al. (1979) classification. They are, however, of interest for wetland functional assessment in terms of relating the site to its surrounding ecosystem. Table 6 provides a synopsis of the Stewart and Kantrud (1971) terminology used in this Guidebook and representative plant associations. Ephemeral ponds are included for illustration. A more extensive list of plant species within the PPR region can be found in Stewart and Kantrud (1972). 


\begin{tabular}{|c|c|}
\hline \multicolumn{2}{|c|}{$\begin{array}{l}\text { Table } 6 \\
\text { Stewart and Kantrud (1971) Classification Corresponding to the } \\
\text { Prairie Pothole HGM Depressional Subclass Described in This } \\
\text { Regional Guidebook }\end{array}$} \\
\hline Class and subclass (water chemistry) & Central zone and representative species \\
\hline Class I- emphemeral ponds & Low -prairie vegetation \\
\hline Fresh & Poa pratensis, Solidago altissima \\
\hline Class II - temporary ponds & Wet - meadow vegetation \\
\hline Fresh & Poa palustris, Boltonia latisquama \\
\hline Slightly Brackish & Hordeum jubatum, Calamagrostis inexpansa \\
\hline Class III - seasonal ponds and lakes & Shallow - marsh vegetation \\
\hline Fresh & Carex atherodes, Glyceria grandis. \\
\hline Slightly Brackish & Scolochloa festucacea, Eleocharis palustris \\
\hline Moderately Brackish & Alisma gramineum, Beckmannia syzigachne \\
\hline
\end{tabular}

Both allogenic and autogenic forces operate to change wetland vegetation. Vegetation responds to wet/dry cycles on both an intra- and inter-annual basis. van der Valk and Davis (1978a) described the vegetation dynamics for prairie depressional systems. The presence and abundance of each species depends on its life history strategies and its adaptation to the site. Propagule dispersal type, seed bank characteristics, competition, mortality, and various combinations of these and other environmental factors are responsible for observed plant distribution along the moisture gradient (van der Valk 1981). Zonation patterns are, therefore, a collective result of hydro-dynamics and individual species' ability to respond to changing environmental conditions.

Species assemblages also vary with the type and intensity of disturbance. Prior to European settlement, plant communities in the PPR evolved in response to fire and grazing by native ungulates. Fire suppression and changes in grazers to domesticated species have altered plant-environmental relations where the "natural disturbance regime" has been changed to an anthropogenic disturbance regime. Little is known about the environmental effects of fire in prairie wetlands (Kantrud 1986). Much of the available information is from inferences on fires set in a variety of vegetation types and some general observations on emergent vegetation response. Fire has been used as a management tool to increase cover interspersion by opening up dense emergent stands, to control exotic species in combination with other treatments, or to select for food sources in waterfowl management practices.

Much more is known about the effects of grazing on wetland plant communities. Low to moderate grazing intensity results in greater plant species diversity and the development of more intricate patterns and sharper boundaries among plant communities (Bakker and Ruyter 1981; Kantrud 1986). Overgrazing can decrease productivity, increase water turbidity, or reduce cover and habitat structural components for fauna requiring wetlands for some or all of their life cycle requirements.

Artificial drainage and cultivation of wetlands habitat has altered species composition and selected for annual or invasive species, or both. Drainage 
features inhibit characteristic hydro-dynamics, which in turn selects for species with opportunistic life-cycle requirements. Cultivation was considered the most drastic type of disturbance by Walker and Coupland (1968) and considered to "override" the effects of other natural gradients. Dix and Smeins (1967) also addressed cultivation and observed an irregularity in stand ordinations for cultivated depressions. As inferred from a comparison of vegetation in less disturbed sites, these authors noted that vegetation composition for cultivated areas was "wetter" on the moisture gradient than would be anticipated.

In their evaluation of vegetation-based indicators for wetland assessment, Kantrud and Newton (1996) stated that basins in "poor-quality" watersheds tended to have fewer communities (zones). Wetland basins within a cultivated catchment also have greater fluctuation in water levels as compared to those having grassland catchments (Euliss and Mushet 1996). Transport of sediments from the tilled upland to the basin is accelerated during runoff events (Martin and Hartman 1987). The covering of seed banks with sediments inhibits recolonization. Disturbance to a wetland by repeated cultivation probably affects all stages in the plant regeneration cycle, an important mechanism in the maintenance of plant species diversity (Grubb 1977). Gleason et al. (2002) evaluated the effects of sediment burial on emergence of plants and invertebrates from seed and egg banks. For vegetation aspects of their study, sediment load experiments indicated that burial depths of only $0.5 \mathrm{~cm}$ caused a 91.7 percent reduction in seedling emergence.

\section{Fauna}

The faunal component of Northern Prairie depressional systems has been extensively studied for both vertebrate and invertebrate taxa. Major syntheses of the literature can be found in Hubbard (1988); Kantrud et al. (1989b); Swanson and Duebbert (1989); Murkin (1989); Batt et al. (1989); and Fritzell (1989). Wet/dry cycles, vegetation composition, water chemistry, and anthropogenic disturbance have all been described as major factors controlling faunal composition. The PPR is a major breeding area for waterfowl (Weller 1987) and, therefore, most literature is focused on relationships of waterfowl to habitat in terms of pair use of different wetland classes, feeding ecology, and nutritional needs for fulfilling life-cycle requirements.

Important roles of invertebrates in ecosystem processes have been summarized by Euliss et al. (1999). These roles include trophic linkage from primary production to secondary consumers, providing specific nutritional components, such as amino acids and micronutrients, for vertebrates, and detrital processing of wetland organic material. This HGM subclass provides isolation for breeding pairs and supplies invertebrate foods for waterfowl early in the nesting period. Small, shallow wetlands in the PPR are the first to "ice-out" in the spring. Rapid warming of these shallow wetlands results in early development of invertebrate populations (Swanson et al. 1974) and provides a major source of protein for laying female ducks (Kantrud et al. 1989a). 
Adamus (1996) stated that there is limited information on amphibian communities for prairie wetlands, but available information suggests sensitivity to some contaminants and lowered population viability from habitat fragmentation. Lehtinen et al. (1999) examined the significance of habitat loss and fragmentation affecting amphibian assemblages in glacial marshes. Results indicated that amphibian species richness was lower with greater wetland isolation and road density.

The PPR ecosystem supports more than 200 species of migratory birds and produces more than 50 percent of the ducks inhabiting North America, even though it accounts for only 10 percent of the entire North American duck breeding area. Kantrud et al. (1989b) discussed the importance of pothole wetlands with observations from North Dakota. Approximately 39 percent of the 353 valid species on the North Dakota bird list (Faanes and Stewart 1982) use wetlands. Of the 223 species with known or inferred breeding status in North Dakota, 26 percent are marsh or aquatic birds other than waterfowl. Information on use of prairie wetlands by migrants and summer visitors is limited, but the regional landscape provides habitat for millions of arctic and subarctic nesting shorebirds and neo-tropical migrants that pass through the PPR each spring and fall.

Avian species habitat preference, response to hydrodynamics, and vegetation manipulation have been summarized by Weller and Spatcher (1965), Swanson and Duebbert (1989), Batt et al. (1989), and Kantrud (1986). These studies state that decreased wetland use by water birds is a result of anthropogenic disruption to natural ecological processes in the upland catchment or within the wetland. In the absence of natural processes, succession trends toward establishment of monotypic hydrophytic stands, thereby decreasing habitat suitability. Adamus (1996) also stated that factors affecting faunal use are principally disturbance oriented and can be interpreted through vegetation structure or other physical features of the surrounding habitat.

Use of prairie wetlands by mammals has been described Fritzell (1989). Species were categorized on the basis of the degree of dependence on wetlands for cover or to obtain a substantial portion of their food. The majority of mammals discussed by Fritzell (1989) regularly makes extensive use of prairie wetlands or completes their life-cycle in moist transition areas. Wetland habitats are of direct importance to many species, and some mammals markedly affect other components of wetland ecosystems. Muskrats (Ondatra zibethicus) are major elements of prairie wetland ecosystems - they alter vegetation composition, habitat structure, and nutrient exchange. Mink are closely associated with basin wetlands and can cause significant mortality of marsh birds (Kantrud et al. 1989a).

When habitat functions are evaluated, an individual assessment site must be analyzed in the context of the surrounding wetland complex. Heterogeneity of wetland types within a complex creates habitat diversity, inducing high species richness (Weller 1978). Talent et al. (1982) found that as many as 10 different basins close to one another were used by mallard broods. Hubbard (1988) discussed the shift in use by waterfowl broods from basins that were seasonally flooded to basins that were semi-permanently flooded within a complex when water availability decreased from year to year. Cowardin et al. (1995) evaluated dabbling duck production and recruitment based on inter-annual precipitation 
cycles. Pond density (basins holding water) decreased within the period of study (1987-1990) in response to drought. Density of breeding pairs per pond was inversely related to pond density, suggesting that breeding ducks tended to concentrate on the remaining ponds as drought intensified. Recruit production followed a similar pattern to breeding size populations.

On both temporal and spatial scales, closeness of wetland basins of different hydroperiods is critical to resource availability and subsequent exploitation by waterfowl. According to Johnson et al. (1994), understanding these two characteristics of the region - spatial heterogeneity and temporal instability-is essential to sound habitat management. Habitat suitability for some species is related to local vegetation conditions within wetlands, while suitability for others is related to landscape structure at larger scales. Gibbs (1993), through simulation modeling, examined how loss of small wetlands altered the wetland mosaic and thereby affected meta-populations of wetland associated organisms. Results suggest that small wetlands play a greater role in meta-population dynamics of certain wetland dependent taxa than the "modest" area of small wetlands may imply. At larger spatial scales, an unfragmented prairie/wetland mosaic provides habitat for more species than wetlands isolated in an agricultural landscape (Naugle et al. 2003).

\section{Anthropogenic Impacts}

PPR wetlands are among the most productive ecosystems in the world. The characteristic drying and re-wetting cycles result in tremendous turnovers in primary productivity and elemental cycling. The high productivity and levels of detritus result in biodiversity comparable to rain forests. The extreme productivity of these wetlands also makes them the target of land use conversion. Many of the potholes were drained to create new lands for agriculture and to increase the efficiency of tillage operations. Wetland functions are lost when human activities physically convert wetlands to upland or deepwater habitats. Often, however, the conversion is not complete, and areas that continue to exist as wetlands have diminished functions.

Despite a lack of precise data on wetland losses in the PPR, the available information indicates losses have been significant. There is widespread agreement that the dominant land use in the region - agriculture - has been the primary cause of continuing wetland decline. Dahl (1990) estimated wetland area losses (percent) from the 1780's to 1980's in the five-state PPR (Table 7). 


\begin{tabular}{|c|c|c|}
\hline \multicolumn{3}{|c|}{$\begin{array}{l}\text { Table } 7 \\
\text { Estimated Wetland Losses for States Within the Prairie Pothole } \\
\text { Region }\end{array}$} \\
\hline State & Percent Loss & Remaining wetland area (ha.) \\
\hline lowa & 89 & 170,870 \\
\hline Minnesota & 42 & $3,523,500$ \\
\hline Montana & 27 & 340,322 \\
\hline North Dakota & 49 & $1,008,450$ \\
\hline South Dakota & 35 & 720,900 \\
\hline
\end{tabular}




\section{Wetland Functions and Assessment Models}

\section{Overview}

The following functions of PPR wetlands were selected for model development.

a. Storing water.

$b$. Recharging groundwater.

c. Retaining particulates (physical processes).

d. Removing, converting, and sequestering dissolved substances (biochemical processes).

e. Plant community resilience and carbon cycling.

f. Providing faunal habitat.

\section{Reference Data}

A total 180 reference sites were evaluated. Two data sets were used in these analyses, one collected by the inter-agency personnel $(n=65)$ and the other collected by the U.S. Geological Survey, Northern Prairie Science Center $(n=115)$ as part of their evaluation of wetland restoration activities throughout the PPR. A detailed description of their study approach and metrics is described in Euliss and Gleason (1997). Data were collected from 1995 through 1999. The model variables selected for describing PPR functions were derived from these data sets.

The reference sites encompass a range of variation, from cultivated to relatively undisturbed. Each site was described as belonging to one of the following treatment groups, which may be referred to in discussion of some variables:

a. Restored wetlands less than 5 years old $(\mathrm{n}=19)$ : Wetlands in the Conservation Reserve Program (CRP) habitats or similar grasslands restored for 1-5 years. CRP type habitats are defined as once farmed lands that have been planted back to grassland cover. 
b. Restored wetlands more than 5 years old $(\mathrm{n}=33)$ : Wetlands in CRP or similar grasslands restored for more than 5-10 years.

c. Drained wetland analogue $(\mathrm{n}=35)$ : These are drained wetlands in CRP habitats or similar grasslands and will be similar to restored wetlands with respect to land-use history, wetland area, catchment area, and soils.

d. Non-drained wetland analogue $(\mathrm{n}=33)$ : These are natural wetlands in CRP habitats or similar grasslands and are similar to restored wetlands with respect to land-use history, wetland area, catchment area, and soils.

e. Reference wetlands $(n=38)$ : These are natural wetlands in grasslands that were never tilled. This may include hay land and native prairie habitats. Hence, land-use history of these wetlands will differ from the other categories, but will be similar with respect to wetland area, catchment area, and soils. This category was the least disturbed anthropogenically and served as candidates for potential reference standard sites.

f. Cultivated wetlands $(\mathrm{n}=22)$ : Those having a cropping history longer than 5 years.

The sampled reference domain includes portions of Montana, North Dakota, South Dakota, Minnesota, and Iowa. Reference sites were also stratified by the Missouri Coteau, Prairie Coteau, and Glaciated Plains physiographic regions. Locations and physiographic group designations for the reference sites are provided in Appendix C-1.

The HGM variables are scale dependent, incorporating zonal, site, catchment, and landscape metrics. Thematic data collected are described below and also summarized in Table 8.

For characterization of each reference site, transects were established so as to intersect the observed vegetation zones. Transect endpoints extended through the hydric soil boundary to surrounding uplands. At selected sites, a secondary transect line was established perpendicular to the main axis when needed. Soils and vegetation data were collected at intervals along the main and secondary transect lines. Vegetation sample locations along the transect were selected so as to characterize species' composition and abundance within each zone. A modified Daubenmire (1959) canopy coverage scale was used. Soil profile descriptions and lab samples were collected at vegetation sampling locations, while additional soil profiles were evaluated at the discretion of the project's soil scientist. Basin topographic data and documentation of sites' features were collected using a theodolite. Attributes collected consisted of elevation and location of hydric soils, plant community boundaries, ditches, drainage tile intakes, culverts, transect endpoints, natural outlet, wetland depths, and locations of vegetation and soils samples.

For catchment characterization, boundaries and area were determined from field surveys, aerial imagery, and topographic maps. Catchment land use and land cover were documented in the field or from aerial photography. Figure 7 shows the spatial relationship of the vegetation zones, wetland, and catchment. 


\begin{tabular}{|c|c|}
\hline \multicolumn{2}{|c|}{$\begin{array}{l}\text { Table } 8 \\
\text { Information Collected at Reference Sites by Scale and Themes } \\
\text { (Adapted from Euliss and Gleason 1997) }\end{array}$} \\
\hline Wetland basin & $\begin{array}{l}\text { UTM coordinates } \\
\text { Relative elevations } \\
\text { Cropping history } \\
\text { Area } \\
\text { Shoreline length }\end{array}$ \\
\hline Soils & $\begin{array}{l}\text { Classification } \\
\text { Percentage organic and inorganic } \\
\text { Particle size } \\
\text { Soil EC }\end{array}$ \\
\hline Hydrology & $\begin{array}{l}\text { Water depths } \\
\text { Maximum water depth } \\
\text { Natural outlets and inlets } \\
\text { Type of drainage } \\
\text { Age of restoration } \\
\text { Number of years ponded (since restoration) } \\
\text { Length of time drained } \\
\text { Completeness of drainage } \\
\text { Elevation drainage plug } \\
\text { Maximum elevation for enhancement } \\
\end{array}$ \\
\hline Vegetation & $\begin{array}{l}\text { Wetland class } \\
\text { Number and extent of vegetation zones } \\
\text { Percent open water } \\
\text { Floristic composition cover estimates }\end{array}$ \\
\hline Catchment basin & $\begin{array}{l}\text { Cropping history } \\
\text { Current land use } \\
\text { Area } \\
\text { Slope/elevation } \\
\text { Generalized vegetation composition }\end{array}$ \\
\hline Landscape-wetland complex & $\begin{array}{l}\text { Inter-wetland distance } \\
\text { Wetland area } \\
\text { Number of wetland basins } \\
\text { Linear distance of roads and drainage features }\end{array}$ \\
\hline
\end{tabular}

For landscape characterization, Geographic Information System (GIS) technology was used in landscape scale analyses. ARC-INFO software (ERSI, Redlands, California) was used for all data processing and analysis of digital data. Digital mapping data pertinent to this study included that of the National Wetland Inventory (NWI) (Wilen et al. 1996) and U.S. Census Bureau 1:100,000 scale data. NWI digital polygon data were recoded into single basin classes as described by Cowardin et al. (1995). Selected linear features from the preceding sources were also used in reference site landscape characterization.

A Landscape Assessment Area (LAA) was circumscribed by a $1.6-\mathrm{km}$ radius from the center of the assessment wetland. The LAA area evaluated was $8.1 \mathrm{~km}^{2}$. This convention was artificially defined and is considered the surrogate for assessing the wetland complex. Inter-wetland distance of a reference site to the nearest five wetlands was measured, as well as the number of basins and area of wetlands within the complex. NWI linear wetland data with an " $x$ " modifier (excavated) or "d" modifier (partly drained), and all classes of roads derived from the U.S. Bureau of Census data were also summarized for the LAA. 


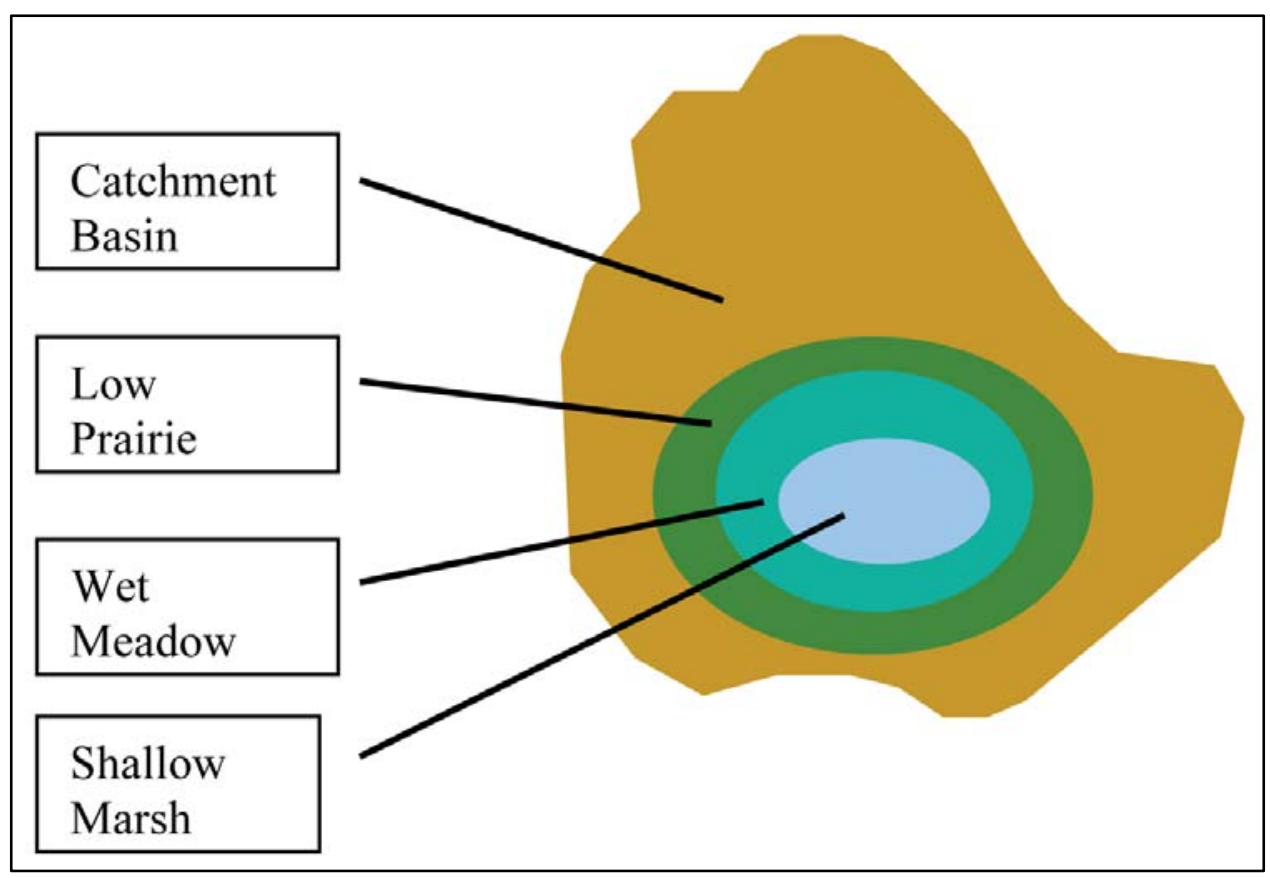

Figure 7. Generalized plan view of vegetation zones in relation to the catchment

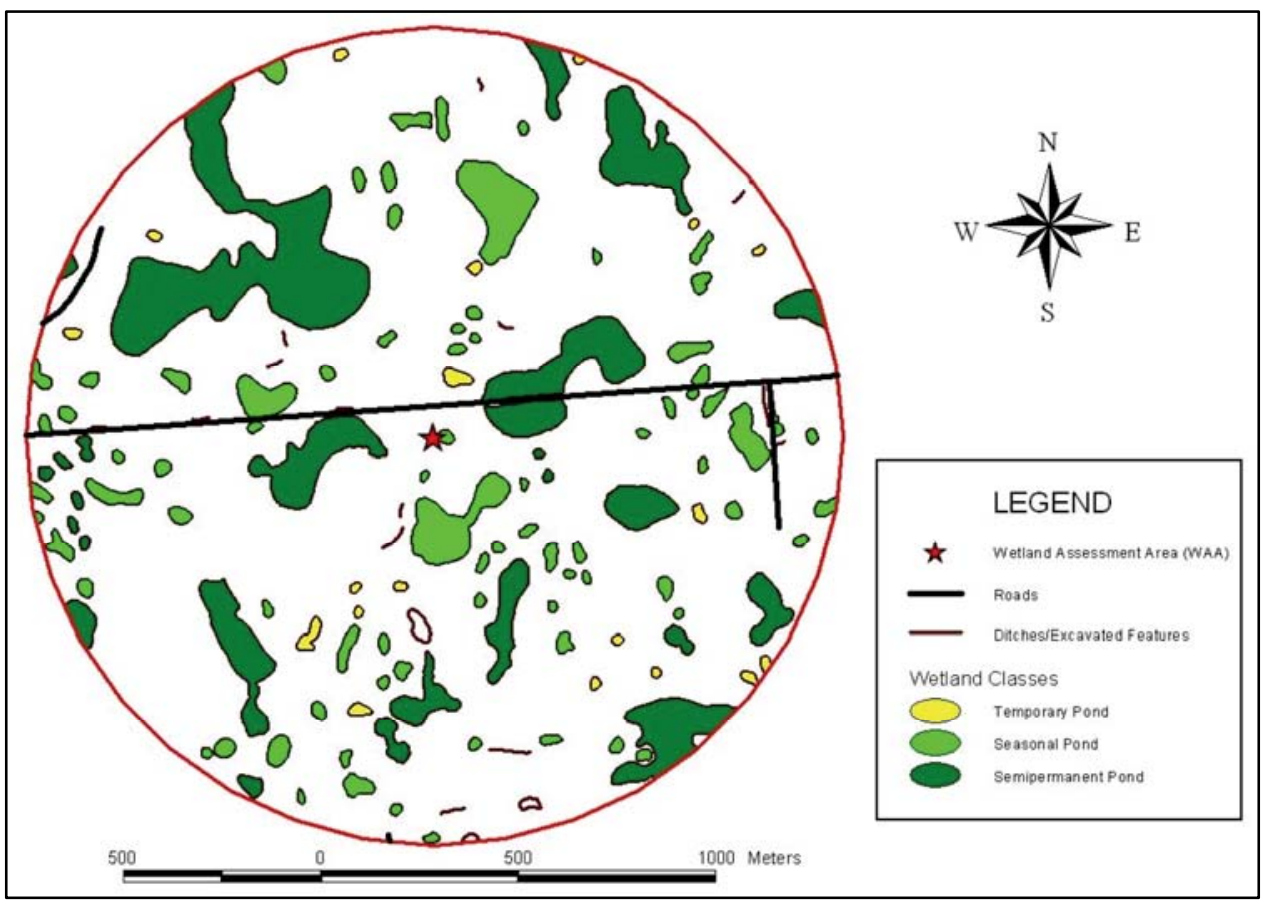

Figure 8. Landscape assessment area associated with a reference site in Stutsman County, North Dakota 


\section{Model Variables}

The following variables integrate the results of reference data collection and are used to calculate the functional capacity indices:

- Vegetation

$V_{\text {GRASSCONT }}=$ continuity of grassland adjacent to the wetland

$V_{\text {GRASSWIDTH }}=$ width of grassland perpendicular to the wetland

$V_{\text {VEGCOMP }}=$ vegetation composition

- Soils

$V_{\text {RECHARGE }}=$ estimated soil recharge potential

$V_{\mathrm{SED}}=$ sediment deposition in the wetland

$V_{\mathrm{SQI}}=$ soil quality index

$V_{\mathrm{SOM}}=$ soil organic matter

- Hydrogeomorphic

$V_{\text {OUT }}=$ wetland surface outlet

$V_{\text {SUBOUT }}=$ subsurface drainage

$V_{\text {SOURCE }}=$ reduction or increase in catchment area

$V_{\mathrm{EDGE}}=$ modified shoreline irregularity index

$V_{\text {CATCHWET }}=$ ratio of catchment area to wetland area

- Land use and landscape

$V_{\text {UPUSE }}=$ land use within the catchment

$V_{\text {WETPROX }}=$ proximity to nearest wetlands

$V_{\text {WETAREA }}=$ wetland density in the landscape assessment area

$V_{\text {BASINS }}=$ number of basins in the landscape assessment area

$V_{\text {HABFRAG }}=$ sum of the length of roads and ditches in the landscape assessment area

In the next sections, each variable is discussed in terms of the metrics, measurements, and the relationship of the metric to the to the variable subindex score. After this information is presented, assessment models for each of the functions are provided.

\section{Vegetation variables}

Grassland Continuity ( $\left.V_{\text {GRASSCONT }}\right)$. This variable represents the average continuity of grassland around the perimeter of the wetland. Grassland continuity is measured by determining the perimeter (in meters) of the wetland boundary that is contiguous with grassland. This measure is then divided by the total perimeter of the assessment wetland and is expressed as a percentage for calculation of the variable subindex score. Percent continuity scores for the reference sites ranged from 0-100 percent. Based on the range of values at reference sites, a sub-index of 0 indicates that $n o$ grassland was contiguous with the wetland edge and a sub-index of 1.0 indicates the entire wetland perimeter was surrounded by grassland. The relationship of the metric to the sub-index score is presented in Figure 9. 


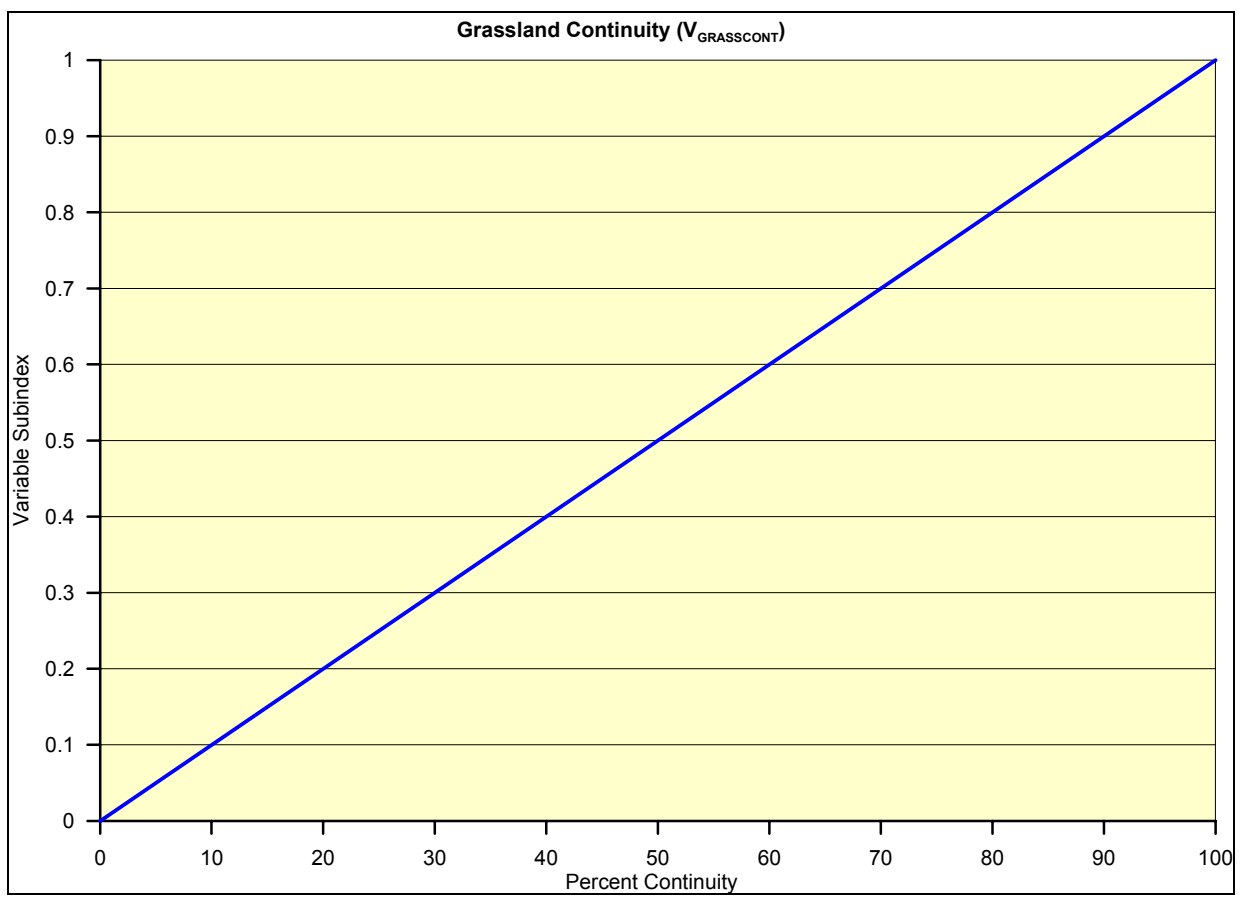

Figure 9. Relationship between the continuity of grassland adjacent to the wetland and the variable subindex

Grassland Width ( $\left.V_{\text {GRASswidTH }}\right)$. This variable represents the average width in meters of grassland adjacent to the wetland edge. Grassland width is measured perpendicular from the wetland perimeter to a length $15 \mathrm{~m}$ distant. The width of grassland is measured at a minimum of 12 equidistant intervals around the perimeter and the average width determined. A score of 0 indicates that there is no grassland surrounding the wetland. A variable sub-index score of 1.0 is assigned when the average grassland width is at least $15 \mathrm{~m}$. For $n=180$, the mean value was $12 \mathrm{~m}$, with a range from $0-15 \mathrm{~m}$. The relationship of the metric to the sub-index score is presented in Figure 10.

Vegetation Composition ( $\boldsymbol{V}_{\text {VEGCOMP }}$ ). This variable represents the floristic quality as determined from a field survey of species present within the wetland. The vegetation within a wetland is assumed to indicate overall native species richness and diversity. Calculation of this variable has been modified from the Floristic Quality Assessment Index procedures as described by Wilhelm and Ladd (1988). This vegetation based index has also been used by Swink and Wilhelm (1994), Andreas and Lichvar (1995), Herman et al. (1997) and Fennessy et al. (1998) to assess ecological integrity and to assist in natural areas analyses.

The process for development of this index depends upon assigning indicators to the regional flora of interest. Each species is assigned an indicator value based upon procedures in Taft et al. (1997). This involves assignment of a coefficient of conservatism (termed "C" value) to species records. Individual species indicators may range from $0-10$ with " 0 " being considered invasive species and " 10 " being considered the highest fidelity to natural areas. General categories for species assignments consist of the following: 


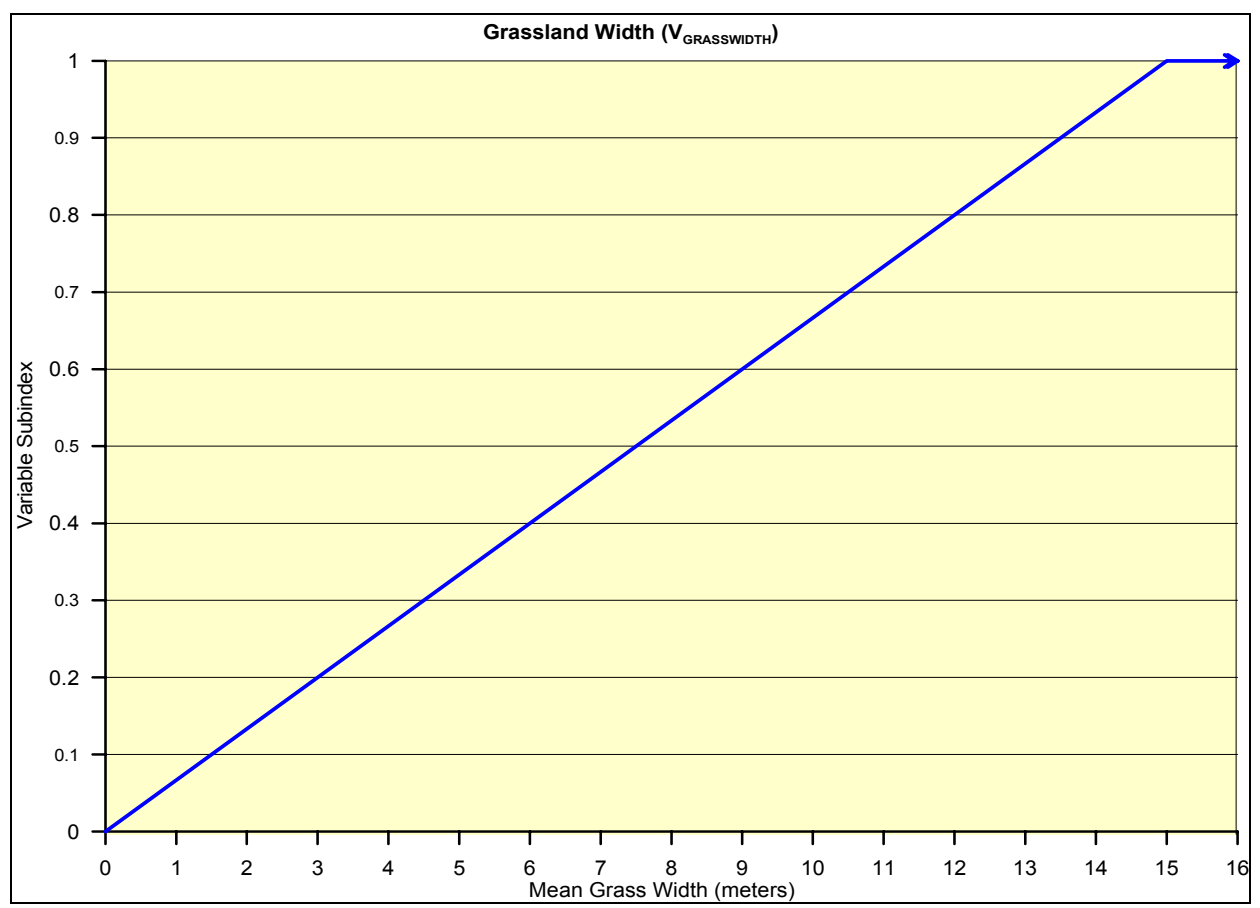

Figure 10. Relationship between the grassland width perpendicular to the assessment wetland and the variable subindex

- $\quad 0-1$ : Taxa that are adapted to severe disturbance, particularly anthropogenic. Disturbance occurs so frequently that often only brief periods are available for growth and reproduction. Generally considered ruderal species-opportunistic invaders.

- 2-3: Taxa within this category are associated with more stable, though degraded habitat. Generally considered ruderal-competitive species, found in a variety of habitats.

- 4-6: Taxa that have a high consistency of occurrence within a given community type and will include many dominant or matrix species for several habitats. Species will persist under moderate disturbance.

- 7-8: Taxa associated mostly with natural areas but can persist where the habitat has been somewhat degraded. Increases in the intensity or frequency of disturbance may result in reduction in population size, or taxa may be subject to local extirpation.

- 9-10: Taxa exhibit a high degree of fidelity to a narrow range of synecological parameters. Species within this category are restricted to relatively intact natural areas.

Source data for assignment of "C" values were from Northern Great Plains Floristic Quality Assessment Panel (2001), with modification. Modifications in assignments relate to woody and non-native species. Native woody species were considered "invasive species" for this herbaceous, depressional subclass. Also, for those plant records having a '*' assignment, meaning non-native taxa, a " 0 " 
was assigned. Species records associated with reference data and "C" value assignments can be found in Appendix C-2. Botanical nomenclature follows conventions of the Northern Great Plains Floristic Quality Assessment Panel (2001).

The Floristic Quality Index is a species richness estimate that uses a square root transformation of $N$ to limit the influence of area alone on species richness (Taft et al. 1997). Calculation of the Floristic Quality Index (FQI) is as follows:

a. Determine the mean coefficient of conservatism $(C)$ by summarizing all coefficients in the inventory unit (reference site or WAA), and divide by the number of taxa $(N)$, or $\bar{C}=\sum C / N$.

$b$. Multiply the mean coefficient of conservatism $(C)$ by the square root of the total number of taxa $(N)$.

The FQI is represented mathematically as:

$$
\mathrm{FQI}=\bar{C} \times(\sqrt{N})
$$

Analyses of reference data indicated a positive correlation of FQI with native species richness and native species abundance. For $n=180$, the Spearman Rank Correlation Coefficient indicated $r=0.908 p>0.01$ for FQI versus native species richness, and for FQI versus native species abundance, $r=0.373, p>0.01$. The mean value of FQI scores was 10.30. Index values ranged from 0.33 to 30.04 . The reference standard condition for this variable was set at values greater than or equal to 16.00 . Owing to the variability of above and below ground biomass on an intra- and inter-annual basis, FQI is used as a surrogate for live biomass. Correlations of floristic quality indices with biomass have been reported by Fennessey et al. (1998b) in Ohio wetlands and by Lawrence (personal communication) for Rainwater Basin depressional wetlands. The relationship of the metric to the sub-index score is presented in Figure 11.

The FQI, using species surveys, is the preferred method for characterization of vegetation composition. Alternate measures for this variable are also based upon plant indicator rankings and are described in Appendix C-3. Measures include a dominance option based on percent concurrence with reference standard dominant species and a weighted average option for use where plant abundance is needed in analyses. Use of these alternate methods is based upon the level of detail required for user-defined assessment objectives.

\section{Soil variables}

Soil is a major structural component of wetland ecosystems, and it has several important functions within them. Soil is a medium for plant growth, while soil biological, chemical, and physical properties influence the structure and function of plant communities. Second, soil properties control the fate of water in the hydrologic cycle. The soil acts as a system for water supply and purification. 
Soil provides habitat for living organisms. Many of these organisms feed on waste products and body parts of other organisms, releasing their constituent elements back into the soil for uptake by plants. The soil thus acts as a recycling system for nutrients and organic wastes (Montgomery et al. 2001). The soil variables used in this guidebook focus on soil properties to estimate the degree of sedimentation, to physically allow movement and storage of water, and biogeochemical cycling, and to provide plant habitat and a building block for wetland food webs. Four variables are presented. For one variable, $V_{\mathrm{SOM}}$, direct and indirect metrics are provided.

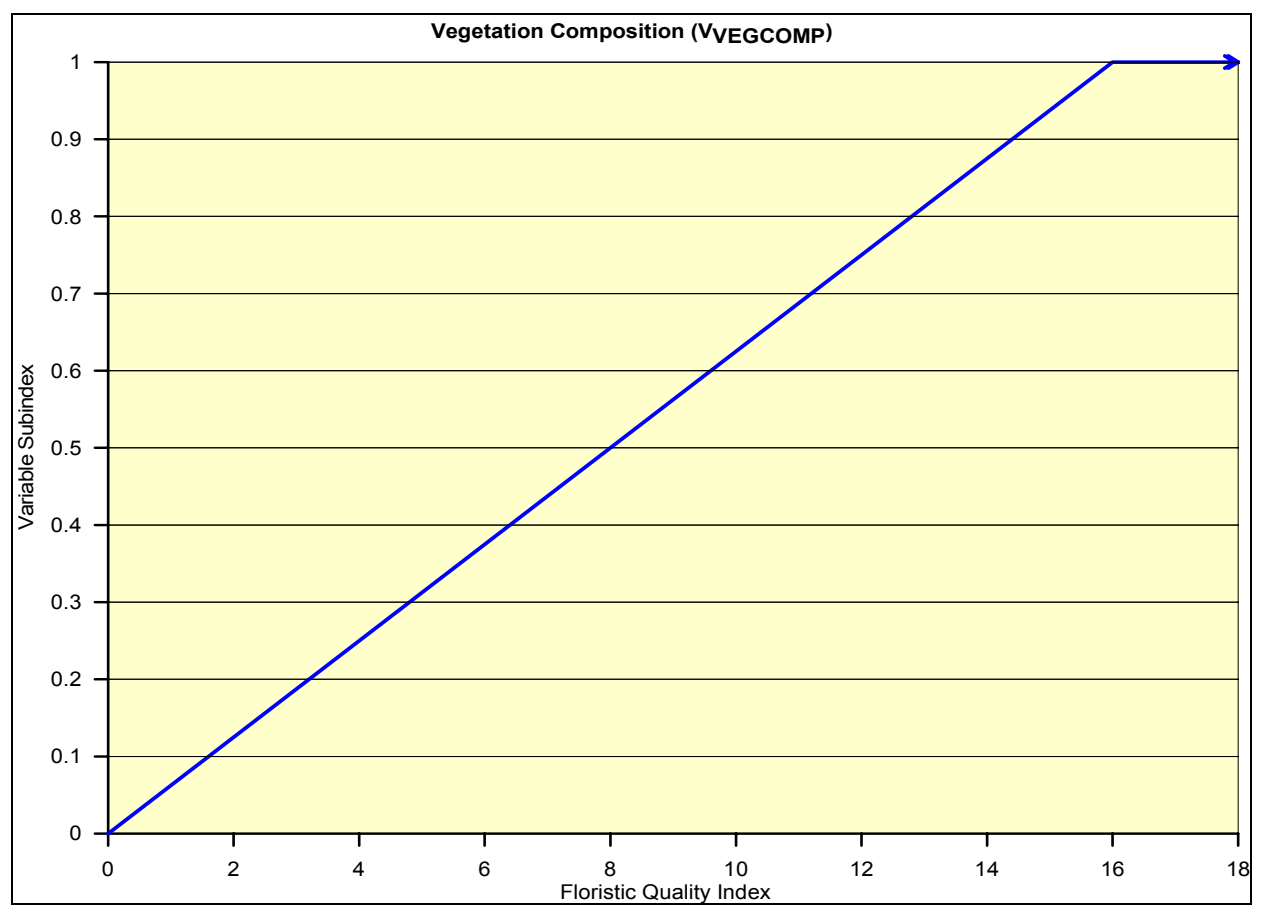

Figure 11. Relationship between the FQI and the variable subindex

Soil Recharge Potential ( $\boldsymbol{V}_{\text {RECHARGE}}$ ). This variable is an indirect measure of potential recharge based on the areal extent of soil types (soil series or Great Group) in the wetland. It is determined on-site by making a site-specific soil map and obtaining the extent of different soil types. The soil types are then used in conjunction with Appendix C-4 to determine a Soil Recharge Potential for the site. For example, wetland area is 80 percent Parnell soil and 20 percent Vallers soil.

Site Soil Recharge Potential $=(0.8 \times 1.0)+(0.2 \times 0)=0.80$

If a soil scientist is not available, a more qualitative method is described below in Table 9. If soil mapping (i.e., soil survey) information is not available, NWI water regimes can be used as a coarse estimation of the variable. For this method, PEMA = sub-index of 1.0, PEMC $=$ sub-index of 0.5 . 


\begin{tabular}{||l|l||}
\hline Table $\mathbf{9}$ \\
Qualitative Method to Determine Soil Recharge Potential (V \\
\hline \hline Measurement or Condition & Index \\
\hline \hline $\begin{array}{l}\text { Soil map unit has recharge potential } \geq 0.75 \text { and NWI water regime is A (e.g., PEMA) (i.e., } \\
\text { wet meadow vegetative zone) }\end{array}$ & 1.0 \\
\hline $\begin{array}{l}\text { Soil map unit recharge potential is } 0.5 \text { to }<0.75 \text { and on-site dominant NWI water regime is } \\
\text { A. } \\
\text { OR } \\
\text { Soil map unit recharge potential is }>0.75 \text { and on-site dominant NWI water regime is C (e.g. } \\
\text { PEMC) (i.e. shallow marsh and wet meadow vegetative zones exist) }\end{array}$ & 0.67 \\
\hline Soil map unit recharge potential is 0.25 to 0.75 and NWI water regime is C. & 0.33 \\
\hline Soil map unit recharge potential is $<0.25$ and NWI water regime is C & 0.1 \\
\hline \hline
\end{tabular}

Sediment $\left(\boldsymbol{V}_{\text {SED }}\right)$. This variable is defined as the extent of sedimentation within the wetland from culturally accelerated sources. $V_{\text {SED }}$ is estimated by determining the depth to the $\mathrm{B}$ horizon for four replicate, averaged sample pedons within the outer ponded depressional soils. Generally, the soils that occur in the area where this is assessed are soils such as Tonka, Tetonka, and Typic or Cumulic Endoaquolls. B depths for the reference sites ranged from 0.0 to $112.0 \mathrm{~cm}(n=180)$. The depth to B in reference standard sites varied throughout the reference domain from a maximum of $74 \mathrm{~cm}$ in the Cumulic soils in Iowa, to a minimum of $12 \mathrm{~cm}$ in the western PPR.

Because of the natural variability associated with soil formation, attributable primarily to climate across the PPR, reference sites were separated by Eastern (Minnesota, Iowa) and Western (South Dakota, North Dakota, and Montana) subreference domains. For reference standard sites in the Eastern PPR, the mean depth to the $\mathrm{B}$ horizon is $50 \mathrm{~cm}$, with a range of 28 to $72 \mathrm{~cm}$. For reference standard sites in the Western PPR, the mean depth to the B horizon is $32 \mathrm{~cm}$, with a range of 19 to $45 \mathrm{~cm}$. Based on data from reference wetland sites, these intervals are assumed to be in the range of natural variation for PPR wetlands and reflect the reference standard condition. As depth to the B decreases, a linearly decreasing sub-index down to 0.1 is assigned. This would indicate excessive sedimentation, resulting in $\mathrm{C}$ horizons being described at the soil surface. Increases in $\mathrm{B}$ depth beyond the reference standard depth are assumed to be from culturally accelerated erosion rates from within the catchment or deposition of fill. Therefore, sub-index scores are assumed to decrease inversely from this point. A variable sub-index score of 0.0 is only assigned if the wetland has been filled to the point of no longer being a depression. None of the sampled reference sites meet this condition. The relationship of the metric to the sub-index score is presented in Figure 12. 

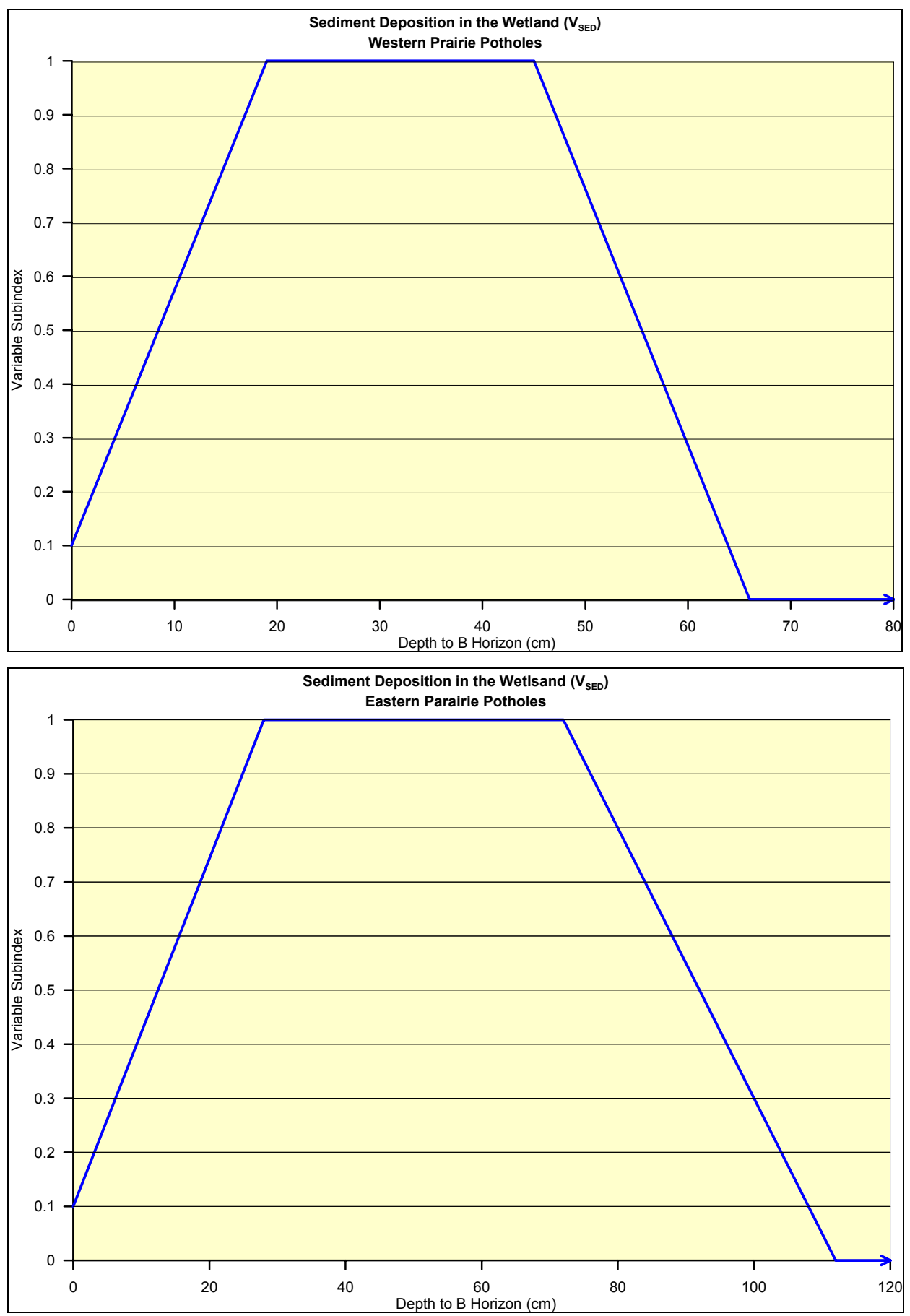

Figure 12. Relationship between the B horizon depth and the variable sub-index for Western and Eastern Prairie Potholes

Soil Quality Index ( $\left.V_{\mathrm{SQI}}\right)$. This variable represents the physical integrity of the upper $30 \mathrm{~cm}$ of the soil (A or Ap horizon) within the outer ponded depressional soil. This variable was evaluated in soils such as Tonka, Tetonka, and Webster. This variable is not calibrated for soils with highly calcareous layers near the surface (i.e., Calciaquolls). "Better" soil quality values on similar soils under different management may indicate soils that have improved aggregation 
and greater macroporosity, both of which may be related to greater soil biological activity (Lowery et al. 1996). Water moving through the soil is important for maintaining plant growth, preventing erosion, carrying solutes into the soil biological "filter," and maintaining wetland surface and soil water storage capability. Soil morphology has been used to estimate permeability (i.e., hydraulic conductivity) (O’Neal 1952; Bouma and Hole 1971; McKeague, Wang, and Topp 1982; Kooistra et al. 1985) and, more recently, soil quality (Grossman et al. 2001).

This variable is measured by describing the soil structure, soil pores and rupture resistance (i.e., consistence) of the upper $30 \mathrm{~cm}$ (Soil Survey Division Staff 1993). Numbers assigned for each characteristic are listed in Table 10. It is recommended that this procedure be used by experienced soil scientists, or by specifically trained personnel.

\begin{tabular}{|c|c|c|c|c|c|c|}
\hline $\begin{array}{l}\text { Table } 10 \\
\text { Soil Chara } \\
\text { Quality Inc }\end{array}$ & $\begin{array}{l}\text { cteristics } E \\
\text { ex }\left(V_{\text {SQI }}\right)\end{array}$ & aluated & Determ & ation of $t$ & le Physi & al Soil \\
\hline & & Assi & ed Value & & & \\
\hline Characteristic & 0 & 1 & 1.5 & 2 & 2.5 & 3 \\
\hline Pores & None & Few & \begin{tabular}{|l|} 
Few to \\
Common
\end{tabular} & Common & $\begin{array}{l}\text { Common to } \\
\text { Many }\end{array}$ & Many \\
\hline $\begin{array}{l}\text { Pore } \\
\text { Continuity }\end{array}$ & None & Low & & Moderate & & High \\
\hline Structure & Massive & $\begin{array}{l}\text { Not } \\
\text { Compound }\end{array}$ & & Compound & & \\
\hline Consistence & $\begin{array}{l}\text { Extremely } \\
\text { Firm or harder }\end{array}$ & $\begin{array}{l}\text { Firm and } \\
\text { Very Firm }\end{array}$ & & Friable & & $\begin{array}{l}\text { Very } \\
\text { Friable }\end{array}$ \\
\hline
\end{tabular}

The summation of these values from a soil description is then used to determine the physical Soil Quality Index (SQI). Data are averaged across replicates within the outer, temporary (i.e., wet meadow) depressional zone. The possible range of values for the SQI is a minimum of 0 (a parking lot) and a maximum of 11 . The actual range for reference data is 3 to 11 . A variable sub-index score of 1.0 was assigned for SQI values of greater than or equal to 10 . The relationship of the metric to the sub-index score is presented in Figure 13.

The rationale for using the SQI as a surrogate for actual measures of organic carbon was verified by non-parametric statistics. The SQI was positively correlated to soil organic carbon (Figure 14). For $n=123$, the Spearman Rank Correlation Coefficient indicated a significant correlation of SQI vs. percent organic carbon $(r=0.298, p>0.01)$.

Exploratory data analyses of the treatment groups also indicated that the SQI is inversely related to soil bulk density (Figure 15). For $n=48$, the Spearman Rank Correlation Coefficient indicated a significant correlation of SQI vs. bulk density $(r=-0.302, p>0.01)$. 


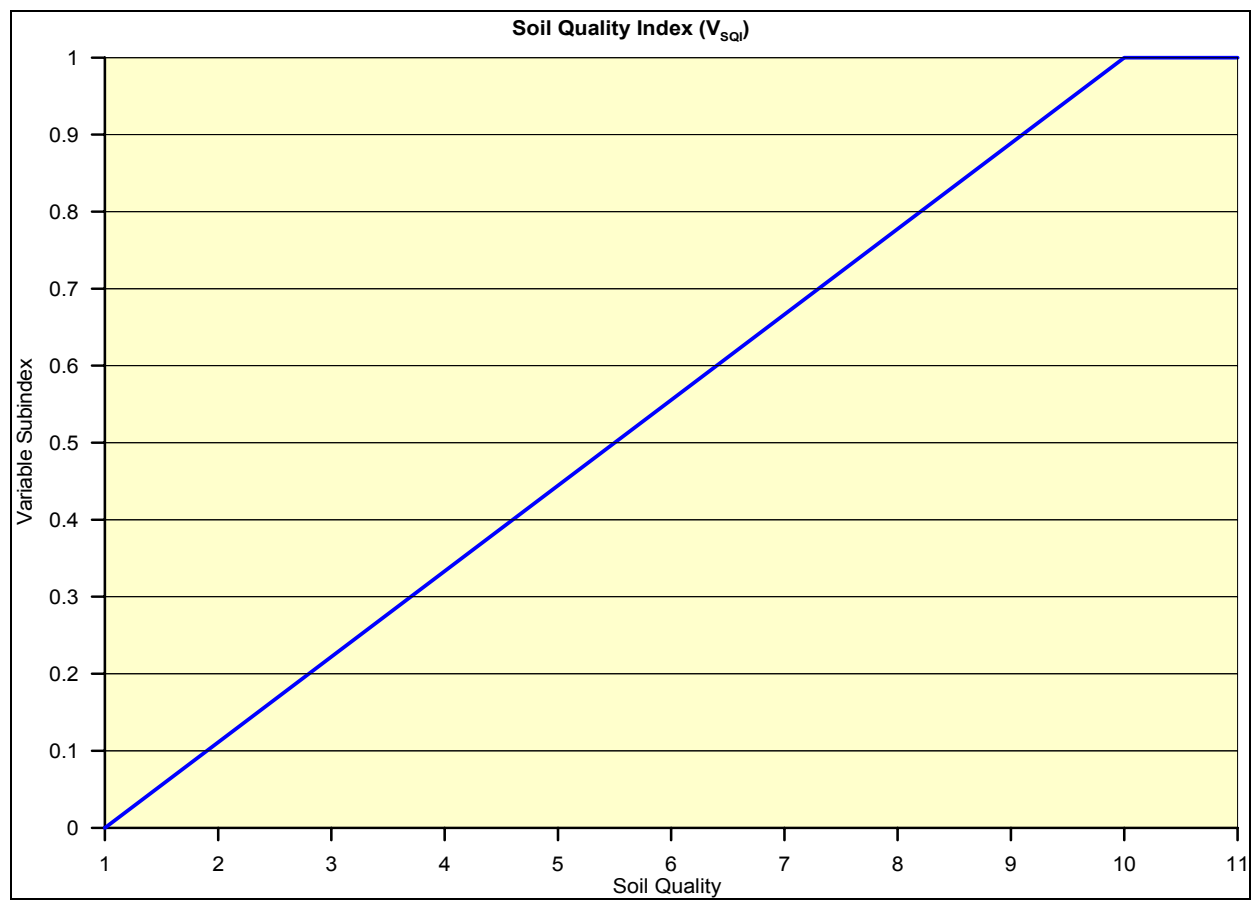

Figure 13. Relationship between the Soil Quality Index and the variable subindex

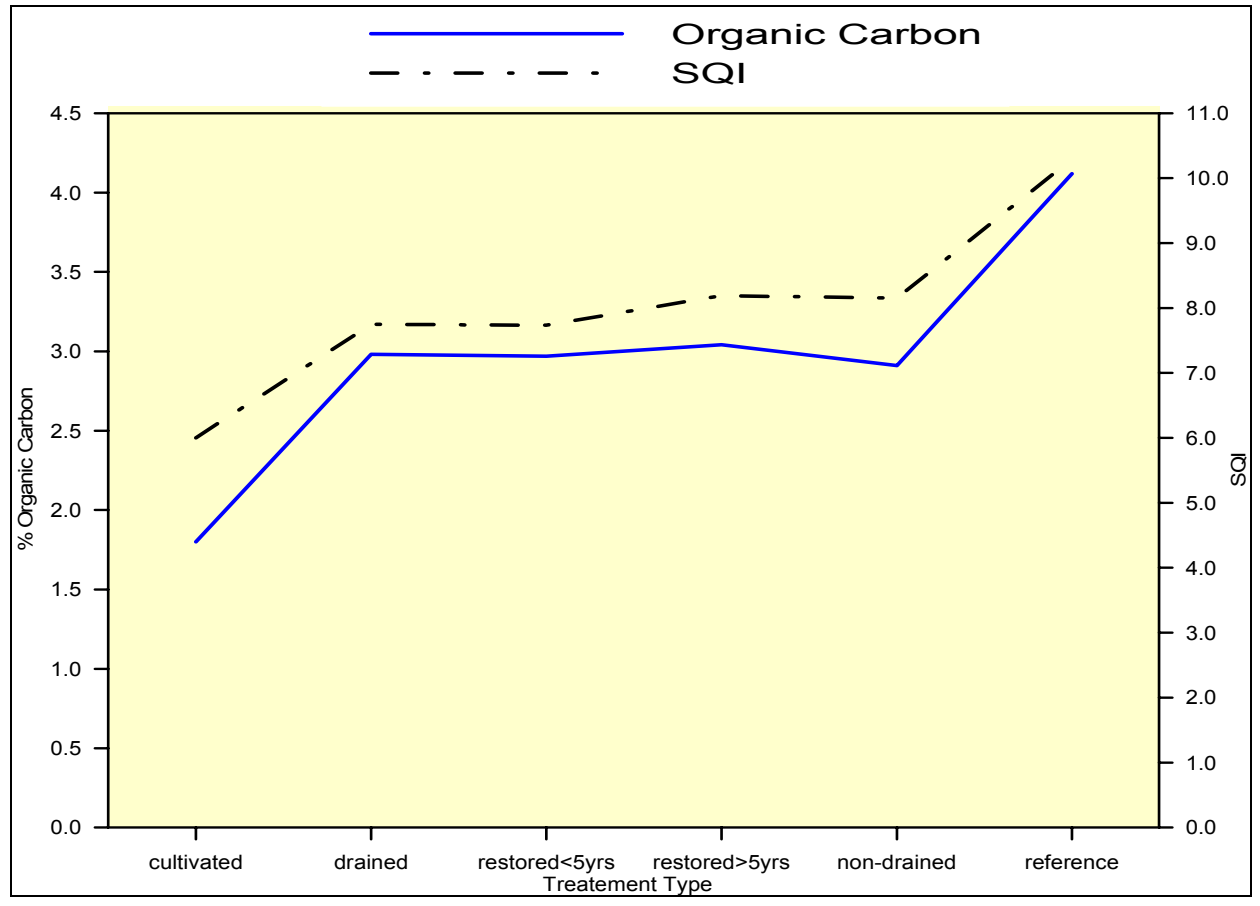

Figure 14. Relationship of the Soil Quality Index to soil organic carbon 


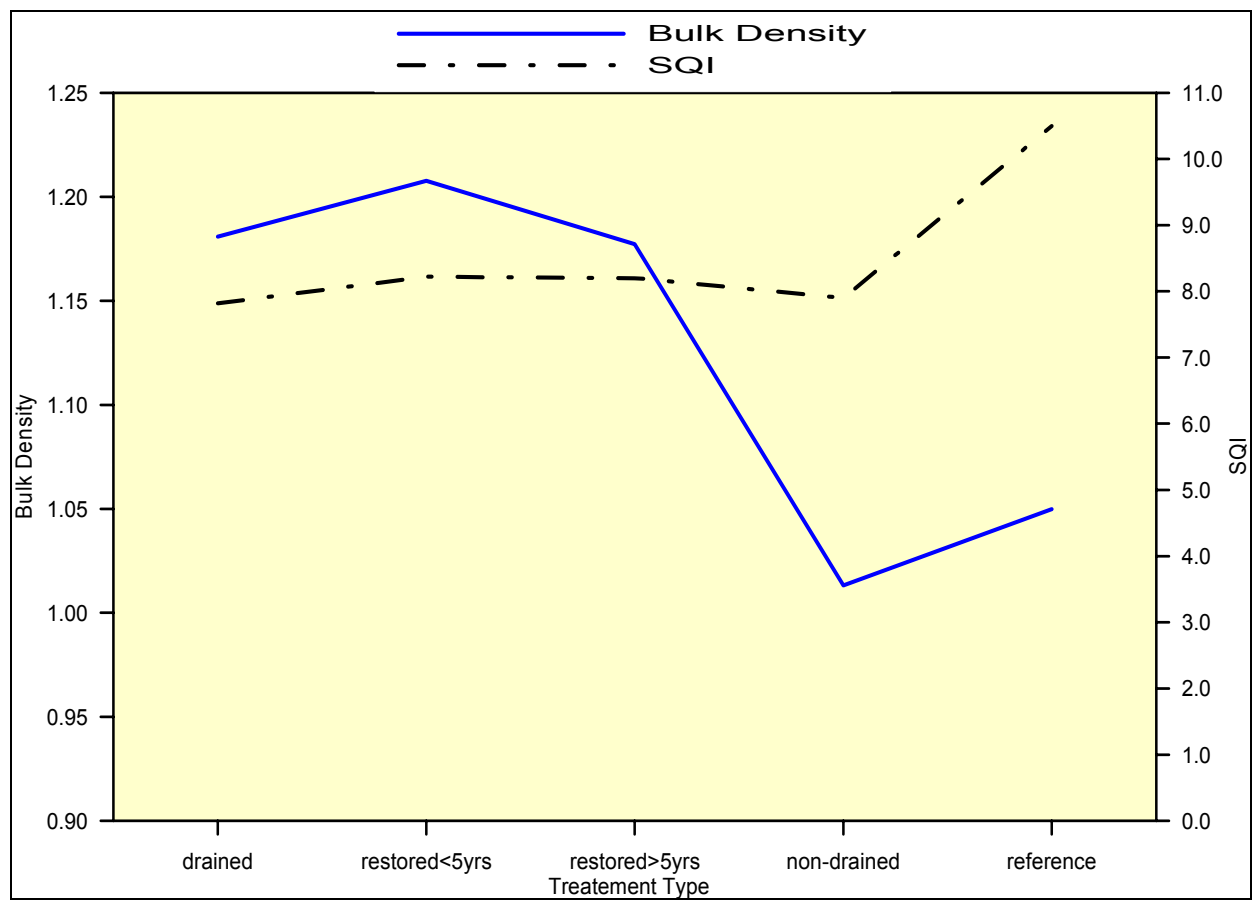

Figure 15. Relationship of the Soil Quality Index to Soil Bulk Density

Soil Organic Matter $\left(\boldsymbol{V}_{\text {SOM }}\right)$. This variable represents the amount of organic matter that is in the upper part of the soil profile. As with most all soil properties, this is a naturally variable property; however, organic matter content can be altered significantly by management practices. For example, drainage and removal of native plant communities can increase soil temperature and decrease soil organic matter content. Soil organic matter is an environmental characteristic that affects soil fertility (therefore, plant community development), oxidationreduction reactions, food webs, soil moisture retention, and water conductivity.

Larson and Pierce (1991) describe SOM as the most important property for assessment of soil quality. For assessing soil organic matter, the upper part (i.e., $30 \mathrm{~cm}$ ) is most important because this is where most of the biogeochemical interactions that depend on soil organic matter take place. It is also the part of the soil profile most responsive to impact-related changes in organic content (VanGestal, Ladd and Amato 1992). The organic matter in the upper part of the soil profile is reduced when soils are affected by plowing, haying, over grazing, and drainage (Ross, Tate, and Cairns 1981; Blank and Fosburg 1989; Garcia and Rice 1994; Parton et al. 1987; Paul and Clark 1996).

This variable is measured in the wet meadow zone. This zone is associated with soils such as Tonka, Tetonka, and Typic or Cumulic Endoaquolls. The variable is measured either through direct laboratory analysis or indirectly through evaluation of soil physical properties in conjunction with undecomposed litter.

For direct measurement, samples are taken at four locations in the wet meadow zone at two depths $(0$ to $15 \mathrm{~cm}$ and 15 to $30 \mathrm{~cm})$. A composite sample is made from the four and submitted for lab analysis. Step-by-step: identify proper zone, take four samples at roughly the four ordinal compass points for the 0 - to 
15-cm depth, mix together, and bag enough for lab analysis. Repeat for the 15- to 30 -cm depth. Samples are analyzed for organic carbon by combusting at $1350{ }^{\circ} \mathrm{C}$ and detectingwith infrared (Olness, personal communication). The relationship of the direct metric $(n=123)$ to the sub-index score is presented in Figure 16.

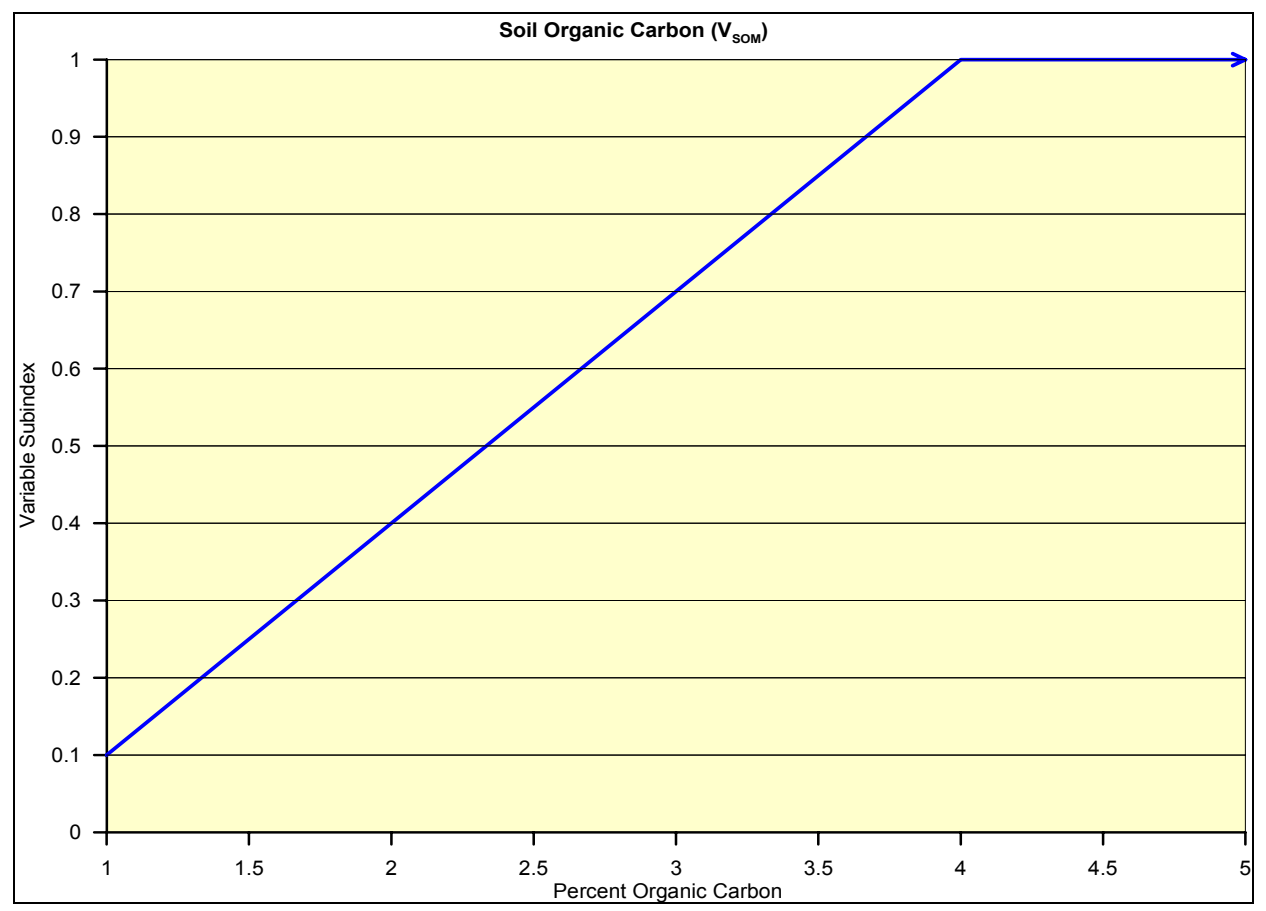

Figure 16. Relationship between the mean percent organic carbon and the variable subindex

Although there is no doubt that soil organic content, as determined by laboratory analysis, is the preferred single method of evaluating soil condition, it is not likely that this procedure will be used often in rapid HGM assessment. Therefore, the following method was developed for use in estimating soil organic content.

Where direct measurement of soil organic matter is impracticable, a regression equation is provided from analyses of reference data. For $n=123$ sites, mean percent organic matter, based on laboratory analysis, is available. Indirect indicators were evaluated against actual measurements of mean percent organic matter. Indicators used in the regression equation (independent variables) are the Soil Quality Index, the A horizon Darkness Index, and litter depth $(\mathrm{cm})$ in the wet meadow zone.

The Soil Quality Index is measured by describing the soil structure, soil pores, and rupture resistance (i.e., consistency) of the upper $30 \mathrm{~cm}$ (Soil Survey Division Staff 1993) as described previously.

The A- horizon Darkness Index metric is included in the regression equation as an indicator of soil organic matter. It is defined as the moist soil color of the uppermost A horizon (A1 or Ap1 horizon). Humified organic matter is the con- 
stituent that influences color of the A horizon. In the Munsell system of soil color, it is the soil color value that is most affected by the organic coloring agents.

An A horizon Darkness Index (ADI) is derived using the following equation: $\mathrm{ADI}=(H+2 V+C), H$ is the hue (where hue of $N=0$, all other hues $=1), V$ is the Value and $C$ is the Chroma. Values of 2.5 (on $2.5 Y, 5 Y$ and $N$ hue color chips) are equal to 2 in this procedure. The moist soil color is observed in four replicate soil profiles located in the outer depressional soil (i.e., temporary zone) and an "average" ADI is obtained. Two examples follow:

- Four replicates of moist soil color are:

o $10 \mathrm{YR} 2 / 1$.

o $10 \mathrm{YR} 2 / 2$.

o $2.5 \mathrm{Y} 2.5 / 1$.

o 10 YR $3 / 1$.

o The average ADI is: $(6+7+6+8) / 4=6.75$.

- Four replicates of moist soil color are:

o 10 YR $2 / 1$.

o $\mathrm{N} 2.5 /$.

o 2.5 Y $2.5 / 1$.

o N3/.

o The average ADI is: $(6+4+6+6) / 4=5.5$.

The ADI in reference sites varied throughout the reference domain from 4 to $12(n=180)$.

Litter depth is included in the soil organic matter regression. It is defined as the depth $(\mathrm{cm})$ of undecomposed litter (i.e., detritus). The measurements of litter thickness are made in the wet meadow zone. It is simply the measure of detritus that has not been incorporated into the soil profile. As with the SOM variable and other soil metrics, four replicate litter depths are determined and averaged for entry into the regression equation. Based on data collected at 180 reference sites, litter depths ranged from 0 to $14.5 \mathrm{~cm}$.

In the prediction of the dependent variable (mean percent organic matter), regression coefficients were first standardized for all independent variables to a mean of 0 and a standard deviation of 1 . The resulting equation is:

$$
\% \mathrm{OM}(\text { est. })=2.71+.23 \times(\mathrm{SQI})-0.22 \times(\mathrm{ADI})+0.13 \times(\text { litter depth }) .
$$

\section{Hydrogeomorphic variables}

Wetland Outlet ( $\left.\boldsymbol{V}_{\text {out }}\right)$. This variable is the ratio of the elevation of the existing (or proposed) constructed outlet to the natural outlet. In rapid assessment it is not practical to measure the depth and duration of ponding. Such a measurement would be preferable; however, assessing the impact to ponding by alteration is more practicable. The elevation of the wetland boundary, basin center, natural outlet, and any proposed or existing constructed outlet are measured and the ratio 
is then derived. For example, the natural outlet is $1.5 \mathrm{~m}$ above the basin central elevation and the proposed project lowers that outlet by $0.25 \mathrm{~m} .1 .25 / 1.5=0.833$, the variable sub-index score would be 0.83 . Based upon analysis of 13 wetlands in the reference data set using SPAW (Saxton 2002), when the natural outlet is more than $1 \mathrm{~m}$ above the wetland boundary, $1 \mathrm{~m}$ is used as the maximum elevation of the natural outlet. Any constructed outlet that is more than $1 \mathrm{~m}$ above the wetland boundary elevation has little to no impact on the wetland ecosystem because water does not reach that elevation except under extreme pluvial conditions. Also, this variable does not consider the capacity of the surface outlet. A ratio of 0.0 for $V_{\text {OUT }}$ does not adequately represent the fact that water will be retained within a basin during pluvial cycles and extreme precipitation events. To represent this, the lowest ratio allowed is 0.05 . For rapid assessment, the only time the $V_{\text {OUT }}$ sub-index score would be equal to 0.0 is when the wetland storage capacity has been totally eliminated by fill or excavation. If user defined assessment objectives require more detailed hydrology information, scope and effect equations and hydrology tools can be used. This information is available at: http://www.wli.nrcs.usda.gov/technical/web_tool/tools_java.html

Features such as drainage ditches, tile intakes, and deep road ditches within the hydric soil footprint, and alteration of natural outlets or overflows are all included in the definition of wetland outlet. Fill that is placed within the wetland is also included when assessing this variable. Users will have to determine the percentage of storage that is lost by the placement of fill. Excavations, such as dugouts for livestock, are also included when assessing this variable. An estimation of the volume of the wetland impacted is entered into the calculation worksheet. (e.g., a dugout is 25 percent of the volume of the original wetland, 25 is entered into the calculation sheet). The volume of an excavated pit, fill, or wetland, can be estimated by many means, including use of Global Positioning Systems, Geographic Information System technology, or standard field survey techniques. The prismoidal formula uses surface areas, mid-depth, and bottom depth, along with the average depth to estimate the volume. Other formulations are also available and can be used (e.g., bowl shape, $V=0.52 \times d \times\left(3 a^{2}+d^{2}\right)$, where, $d=$ depth in center, and $a=$ radius of area). Users should consult the Engineering

Field Handbook, Chapter 11, pages11-44 for more detailed guidance. This information can be found at: http://www.info.usda.gov/CED/ftp/CED/EFHCh11.pdf

Alterations can occur singly or in various combinations and may have a significant effect on wetland hydrology. Alterations that extend only into the wet meadow zone of a seasonal wetland often allow some ponding to remain. Those that are situated or extend into the deepest portion of the wetland generally drain the entire area.

Where detailed basin morphometry data are available for seasonal wetlands $(n=87)$ in the reference data set, the mean wetland volume available for storage is 64 percent in the temporary zone, and 36 percent in the seasonal zone. This means approximately $2 / 3$ of a seasonally inundated prairie pothole wetlands volume exists in the shallower, temporarily inundated (wet meadow zone) portion of the wetland. The relationship of the metric to the sub-index score is presented in Figure 17. 


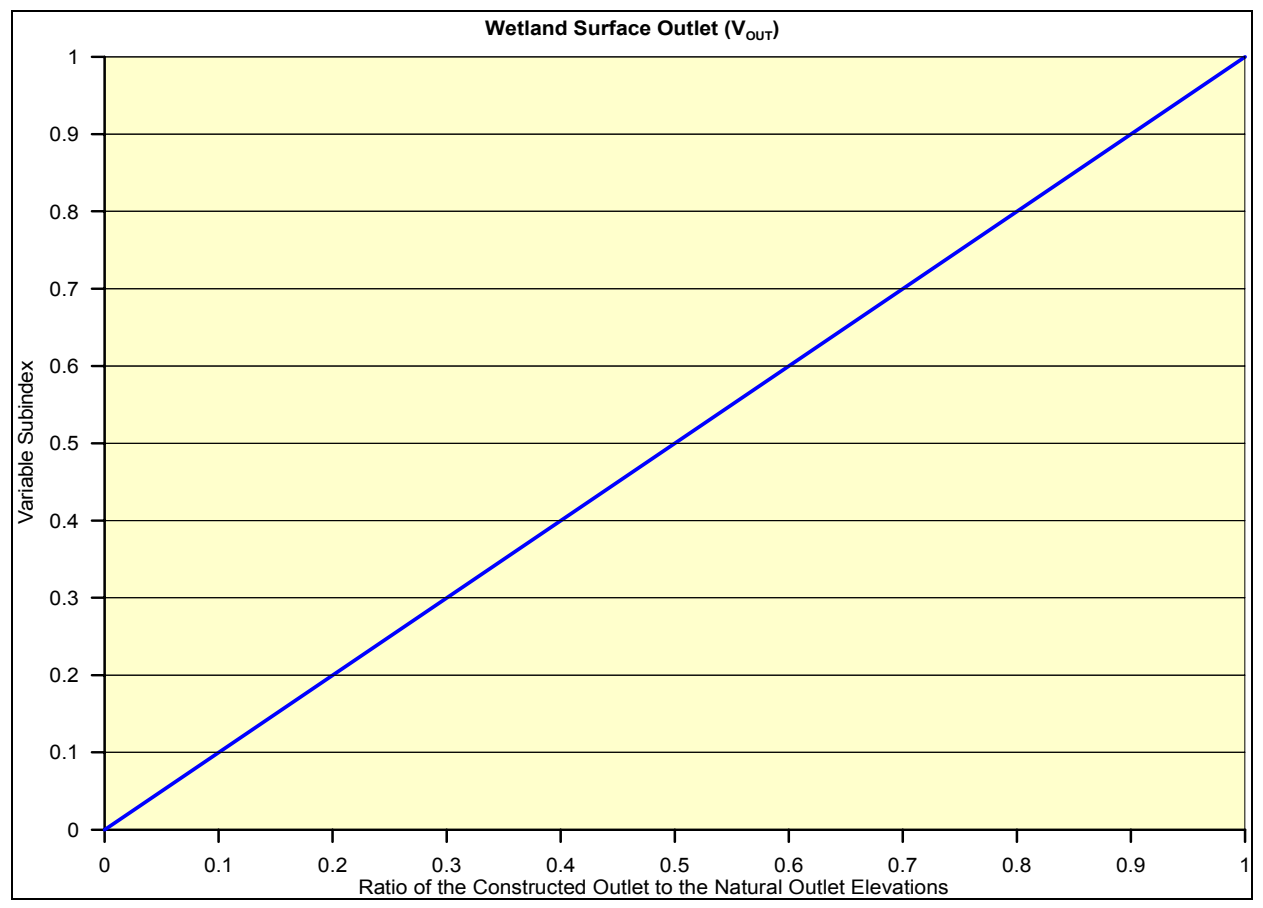

Figure 17. Relationship between the ratio of the constructed outlet elevation to the natural outlet elevation and the variable subindex

Subsurface Outlet $\left(\mathbf{V}_{\text {SUBout }}\right)$. This variable is defined as the presence of constructed drainage outside the boundary of the wetland or subsurface drainage (e.g., tile) within the wetland. The effectiveness of drainage outside the wetland is based upon features such as distance of drain, capacity of drain, depth below wetland elevation, and soil permeability (hydraulic conductivity). For a more complete discussion see U.S. Department of Agriculture (USDA) (1997). Tile drainage beneath or adjacent to the wetland affects the ability of a wetland to maintain saturated, anaerobic conditions, increases peak flows downstream (Moore and Larson 1980) and can increase movement of elements and compounds (such as pesticides and nitrogen) downstream. The effectiveness of tile drainage is based on characteristics that include tile spacing, depth, diameter, and soil permeability (hydraulic conductivity). The relationship of the categorical condition to the index score is presented in Table 11. Table 11 was developed using the van Schilfgaarde equation for lateral effect (USDA 1997). Data input was derived from a typical soil of Hamerly/Tonka, with a surface outlet approximately $3.5 \mathrm{ft}$ in depth. The user should be cautioned that wetland impacts of subsurface outlets will depend on soil types and depth of subsurface outlet. 


\begin{tabular}{|c|c|}
\hline \multicolumn{2}{|l|}{$\begin{array}{l}\text { Table } 11 \\
V_{\text {subout }} \text { Categorical Variable }\end{array}$} \\
\hline Measurement or Condition & Index \\
\hline $\begin{array}{l}\text { Subsurface flow is not impacted or if there is a nearby subsurface/surface drainage feature, } \\
\text { it is greater than } 150 \mathrm{ft} \text { from wetland edge. } \\
\text {-OR- } \\
\text { Wetland has been restored to natural outlet elevation and there is no evidence of subsur- } \\
\text { face flow (e.g., hydrophytic vegetation, water seepage, etc.) within } 50 \mathrm{ft} \text { of the downstream } \\
\text { toe of the natural outlet. }\end{array}$ & 1.0 \\
\hline $\begin{array}{l}\text { Subsurface or surface drainage feature is between } 75 \text { and } 150 \mathrm{ft} \text { from the wetland edge and } \\
\text { is greater than } 3 \mathrm{ft} \text { below the top elevation of the temporary (i.e., wet meadow) zone. } \\
\text {-OR- } \\
\text { Wetland has been restored with the use of a ditch plug and there is no evidence of subsur- } \\
\text { face flow (e.g., hydrophytic vegetation, water seepage, etc.) within } 50 \mathrm{ft} \text { of the downstream } \\
\text { toe of the ditch plug. }\end{array}$ & 0.75 \\
\hline $\begin{array}{l}\text { Subsurface or surface drainage feature is between } 75 \text { and } 25 \mathrm{ft} \text { from wetland edge and } \\
\text { greater than } 2 \mathrm{ft} \text { below the top elevation of the temporary (i.e., wet meadow) zone. } \\
\text {-OR- } \\
\text { Wetland has been restored with the use of a ditch plug and there is evidence of subsurface } \\
\text { flow (e.g., hydrophytic vegetation, water seepage, etc.) within } 50 \mathrm{ft} \text { of the downstream toe of } \\
\text { the ditch plug. }\end{array}$ & 0.5 \\
\hline $\begin{array}{l}\text { Subsurface or surface drainage feature is within } 25 \mathrm{ft} \text { of wetland edge and greater than } 2 \mathrm{ft} \\
\text { below the top elevation of the temporary (i.e., wet meadow) zone. } \\
\text {-OR- } \\
\text { Wetland has poorly functioning tile within the wetland basin (i.e., saturation conditions still } \\
\text { exist within the basin). }\end{array}$ & 0.25 \\
\hline $\begin{array}{l}\text { Properly functioning tile or pattern tile within the basin. Almost all water moving through soil } \\
\text { profile below the wetland is intercepted by drainage tile. }\end{array}$ & 0.1 \\
\hline
\end{tabular}

If user-defined assessment objectives require more detailed assessment of subsurface hydrology impacts, site specific soils information along with distance of drain, capacity of drain, and depth below wetland elevation should be obtained. Using site specific information, a lateral effect equation such as van Schilfgaarde or similar equations found in USDA (1997) should be used to determine the zone of impact of the subsurface drainage feature. Variable subindex scoring should be based on a linear relationship of the maximum distance relative to the distance of the wetland from the drainage feature. Example: If the van Schilfgaarde equation indicates a maximum lateral effect distance of $300 \mathrm{ft}$ and the subsurface drainage feature is $100 \mathrm{ft}$ from the boundary of the wetland, the variable subindex score for $V_{\text {SUBOUT }}$ would equal 0.33 .

Wetland Source Area ( $\left.V_{\text {SOurce }}\right)$. This variable is a measure of the percentage change in the catchment area surrounding a wetland. Change can be an increase, decrease, or combination of both. In some catchments it is not unusual to have both an increase to the catchment along with a decrease owing to a combination of the various alterations. Alterations in the catchment have a direct effect on the amount of water flowing off the landscape into the wetland. In some instances (e.g., land leveling for irrigation or consolidated drainage), an actual increase in catchment size has resulted. More commonly, the placement of drainage ditches, tile drainage, county roads, and other alterations within the catchment have intercepted or diverted flows away from wetlands. By using soil survey maps, aerial photos, and topographic maps, the original or historical catchment boundary can be delineated with relative accuracy. Then, additions or reductions to the catchment are determined to find the percentage change. Index values are scored categorically, based on the appropriate description of catchment condition, as indicated in Table 12. 


\begin{tabular}{||l|l||}
\hline \hline Table 12 \\
V Source Categorical Variable \\
\hline \hline Measurement or Condition & Index \\
\hline \hline $\begin{array}{l}\text { Minimal alteration of the upland catchment source area through structural surface altera- } \\
\text { tions (e.g., terraces, road ditches, etc.), subsurface alterations (e.g., tile drainage, ditches), } \\
\text { or irrigation additions. More than 90 percent of catchment area is intact. }\end{array}$ & 1.0 \\
\hline $\begin{array}{l}\text { Surface alterations of the upland catchment source area that impact overland flow into the } \\
\text { wetland have occurred; however, there have been no tile drainage in the catchment that } \\
\text { "de-waters" the wetland being assessed or no irrigation additions. } 75 \text { to } 90 \text { percent of catch- } \\
\text { ment area is intact. }\end{array}$ & 0.75 \\
\hline $\begin{array}{l}\text { Upland catchment source area is changed to alter the dominant surface or subsurface flow } \\
\text { path, or both, of water to the wetland (e.g., drainage or irrigation return). However, the } \\
\text { alterations do not change the wetland water regime class. } 25 \text { to 75 percent of catchment } \\
\text { area is intact. }\end{array}$ & 0.50 \\
\hline $\begin{array}{l}\text { Upland catchment source area is changed to alter the dominant surface or subsurface flow } \\
\text { path, or both, of water to the wetland (e.g., drainage or irrigation return) and alteration } \\
\text { changes the wetland water regime class. (e.g., a seasonal wetland is changed to semi- } \\
\text { permanent or temporary). Less than } 25 \text { percent of catchment area is intact. }\end{array}$ & 0.10 \\
\hline $\begin{array}{l}\text { The upland catchment source area is extremely altered such that almost all surface and } \\
\text { sub-surface water flow to the wetland is eliminated. (e.g., tile drainage intercepts water and } \\
\text { diverts it from wetland, urbanization moves water to another area, etc.) }\end{array}$ & 0.00 \\
\hline \hline
\end{tabular}

Wetland Edge Index ( $\boldsymbol{V}_{\text {EDGE }}$ ). This variable is a measure of the degree of shoreline irregularity, expressed as ratio of the perimeter of the assessment wetland to the perimeter of a circular wetland of equal area. The closer this ratio is to 1 , the more circular the wetland. A larger ratio means the shoreline (edge) is more crenulated. Rate of water loss from prairie potholes varies directly with length of shoreline per unit area and inversely with size of individual sloughs; hence, with higher ratios, there is a higher potential for recharge (Millar 1971). Shoreline irregularity also represents the ecotonal overlap between two communities (edge effect), displaying a distinct species composition or abundance as compared to adjacent patches. A modified shoreline irregularity index as adapted from Wetzel (1975) was used in computation of this variable. The metric for this variable is calculated as follows:

$$
V_{\mathrm{EDGE}}=\frac{\text { wetland perimeter }}{2 \times \sqrt{\pi \times \text { wetland area }}}
$$

Reference data analysis indicated a range of values from 1.0 to 1.92. Mean value was 1.24. Based on measurements at reference standard sites, the 1.0 variable sub-index score was set at 1.4. The relationship of the metric to the variable sub-index score is assumed to be linear (Figure 18). 


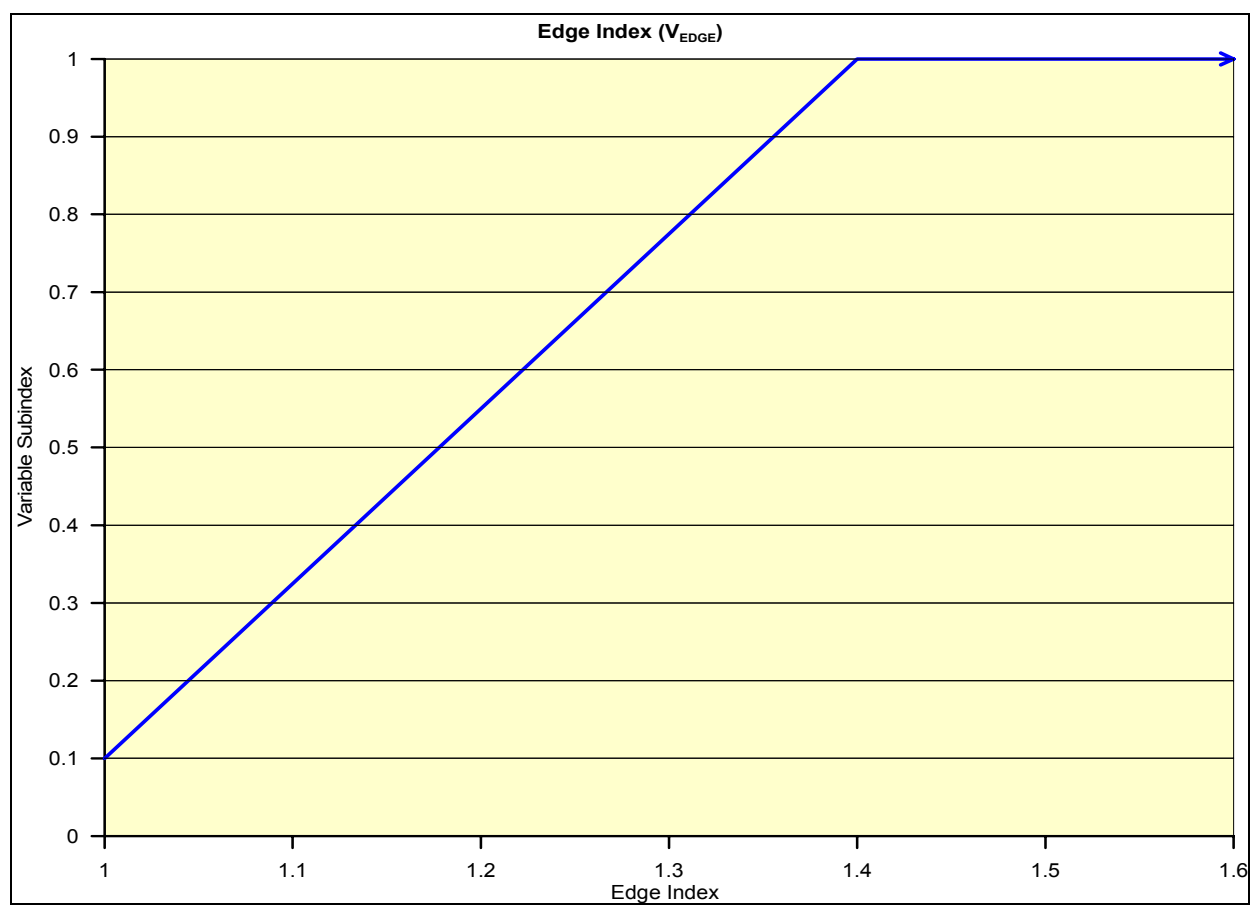

Figure 18. Relationship between the shoreline irregularity index and the variable sub-index

Catchment : Wetland Ratio ( $\left.\boldsymbol{V}_{\text {CATCHWET }}\right)$. This variable is the ratio of catchment size to wetland size. Wetlands that have a higher catchment-to-pond ratio are more likely to contribute water to recharge (Arndt and Richardson 1988). The number is calculated using the formula: (1/wetland area) $\times($ area of the catchment). The catchment area includes the wetland. Catchment: wetland ratios $(n=155)$ in the reference data range from a low of 1.03 in Minnesota to a high of 17.70 in Montana. The mean catchment: wetland ratio $(n=155)$ is 4.02 . Arndt and Richardson (1988) suggest that wetlands with a ratio $\geq 5.7$ are recharge wetlands and ratios as low as 4.5 can still indicate recharge conditions in a flow through wetland. Hayashi, van der Kamp, and Rudolph (1998a) reports that summertime decline of water levels in a seasonal, small wetland with a catchment:wetland ratio of 10:1 essentially represents recharge of groundwater. A sub-index of 1.0 is assigned to ratios $>5.5$. The relationship of the metric to the variable sub-index score is assumed to be a linear relationship (Figure 19).

\section{Land use and landscape variables}

Upland Land Use ( $\boldsymbol{V}_{\text {UPUSE }}$ ). This variable represents the condition of the terrestrial cover, as represented by land use/land cover categories within the present-day catchment of the wetland being assessed. It is measured by determining an area based weighted average runoff curve for the catchment. Curve numbers (weights) corresponding to reference data land use categories are provided in Table 13.

If more detail is required, the user has the option of using the above table or consulting the Engineering Field Handbook's curve numbers. Source informa- 
tion for runoff curve numbers can be found at: http://www.nrcs.usda.gov/ technical/ENG/efh.html

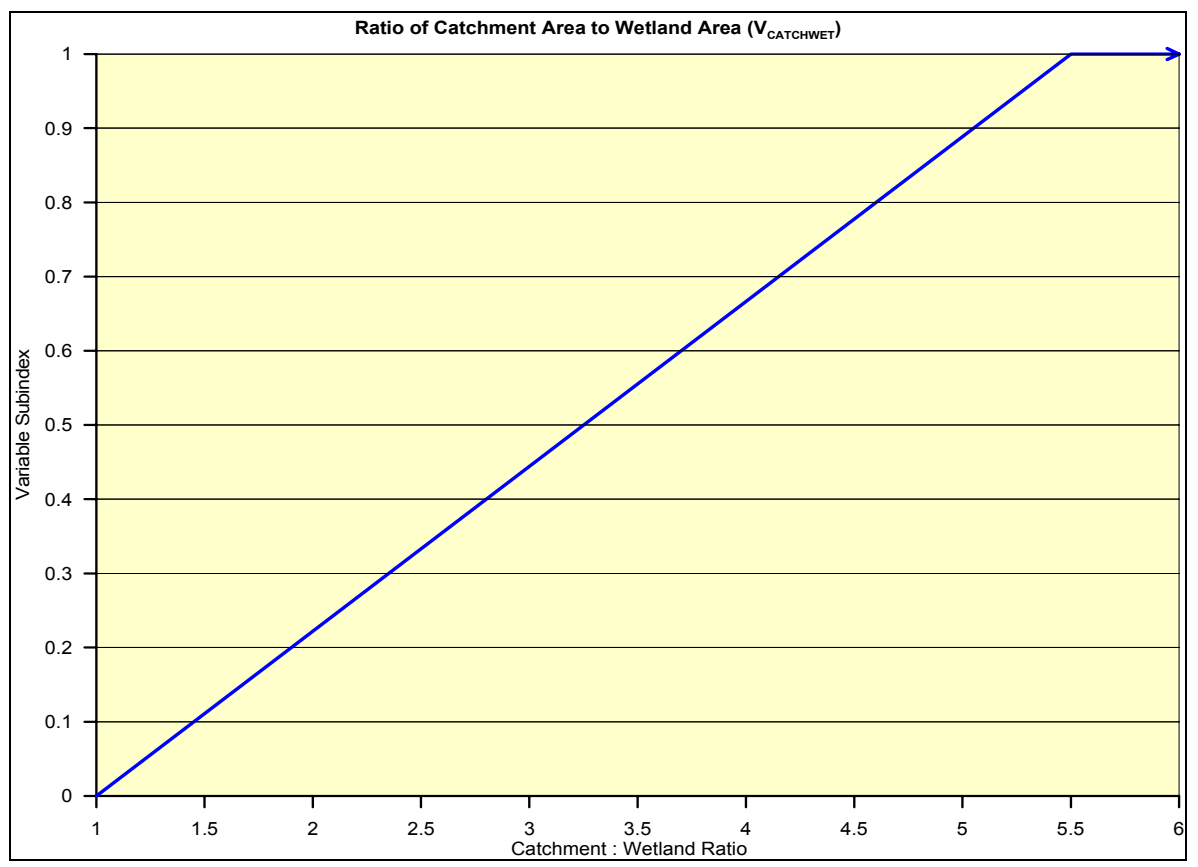

Figure 19. Relationship between the ratio of catchment area to wetland area and the variable subindex

\section{Table 13}

\section{Runoff Curve Numbers for $V_{\text {UPUSE }}$}

\begin{tabular}{|c|c|}
\hline Upland Land Use "Condition" & $\begin{array}{l}\text { Curve Number } \\
\text { Hydrologic Soil } \\
\text { Group B }\end{array}$ \\
\hline Urban, semi-pervious, or impervious surface & 98 \\
\hline Feedlot & 90 \\
\hline Conventional tillage row crop & 79 \\
\hline No-till row crop or high residue crops & 77 \\
\hline Row crop -contoured and terraced & 72 \\
\hline Conventional tillage small grain & 75 \\
\hline No-till small grain or high residue crops & 73 \\
\hline Small Grain-contoured and terraced & 71 \\
\hline Minimum till in a grass/legume rotation & 72 \\
\hline Farmsteads & 74 \\
\hline "Permanent" hay land & 69 \\
\hline $\begin{array}{l}\text { Rangeland-Native or non-native species, overgrazed, high amount of bare } \\
\text { ground, low plant vigor, and evidence of soil erosion (e.g., gullies, rills, etc.) }\end{array}$ & 79 \\
\hline $\begin{array}{l}\text { Rangeland-Native or non-native species, often overgrazed, some bare } \\
\text { ground, low plant vigor }\end{array}$ & 74 \\
\hline $\begin{array}{l}\text { Rangeland dominated by non-native species under some type of management } \\
\text {-OR- } \\
\text { Rangeland-native species with fair grazing management such as season- } \\
\text { long grazing at slight or moderate intensity } \\
\text {-OR- } \\
\text { Rangeland-idle grassland cover. (Includes idle native range and CRP) }\end{array}$ & 69 \\
\hline $\begin{array}{l}\text { Native prairie that allows for adequate plant recovery time between vegetation } \\
\text { removal }\end{array}$ & 61 \\
\hline
\end{tabular}


Based on data from reference wetlands, a variable sub index score of 1.0 is assigned for a weighted average score of less than or equal to 61 . Values for the reference sites ranged from 61 to 79 ; mean value was 69.6 for $n=180$. The relationship of the metric to the variable sub-index score is assumed to be a linear relationship (Figure 20).

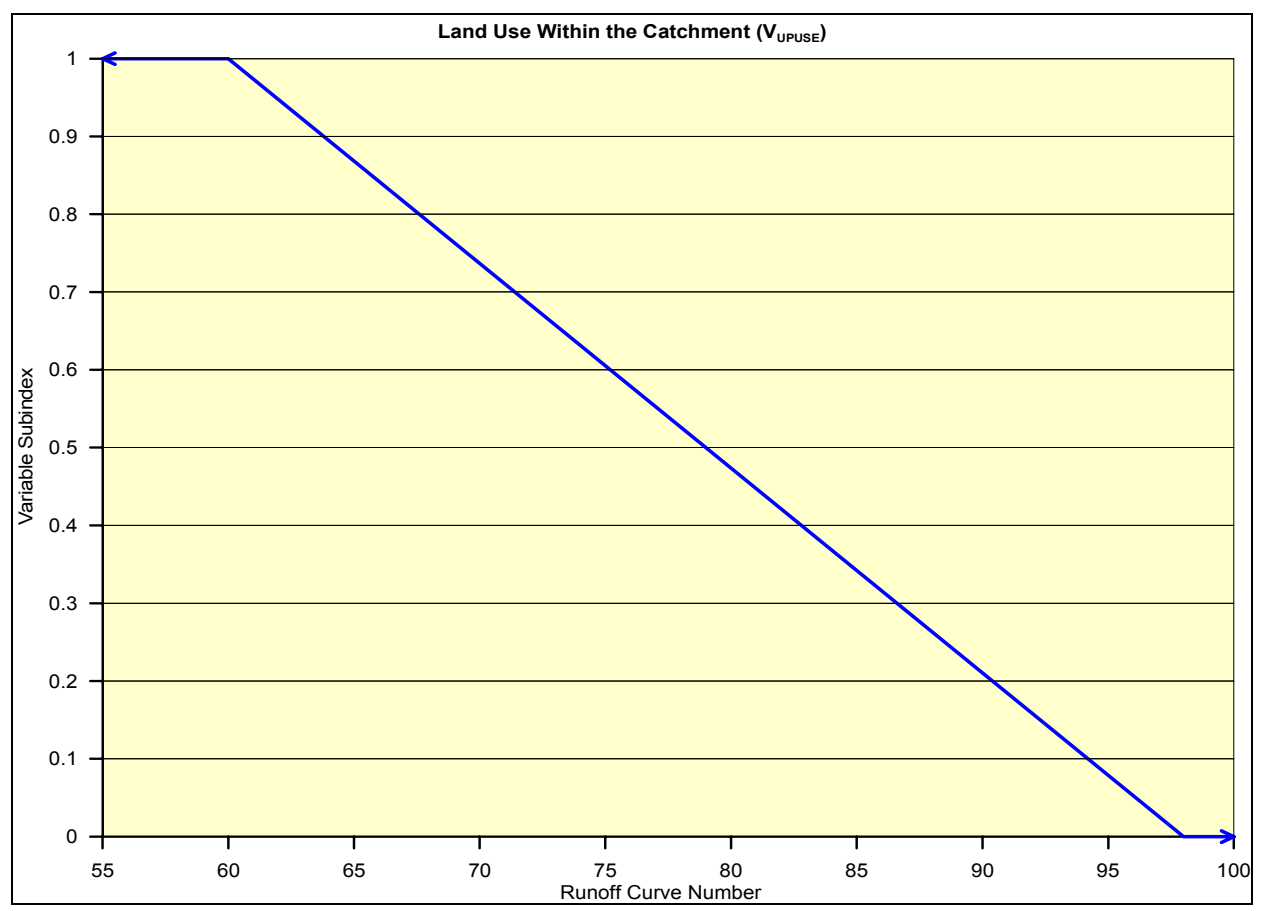

Figure 20. Relationship between the curve number and the variable subindex

Wetlands Proximity ( $\boldsymbol{V}_{\text {WETPRox }}$ ). This variable is a measure of the proximity of the assessment wetland to other palustrine wetlands. This is a critical landscape variable that affects the ability of species and propagules to move from one wetland to another. It is also used as an indicator of the wetland complex condition, with emphasis at a finer scale of resolution as compared to the other landscape variables. As illustrated in Figure 21, $V_{\text {WETPROX }}$ is measured as the mean inter-wetland distance (edge to edge) from the assessment wetland to the nearest five wetlands. These distances are then averaged.

Reference data ranged from 58 to $862 \mathrm{~m}$, with a mean of $209 \mathrm{~m}$. Based on conditions measured at reference standard sites, this variable achieved a maximum score of 1 as the average inter-wetland distance approached about $80 \mathrm{~m}$. Alternately, the variable sub-index score equals 0 when the average inter-wetland distance approached $330 \mathrm{~m}$.

The relationship of the metric to the variable sub-index score is assumed to be an inverse linear relationship (Figure 22). 


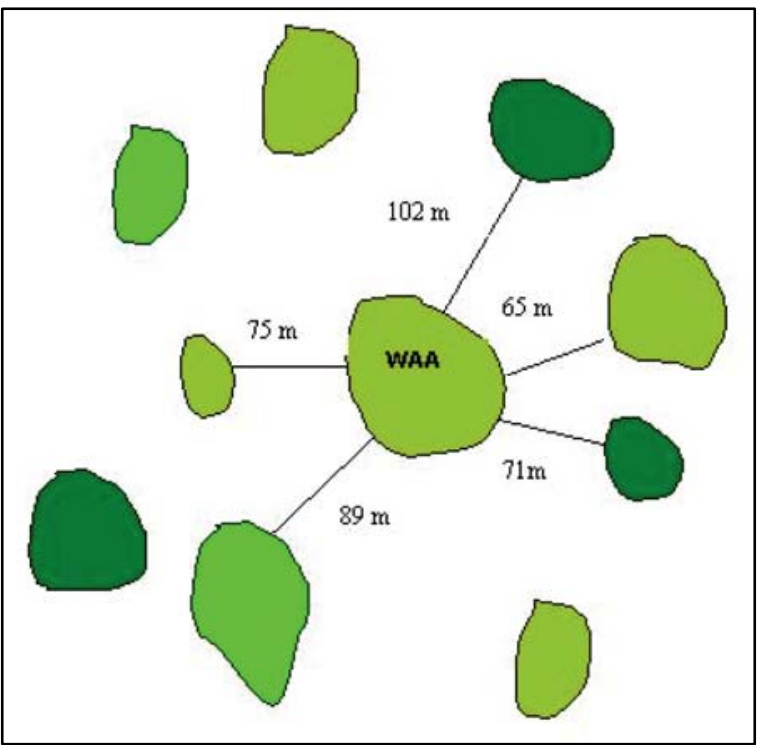

Figure 21. Example of inter-wetland distance measurements for $V_{\text {WETPROX }}$

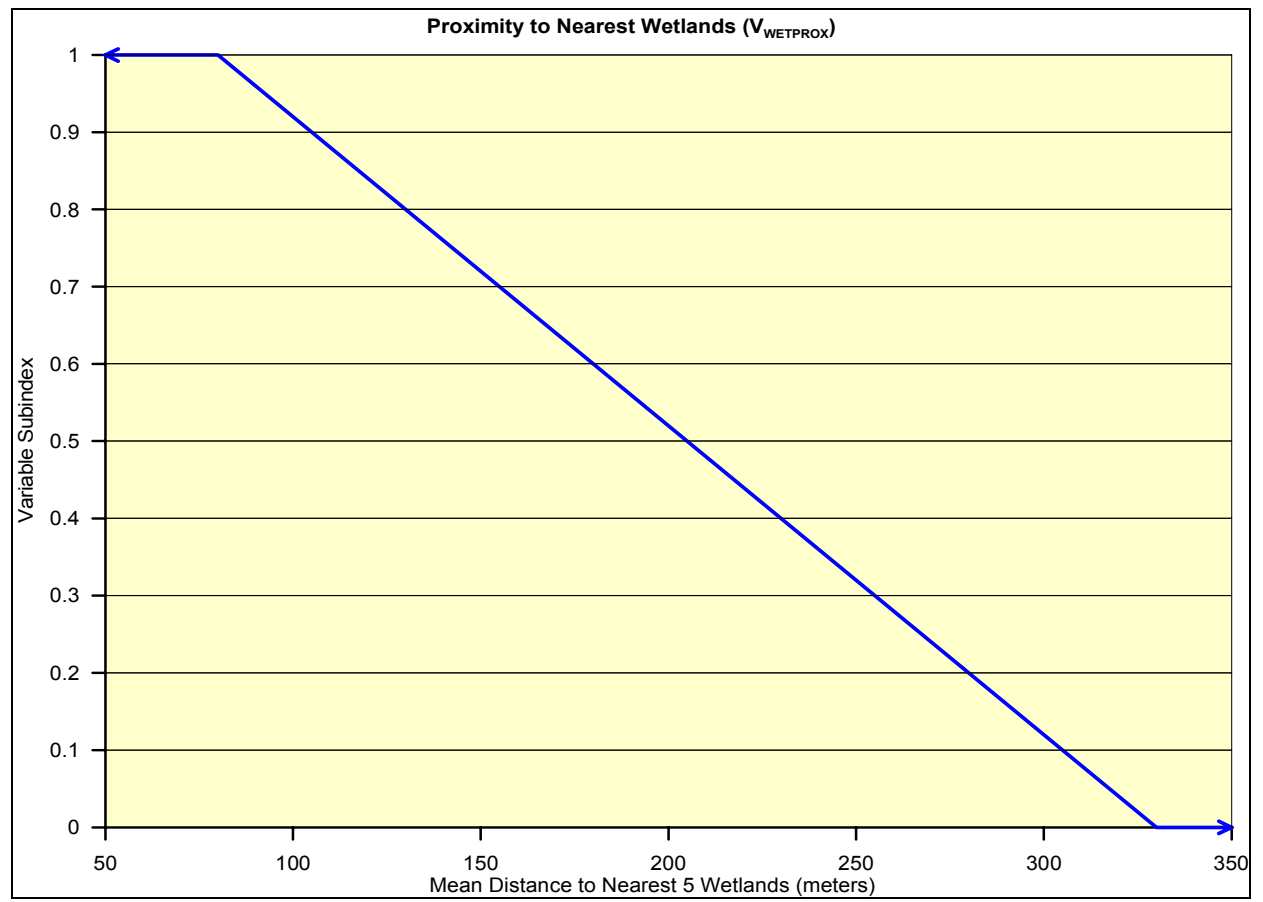

Figure 22. Relationship between the mean inter-wetland distance and the variable subindex

Wetland Density in the Landscape Assessment Area ( $\left.\mathbf{V}_{\text {WETAREA }}\right)$. This is used as a measure of the condition of the wetland complex associated with the assessment wetland. The area of palustrine wetlands (in hectares) occurring within a wetland complex is measured. A Landscape Assessment Area (LAA) was circumscribed from a 1.6-km radius from the reference sites' centroid. The LAA was $8.1 \mathrm{~km} 2$ and serves as the wetland complex for analyses. 
Both polygon and point data from source NWI digital data were used. Palustrine point data were assigned an area value of 0.1 ha and included in calculations. Wetland complex area measurements ranged from approximately 4 to $385 \mathrm{ha}$. Mean area for the reference sites' complex $(\underline{n}=180)$ was $97 \mathrm{ha} / 8.1 \mathrm{~km}^{2}$. The reference standard condition was defined as greater than or equal to $160 \mathrm{ha} / 8.1 \mathrm{~km}^{2}$. The relationship of the metric to the variable sub-index score is assumed to be a linear relationship (Figure 23).

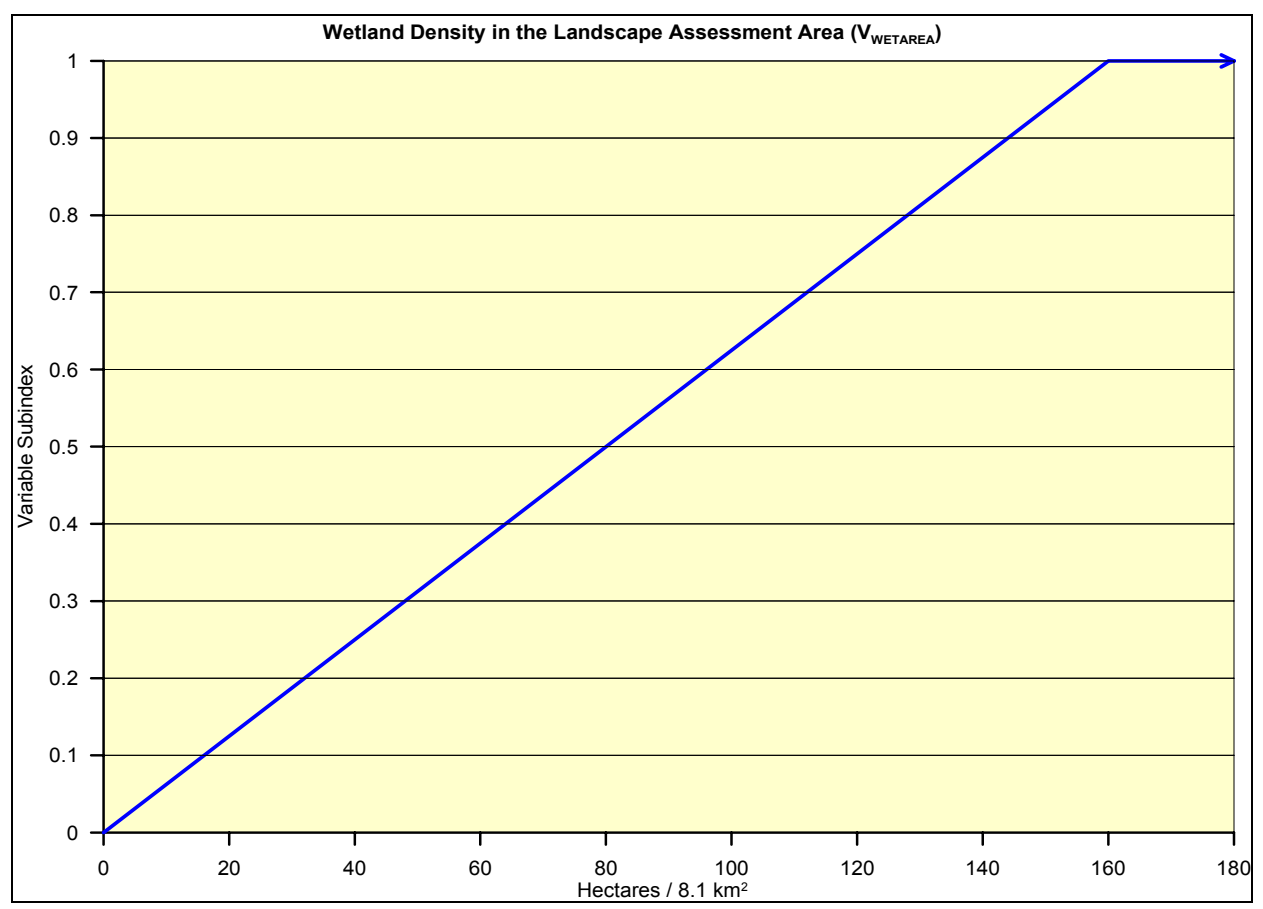

Figure 23. Relationship between wetland area in the LAA and the variable subindex

Number of Basins in the Landscape Assessment Area ( $\left.V_{\text {BASINS }}\right)$. This variable is the number of palustrine wetlands within the LAA. Basin counts were derived from recoded NWI polygon data. Point data were included in the basin counts. The LAA was circumscribed from a $1.6-\mathrm{km}$ radius from the reference site's center. The LAA area evaluated was $8.1 \mathrm{~km}^{2}$ and serves as the wetland complex for analyses. For the reference data set, mean number of basins was $120 / 8.1 \mathrm{~km}^{2}$ with number of basins ranging from $6-365 / 8.1 \mathrm{~km}^{2}$. The reference standard was defined as more than $200 / 8.1 \mathrm{~km}^{2}$. The relationship of the metric to the variable sub-index score can be found in (Figure 24). 


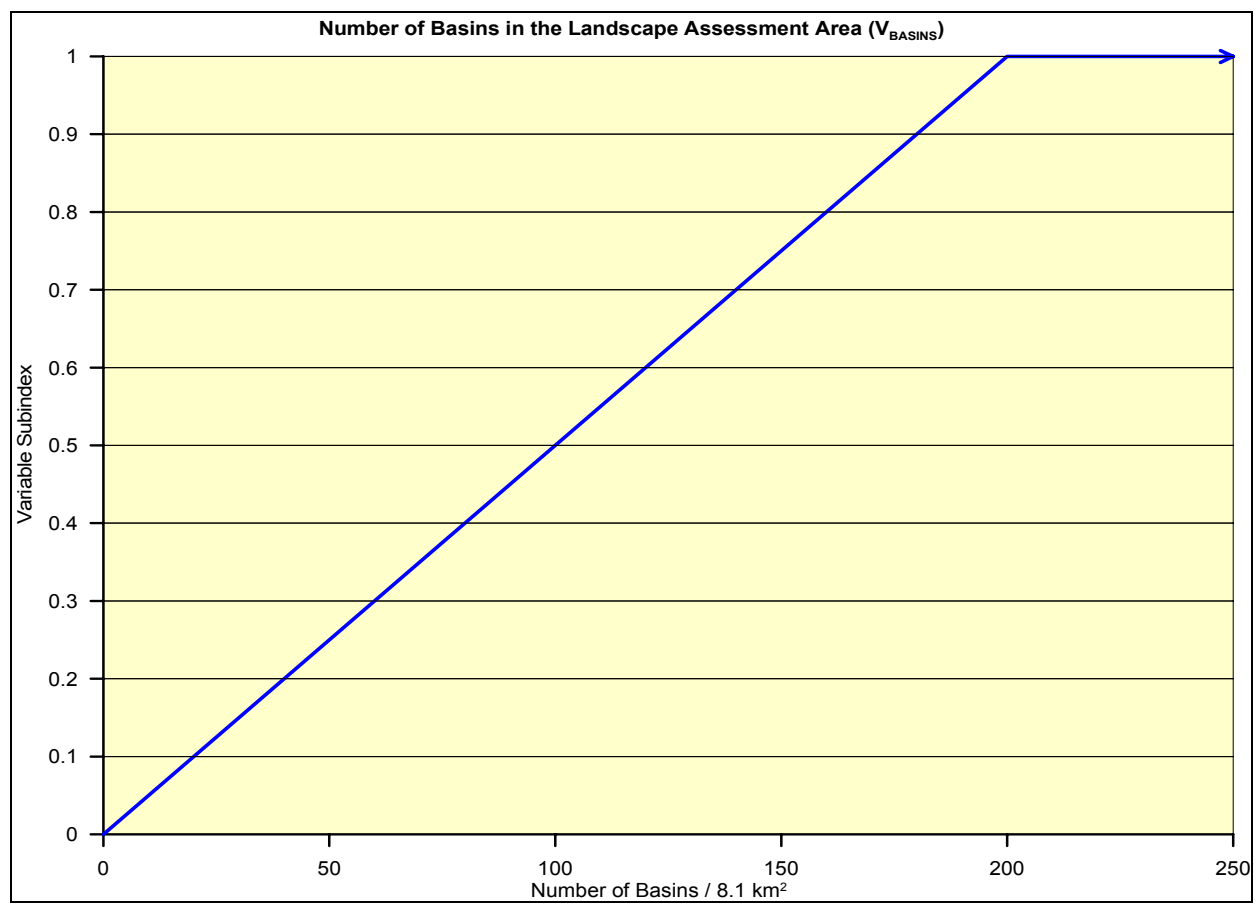

Figure 24. Relationship between the number of basins in the LAA and the variable subindex

Landscape Habitat Fragmentation $\left(\mathrm{V}_{\text {HABFRAG }}\right)$. This variable is the sum of the linear extent of roads and drainage features (in kilometers) within the LAA. It is used to account for fragmentation within the wetland complex. Wetlands are often intersected by roads, thereby fragmenting the historical basins. Roads, ditches, and drainage features contribute to alteration of basins hydrodynamics, alter groundwater flow patterns, reduce storage, alter connectivity, and reduce habitat suitability.

The LAA was circumscribed from a 1.6-km radius from the reference site's centroid. The LAA was $8.1 \mathrm{~km}^{2}$. Roads data were derived from the U.S. Census Bureau 1:100,000 scale data. Linear attributes were from NWI data. Linear attributes include both the " $d$ " or " $x$ " modifier (partly drained and excavated respectively (Cowardin et al. 1979).

For the reference data set, mean length of linear features was $10.6 \mathrm{~km} / 8.1$ $\mathrm{km}^{2}$ with values ranging from 1.1 to $22.1 \mathrm{~km} / 8.1 \mathrm{~km}^{2}$. The reference standard condition for $V_{\text {HABFRAG }}$ was less than or equal to $6.0 \mathrm{~km} / 8.1 \mathrm{~km}^{2}$. The relationship of the metric to the variable sub-index score can be found in Figure 25. 


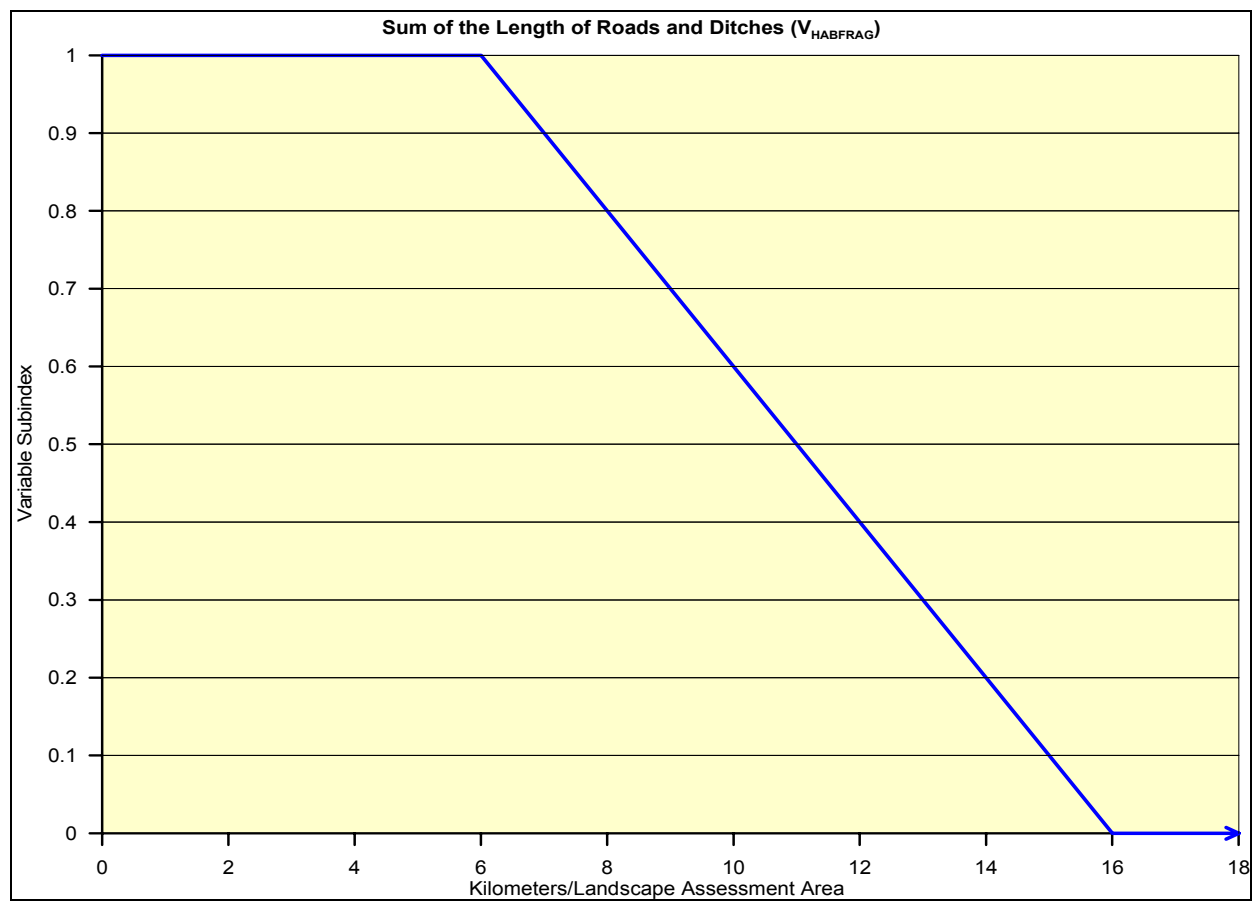

Figure 25. Relationship between the length of linear features in the LAA and the variable subindex

\section{Prairie Pothole Wetland Functions}

The following sequence is used in articulation of the selected functions.

- Definition: Defines the function and identifies an independent quantitative measure that can be used to validate the functional index.

- Rationale for selecting the function: Provides the rationale for why a function was selected and discusses onsite and offsite effects that may occur as a result of lost functional capacity.

- Characteristics and processes that influence the function: Describes the characteristics and processes of the wetland and the surrounding landscape that influence the function.

- Functional capacity index: Describes the assessment model from which the functional capacity index is derived and discusses how model variables interact to influence functional capacity.

\section{Function 1: Water Storage}

Definition. This function reflects the capacity of a prairie pothole wetland to collect and retain inflowing surface water, direct precipitation, and discharging groundwater as standing water above the soil surface, pore water in the saturated zone, or soil moisture in the unsaturated zone. A potential independent 
quantitative measure of this function would be the amount of water stored in the wetland per a given time (e.g., hectare-meters/year).

Rationale for selecting the function. This function is critical to the maintenance of the wetland and is often considered as the main forcing function for all other wetland processes. Water storage in PPR wetlands is important for three reasons. First, water that is delayed or stored in the wetland reduces the amount of runoff down slope, thereby ensuring a decrease in flood crests down gradient. Second, it guarantees that sufficient moisture is available to allow the development and maintenance of hydric soils and appropriate hydrophytic plant communities. The presence of these plant communities ensures that wildlife habitat is available for a variety of species, both resident and migratory. Subsurface water storage may also benefit crop production and wildlife production, because during the non-growing season period, subsurface storage of water becomes a crucial determinant of crop yields the following growing season (Schroeder and Bauer 1984). And finally, water storage supports the biogeochemical processes that occur in wetlands, such as the removal of nutrients and particulates. This process results in improved water quality.

Prairie pothole basins have considerable potential for storing runoff. In the large wetland complexes of Salyer National Wildlife Refuge of North Dakota, undrained, mostly unconnected wetlands were reported to be storing 58 percent of the inflow, plus all local runoff (Malcolm 1979). In the Devils Lake Basin of North Dakota, wetland basins store between 41 percent of the runoff from severe (100-year) storm events, and up to 72 percent of the runoff from smaller events (Ludden, Frink, and Johnson 1983). In the Pembina River Basin of North Dakota, each undrained wetland can store up to 0.123 ha-m (1 acre-ft) of runoff (Kloet 1971), a figure also supported by the data of Hubbard and Linder (1986) from 213 wetlands in northeastern South Dakota. Seasonal wetlands in the reference data set store approximately 0.1476 ha-m (1.2 acre-ft) of water.

Prairie pothole wetlands facilitate detention of runoff because many lack well-defined surface water outlets and, between basins, subsurface flows in glacial till are slow (e.g., $0.05 \mathrm{~m} /$ day, Tipton et al. 1972). When runoff is detained in a regionally dispersed manner by pothole basins, pulses of water that eventually enter downstream areas in most cases are staggered (desynchronized). This broadens the storm hydrograph and reduces streamflow peaks. Wetland basins in the reference data set store as much as 40 percent of their water in the catchment area beyond the jurisdictional wetland boundary.

Characteristics and processes that influence the function. The characteristics and processes that influence the capacity of a pothole wetland to store water over an extended period are related natural factors, such as climate, geomorphic characteristics, soils, and vegetation. Additionally, anthropogenic factors play a significant role on many landscapes in the Prairie Pothole Region. This includes hydrogeomorphic modification of the wetland through ditching or the placement of tile drainage, and modifications of the surrounding landscape that can alter the timing and amount of water reaching the wetland. Kittelson (1988) reports that changes in peak flows attributable to a depressional wetland varies according to the interaction among outlet capacity, storage available within the site, and the amount of water coming into a wetland. 
The characteristics associated with the performance of this function focus on land use, as it influences the volume and timing of water entering the wetland, the volume of the wetland available for storage, the condition of the soils and plants (evapotranspiration, seepage, and soil storage), and activities that reduce retention time (e.g., artificial drainage). Activities above or within the wetland affect the rate and quantity of surface and subsurface water entering and leaving the wetland. Land use activities also affect erosion up slope and sediment import into the wetlands. An increased sediment load will decrease the wetland's capacity to store water, sometimes nearly eliminating storage capacity (Luo et al. 1997). Finally, the elevation and capacity of any constructed outlet below the storage boundary directly affects the height of the water level and, therefore, the ability of the depression to capture and retain water.

Although accumulation and retention of sediments and particulates are recognized functions of depressional wetlands resulting in improved water quality, it has a negative effect on wetland hydrology. Most PPR wetlands are closed basins; thus, sediment inputs are derived primarily from wind and water erosion of upland soils within the catchment. Upland land use affects the movement of water, sediment, and pollutants into the wetland. Generally, the higher the percentage of catchment under perennial cover, the better the condition of the wetland. Properly managed perennial cover helps to slow the movement of water down slope, which aids in the filtering of sediments and entrapment of pollutants. The chief negative impact to wetlands of accelerated sedimentation is loss of volume from filling. In the playa wetlands of Texas, Luo et al. (1997) found that basins in cultivated catchments had lost nearly all of their original volume because of filling by sediment. Precipitation that was once lost through evapotranspiration or infiltration to groundwater before entering wetlands with grassland catchments enters via spates of surface runoff from tilled catchments (Euliss and Mushet 1996). The accelerated runoff often brings erosional sediments from the surrounding landscape, contributing to filling the basin with soil. In addition to the alteration of hydrologic inputs, the loss of basin volume from siltation reduces the water storage capacity and flood attenuation benefits of wetlands (Brun et al. 1981; Ludden, Frink, and Johnson 1983). Gleason (2001) estimated that over 200 years, 50 percent of prairie pothole wetland storage volume would be eliminated owing to accelerated sedimentation in cultivated catchments, vs. a 20 percent loss of volume for wetlands in perennially vegetated catchments.

Functional Capacity Index. The assessment model for calculating the FCI for the function "Water Storage" is as follows:

$$
\mathrm{FCI}=\sqrt{\left(\text { Minimum of } V_{\text {out }}, V_{\text {SUbout }}\right) \times \frac{\left[V_{\text {Sed }}+\frac{\left(V_{\text {SOURCE }}+V_{\text {UpUSE }}\right)}{2}\right]}{2}}
$$

In the model, the variables having the greatest impact on the ability of a wetland to perform this function are anthropogenic drainage features (surface outlets or tile drains). Alterations that remove water from the wetland year round have a major effect on hydrology. Simply stated, if the wetland has been so 
hydrologically modified that it is completely drained (sub-index $=0$ ), then the wetland no longer has the capacity to perform the function "Water Storage" and the FCI equals zero.

$V_{\mathrm{SED}}$ is used to estimate the amount of storage reduction attributable to sedimentation. The variables $V_{\text {UPUSE }}$ and $V_{\text {SOURCE }}$ are used to estimate the timing and amount of runoff coming into the wetland. If the source area is changed, there is more or less water coming into the system, so the function lessens. If the land use in the catchment is less than reference standard, water can come in "spates" and decrease the ability of an individual wetland to perform the water storage function.

\section{Function 2: Groundwater Recharge}

Definition. This function is the capacity of a prairie pothole wetland to move surface water downward into local or regional groundwater flow paths. Groundwater recharge is the entry into the saturated zone of water made available at the water table surface, together with the associated flow away from the water table within the saturated zone (Freeze and Cherry 1979). A potential independent, quantitative measure of this function is the volume of water lost to groundwater per unit area per unit of time $\left(\left[\mathrm{m}^{3} / \mathrm{ha}\right] /\right.$ time $)$. Usually, this is measured or estimated on a net annual basis.

Rationale for selecting the function. Traditionally, groundwater recharge has been listed as one of the most important attributes of wetlands (Carter et al. 1979; Mitsch and Gosselink 1993). Water that infiltrates and recharges groundwater contributes to the local and regional groundwater flow net, thus contributing to higher base flows and improved distribution of seasonal flows (Ackroyd, Walton, and Hills 1967). Recharge is important for replenishing aquifers used for water supply. Recharge from wetlands in a 1600 -acre prairie pothole area was estimated to provide 12 acre-ft to the aquifer, enough to support 1699 head of cattle for one year (Hubbard and Linder 1986). Estimates of recharge from small prairie wetlands to regional aquifers as summarized by Hayashi, van der Kamp, and Rudolph (1998b) suggests that small pothole wetlands may be the main source of water to regional aquifers.

Characteristics and processes that influence the function. The attributes of depressional wetlands that allow them to recharge groundwater are not completely understood. Many studies indicate that wetlands, especially in humid climates, are principally discharge areas (Lissey 1971). The complexities of groundwater interactions with depressional wetlands make it difficult to model groundwater functions. The recharge/discharge function of pothole wetlands has been shown to change seasonally (Winter and Carr 1980; Winter and Rosenberry 1995), annually, cyclically through drought and pluvial cycles (Lissey 1971), and some pothole wetlands have been shown to function as both hydrologic sources and sinks simultaneously (Williams 1968; Winter and Rosenberry 1995).

One of the criteria for the classification of this regional subclass is that these are primarily groundwater recharge wetlands. However, even within the narrowly defined subclass, natural climatic and geomorphic characteristics result in pre- 
sumed differences in this function on a regional scale. Additionally, anthropogenic disturbances can dramatically affect the ability of a given pothole wetland to perform this function.

The ability of any portion of the earth's surface to be a groundwater recharge area can be simplified to two components: hydraulic head and hydraulic conductivity (Freeze and Cherry 1979). Hydraulic head is provided by two characteristics - the elevation of the wetland relative to the groundwater surface (elevation head) and the mass and pressure of water (pressure head). In the depression focused recharge (Lissey 1968) that occurs in prairie potholes, the pressure head is provided by the ability of the basin to collect and pond water (both within and above the wetland "boundary") and the elevation head generally depends on the basin's position in the groundwater flow path. The overall hydraulic conductivity depends on soil infiltration and hydraulic conductivity and by the underlying geologic materials (Winter and Rosenberry 1995).

The variables associated with the performance of this function focus on hydrogeomorphic characteristics that affect the hydraulic head and water movement rates. Characteristics that affect the ability of a pothole wetland to transmit surface water to groundwater include soil morphology and alterations to the plant community that affect evapotranspiration and seepage rates (Eisenlohr 1975). Seepage outflow rates are much higher in ephemeral and temporary potholes than rates in seasonal and semi-permanent potholes (Sloan 1970). Smaller temporary wetlands in higher landscape positions are more likely to function as recharge sites and more permanent depressional wetlands in topographic lows are more likely to be sites of groundwater discharge (Eisenlohr and Sloan 1968; Winter 1989).

Wetlands that have a higher catchment-to-pond ratio are more likely to contribute water to recharge (Arndt and Richardson 1988). The variable that represents this phenomenon is $V_{\text {САТС }}$. This variable is also considered to reflect water chemistry, which is an indication of recharge. Potholes with water of low conductivities indicate a net seepage outflow condition and water of high conductivity indicates of a net seepage inflow. (Eisenlohr and Sloan 1968; Rozkowski 1967). In the realm of rapid assessment, it is not practical that a onetime measure of water chemistry can be used for several reasons. The principal reasons are that there may not be any water in the pothole wetland at the time of assessment, and temporal changes in surface water chemistry can be significant. It has been shown that prairie pothole soil types can indicate water chemistry and recharge potential (Arndt and Richardson 1988). Use of the soil classification as it relates to recharge potential is $V_{\text {RECHARGE}}$.

Basins with high shoreline-to-pond ratios also may be an indication of recharge because water often percolates downward on wetland edges. The higher perimeter per unit of surface area of smaller wetlands allows more water to spread out from depressional wetlands (Millar 1971). The rate of water loss from prairie potholes varies directly with length of shoreline per unit area and inversely with size of individual sloughs. The $V_{\mathrm{EDGE}}$ variable is used for defining the relationship of shoreline to area. 
Land use activities also affect erosion up slope and sediment import into the wetlands. An increased sediment load will decrease the wetland's capacity to store water. The degree of sedimentation is captured by $V_{\mathrm{SED}}$. Undisturbed soil within the wetland is closely related to water movement because the soil allows water to infiltrate and move downward. This soil condition is described in $V_{\mathrm{SQI}}$. Local groundwater is directly influenced by the presence of nearby subsurface drainage (e.g., ditches, tile drains, etc.), which, in turn, influences surface water and, therefore, the amount of seasonal water that the depression can capture and hold. $V_{\text {SUBOUT }}$ reflects this aspect of the function. Finally, the elevation of the surface outlet directly affects the height of the water level and, therefore, the ability of the depression to provide the pressure head necessary for depression focused recharge. If a wetland that recharges groundwater is drained, the recharge function of the wetland will no longer exist (Winter 1989). $V_{\text {OUT }}$ is used to reflect this aspect of the function.

Functional Capacity Index. The assessment model for calculating the functional capacity index (FCI) is as follows:

$$
\mathrm{FCI}=\sqrt{\left(\text { Minimum of } V_{\text {oUt }}, V_{\text {SUBgut }}\right) \times \frac{\left[\frac{\left(V_{\text {RECHARGE }}+V_{\text {EDGE }}+V_{\text {CATCHWET }}\right)}{3}\right]+\left[\frac{\left(V_{\text {SQI }}+V_{\text {SED }}\right)}{2}\right]}{2}}
$$

In the model, the capacity of a depressional wetland to recharge groundwater depends on several characteristics. In the first part of the model, the lesser of $V_{\text {OUT }}$ or $V_{\text {SUBOUT }}$ indicate the drawdown of water by surface or subsurface drainage, which decreases pressure head or intercepts the water before it can recharge groundwater. If the outlet has the capacity to remove surface water completely, the sub-index would equal 0.0. Or, if the subsurface drainage intercepts all water below the wetland, the sub-index would equal 0.0. In these cases, the corresponding FCI would also be equal to 0.0 .

$V_{\text {RECHARGE, }} V_{\text {EDGE, }}$, and $V_{\text {CATCHWET }}$ are all hydrogeomorphic variables that reflect a prairie pothole's natural affinity to recharge groundwater. The $V_{\mathrm{SQI}}$ and $V_{\mathrm{SED}}$ variables are used to assess near surface alteration of the soils hydraulic conductivity and basin storage.

\section{Function 3: Retain Particulates}

Definition. Retain particulates is defined as the capacity of a wetland to physically remove and retain inorganic and organic particulates $>0.45 \mu \mathrm{m}$ (Wotten 1990) from the water column. A potential independent measure of this function is the amount of particulates retained per unit area per unit time (i.e., $\left.\left[\mathrm{g} / \mathrm{m}^{2}\right] / \mathrm{yr}\right)$.

Rationale for Selection of Function. Sediment retention by wetlands is often described as a water quality benefit (Boto and Patrick 1978). Sediment deposition is a natural geologic process that is maintained over thousands of years. However, accelerated sedimentation may be the most detrimental impact 
on depressional wetlands. Retention applies to particulates arising from both onsite and offsite sources. The retention function contrasts with the removal of elements and compounds function because of the emphasis on physical processes (e.g., sedimentation and particulate removal) rather than elements and compounds, many of which are in the dissolved state. There are two primary benefits of this function. First, the removal of particulates reduces the load of particle bound nutrients, heavy metals, pesticides, and other pollutants into groundwater, and nearby rivers and streams. Second, at natural sustainable levels, these inputs are necessary for the overall maintenance of the nutrient budget and associated characteristic plant and animal communities of prairie pothole wetlands.

Characteristics and Processes that Influence the Function. The characteristics and processes that influence a depressional wetland's ability to perform this function can be divided into two groups. The first deals with the sources and mechanisms by which particulates are transported to, or prevented from entering into, the wetland, or both. Sediment inputs into prairie potholes are derived primarily from wind and water erosion of soils in the immediate catchment and adjacent upwind landscapes. The second group of characteristics and processes relate to the immobilization of the particulates that are transported into the wetland. The primary characteristic that causes sediment accumulation in prairie pothole wetlands is landscape position. Because most prairie pothole wetlands occur in surficially closed basins they become "targets" for the retention of water-borne sediment. Vegetation structure also influences the ability of the wetland to trap sediment, both from water and wind erosion. Accumulation of sediment in depressional wetlands decreases wetland volume (Luo et al. 1997), decreases the duration wetlands retain water (Gleason and Euliss 1998), and changes plant community structure by burial of seed banks (van der Valk and Pederson 1989; Jurik, Wang, and van der Valk 1994; Wang, Jurik, and van der Valk 1994). Sediment retain elements and compounds through burial and chemical precipitation (e.g., removal of phosphorus by iron III). Dissolved forms may be transported with the particles through sorption and chelation (i.e., heavy metals mobilized with humic and fulvic compounds). Imported sediment can undergo renewed pedogenesis on site, which potentially involves weathering and release of elements that were previously inaccessible to mineral cycling.

Particulates are transported into pothole wetlands from several sources. They include dry deposition and precipitation from the atmosphere, overland flow from adjacent uplands, and occasional overflows connecting wetlands during wet periods of high storage (Adomaitis, Kantrud, and Shoesmith1967; Leonard 1988; Grue et al. 1989; Winter and Rosenberry 1995; Waite et al. 1992). Atmospheric sources are assumed to account for a relatively small amount of the total particulates that typically impact pothole wetlands. However, in areas of intense agriculture, atmospheric deposition of sediments may be significant (Adomaitis, Kantrud, and Shoesmith1967; Frankforter, 1995). The dominant mechanisms for the input and output of particulates among pothole wetlands are surface sources such as overland flow, surface connections between wetlands during wet periods, and man-made ditches. These sources are a function of wetland basin morphology (e.g., catchment size, slope gradient, and natural or man-made surface connections). 
Dense vegetation cover reduces surface water velocities and allows for greater infiltration and filtration of particulates, and soils are less likely to erode. Therefore, uplands with dense vegetation cover and wetlands with buffers of perennial vegetation around them will supply fewer particulate inputs to the wetland than uplands with sparse vegetation (Neely and Baker 1989; Luo et al. 1987;

Dieter 1991; Gleason and Euliss 1998). Martin and Hartman (1987) found prairie wetlands with cultivated (sparse vegetation cover) catchments accumulated sediments at a rate about two times that of basins with dense grassland cover.

Functional Capacity Index. The assessment model for calculating the functional capacity index (FCI) is as follows:

$\mathrm{FCI}=\sqrt{V_{\text {SED }} \times \frac{\left[\frac{\left(V_{\text {UPUSE }}+V_{\text {GRASSCONT }}+V_{\text {GRASSwidH }}\right)}{3}\right]+\left[\frac{\left(V_{\text {VEGCOMP }}+\left(\text { Minimum of } V_{\text {OUT }}, V_{\text {SUBoUt }}\right)\right)}{2}\right]}{2}}$

In this model, the capacity of a prairie pothole wetland to retain particulates depends upon three characteristics: the ability of the depression to physically store sediment, the ability of sediment to reach the wetland, and the slowing of surface waters long enough to allow particulates to settle. In the first part, $V_{\text {SED }}$ indicates whether there is any capacity in the basin to trap additional sediment. If the depressional characteristic of the wetland is eliminated, there is no place for the sediment to be stored.

In the second part of the model, $V_{\text {UPUSE}}, V_{\text {GRASSCONT }}$, and $V_{\text {GRASSWIDTH }}$ represent the ability of the surrounding landscape to deliver or prevent particulates from reaching the wetland. For slopes more than 15 percent, most sediment settling occurs within a 7.4- to 9-m wide buffer of grass (Dosskey, Schultz, and Isenhart 1997). These variables are partially compensatory and assumed to be independent and to contribute equally to the performance of the function. The variables are combined using an arithmetic mean that reduces the influence of lower subindices on the FCI (Smith and Wakeley 2001), which in this case is consistent with the assumption that these variables have less of an influence on the function. For example, the presence of a buffer will reduce the amount of sediment that actually reaches the wetland even if the $V_{\text {UPUSE }}$ Sub-index is 0.0 .

In the third part of the model, $V_{\mathrm{VEGCOMP}}$ and $V_{\mathrm{OUT}}$ reflect the ability of the wetland to reduce the velocity of the water moving into and through the wetland. These variables are partially compensatory and assumed to be independent and to contribute equally to the performance of the function. The variables are combined using an arithmetic mean that reduces the influence of lower subindices on the FCI (Smith and Wakeley 2001), which in this case is consistent with the assumption that these variables have less of an influence on the function. For example, even if the sub-index for $V_{\text {OUT }}$ is 0.0 , the roughness contributed by plants will still retain some of the particulates. 
In the aggregation equation $V_{\mathrm{SED}}$ is weighted more heavily by the use of a geometric mean. The logic for this is simple, if there is no depression left, there is no place to store sediment and the "wetland" could actually become a source of sediment.

\section{Function 4: Remove, Convert, and Sequester Dissolved Substances}

Definition. Remove, Convert and Sequester Dissolved Substances is defined as the ability of a wetland to remove and sequester imported nutrients, contaminants, and other elements and compounds. The term "removal" is used to imply permanent loss of nutrients, contaminants, or other elements and compounds through or conversion by biogeochemical reactions. The term "sequestration" implies relatively long-term accumulation of elements and compounds. such as by uptake and incorporation into long-lived perennial herbaceous biomass. Elements include macronutrients essential to plant growth (e.g., nitrogen, phosphorus, potassium, etc.) and other elements such as heavy metals (e.g. zinc, chromium, etc.) that can be toxic at high concentrations. Compounds include herbicides, pesticides, and other imported materials. A potential independent, quantitative measure of this function is the amount of one or more imported elements and compounds removed or retained per unit area during a specified period of time (e.g., $\mathrm{g} / \mathrm{m}^{2}$ per year).

Rationale for Selection of Function. The functioning of wetlands as interceptors of non-point source pollution is well documented (Johnston 1991). Elements and contaminants in surface and groundwater that come in contact with wetland soils and vegetation are either removed over the long term by sedimentation or are transformed into innocuous and biogeochemically inactive forms. There are several reviews on nutrient removal by wetlands, including those of Faulkner and Richardson (1989) and Johnston (1991). From the mid-1970s to the mid-1980s, much research and development effort was invested in utilizing wetlands as sites for tertiary treatment of wastewater. Much of this work is summarized in U.S. Environmental Protection Agency (1983); Godfrey et al. (1985); and Ewel and Odum (1984). Because of their location on the landscape, pothole wetlands are strategically located to process nutrients and contaminants before they can contribute to groundwater or surface water pollution (Crumpton and Baker 1993). Jones, Borofka, and Bachmann (1976) showed that even a slight increase in the percentage of wetlands in an agricultural watershed reduced the amount of nitrate loads of streams leaving the watershed. Studies of natural wetlands receiving cropland runoff have shown a nitrate nitrogen removal rate as high as 90 percent (Baker 1992).

The primary benefit of this function is that the removal, conversion, and sequestration of dissolved substances by pothole wetlands reduce the load of nutrients and pollutants in groundwater and in any surface water leaving the wetland. This translates into better water quality and aquatic habitat in adjacent wetlands and down gradient streams and lakes.

Characteristics and Processes that Influence the Function. There are two categories of characteristics and processes that influence the capacity of a pothole wetland to remove, convert, and sequester dissolved substances. The first deals 
with the mechanisms by which the elements and compounds are transported to the wetland, and the second deals with the structural components and biogeochemical processes involved in the function.

For rapid assessment, a very broad approach has been taken to both the elements and compounds of interest and the mechanisms by which they are removed. This is in contrast to most of the research on the topic that is conducted on one element or mechanism at a time. Elements and compounds can enter the wetland environment via overland flow (i.e., in water and attached to sediment), aeolian snow-soil (Adomaitis, Kantrud, and Shoesmith 1967), wind-born dust, airborne drift or direct over-spray, or precipitation (Goldsborough and Crumpton 1998). Pothole wetlands may be especially subject to contamination by surface runoff because they occur in landscape positions that receive or concentrate runoff, or both. Sequestration of imported elements and compounds occurs through exposure to solar irradiance for pesticide photolysis (Goldsborough and Crumpton 1998), adsorption, sedimentation, microbial biodegradation, denitrification, burial, uptake and incorporation into perennial biomass, and similar processes (Brinson et al. 1995).

Nitrogen and phosphorus are removed from incoming water in very different ways because the former is part of a gaseous biogeochemical cycle and the latter a sedimentary cycle (Schlesinger 1997). The major reactions that result in the removal of nitrogen from the wetland system are microbially mediated nitrification-denitrification reactions (Reddy and Patrick 1984). For phosphorous, plant uptake and interaction with the solid phase $\mathrm{P}$ components are the major removal processes (Mitsch et al. 1995). Microbial reactions generally play a smaller role in the storage of phosphorous but can play a significant role in its release from wetlands (Masscheleyn and Patrick 1993). The dissipation of pesticides in wetlands is less understood and is complicated by the large variety of pesticide compounds (Goldsborough and Crumpton 1998). Generally, research indicates that pesticide contaminants of surface and groundwater disappear rapidly from wetland waters, primarily as a result of adsorption by decomposing litter and the soil organic fraction (Huckins, Petty, and England 1986; Matter 1993; Crumpton et al. 1994). Wetlands are capable of trace metal removal (Masscheleyn and Patrick 1993), although the information on the effectiveness to remove these elements is incomplete. The three major mechanisms are: binding to soils and soluble organics; precipitation as insoluble salts, principally sulfides and oxyhydroxides; and uptake by plants, including algae, and by bacteria (Kadlec and Knight 1996).

Nitrogen exists in many forms in wetland water columns and substrates, and has a complex cycle. Nitrogen is removed largely by four processes (Reddy and Patrick 1984), some of which are microbial: 1) uptake by plants, 2) immobilization by microorganisms into microbial cells during the decomposition of plant material, 3) adsorption of ammonium nitrogen onto the organic matter and the clay cation exchange complex, and 4) most importantly, mineralization-nitrification-denitrification reactions. Within soils, two major conversion routes are dominant. Nitrification is the biological oxidation of reduced organic or inorganic $\mathrm{N}$ forms, usually $\mathrm{NH}_{4}+$ to more oxidized forms, especially $\mathrm{NO}_{3}-$. The second, denitrification, transforms nitrate $\left(\mathrm{NO}_{3}\right)$, which releases nitrogen gases $\left(\mathrm{N}_{2} \mathrm{O}\right.$ and $\left.\mathrm{N}_{2}\right)$ to the atmosphere. It is the coupling of aerobic (nitrification) and anaerobic (denitrification) reactions that allows wetlands to function most 
effectively to "remove" nitrogen from the ecosystem. In contrast to deeper aquatic systems, the shallow water-sediment interface (Engler and Patrick 1974), root rhizospheres (Reddy, Patrick, and Lindau 1989), and alternating dry and inundated conditions of wetlands favor nitrification-denitrification reactions (Ponnamperuma 1972). This is the reason that the conversion of shallow, more seasonal type wetlands to deeper, more permanent type wetlands actually decreases many of the microbially mediated biogeochemical functions. Denitrification is dependent upon amount of organic carbon (Pastor et al. 1984), soil drainage (Groffman and Hanson 1997), soil redox potentials (Merrill and Zak 1992; Olness et. al. 1997), vegetation structure (Rose and Crumpton 1996), detritus (Howard-Williams and Howard-Williams 1978), and, most of all, nitrogen loading rates (Crumpton and Baker 1993; Isenhart 1992). Studies have shown that nitrogen loading dramatically increases denitrification and wetlands may be nitrogen limited systems (Crumpton and Goldsborough 1998).

Phosphorus is removed from the water column in wetlands through plant uptake, immobilization by microorganisms into microbial cells during decomposition of plant material, adsorption of orthophosphate onto clay and oxyhydroxide surfaces, and precipitation with cations such as calcium, magnesium and iron (Patrick 1992; Mitsch et al. 1995). The best long-term removal process is uptake by growing plants, and the storage of plant remains as peat or removal of plant material by harvest (Patrick 1992). There is a limit to the amount of phosphorous that can be adsorbed because adsorption sites can become saturated with phosphorous. Normally, most phosphorus is associated with particulate materials that are removed from the water column as sediments settle. Annual net uptake of phosphorus by growing vegetation, although significant, usually represents a small quantity relative to the soil/sediment sinks of phosphorus (Brinson 1985). Organic matter can also have high adsorptive capacity for compounds like phosphorous and heavy metals.

A major mechanism that contributes to removal of elements and compounds from water entering a wetland is reduction. Denitrification will not occur unless the soil is anaerobic and the redox potential falls below a certain level. In addition, sulfate is reduced to sulfide that then reacts with metal cations to form insoluble metal sulfides such as $\mathrm{CuS}, \mathrm{FeS}, \mathrm{PbS}$, and others.

Heavy metals can be sequestered from incoming waters by adsorption onto the charged surfaces (functional groups) of clay minerals, by specific adsorption onto $\mathrm{Fe}$ and $\mathrm{Al}$ oxide minerals, by chemical precipitation as insoluble sulfide compounds, or by plant uptake (Kadlec and Knight 1996). These processes, other than plant uptake, are often controlled by the redox status of the soil (Masscheleyn and Patrick 1993). This function (Function 4) is focused on the chemical portion of the biogeochemical cycle, Function 3 (Retention of Particulates) focuses on the physical (geo) part of the cycle.

The variables of this function reflect land use and the biotic and abiotic components of the PPR ecosystem. Land use activities impact the elements and compounds entering the system and the natural removal and retention processes of these elements and compounds. The related variables are grassland width, grassland continuity, upland land use, and sediment. Biotic components remove elements and compounds through plant growth and decay. Rates of decomposition 
are slow enough to sequester or remove nutrients within the wetland. The related variable is vegetation composition. Abiotic components assist the reduction and oxidation processes that biogeochemically sequester elements and compounds. The related variables are wetland outlet, subsurface outlet, source area of flow, and soil organic matter.

Functional Capacity Index. The assessment model for the function "Remove, Convert and Sequester Dissolved Substances" is:

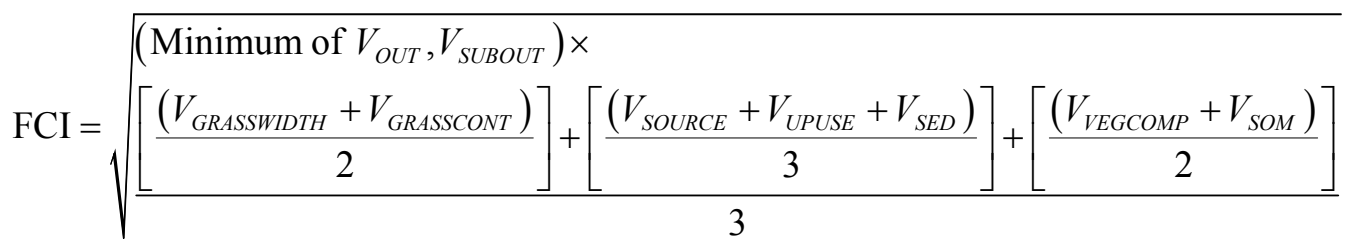

In this model, the capacity of a depressional wetland to remove, convert, and sequester dissolved substances is made up of three parts. The first focuses on maintaining a wet, anaerobic environment in the wetland. The lesser of $\mathrm{V}_{\text {OUT }}$ or $\mathrm{V}_{\text {SUBOUT }}$ is used because the degree of wetness is the major driver in maintaining this biochemical function. The second portion of the model deals with the mechanisms by which the elements and compounds are transported to the wetland and is represented by the variables $\mathrm{V}_{\text {GRASSwidTH, }}, \mathrm{V}_{\text {GRASSCONT, }}, \mathrm{V}_{\text {SOURCE}}$, $\mathrm{V}_{\text {UPUSE}}$, and $\mathrm{V}_{\mathrm{SED}}$. The five variables are equally independent. The third part deals with the biogeochemical processes involved in the function and is represented by the variables $\mathrm{V}_{\text {SOM }}$ and $\mathrm{V}_{\mathrm{VEGCOMP}}$. The two variables are partially compensatory, based on the assumption that they are independent and contribute equally to performance of the function.

The second part of the model is averaged because the variables are considered to be interdependent and equally important. Therefore, a characteristic level of removing, converting, and sequestering will not be achieved if mechanisms and processes are reduced. An arithmetic, rather than geometric, mean is used because it may be possible, under certain circumstances, for some variable subindices to drop to 0.0 for a short time. This would not result in the function being eliminated. A geometric mean is used for the subindices that are the indicators of anaerobic conditions $\left(\mathrm{V}_{\text {SUBOUT }}\right.$ or $\left.\mathrm{V}_{\text {OUT }}\right)$ because without maintaining anaerobic conditions, the functional capacity of a wetland is dramatically diminished. The primary mechanism for transforming many of the elements and compounds is based upon the presence of water (i.e., anaerobic conditions).

\section{Function 5: Plant Community Resilience and Carbon Cycling}

Definition. Plant Community Resilience and Carbon Cycling is defined as the ability of a pothole wetland to sustain native plant community patterns and rates of processes in response to the variability inherent in its natural disturbance regimes. Plant communities develop and respond to changing environmental conditions, including soil condition, hydrology cycles, wetland land use, and land use within the catchment. Even when not influenced by human activities, 
ecosystems show a high degree of variability, at different temporal and spatial scales, in diversity, structure, and function. Plant community sustainability also requires the maintenance of plant community properties such as seed dispersal, vegetative propagule production, plant densities, and growth rates that permit response to variation in climate and disturbance. In assessing this function, one must consider the extant plant community as a response to previous hydrologic cycles and the synergistic effects of natural and anthropogenic disturbances.

A variety of approaches have been developed to describe and assess plant community characteristics that might be appropriately applied in developing independent measures of this function. These include quantitative measures based on vegetation composition and abundance, such as similarity indices (Ludwig and Reynolds 1988), indirect multivariate techniques such as detrended correspondence analysis (Kent and Coker 1995), and techniques that employ both vegetation and environmental factors, such as canonical correlation analysis (ter Braak 1994). Whether descriptive, comparative, or multi-variate statistical analyses are used for vegetation characterization and determination of explanatory environmental variables, the goal of the assessment is to describe both the reference standard condition and deflection from the reference standard. Invasion by non-native plants or ruderal native species is an indication that this function has been diminished.

Rationale for selecting the function. The ability to maintain plant community productivity and processes is important because of the contribution to biodiversity and the many attributes and processes of pothole wetlands that influence other functions. Emergent macrophytes represent the majority of biomass in primary productivity and subsequent loading into nutrient cycling processes. The macrophytic vegetation conducts the preponderant portion of the wetland's primary production (Richardson 1979), nutrient cycling (McKee and McKevlin 1993), contribution to annual detrital accumulations, and soil development. The physical characteristics of the living and dead plants are closely related to ecosystem functions associated with abundance and diversity of animal species (Gregory et al. 1991). Macrophytic vegetation also provides most of the trophic support for secondary production (Crow and Macdonald 1978), whether that production is based on direct grazing of living plant biomass or whether the energy is shunted through the detrital-based food web. In addition to these trophic relationships, vegetation provides a structural component for fauna that depend on wetlands for fulfillment of some or all of their life cycle requirements. Vegetation patterns are likely to control major aspects of wetland biogeochemistry and trophic dynamics, and wetlands should be viewed as complex mosaics of habitats with distinct structural and functional characteristics (Rose and Crumpton, 1996). The structure and composition of the plant communities may also directly or indirectly influence floodwater retention, sediment retention, and surfacegroundwater interaction at a local or regional scale.

Characteristics and processes that influence the function. Disturbance maintains the current plant community or resets successional processes to different stages. Plant community dynamics are influenced by the type and timing of disturbance (whether recurrent or catastrophic). Disturbances initiating directional community change or maintenance of community dynamics include hydrological variation, herbivory, or fire. Wetland vegetation should not be 
considered as temporally static, but rather as changing in composition and characteristics over a hierarchy of temporal scales - annual cycles, multi-year life history cycles, and longer climatic cycles (van der Valk 2000). Wetland vegetation is an interactive component of ecosystem structure and function, operating both in response to the preceding disturbance-based driving mechanisms, as well as a driving mechanism for other wetland functions (e.g., faunal habitat, primary productivity).

Both plant community response and driver mechanisms are influenced by human disturbance. Anthropogenically induced changes in water movement, water quantity or quality, and sediment transport influence the ability to maintain characteristic plant communities and processes. Alterations to the disturbance regime outside of the "normal range of variation" alter ecosystem processes, which in turn alter their characteristic spatial and compositional attributes. Communities affected by human activity also exhibit reduced resistance to natural stressors (De Leo and Levin 1997). The natural fluctuation of water levels is the most important driver of vegetational change in prairie wetlands. Anthropogenic alterations both within the catchment and the wetland basin, as manifested by surface ditches, underground tiles, dugouts, impoundments, and road construction, alters hydro-dynamics and hence the wetlands' resilience in responding to change. Some wetland basins, although not directly drained, no longer hold water because of the effects of drainage elsewhere within the local hydrologic systems. This alteration of basins' recharge-discharge relationships can similarly contribute to "un-natural" variability in hydro-dynamics with decreased plant community resilience.

Conversion of the source catchment from low to high impact land uses causes movement of topsoil into wetland basins with potential increases in nutrients. Anthropogenic sedimentation potentially suppresses primary production and alters natural food chain interactions. Sedimentation has been shown to significantly reduce species richness, propagule emergence, and germination of wetland macrophytes (Gleason and Euliss 1998). Basins in poor-quality watersheds tended to have slightly fewer communities (Kantrud and Newton 1996). Increasing nutrients are often associated with the invasion of exotic species. Increased sedimentation selects for monotypic stands of aggressive native species (e.g. Typha spp.) or invasive exotic species (Phalaris arundinacea).

Similarly, land use practices within the wetland can affect plant community composition, and substrate and nutrient dynamics. The mechanical disturbance to a wetland by repeated cultivation affects all stages in the plant regeneration cycle, an important mechanism in the maintenance of plant species diversity and plant community processes (Grubb 1977; Euliss and Gleason 1998). Such disturbances may eliminate characteristic normal emergent phase-wet phase-dry phase community dynamics, thereby allowing rapidly maturing annuals and relatively short, deep-rooted perennials more characteristic of the cropland drawdown and cropland tillage phases conditions to persist. Development of monotypic stands of macrophytes may effectively remove some of the variation in decomposer organisms that could act to maintain or increase vegetation heterogeneity (Kantrud 1986). Buildup of litter in monotypic stands may also result in altered rates of decomposition (Kantrud, Millar, and van der Valk 1989). Cultivation of various emergent wet-meadow and shallow-marsh communities during dry years 
creates coarse-grained vegetation mosaics with fewer communities (Kantrud and Newton 1996).

In addition to cultivation, wetland vegetation also responds to "idle" conditions, haying, burning, and grazing. Characteristic dominant species are often associated with each land use type. Fulton, Richardson, and Barker (1986) provided a listing of common emergent species response to various intensities of grazing, mowing, and burning. Species were categorized as present under a given land use type, or decreasing or increasing in abundance in response to the land use. Stewart and Kantrud (1972) and Kantrud (1989a) provide a listing of common dominants associated with varying land use practices. Woody plants can invade idle wetlands, especially in formerly disturbed wet-meadow zones (Kantrud and Newton 1996). The effects of grazing on wetland plant communities vary with timing, frequency, and intensity. Both compositional and structural attributes may change in response to grazing. Unless unusually severe, grazing can result in greater plant species diversity, increased vegetation-open water interspersion, and sharper boundaries among plant communities (Bakker and Ruyter 1981). Long-term overgrazing can reduce the wet meadow zones to bare soil, affect the height and density of wetland vegetation, and may cause a decrease in primary production.

To assess this function, vegetation composition and environmental factors known to influence vegetation establishment and regeneration need to be evaluated. Also, human disturbances that mimic or simulate natural disturbances are less likely to threaten plant community integrity than are disturbances radically different from the natural disturbance regime (Noss 1995).

Functional Capacity Index. The assessment model for calculating the functional capacity index (FCI) is as follows:

$\mathrm{FCI}=\sqrt{\left(\text { Minimum of } V_{\text {OUT }}, V_{\text {SUBOUT }}\right) \times \frac{\left[\frac{\left(V_{\text {UpUSE }}+V_{\text {GRASSCONT }}+V_{\text {GRASSWIDTH }}\right)}{3}\right]+\left[\frac{\left(V_{\text {SED }}+V_{\text {SOM }}\right)}{2}\right]+V_{\text {VEGCOMP }}}{3}}$

In the model, the lesser of $\mathrm{V}_{\text {OUT }}$ or $\mathrm{V}_{\text {SUBOUT }}$ is used because hydrodynamics is the major driver in plant community processes and subsequent responses. $\mathrm{V}_{\text {UPUSE }}$ indicates the condition of the catchment and this is averaged with $\mathrm{V}_{\text {GRASSCONT }}$ and $\mathrm{V}_{\text {GRASSWIDTH. }}$ This provides an indication of the immediate area surrounding the wetland, which will potentially affect the inputs of sediment or pollutants.

Although $\mathrm{V}_{\text {UPUSE }}, \mathrm{V}_{\text {GRASSCONT }}$, and $\mathrm{V}_{\text {GRASSwidTH }}$ variables are related as source input areas, decreasing any of these variables is capable of diminishing this function. $\mathrm{V}_{\mathrm{SED}}$ is then averaged with $\mathrm{V}_{\mathrm{SOM}} \cdot \mathrm{V}_{\mathrm{SED}}$ is the amount of sediment that has accumulated within the wetland and is used in this assessment model primarily to represent the assessment wetland as a sink for pollutants. Secondarily, accelerated sediment inputs can reduce wetland volume, bury seed banks, and alter characteristic vegetation dynamics and zonation. $\mathrm{V}_{\mathrm{SOM}}$ represents inputs and availability of nutrients for carbon cycling. $\mathrm{V}_{\mathrm{VEGCOMP}}$ is the most direct indication of how similar the plant community is to the reference standard conditions.

$\mathrm{V}_{\mathrm{VEGCOMP}}$ was, therefore, given a higher weighting within the assessment model. 


\section{Function 6: Provide Faunal Habitat}

Definition. The function Provide Faunal Habitat is defined as the ability of a prairie pothole to support aquatic and terrestrial vertebrate and invertebrate populations during some or part of their life cycle. Prairie wetland fauna have high variability in spatial and temporal use of wetlands and the surrounding landscape. Wildlife species diversity is generally highest when the wetland is structurally complex (Weller 1987). No single species, or species guild, can serve as a definitive, all-inclusive indicator of wetland habitat functions or carrying capacity (Weller 1988).

Habitat provided by wetlands and the landscape matrix changes between years and within seasons in response to natural or anthropogenic disturbance regimes. Given this variability, long term surveys of faunal diversity and abundance would be required to adequately assess the faunal function. These surveys would be more appropriate as an independent, quantitative verification of this function. Extensive surveys for HGM rapid assessment applications are impractical. Instead, structural and compositional multi-scale metrics that are less subject to these fluctuations are assessed. Emphasis is on the capacity of the wetland to maintain the habitats and resources necessary for characteristic faunal diversity and abundance.

Potential independent, quantitative measures of this function are species inventory approaches, with data analysis usually employing comparisons between sites using similarity indices (Odum 1950; Sorenson 1948). Another independent measure would be Habitat Evaluation Procedures (U.S. Fish and Wildlife Service 1980). For biodiversity considerations at the landscape scale, waterfowl recruitment models (Reynolds, Cohan, and Johnson 1996; Cowardin, Shaffer, and Arnold 1995) or models assessing patch dynamics can be used (Forman and Godron 1986; Jongman et al. 1996).

Rationale for selecting the function. It is generally recognized that most macrophyte production eventually ends up as detritus (Davis and van der Valk 1978b). Invertebrates are a critical link between the primary production-detrital resources of the system and the higher order consumers (Murkin and Wrubleski 1988; Driver, Sugden, and Kovach 1974). Specifically, invertebrate fauna: 1) process organic matter and are often major contributors to decomposition, 2) play an essential role in nutrient cycling, and, 3) provide important conduits of trophic support for higher level consumers through secondary production (Euliss, Mushet, and Wrubleski 1999). The abundant production of detritus may be the most important source of nutrients and energy for the invertebrates in wetland habitats and subsequent exploitation by higher order consumers (Batt et al. 1989; Murkin 1989).

Wetlands should be viewed as complex mosaics of habitats with distinct structural and functional characteristic (Rose and Crumpton, 1996). Vertebrate species utilizing wetlands of the Prairie Pothole Region respond to hydrodynamics, vegetation composition and structure, and proximity to other habitats. A full range of habitat conditions is provided for wide-ranging or migratory animals, ecological generalists that possess the necessary adaptations to tolerate environmental extremes, and selected endemic species requiring specialized 
habitats. Populations also require exchange of genetic material between metapopulations to maintain long-term viability.

Characteristics and processes that influence the function. Northern prairie wetlands have been greatly altered by human-induced changes that include drainage, alteration of catchments, accelerated sedimentation, suppression of fire, the removal or alteration of natural grazing patterns, and the introduction of exotic species. These alterations have often resulted in a more static system and a subsequent reduction in habitat diversity.

Increases in water level fluctuations or accelerated sedimentation due to tillage may ultimately affect the composition of a wetland's flora and fauna. Sediments may bury invertebrate egg banks that are important for maintenance and cycling of biotic communities during wet-dry cycles (Gleason et al. 2002). As vegetation controls major aspects of wetland biogeochemistry and trophic dynamic (Rose and Crumpton 1996), any anthropogenic influences affecting vegetation pattern and composition will also impact food chain dynamics.

Leibowitz and Vining (2003) noted that intermittent surface-water connections between depressional wetlands could affect biodiversity or population dynamics through the transport of individuals or reproductive bodies. However, local wetland drainage and road construction may have altered historical connectivity. Wetlands bisected by or close to highways and roads fragment the landscape and have an immediate impact on wildlife mortality (O'Neill et al. 1997). Localized fragmentation limits the ability of organisms to move within and between wetlands. Trombulak and Frissell (2000) reviewed the scientific literature on the ecological effects of roads and found support for the general conclusion that they are associated with negative effects on biotic integrity in both terrestrial and aquatic ecosystems.

Within the Prairie Pothole Region, wetland drainage has focused mostly on shallow temporary and seasonal wetlands within agricultural fields. The result has been a shift in the proportion of available wetland classes and alteration of hydrologic regimes of many non-drained wetlands. Small wetlands are critical components of the surrounding landscape that influence habitat suitability of larger wetlands (Naugle et al. 2003). The destruction of even small depressional wetlands can lower the water table through an area and change hydrologic functions of other wetlands (Winter 1988). These include local, intermediate, and regional connections and hydrologic groundwater dependencies that maintain water storage and diversity of wetlands.

Landscape scale characteristics affect the ability of a wetland to provide faunal habitat. Analyses by Naugle et al. (2003) indicated that habitat suitability for some species (e.g., Virginia rail, pied-billed grebe) is related to local vegetation conditions within wetlands, while suitability for others (e.g., northern pintail, black tern) is related to landscape structure at larger scales. As a result, unfragmented wetland complexes embedded within upland grasslands provide habitat for more species than isolated wetlands in agricultural lands. Marsh isolation has been shown to reduce bird densities (Brown and Dinsmore 1991). Lehtinen, Galatowitsch, and Tester (1999) examined habitat loss and fragmentation, as well as selected within-wetland conditions potentially affecting amphibian 
assemblages. Amphibian species richness was lower with increased wetland isolation and road density.

The decline of many species has been linked directly to habitat loss and fragmentation (Schumaker 1996). Species most vulnerable to loss of small wetlands are those that exploit resources over broad spatial scales (Naugle et al. 2003). Habitat fragmentation exacerbates the problem of habitat loss for both grassland and wetland birds. According to Johnson (2001), remaining patches of grasslands and wetlands may be too small, too isolated, and too influenced by edge effects to maintain viable populations of some breeding birds. Greenwood et al. (1995) found that duck nest success in the Canadian PPR was negatively correlated with the amount of cropland present.

Continuity of vegetation, connectivity of specific vegetation types, the presence and extent of corridors between upland and wetland habitats, and corridors between wetlands all have direct bearing on the movement and behavior of animals that use wetlands (Sedell et al. 1990). Such connections between habitats help maintain higher animal and plant diversity across the landscape than would be the case if habitats were more isolated from one another (Brinson et al. 1995) The functional redundancy of diverse hydrogeomorphic classes on the landscape plays a fundamental role in maintaining an ecosystem's ability to respond to changes and disturbance by providing resilience from stresses and catastrophes (Levin 1995, 1997). Fragmentation of landscapes effectively reduces the size of habitat units as well as diminishing habitat continuity.

Functional capacity index. The assessment model for calculating the functional capacity index (FCI) is as follows:

$$
\mathrm{FCI}=\sqrt{\frac{\left[\frac{\left(V_{\text {UPUSE }}+V_{\text {SED }}\right)}{2}\right]+\left[\frac{\left(V_{\text {GRASSCONT }}+V_{\text {GRASSWITH }}+V_{\text {EDGE }}+V_{\text {WETPROX }}\right)}{4}\right]+V_{\text {VEGCOMP }}}{3}}
$$

Hydrology ( $\left.V_{\text {OUT }}, V_{\text {SUBOUT }}\right)$ was given the greatest weight in the equation. The alteration of a wetland's hydroperiod will result in the greatest impact to wetland dynamics, subsequent plant community responses and ultimately effect habitat selection and utilization by fauna. Next in the equation are the variables $V_{\text {UPUSE }}$ and $V_{\text {SED }} . V_{\text {UPUSE }}$, the land use-land cover of the catchment, affects sedimentation rates and hydro-dynamics within the wetland. Additionally, the condition of the surrounding upland influences faunal movement between wetlands and provides cover for wetland dependent wildlife. $V_{\text {SED }}$ is measured in the wetland and is a response to $V_{\text {UPuSE. }}$ These two variables are averaged in the assessment model. Excessive sediment can bury plants, seed banks, and invertebrates (Gleason and Euliss 1998; Luo et al. 1997), thereby altering trophic relationships. Accelerated sedimentation leads to wetland volumetric reductions and less diverse wetland bottom topography. The establishment and spread of invasive species such as reed canary grass, cattail, and river bulrush is selected for in these 
instances. Monotypic stands of these species develop, further reducing faunal utilization.

The variables in the equation directly related to vegetation structure and composition as they influence fauna are $V_{\text {GRASSCONT }}, V_{\text {GRASSWIDTH, }} V_{\mathrm{EDGE}}$, $V_{\text {WETPROX }}$, and $V_{\text {VEGCOMP. }}$ The continuity and extent of grassland cover around a wetland influences habitat for fauna, provides movement corridors, and influences the vegetative structure and composition of the wetland by serving as a seed bank in these mesic, ecotonal areas. $V_{\text {GRASSCONT, }} V_{\text {GRASSWIDTH, }} V_{\text {WETPROX }}$, and $V_{\text {EDGE }}$ are averaged in the assessment model. These four variables, in combination, provide an indication of habitat inter-connectivity at a local scale. The composition of the wetland vegetation $\left(V_{\mathrm{VEGCOMP}}\right)$, although subject to cyclic changes, has a direct effect on faunal habitat and can also provide a measure of long-term habitat suitability.

Important to fauna is the spatial relationship of an individual wetland with respect to adjacent wetlands within a "complex." Hubbard (1988) defined a wetland complex as an assemblage of individual wetland basins relatively close to each other.

For projects involving multiple wetlands over a larger landscape area,

$$
\sqrt{V_{\text {HABrRAG }} \times\left[\frac{\left(V_{\text {BAsins }}+V_{\text {wetAREA }}\right)}{2}\right]}
$$

in this form, is substituted for

$$
\left[\frac{\left(V_{\text {GRASSCONT }}+V_{\text {GRASSWITH }}+V_{\text {EDGE }}+V_{\text {WEtrRox }}\right)}{4}\right]
$$

in the preceding assessment model. The assessment model for multiple projects would then be:

$\mathrm{FCI}=\sqrt{\left(\text { Minimum of } V_{\text {out }}, V_{\text {SUbout }}\right) \times \frac{\left[\frac{\left(V_{\text {Upuse }}+V_{\text {Sed }}\right)}{2}\right]+\sqrt{V_{\text {Habrrag }} \times\left[\frac{\left(V_{\text {BAsins }}+V_{\text {WetakeA }}\right)}{2}\right]}+V_{\text {Vegcomp }}}{3}}$

$V_{\text {OUT }}, V_{\text {UPUSE, }} V_{\text {SED }}$, and $V_{\text {VEGCOMP }}$ are used in the landscape assessment option to maintain the linkage of the assessment wetland to the surrounding ecosystem. 


\section{Assessment Protocol}

\section{Overview}

In previous sections of this Guidebook, we provide: a) background information on the HGM Approach, b) wetland variables that are indicators of the level of function, c) the assessment models (FCI's) consisting of those indicator variables, and d) how those indicators and models are used to describe level of function. This chapter provides the specific protocols that should be followed to conduct a functional assessment of Prairie Pothole depressional wetlands. These protocols are designed for, and will generally be used within the context of the Clean Water Act (CWA) Section 404 permit review process and for determining minimal effects under the Food Security Act (FSA). They may also be used for other wetland management goals or objectives (e.g., monitoring, evaluation) that require measures of function.

The typical assessment scenario is a comparison of pre-project and postproject conditions in the wetland. In practical terms, this translates into a comparison of the functional capacity of the wetland assessment area (WAA) under both pre-project and post-project conditions with the subsequent determination of how FCI's have changed as a result of the project. Data for the pre-project assessment are collected under existing conditions at the project site, while data for the post-project assessment are normally based on the conditions that are expected to exist following proposed project impacts. A skeptical, conservative, and well-documented approach is required in defining post-project conditions.

This chapter discusses each of the tasks required to complete an assessment of Prairie Pothole depressional wetlands, including:

a. Define assessment objectives

b. Characterize the project area

c. Screen for red flags

d. Define the Wetland Assessment Area

e. Collect field data

f. Data entry and analysis

g. Apply the results of the assessment 


\section{Define Assessment Objectives}

Begin the assessment process by identifying the purpose for conducting the assessment. This can be as simple as stating, "The purpose of this assessment is to determine how the proposed project will impact wetland functions." Other potential objectives could be: a) compare several wetlands as part of an alternatives analysis, b) identify specific actions that can be taken to minimize project impacts, c) document baseline conditions at the wetland site, d) determine mitigation requirements, e) determine mitigation success, or f) determine the effects of a wetland management technique. Frequently, there will be multiple purposes identified for conducting the assessment. Defining the purposes will facilitate communication and understanding between the people involved in conducting the assessment and will make the purposes clear to other interested parties. In addition, it will help to establish the approach that is taken. The specific approach will vary to some degree, depending on whether the project is a Section 404 permit review, an Advanced Identification (ADID), an FSA minimal effects determination, or some other scenario.

\section{Characterize the Project Area}

Characterizing the project area involves describing the project area in terms of climate, geomorphic setting, hydrology, vegetation, soils, land use, proposed impacts, and any other characteristics and processes that have the potential to influence how wetlands at the project area perform functions. The characterization should be written and should be accompanied by maps and figures that show project area boundaries, jurisdictional wetlands, WAA, proposed impacts, roads, ditches, buildings, streams, soil types, plant communities, threatened or endangered species habitat, and other important features.

The following list identifies some information sources that will be useful in characterizing a project area.

a. Aerial photographs or digital ortho-photos covering the wetland and surrounding landscape.

b. Topographic and National Wetland Inventory maps (1:24000 scale) covering the wetland and the surrounding landscape with a $1.6 \mathrm{~km}$ radius.

c. County Soil Survey.

d. Preceding five years of Farm Service Agency aerial compliance slides.

e. Climatic records.

f. Farm Service Agency wetlands determination maps.

\section{Screen for Red Flags}

Red flags are features within, or in the vicinity of, the project area to which special recognition or protection has been assigned on the basis of statutory criteria (Table 14). Many red flag features, such as those based on national criteria or 
programs, are similar from region to region. Other red flag features are based on regional or local criteria. Screening for red flag features represents a pro-active attempt to determine if the wetlands or other natural resources in and around the project area require special consideration or attention that may preempt or postpone an assessment of wetland function. The assessment of wetland functions may not be necessary if the project is unlikely to occur as a result of a red flag feature.

\begin{tabular}{|c|c|}
\hline \multicolumn{2}{|c|}{$\begin{array}{l}\text { Table } 14 \\
\text { Red Flag Features and Respective Program/Agency Authority }\end{array}$} \\
\hline Red Flag Features & Authority ${ }^{1}$ \\
\hline Native Lands and areas protected under the American Indian Religious Freedom Act & A \\
\hline Hazardous waste sites identified under CERCLA or RCRA & 1 \\
\hline Areas protected by a Coastal Zone Management Plan & $E$ \\
\hline Areas providing Critical Habitat for Species of Special Concern & $\mathrm{B}, \mathrm{C}, \mathrm{F}$ \\
\hline Areas covered under the Farmland Protection Act & $\mathrm{K}$ \\
\hline Floodplains, floodways, or flood-prone areas & $\mathrm{J}$ \\
\hline Areas with structures/artifacts of historic or archeological significance & G \\
\hline Areas protected under the Land and Water Conservation Fund Act & $\mathrm{K}$ \\
\hline Areas protected by the Marine Protection Research and Sanctuaries Act & $B, D$ \\
\hline National wildlife refuges and special management areas & C \\
\hline Areas identified in the North American Waterfowl Management Plan & $\mathrm{C}, \mathrm{F}$ \\
\hline Areas identified as significant under the RAMSAR Treaty & $\mathrm{H}$ \\
\hline Areas supporting rare or unique plant communities & $\mathrm{C}, \mathrm{H}$ \\
\hline Areas designated as Sole Source Groundwater Aquifers & $\mathrm{I}, \mathrm{L}$ \\
\hline Areas protected by the Safe Drinking Water Act & $\mathrm{I}, \mathrm{L}$ \\
\hline City, County, State, and National Parks & $\mathrm{D}, \mathrm{F}, \mathrm{H}, \mathrm{L}$ \\
\hline Areas supporting threatened or endangered species & $\mathrm{B}, \mathrm{C}, \mathrm{F}, \mathrm{H}, \mathrm{I}$ \\
\hline Areas with unique geological features & $\mathrm{H}$ \\
\hline Areas protected by the Wild and Scenic Rivers Act or Wilderness Act & $\mathrm{D}$ \\
\hline $\begin{array}{l}{ }^{1} \text { Program Authority and Agency } \\
\text { A = Bureau of Indian Affairs } \\
\text { B = National Marine Fisheries Service } \\
\text { C = U.S. Fish and Wildlife Service } \\
\text { D = National Park Service } \\
\text { E = State Coastal Zone Office } \\
\text { F = State Departments of Natural Resources, Fish and Game, etc. } \\
\text { G = State Historic Preservation Office } \\
\text { H = State Natural Heritage Offices } \\
\text { I = U.S. Environmental Protection Agency } \\
\text { J = Federal Emergency Management Administration } \\
\text { K = National Resource Conservation Service } \\
\text { L = Local Government Agencies }\end{array}$ & \\
\hline
\end{tabular}

For example, if a proposed project has the potential to impact a threatened or endangered species or habitat, an assessment of wetland functions may be unnecessary since the project may be denied or modified strictly on the impacts to threatened or endangered species or habitat. 


\section{Define the Wetland Assessment Area}

The WAA is an area of wetland within a project area that belongs to a single regional wetland subclass and is relatively homogeneous with respect to the sitespecific criteria used to assess wetland functions (i.e., hydrologic regime, vegetation structure, topography, soils, seral stage, etc.). In most project areas, there will be just one WAA representing a single regional wetland subclass as illustrated in Figure 25. However, as the size and heterogeneity of the project area increases, it is possible that it will be necessary to define and assess multiple WAAs within a project area.

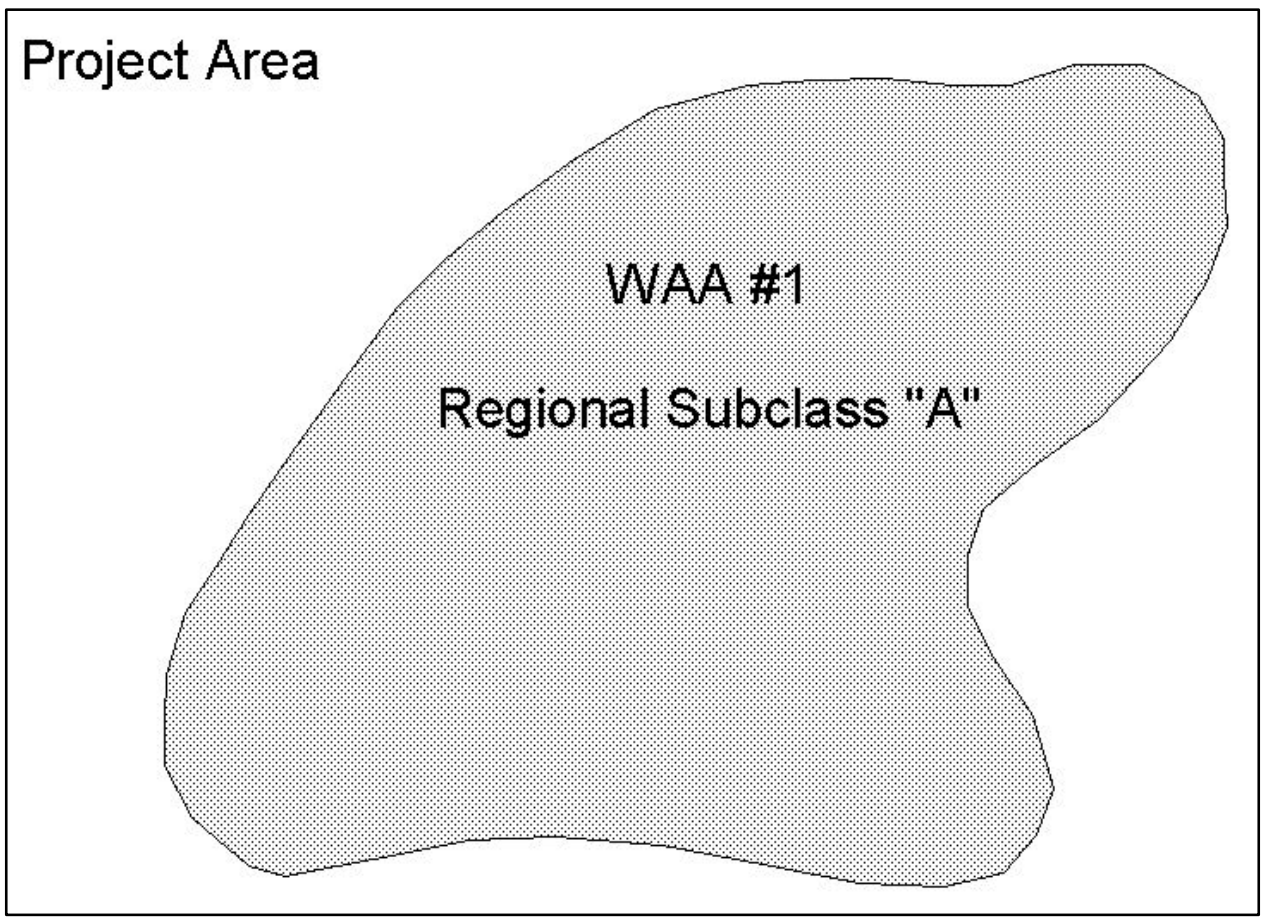

Figure 25. A single WAA within a project area

At least three situations necessitate defining and assessing multiple WAAs within a project area. The first situation exists when widely separated wetland patches of the same regional subclass occur in the project area (Figure 26). The second situation exists when more than one regional wetland subclass occurs within a project area (Figure 27). The third situation exists when a physically contiguous wetland area of the same regional subclass exhibits spatial heterogeneity with respect to hydrology, vegetation, soils, disturbance history, or other factors that translate into a significantly different value for one or more of the site-specific variable measures. These differences may be a result of natural variability or cultural alteration (e.g., farming, urban development, hydrologic alterations) (Figure 28). Designate each of these areas as a separate WAA and conduct a separate assessment on each area. 


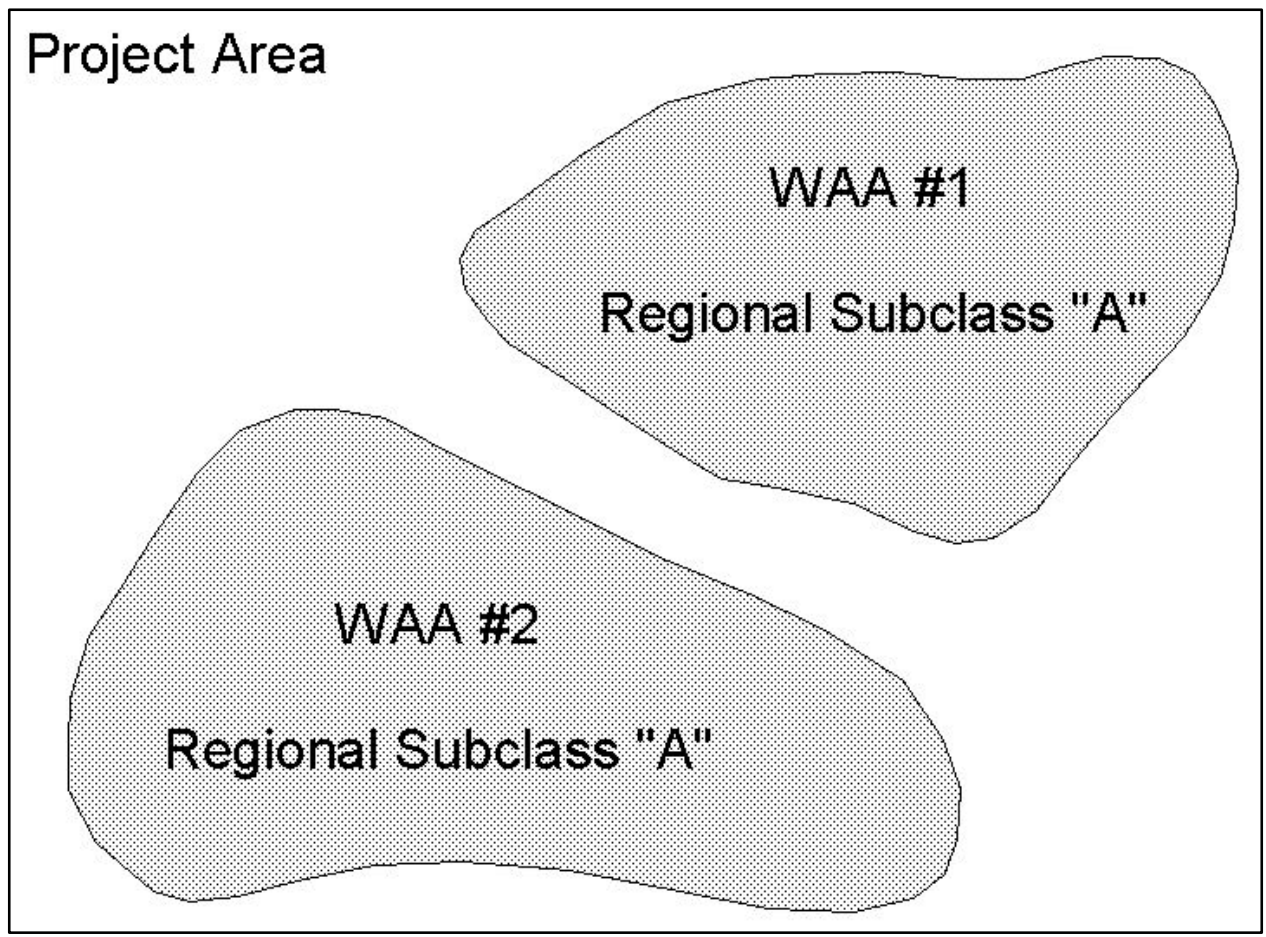

Figure 26. Spatially separated WAA from the same regional wetland project area

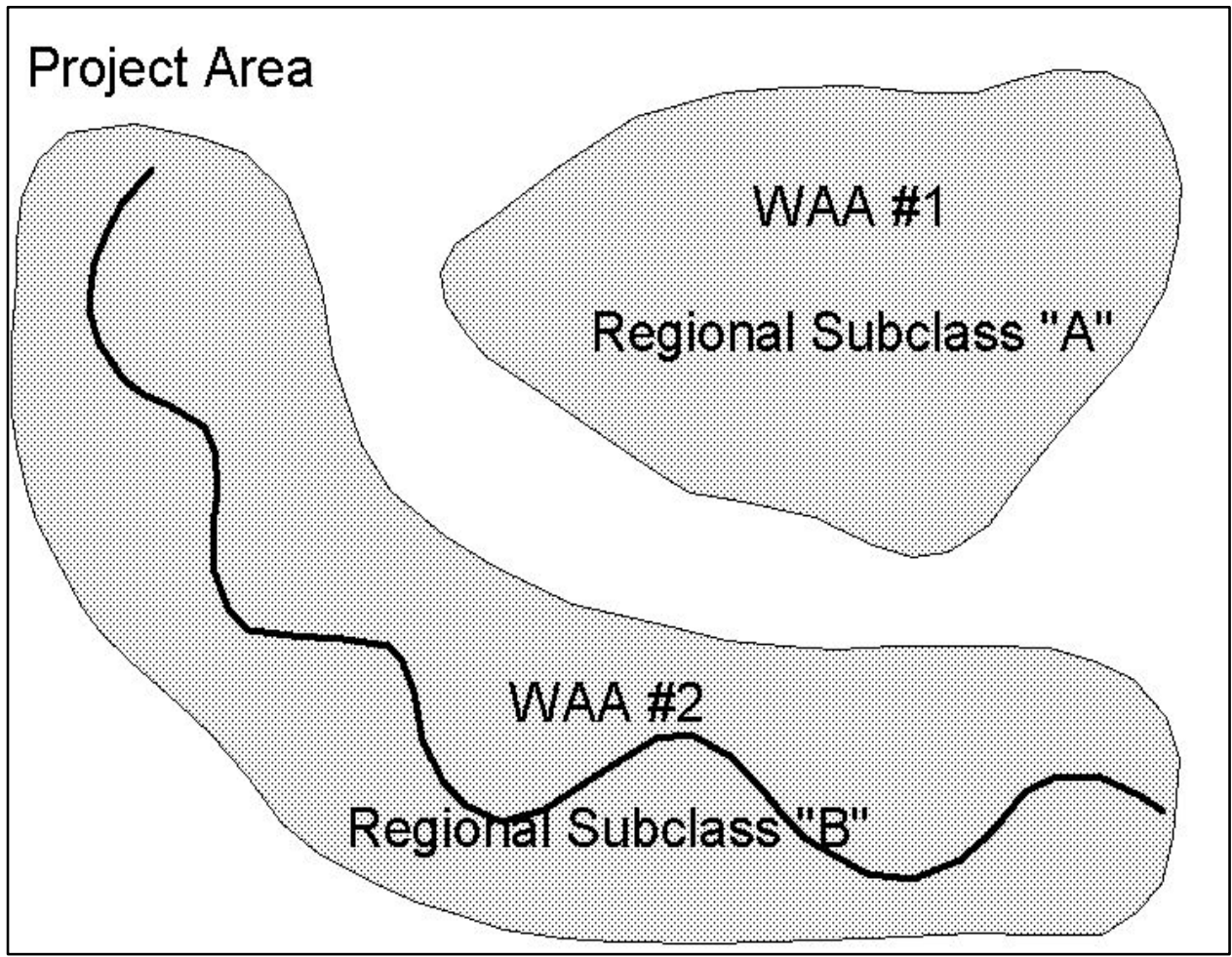

Figure 27. Spatially separated WAAs from different regional wetland subclasses within a project area 


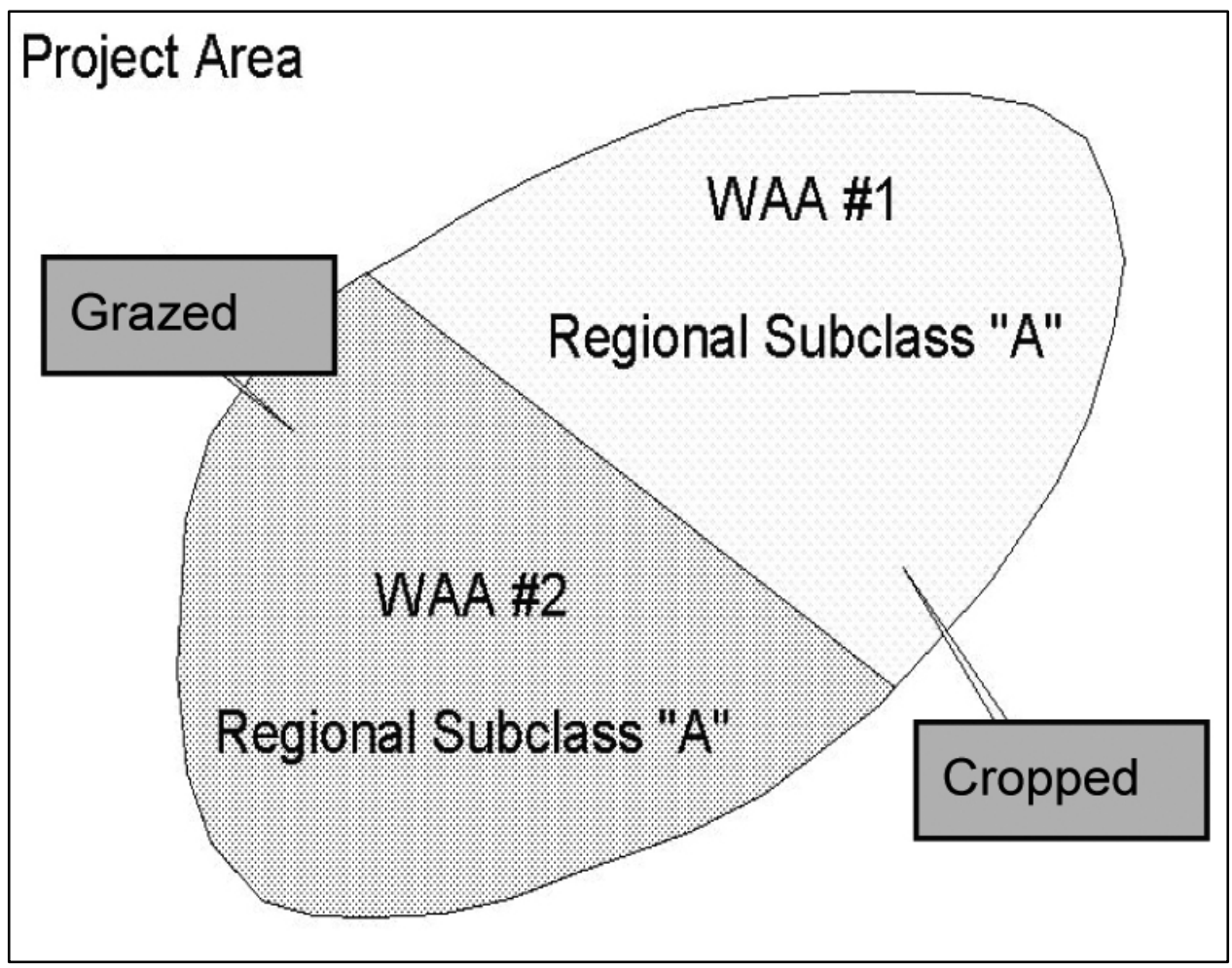

Figure 28. WAA defined based on differences in site specific characteristics

There are elements of subjectivity and practicality in determining what constitutes a "significant" difference in portions of the WAA. Field experience with the regional wetland subclass under consideration should provide the sense of the range of variability that typically occurs and the "common sense" necessary to make reasonable decisions about defining multiple WAAs. Splitting an area into many WAAs in a project area, based on relatively minor differences, will lead to a rapid increase in sampling and analysis requirements. In general, differences resulting from natural variability should not be used as a basis for dividing a contiguous wetland area into multiple WAA's. However, zonation caused by different hydrologic regimes or disturbances caused by rare and destructive natural events should be used as a basis for defining WAA's.

\section{Collect Field Data}

The following equipment is necessary to collect field data:

- Plant identification keys

- Soil sharpshooter shovel

- County Soil Survey

- Munsell color book and hydric soil indicator list (U.S. Department of Agriculture, NRCS 2002)

- 50-m distance measuring tape and meter sticks, stakes, and flagging 
Information and data about the variables used to assess the functions of Prairie Pothole depressional wetlands are collected at several different spatial scales. Information about landscape scale variables, such as land use, is collected using aerial photographs, maps, and field reconnaissance of the area surrounding the WAA. Subsequently, information about the WAA in general is collected during a walking reconnaissance of the WAA. Finally, detailed site-specific information is collected using sample plots and transects at a number of representative locations throughout the WAA.

The exact number and location of these data collection points are dictated by the size and heterogeneity of the WAA. If the WAA is relatively small (i.e., less than $0.8-1.2 \mathrm{ha}$ ) and homogeneous with respect to the characteristics and processes that influence wetland function, then three or four sample points in representative locations are probably adequate to characterize the WAA. However, as the size and heterogeneity of the WAA increases, more sample plots are required to accurately represent the site.

As in defining the WAA, there is an element of subjectivity and practical limitations in determining the number of sample locations for collecting sitespecific data. Experience has shown that the time required to complete an assessment at a several-hectare WAA is $2-4$ hours. Training and experience will reduce the required time to the lower end of this range.

Data and information relating to the variables in this model should be collected according to methods and guidelines provided in Appendix B-2. Data should be recorded on the field forms also found in Appendix B. Be sure you have collected all on-site data needed to avoid a second follow-up site visit.

\section{Data Analysis}

\section{Data entry}

Follow the assessment protocols given above to complete a wetland functional assessment using this Guidebook. It is critical that all data entries are made on the field forms provided with this Guidebook in Appendix B-2. This will greatly reduce confusion about what data need to be collected and will help the user from accidentally skipping over necessary field data while visiting the WAA. Much of the initial site characterization and map data will come from preexisting databases, Internet sources (e.g., USGS, NRCS) or office source materials (e.g., NWI maps, County soil survey maps). The time necessary to collate these materials and analyze the maps and complete data entry of Landscape Scale variables from pre-existing databases is generally $2-3$ hours. Collection of field data for a single Prairie Pothole wetland of moderate size and complexity will generally require two people $2-4$ hours of field time to complete.

\section{Data analysis}

The primary objective of the HGM Approach to the Functional Assessment of Wetlands is the determination of Functional Capacity Indices (FCI), which 
when combined with area produces a Functional Capacity Unit (FCU), which in turn provides a basis for determination of impact and mitigation.

\section{Manual determination of FCI}

After completing the above protocols to collect all data and the completion of the field data forms found in Appendix B-2, fill out the Functional Capacity Index worksheet, provided in Appendix B-3.. The metric to variable sub-index score relationships are based on the reference wetland data set collected during the development of this Guidebook. The variable sub-index scores are employed in the six Functional Capacity Index algorithms discussed and explained in chapters 4 and Appendix B-1 of this Guidebook. The Guidebook user can then determine, by hand calculation, the Functional Capacity Indices (FCI) of each function.

\section{Spreadsheet determination of $\mathrm{FCl}$}

The data sheets are designed to assist the user enter the raw data collected from each site. The regression equations needed to calculate the variable subindex for each wetland function are already entered into this spreadsheet. The presence of these equations is designated by gray blocks within the spreadsheet (Figure 29). All other blocks indicate where the user is expected to enter their data. Instructions for each function are included in the spreadsheet and follow the format of the data sheets found in Appendix B-3. Each category, along with the corresponding variables, is located in one of worksheets. These worksheets are labeled by category. The functional capacity indices (FCI's) are also entered in the spreadsheet and can be found in the worksheet labeled 'FCI'. After each variable sub-index has been calculated using the raw data entered by the user, the FCI's will be automatically computed.

\section{Apply the Results of the Assessment}

Once the assessment and analysis phases are complete, the results can be used to compare the same wetland assessment area at different points in time, comparing different wetland assessment areas at the same point in time, comparing different alternatives to a project or comparing different hydrogeomorphic classes or subclasses as per Smith et al. (1995). 


\begin{tabular}{l} 
Vout \\
Wetland surface outlet. \\
Elevation of wetland outlets, natural or constructed in relation to edge of the wetland and hydric soils; \\
also, the volume of excavations/fill present within the hydric soil footprint of the wetland. \\
Fixed bounce storage limit 3.28 feet (1 meter) \\
Record: $\quad$ USER NOTE: Multiply feet by 0.305 to convert into meters. \\
a) Historic Invert elevation in relation to wetland maximum depth: \\
b) Present (or constructed) Invert elevation \\
c) Elevation of the edge of the historic wetland: \\
d) Elevation of a representative deepest portion of the wetland: \\
e) Difference between c) and a) \\
Difference between b) and d) \\
Difference between a) and d) \\
Difference between c) and b) \\
If eval. PITor fill, enter \%vol of pit/fill versus wetland (ex. 25\%=25), otherwise enter 0 \\
f) Ratio of the constructed elevation to the natural outlet elevation: \\
g) VARIABLE SUBINDEX SCORE for Vout: \\
\hline \#DIV/0! \\
\hline \#DIV/0! \\
\hline
\end{tabular}

Figure 29. Sample spreadsheet for data entry and $\mathrm{FCl}$ calculations 


\section{References}

Ackroyd, E. A., Walton, W. C., and Hills, D. L. (1967). "Groundwater contribution to streamflow and its relation to basin characteristics in Minnesota," Minnesota B1 Geological Survey Report of Investigations 6.

Adamus, P. R. (1996). "Bioindicators for assessing ecological integrity of prairie wetlands," EPA/600/R-96/082, U.S. Environmental Protection Agency Environmental Research Laboratory, Western Division, Corvallis, OR.

Adomaitis, V. A., Kantrud, H. A., and Shoesmith, J. A. (1967). "Some chemical characteristics of aeolian deposits of snow-soil on prairie wetlands," Proceedings of the North Dakota Academy of Science 21, 65-69.

Andreas, B. K., and Lichvar, R. W. (1995). "Floristic index for establishing assessment standards: A case study for northern Ohio," Wetlands Research Program Technical Report WRP-DE-8, U.S. Army Engineer Waterways Experiment Station, Vicksburg, MS.

Arndt, J. L. and Richardson, J. L. (1988). "Hydrology, salinity and hydric soil development in a North Dakota Prairie-Pothole system," Wetlands 8, 93-108.

Bakker, J. P., and Ruyter, J. C. (1981). "Effects of five years of grazing on a salt marsh," Vegetation 44, 81-100.

Baker, L. A. (1992). "Introduction to nonpoint source pollution in the United States and prospects for wetland use," Ecological Engineering 1, 1-26.

Batt, B. D. J., Anderson, M. G., Anderson, C. D., and Caswell, F. D. (1989). "The use of prairie potholes by North American ducks." Northern Prairie Wetlands. A.G. van der Valk, ed., Iowa State University Press, Ames, IA.

Bigler, R. J. (1981). "The correlation of soil morphology and taxonomic units with wetland plant communities." M.S. Thesis, Department of Soil Science, North Dakota State University, Fargo, ND.

Blank, R. R. and Fosberg, M. A. (1989). "Cultivated and adjacent virgin soils in northcentral South Dakota: I. Chemical and physical comparisions," Soil Science Society of America Journal 53, 1484-90. 
Bluemle, J. P. (1986). "Depth to bedrock in North Dakota," North Dakota Geological Survey Misc. Map 26.

Bluemle, J. P. (1991). "The face of North Dakota. The geologic story." Revised Edition. North Dakota Geologic Survey Educational Series 21, 177 pages.

Bolen, E. G., Smith, L. M., and Schramm, H. L. (1989). "Playa lakes - Prairie wetlands of the southern high plains," Bioscience 39, 615-23.

Boto, K. G. and W. H. Patrick Jr. (1978). "Role of wetlands in the removal of suspended sediments." Wetland Functions and Values: The State of Our Understanding. P. E. Greeson, J. R. Clark and J. E. Clark eds., American Water Resources Association, Minneapolis, MN.

Bouma, J. and Hole, F. D. (1971). "Soil structure and hydraulic conductivity of adjacent virgin and cultivated pedons at two sites: A typic Argiudoll and a typic Eutrochrept," Soil Science Society of America Proceedings 35, 316-19.

Brinson, M. M. (1985). "Management potential for nutrient removal in forested wetlands." Ecological Considerations in Wetlands Treatment of Municipal Wastewaters. P.J. Godfrey, et al., eds., Van Nostrand Reinhold, New York, NY.

(1993). "A hydrogeomorphic classification for wetlands," Wetlands Research Program Technical Report WRP-DE-4, U.S. Army Engineer Waterways Experiment Station, Vicksburg, MS.

. (1995a). "The hydrogeomorphic approach explained," National Wetlands Newsletter, November/December, Environmental Law Institute, Washington, DC.

. (1995b). "Assessing wetland functions using HGM," National Wetlands Newsletter, January/February, Environmental Law Institute, Washington, DC.

Brinson, M. M., Hauer, F. R., Lee, L. C., Nutter, W. L., Rheinhardt, R. D., Smith, R. D., and Whigham, D. (1995). "A guidebook for application of hydrogeomorphic assessments to riverine wetlands," Wetlands Research Program Technical Report WRP-DE-1, U.S. Army Engineer Waterways Experiment Station, Vicksburg, MS.

Brinson, M. M., Smith, R. D., Whigham, D. F., Lee, L. C., Rheinhardt, R. D., and Nutter, W. L. (1998). "Progress in development of the hydrogeomorphic approach for assessing the functioning of wetlands." Proceedings, INTECOL International Wetland Conference. Perth, Australia.

Brown, M. and Dinsmore, J. J. (1991). "Area-dependent changes in bird densities in Iowa marshes," Journal of Iowa Academy Science 98(3), 124-26. 
Brun, L.J., Richardson, J. L., Enz, J. W., and Larsen, J. K. (1981). "Stream flow changes in the southern Red River Valley of North Dakota," North Dakota Farm Research 38(5), 11-14.

Carter, V., Bedinger, M. S., Novitzki, R. P., and Wilen, W. O. (1979). "Water resources and wetlands." Wetland Functions and Values: The State of Our Understanding. P. E. Greeson, J. R. Clark, and J. E. Clark, eds., American Water Resources Association, Minneapolis, MN.

Cowardin, L. M., Carter, V., Golet, F. C., and LaRoe, E. T. (1979). "Classification of wetlands and deepwater habitats of the United States," FWS/OBS79/31, Office of Biological Services Report, U.S. Fish and Wildlife Service, Washington, DC.

Cowardin, L. M., Shaffer, T. L., and Arnold, P. M. (1995). "Estimates of duck habitat and populations from a remote-sensing based system," U.S. Biological Survey, Biological Science Report 2.

Crow, J. H., and K. B. Macdonald. (1978). "Wetland values: Secondary production." Wetland Functions and Values: The State of Our Understanding. P. E. Greeson, J. E. Clark, and J. R. Clark, eds., American Water Resources Association, Minneapolis, MN.

Crumpton, W. G. and Baker, J. L. (1993). "Integrating wetlands into agricultural drainage systems: Predictions of nitrate loading and loss in wetlands receiving agricultural subsurface drainage.” Proceedings, International Symposium on Integrated Resource Management \& Landscape Modification for Environmental Protection. American Society of Agricultural Engineers.

Crumpton, W. G., Fisher, S. W., Isenhart, T. M., Matter, M. P., and van der Valk, A. G. (1994). "Transformation and fate of nitrate and atrazine in freshwater wetlands," Project Completion Report, Leopold Center for Sustainable Agriculture, Ames, IA.

Crumpton, W.G. and Goldsborough, L. G. (1998). "Nitrogen transformation and fate in prairie wetlands," Great Plains Research 8(1), 57-72.

Dahl, T. E. (1990). Wetland losses in the United States, 1780s to 1980s. U.S. Fish and Wildlife Service, Washington, D.C.

Daubenmire, R. (1959). "A canopy-coverage method of vegetational analysis," Northwest Science 33(1), 43-64.

Davis, C. B., and van der Valk, A. G. (1978). "Litter decomposition in prairie glacial marshes." Freshwater wetlands: ecological processes and management potential. R. E. Good, D. F. Whigham, and R. L. Simpson, eds., Academic Press, New York.

De Leo, G. A., and Levin, S. (1997). "The multifaceted aspects of ecosystem integrity," Conservation Ecology 1(1), 3-23. 
Diaz, H. F. (1983). "Some aspects of major dry and wet periods in the contiguous United States, 1895-1981," Journal of Climate and Applied Meteorology 22, 3-16.

Diaz, H. F. (1986). "An analysis of twentieth century climate fluctuations in northern North America," Journal of Climate and Applied Meteorology 25, 1625-57.

Dieter, C. D. (1991). "Water turbidity in tilled and untilled prairie wetlands," Journal of Freshwater Ecology 6(2), 185-89.

Dirschl, H. J. and Coupland, R. T. (1972). "Vegetation patterns and site relationships in the Saskatchewan River Delta," Canadian Journal of Botany 50, 64775.

Dix, R. L., and Smeins, F. E. (1967). "The prairie, meadow, and marsh vegetation of Nelson County, North Dakota," Canadian Journal of Botany 45, 2158 .

Dosskey, M., Schultz, D., and Isenhart, T. (1997). "How to design a riparian buffer for agricultural land," AF Note-4, USDA National Agroforestry Center, Lincoln, NE.

Driver, E. A., Sugden, L. G., and Kovach, R. J. (1974). "Calorific, chemical and physical values of potential duck foods," Freshwater Biology 4, 281-92.

Duvick, D. N., and T. J. Blasing. (1981). "A dendroclimatic reconstruction of annual precipitation amounts in Iowa since 1680," Water Resource Research $17,1183-89$.

Eisenlohr, W. S. Jr. (1975). "Hydrology of marshy ponds on the Coteau du Missouri." Hydrology of Marsh-ridden Areas; Proceedings of the Minsk Symposium, June 1972. The UNESCO Press and IAHS, Paris, France.

Eisenlohr, Jr., W. S. and C. E. Sloan. (1968). "Generalized hydrology of prairie potholes on the Coteau du Missouri, North Dakota," U.S. Geological Survey Circular 558, 12 pages.

Engler, R. M. and Patrick Jr., W. H. (1974). "Nitrate removal from floodwater overlying flooded soils and sediments," Journal of Environmental Quality 3, 409.

Environmental Laboratory. (1987). "Corps of Engineers wetlands delineation manual," Technical Report Y-87-1, U.S. Army Engineer Waterways Experiment Station, Vicksburg, MS. NTIS No. AD A176 912

Euliss, Jr., N. H., and Gleason, R. A. (1997). "Standard operating procedures: Extensive variables for studyplan 168.01: Evaluation of restored wetlands in the Prairie Pothole Region of the United States (Draft)," U.S. Geological Survey, Biological Resources Division, Northern Prairie Wildlife Research Center, Jamestown, N.D. 
Euliss, Jr., N. H., and Mushet, D. M. (1996). "Water-level fluctuation in wetlands as a function of landscape condition in the prairie pothole region," Wetlands $16,587-593$.

Euliss, Jr., N. H., Mushet, D. M., and Wrubleski, D. A. (1999). "Wetlands of the Prairie Pothole Region: Invertebrate Species Composition, Ecology, and Management." Invertebrates in Freshwater Wetlands of North America: Ecology and Management. D. P. Batzer, R. B. Rader, and S. A. Wissinger, eds., John Wiley \& Sons, New York.

Ewel, K. C., and Odum, H. T. (1984). Cypress swamps. University Presses of Florida, Gainesville, FL.

Faanes, C. A., and Stewart, R. E. (1982). "Revised checklist of North Dakota birds," Prairie Naturalist 14, 81-92.

Faulkner, S. P. and Richardson, C. J. (1989). "Physical and chemical characteristics of freshwater wetland soils." Constructed Wetlands for Wastewater Treatment. D. A. Hammer, ed., Lewis Publishers, Chelsea, MI.

Fenneman, N. M. (1931). Physiography of Western United States. McGrawHill, New York.

Fennessy, M.S., Geho,R.,Elifritz,B. and Lopez,R.1998. Testing the Floristic Quality Assessment Index as an Indicator of Riparian Quality,Final Report to the U.S.Environmental Protrction Agency,Columbus.Ohio Environmental Protection Agency, Division of Surface Water.

Ferren, Jr., W. R., Fiedler, P. L., Leidy, R. A., Lafferty, K. D., and Mertes, L. A. K. (1996a). "Wetlands of California. Part II. Classification and description of wetlands of the central California and southern California coast and coastal watershed," Madrono 43, 125-82.

. (1996b). "Wetlands of California. Part III. Key to the catalogue of wetlands of the central California and southern California coast and coastal watershed," Madrono 43, 183-233.

Forman, R. T. T., and Godron, M. (1986). Landscape ecology. Wiley, New York.

Frankforter, J. D. (1995). "Association between local land use and herbicide concentrations in wetlands in the Platte River Basin, Nebraska." Versatility of Wetalnds in Agricultural Landscape. K. L. Campbell, ed., American Society of Agricultural Engineers, Tampa, FL.

Freeze, R.A. and Cherry, J. A. Groundwater. Prentice Hall, Englewood Cliffs, NJ. 1979

Freeland, J.A. and Richardson, J. L. (1996). "Soils and sediments as indicators of agricultural impacts on northern prairie wetlands." Pilot Test of Wetland Condition Indicators in the Prairie Pothole Region of the United States. 
EPA/620/R-97/002, USEPA Office of Research and Development, Washington, DC.

Fritzell, E. K. (1989). "Mammals in prairie wetlands." Northern prairie wetlands. A. G. van der Valk, ed., Iowa State University Press, Ames.

Fulton, G. W., Richardson, J. L., and Barker, W. T. (1986). "Wetland soils and vegetation," North Dakota Agric. Exp. Sta. Resear. Rep. 106, 16 pages.

Galatowitsch, S. M. and van der Valk, A. G. (1994). Restoring prairie wetlands, an ecological approach. Iowa State University, Ames, Iowa.

Garcia, F. O. and Rice, C. W. (1994). "Microbial biomass dynamics in tallgrass prairie,” Soil Science Society of America Journal 58, 816-23.

Gibbs,J.P.(1993).Importance of small wetlands for the persistence of local populations of wetland-associated animals. Wetlands 13(1):25-31.

Gleason, Robert Andrew. 2001. Invertebrate egg and plant seed banks in natural, restored, and drained wetlands in the Prairie Pothole Region (USA)and potential effects of sedimentation on recolonization of hydrophytes and aquatic invertebrates. PHd Dissertation, Biological Sciences, Wildlife Science Specialization, South Dakota State University, Brookings, SD.

Gleason, R. A. and Euliss, Jr., N. H. (1998). "Sedimentation of prairie wetlands," Great Plains Research 8(1), 97-112.

Gleason, R. A., Euliss, Jr., N. H., Hubbard, D. E., and Duffy, W. G. (2002). "Effects of sediment load on emergence of aquatic invertebrates and plants from wetland soil egg and seed banks," Wetlands 22(4), 26-34.

Godfrey, P. J., Kaynor, E. R., Pelczarski, S., and Benforado, J. (1985). Ecological Considerations in Wetlands Treatment of Municipal Wastewaters. Van Nostrand Reinhold Company, New York, NY:

Goldsborough, L. G. and Crumpton, W. G. (1998). "Distribution and environmental fate of pesticides in prairie wetlands," Great Plains Research 8(1), 7396.

Golet, F. C., and Larson, J. S. (1974). "Classification of freshwater wetlands in the glaciated Northeast," Resource Publication 116, Fish and Wildlife Service.

Gregory, S. V., Swanson, F. J., McKee, W. A., and Cummins, K. W.(1991). “An Ecosystem Perspective of Riparian Zones,” Bioscience 41,540-551

Groffman, P. M. and Hanson, G. C. (1997). "Wetland denitrification: Influence of site quality and relationships with wetland delineation protocols," Soil Science Society of America Journal 61, 323-29. 
Grossman, R.B., D.S. Harms, C.A. Seybold, and M.T. Sucik. 2001. A morphology index for soil quality evaluation of near surface mineral horizons. Pages 637-664. InD.E. Stott, R.H. Mohtar, and G.C. Steinhardt (eds). 2001. Sustaining the Global Farm. Selected papers from the 10th International Soil Conservation Organization Meeting helg May 24-29, 1999 at Purdue University and the USDA-ARS National Soil Erosion Research Laboratory.

Grubb, P. J. (1977). "The maintenance of speciew-richness in plant communitites: the importance of the regeneration niche," Biological Review 52, 107 45 .

Grue, C. E., Tome, M. W., Messmer, T. A., Henry, D. B., Swanson, G. A., and DeWeese, L. R. (1989). "Agricultural chemicals and prairie pothole wetlands: Meeting the needs of the resource and the farmer-U.S. perspective," Transactions of the North American Wildlife and Natural Resources Conference 54, 43-58.

Hare, F. K, and Hay, J. E. (1974). "The climate of Canada and Alaska." Climates of North America. R.A. Bryson and F.K. Hare, eds. Elsevier, New York.

Harr, D. C., Roosa, D. M., Cutler Prior, J., and Lohmann, P. J. (1990). "Glacial Landmarks Trail: Iowa's Heritage of Ice. Adapted from Glacial Landmarks Trail: Iowa's Heritage of Ice brochure," Sponsored by Iowa Department of Natural Resources and Iowa's State Preserves Advisory Board, $<$ http://www.igsb.uiowa.edu/browse/glatrail/glatrail.htm> (June 1990).

Hauer, F. R., and Smith, R. D. (1998). "The hydrogeomorphic approach to functional assessment of riparian wetlands: evaluating impacts and mitigation on river floodplains in the U.S.A.," Freshwater Biology 40, 517-30.

Hayashi, M., van der Kamp, G., and Rudolph, D. L. (1998a). "Water and solute transfer between a prairie wetland and adjacent uplands, 1. Water balance," Journal of Hydrology, June 1998.

Hayashi, M., van der Kamp, G., and Rudolph, D. L. (1998b). "Water and solute transfer between a prairie wetland and adjacent uplands, 2. Chloride Cycle," Journal of Hydrology, June 1998.

Herman, K. D., Masters, L. A., Penskar, M. R., Reznicek, A. A., Wilhelm, G. S., and Brodowicz, W. W. (1997). "Floristic quality assessment: Development and application in the state of Michigan (USA)," Natural Areas Journal 17, 265-79.

Howard-Williams, C. and Howard-Williams, W. (1978). "Nutrient leaching from the swamp vegetation of Lake Chilwa, a shallow African lake," Aquatic Botany 4, 257-67.

Hubbard, D. E. and Linder, R. L. (1986). "Spring runoff retention in prairie pothole wetlands," Journal of Soil and Water Conservation 41(41), 122-25. 
Hubbard, D. E., Millar, J., Malo, D. D., and Higgins, K. F. (1988). "Soil vegetation correlations in prairie potholes of Beadle and Duel counties, South Dakota," U.S. Fish and Wildlife Service Biological Report 88(22), U.S. Government Printing Office, Washington, DC.

Hubbard, D. E., Beck, D. A., and Schultz, B. D. (1987). "Chemical constituents and IVDDM of hybrid cattail in South Dakota," Project No. W-75-R, Study No. 7528, Job No.3, South Dakota Game, Fish and Parks, Pierre, SD. (unpublished report).

Hubbard, D. E. (1988). "Glaciated prairie wetland functions and values: A synthesis of the literature," Biological Report 88, 43, U.S. Fish and Wildlife Service, Washington, DC.

Huckins, J. N., Petty, J. D., and England, D. C. (1986). "Distribution and impact of triflurin, atrazine, and fonofos residues in microcosms simulating a northern prairie wetland," Chemosphere 15, 563-88.

Isenhart, T. M. (1992). Transformation and Fate of Nitrate in Northern Prairie Wetlands [Ph.D. Diss.]. Iowa State University, Ames, IA.

Johnson, D. H., Haseltine, S. D., and Cowardin, L. M. (1994). "Wildlife habitat management on the northern prairie landscape," Landscape and Urban Planning $28,5-21$.

Johnson, D. H. (2001). "Habitat fragmentation effects on birds in grasslands and wetlands: A critique of our knowledge," Great Plains Research 11(2), 21131 .

Johnston, C. A. (1991). "Sediment and nutrient retention by freshwater wetlands: Effects on surface water quality," Critical Reviews in Environmental Control $21(5,6)$.

Jones, J. R., Borofka, B. P., and Bachmann, R. W. (1976). "Factors affecting nutrient loads in some Iowa streams," Water Research 10, 117-22.

Jongman,R.H.G.,ter Braak,C.J.F. and van Tongeren,O.F.R.(editors). 1995.Data Analysis in Community and Landscape Ecology (Second Edition). Cambridge University Press.

Jurik, T. W., Wang, Shih-Chin, and van der Valk, A. G. (1994). "Effects of sediment load on seedling emergence from wetland seed banks," Wetlands 14(3), 159-65.

Kadlec, R. H. and Knight, R. L. (1996). Treatment Wetlands. Lewis Publishers, CRC Press, Boca Raton, FL.

Kantrud, H. A. (1986). "Effects of vegetation manipulation on breeding waterfowl in prairie wetlands -- A literature review," Fish and Wildlife Technical Report 3, U.S. Fish \& Wildlife Service, Washington, DC., 15 pages. 
Kantrud, J. A., Krapu, G. L., and Swanson, G. A. (1989). "Prairie basin wetlands of the Dakotas: A community profile," Biological Report 85 (7.28), U.S. Fish and Wildlife Service, Washington, DC.

Kantrud, H. A., Millar (probably Millar), J. B., and van der Valk, A. G. (1989). "Vegetation of wetlands in the Prairie Potholes Region." in Northern prairie wetlands. A. G. van der Valk, ed., Iowa State University Press, Ames, IA.

Kantrud, H. A. and Newton, W. E. (1996). "A test of vegetation-related indicators of wetland quality in the prairie pothole region," Journal of Aquatic Ecosystem Health Management 5, 177-91.

Karl, T. R. and Koscielny, A. J. (1982). "Drought in the United States: 18951981," Journal of Climatology 2, 313-29.

Karl, T. R. and Riebsame, W. E. (1984). "The identification of 10 to 20 year temperature and precipitation fluctuations in the contiguous United States," Journal of Climate and Applied Meteorology 23, 950-66.

Kent, M., and Coker, P. (1995). Vegetation description and analysis, a practical approach. John Wiley and Sons, New York.

Kittelson, J. M. (1988). "Analysis of flood peak moderation by depressional wetland sites." The Ecology and Management of Wetlands, Vol.1: Ecology of Wetlands. D. D. Hook, W. H. McKee Jr., H. K. Smith, J. Gregory, V. G. Burrell Jr., M. R. DeVoe, R. E. Sojka, S. Gilbert, R. Banks, L. H. Stolzy, C. Brooks, T. D. Matthews, and T. H. Shear eds., Timber Press, Portland, Oregon.

Kloet, L. (1971). Effects of drainage on runoff and flooding within the Pembina River Basins, North Dakota-Manitoba. U.S. Fish \& Wildlife Service, Jamestown, ND.

Kooistra, M. J., Bouma, J., Boersma, O. H., and Jager, A. (1985). "Soil structure differences and associated physical properties of some loamy typic fluvaquents in the Netherlands," Geoderma 36:215-28.

Kurz, H., and Wagner, K. A. (1953). "Factors in cypress dome development," Ecology 34, 157-64.

Larson, W. E. and Pierce, F. J. (1991). "Conservation and Enhancement of Soil Quality." Evaluation of Sustainable Management in the Developing World, Volume 2. Technical Papers, IBSRAM Proceedings 12(2), International Board for Soil Resources and Management, Bangkok, Thailand.

Lee, L. C., Brinson, M. M., Kleindl, W. J., Whited, P. M., Gilbert, M., Nutter, W. L., Whigham, D. F., and DeWald, D. (1997). Operational draft guidebook for the hydrogeomorphic assessment of temporary and seasonal prairie pothole wetlands. Seattle, WA. 
Lehtinen, R. M., Galatowitsch, S. M., and Tester, J. R. (1999). "Consequences of habitat loss and fragmentation for wetland amphibian assemblages," Wetlands 19(1), 1-12.

Leibowitz, S. G., and Hyman, J. B. (1997). "Use of scale invariance in assessing the quality of judgement indicators," U.S. Environmental Protection Agency Laboratory, Corvallis, OR.

Leibowitz, S. G. and Vining, K. C. (2003). "Temporal connectivity in a Prairie Pothole complex," Wetlands 22(4), 13-25.

Leonard, R. A. (1988). "Herbicides in surface waters, Volume 1." Environmental Chemistry of Herbicides. R. Grover, ed., CRC Press, Boca Raton, FL.

Levin, S.A. (1995). "Scale and sustainability: a population and community perspective." Defining and measuring sustainability: the biogeophysical foundations. M. Munasinghe and W. Shearer, eds., The United Nations University, New York, New York, and The World Bank, Washington, DC.

Levin, S.A. (1997). Biodiversity: interfacing populations and ecosystems. Pages 277-288 in T. Abe, S. A. Levin, and M. Higashi, editors. Springer- Verlag, New York, NY, USA. “

Lissey, A. (1968). Surficial mapping of groundwater flow systems with application to the Oak River Basin, Manitoba. Ph.D. Thesis, University of Saskatchewan, Saskatoon, Canada.

Lissey, A. (1971). "Depression-focused transient groundwater flow patterns in Manitoba," Geological Association of Canada Special Paper 9, 333-41.

Lowery, B. M., Arshad, A., Lal, R., and Hickey, W. J. (1996). "Soil water parameters and soil quality.” Methods for Assessing Soil Quality. J. W. Doran and A. J. Jones, eds., Soil Science Society of America, Madison, WI.

Ludden, A. P., Frink, D. F., and Johnson, D. H. (1983). "Water storage capacity of natural wetland depressions in the Devils Lake Basin of North Dakota," Journal of Soil and Water Conservation 38, 45-8.

Ludwig, J. A., and Reynolds, J. F. (1988). Statistical ecology: A primer on methods and computing. John Wiley and Sons, New York.

Luo, Hong-Ren, Smith, L. M., Allen, B. L., and Haukos, D. A. (1997). "Effects of sedimentation on playa wetland volume," Ecological Applications 7, 24752 .

Malcolm, J. M. (1979). The Relationship of Wetland Drainage to Flooding and Water Problems and its Impacts on the J. Clark Salyer National Wildlife Refuge. U.S. Fish \& Wildlife Service, Bismarck, ND. 
Malo, D. D. (1975). Geomorphic, pedologic, and hydrologic interactions in a closed drainage system. Ph.D. dissertation, North Dakota State University, Fargo, ND.

Mann, G. E., (1974). "The prairie pothole region--a zone of environmental opportunity," Naturalist 25(4), 2 (map).

Martin, D. B. and Hartman, W. A. (1987). "The effect of cultivation on sediment composition and deposition in prairie pothole wetlands," Water, Air and Soil Pollution 34, 45-53.

Masscheleyn, P. H. and Patrick Jr., W. H. (1993). "Biochemical processes affecting selenium cycling in wetlands," Environmental Toxicology and Chemistry 12, 2235-43.

Matter, M. P. (1993). Sorption kinetics of atrazine and hydroxyatrazine in freshwater wetlands. Master's Thesis, Iowa State University, Ames, IA.

McAndrews, J. H., Stewart, Jr., R. E., and Bright, R. C. (1967). "Paleocology of a prairie pothole: a preliminary report." Glacial Geology of the Missouri Coteau and Adjacent Areas. L. Calyton and T. F. Freers, eds., North Dakota Geological Survey, Misc. Series 30, Grand Forks, ND.

Mckee, W. H. and Mckevlin, M. R. (1993). "Geochemical processes and nutrient uptake by plants in hydric soils," Environmental Toxicology and Chemistry 12(12), 2197-207.

McKeague, J. A., Wang, C., and Topp, G. C. (1982). "Estimating saturated hydraulic conductivity from soil morphology," Soil Science Society of America Journal 46, 1239-44.

Merrill, A. G. and Zak, D. R. (1992). "Factors controlling denitrification rates in upland and swamp forests," Canadian Journal of Forestry Research 22, 15971604.

Millar, J. B. (1971). "Shoreline-area ratio as a factor in rate of water loss from small sloughs," Journal of Hydrology 14, 259-84.

Millar, J. B. (1973). "Vegetation changes in shallow marsh wetlands under improving moisture regime," Canadian Journal of Botany 51, 1443-57.

Miller, J. J., Acton, D. F., and St. Arnaud, R. J. (1985). "The effect of groundwater on soil formation in a morainal landscape in Saskatchewan," Canadian Journal of Soil Science 65, 293-307.

Mitsch, W. J., Cronk, J. K., Wu, X., and Nairn, R. W. (1995). "Phosphorous retention in constructed freshwater marshes," Ecological Applications 5, $830-45$.

Mitsch, P. P., and Gosselink, J. G. (1993). Wetlands. Van Nostrand Reinhold, New York. 
Montgomery, J. A., Tandarich, J. P., and Whited, P. M. (2001). "Use of soil information for hydrogeomorphic assessment." Wetland Soils. J. L. Richardson and M. J. Vepraskas, eds., Lewis Publishers, CRC Press, Boca Raton, FL.

Moore, I. D. and Larson, C. L. (1980). "Hydrologic impact of draining small depressional wetlands," Journal of Irrigation and Drainage EngineeringASCE 106(4), 345-63.

Murkin, H. R. (1989). "The basis for food chains in prairie wetlands." Northern Prairie Wetlands. A. van der Valk, ed., Iowa State University Press, Ames, IA.

Murkin, H. R. and Wrubleski, D. A. (1988). "Aquatic invertebrates of freshwater wetlands: function and ecology." The Ecology and Management of Wetlands. Vol. 1: Ecology of Wetlands. D. D. Hook, W. H. McKee, Jr., H. K. Smith, J. Gregory, V. G. Burrell, Jr., M. R. DeVoe, R. E. Sojka, S. Gilbert, R. Banks, L. H. Stolzy, D. Brooks, T. D. Matthews, and T. H. Shear, eds., Croom Helm, London \& Sydney.

National Interagency Implementation Team. (1996). "National action plan to impement the hydrogeomorphic approach (NAP)," Federal Register Volume 61 Number 160, 42593-42603, Washington, DC.

Naugle, D. E., Johnson, R. R., Estey, M. E., and Higgins, K. F. (2003). “A landscape approach to conserving wetland bird habitat in the Prairie Pothole Region of eastern South Dakota," Wetlands 21(1), 1-17.

Neely, R. K. and Baker, J. L. (1989). "Nitrogen and phosphorous dynamics and the fate of agricultural runoff." Northern Prairie Wetlands. A. G. van der Valk, ed., Iowa State University Press, Ames, IA.

Northern Great Plains Floristic Quality Assessment Panel. (2001). "Floristic quality assessment for plant communities of North Dakota, South Dakota (excluding the Black Hills), and adjacent grasslands,"

$<$ http://www.npwrc.usgs.gov/index.htm> (June 13, 2001).

Noss, R.F. (1995). "Maintaining ecological integrity in representative reserve networks," Discussion paper, World Wildlife Fund Canada/World Wildlife United States.

Odum, E. P. (1950). "Bird populations of the Highlands (North Carolina) Plateau in relation to plant succession and avian invasion," Ecology 31, 587-605.

Olness, Alan, Staricka, J. A., and Daniel, J. A. (1997). "Oxidation-reduction and groundwater contamination in the prairie pothole region of the northern great plains." Water for Agriculture and Wildlife and the Environment. J. Schaack and S. S. Anderson eds., Win-Win Opportunities, Proceedings USCID Wetlands Seminar, Bismarck, ND. 
Olness, Alan, Euliss, Jr., N. H., and Gleason, R. A. (2002). "Carbon and Nitrogen Sequestration in Northern Native and Restored Prairie Wetlands."Prairie Wetland Carbon Research Meeting." Abstact from a meeting held at U.S.Geological Survey - Northern Prairie Wildlife Research Center, Jamestown, ND, May $15-16,2002$

Olsen, S. R., Cole, C. V., Watenabe, F. S., and Dean, L. A. (1954). "Estimation of available phosphorous in soils by extraction with sodium bicarbonate," USDA Circular 939, 1-19.

O’Neal, A. M. (1952). "A key for evaluating soil permeability by means of certain field clues," Soil Science Society of America Proceedings 16, 312-15.

O’Neill, R. V., Hunsaker, C. T., Jones, K. B., Ritters, K. H., Wickham, J. D., Schwartz, P. M., Goodman, I. A., Jackson, B. L., and Baillargeon, W. S. (1997). "Monitoring environmental quality at the landscape scale," BioScience 47(8), 513-19.

Parton, W. J., D. S. Schimel, C. V. Cole, and D. S. Ojima. 1987. Analysis of factors controlling soil organic matter levels in Great Plains grasslands. Soil Sci. Soc. Am. J.; 51(1173-1179).

Pastor, J., Aber, J. B., McClaugherty, C. A., and Melillo, J. M. (1984). “Aboveground production and $\mathrm{N}$ and $\mathrm{P}$ cycling along a nitrogen mineralization gradient on Blawkhawk Island, Wisconsin," Ecology 65, 256-68.

Patrick Jr., W. H. (1992). "Wetland Biogeochemistry Institute, Louisiana State University, Baton Rouge, LA 70803'" Phosphorus, life and environment, 1992 Sep 8-1992 Sep 11, Gand, Belgique.

Paul, E. A. and Clark, F. E. (1996). Soil microbiology and biochemistry. Academic Press, 2nd ed., San Diego, CA.

Ponnamperuma, F. M. (1972). "The chemistry of submerged soils," Advances in Agronomy 24, 29-96.

Reddy, K. R. and Patrick Jr., W. H. (1984). "Nitrogen transformations and loss in flooded soils and sediments," Critical Reviews in Environmental Control 13(4), 273-309.

Reddy, K. R., Patrick Jr., W. H., and Lindau, C. W. (1989). "Nitrification denitrification at the plant root-sediment interface in wetlands," Limnology and Oceanography 34, 1004.

Reynolds, R. E., Cohan, D. R., and Johnson, M. A. (1996). "Using landscape information approaches to increase duck recruitment in the Prairie Pothole Region," Transactions of the North American Wildlife and Natural Resource Conference 61, 86-93.

Rheinhardt, R. D., Brinson, M. M., and Farley, P. M. (1997). “A preliminary reference data set for wet forested flats in North Carolina and its application to 
wetland functional assessment, mitigation, and restoration," Wetlands 17 , 195-215.

Richardson, J. L., Arndt, J. L., and Eilers, R. G. (1991). "Soils in three prairie pothole wetland systems." Soils Department, North Dakota State University, Fargo, ND.

Richardson, J. L., Arndt, J. L., and Freeland, J. (1994). "Wetland soils of the prairie potholes," Advances in Agronomy 52, 121-71.

"Richardson, C.J. 1979, Primary productivity values in freshwater wetlands, in Wetland Functions and Values: The State of Our Understanding, P.E.Greeson, J.R. Clark and J.E. Clark, eds. American Water Resources Association, Minneapolis, MN, pp. 131-145.”

Rose, C. and Crumpton, W. G. (1996). "Effects of emergent macrophytes on dissolved oxygen dynamics in a prairie pothole wetland," Wetlands 16(4), 495502 .

Rose, C. and Crumpton, W. G. (1996). "Effects of emergent macrophytes on dissolved oxygen dynamics in a prairie pothole wetland," Wetlands 16 (4), 495502.

Ross, D. J., Tate, K. R., and Cairns, A. (1982). "Biochemical changes in a yellow-brown loam and a central gley soil converted from pasture to maize in the Waikato area," New Zealand Journal of Agricultural Research 25, 3542 .

Rozkowski, A. (1967). "The origin of hydrogeochemical patterns in hummocky moraine," Canadian Journal of Earth Sciences 4, 1065-92.

Saxton, K.E. (2002). SPAW - Soil-Plant-Atmosphere-Water Field and Pond Hydrology. http://www.bsyse.wsu.edu/saxton/spaw/Index.htm

Schlesinger, W. H. (1997). Biogeochemistry: An Analysis of Global Change. Second Edition.Academic Press. San Diego.558pp.

Schneider, D. C. (1994). Quantitative ecology: Spatial and temporal scaling. Academic Press, New York.

Schroeder, S. A. and Bauer, A. (1984). "Soil water variation in spoil and undisturbed sites in North Dakota," Soil Science Society of America Journal $48(3)$.

Schumaker, N. H. (1996). "Using landscape indices to predict habitat connectivity,” Ecology 77, 1210-25.

Sedell, J. R., Reeves G. H., Hauer F. R., Stanford J. A., and Hawkins C. P. (1990). "Role of refugia in recovery from disturbances: modern fragmented and disconnected river systems," Environmental Management 14, 711-24. 
Shjeflo, J. B. (1968). "Evapotranspiration and the water budget of prairie potholes in North Dakota,” U.S.G.S. Professional Paper 585-B.

Sloan, C. E. (1970). "Biotic and hydrologic variables in prairie potholes in North Dakota," Journal of Range Management 23(4), 260-63.

Sloan, C. E. (1970). "Prairie potholes and the water table," U.S. Geological Survey Professional Paper 700-B: B227-B-231.

Sloan, C. E. (1972). "Ground-water hydrology of prairie potholes in North Dakota," U.S.Geological Survey Professional Paper 585-C.

Smith, R. D. (2001). "Hydrogeomorphic approach to assessing wetland functions: Guidelines for developing regional guidebooks; Chapter 3, Developing a reference wetland system," ERDC/EL TR-01-29, U.S. Army Engineer Research and Development Center, Vicksburg, MS.

Smith, R. D., Ammann, A., Bartoldus, C., and Brinson, M. M. (1995). “An approach for assessing wetland functions using hydrogeomorphic classification, reference wetlands, and functional indices." Technical Report WRPDE-9, U. S. Army Engineer Waterways Experiment Station, Vicksburg, MS.

Smith, R. D., and Wakeley, J. S. (2001). "Hydrogeomorphic approach to assessing wetland functions: Guidelines for developing regional guidebooks. Chapter 4, Developing assessment models," ERDC/EL TR-01-30, U.S. Army Engineer Research and Development Center, Vicksburg, MS.

Sorenson, T. A. (1948). "A method of establishing groups of equal amplitude in plant sociology based on similarity of species content, and its application to analyses of the vegetation on Danish commons," Kongelige Danske Videnskabernes Selskab Biologiske Skrifter 56, 1-34.

Soil Survey Division Staff. (1993). Soil Survey Manual. Handbook No. 18, United States Department of Agriculture, Washington, DC.

Stevens, O. A. (1963). Handbook of North Dakota plants. North Dakota Institute for Regional Studies, Fargo, ND, USA.

Stewart, R. E., and Kantrud, H. A. (1971). "Classification of natural ponds and lakes in the glaciated prairie region," Resource Publication 92, U.S. Fish and Wildlife Service, Washington, DC.

Stewart, R. E., and Kantrud, H. A. (1972). "Vegetation of prairie potholes, North Dakota in relation to quality of water and other environmental factors," U.S. Geological Survey Professional Paper 585-D.

Swanson, G. A., Meyer, M. I., and Serie, J. R. (1974). "Feeding ecology of breeding blue-winged teals," Journal of Wildlife Management 38, 396-407. 
Swanson, G. A., and Duebbert, H. F. (1989). "Wetland habitats of waterfowl in the prairie pothole region." Northern prairie wetlands. A. G. van der Valk, ed., Iowa State University Press, Ames, IA.

Swink, F. A., and G. S. Wilhelm. (1994). Plants of the Chicago region, 4th edition. Indiana Academy of Science, Indianapolis, IN, USA.

Taft, J. B., Wilhelm, G. S., Ladd, D. M., and Masters, L. A. (1997). "Floristic quality assessment for vegetation in Illinois, a method for assessing vegetation integrity," Erigenia 15, 3-95.

Talent, L. G., Krapu, G. L., and Jarvis, R. L. (1982). "Habitat use by mallard broods in south central North Dakota," Journal of Wildlife Management 46, 629-35.

ter Braak, C. J. F. (1994). "Canonical community ordination. Part 1: Basic theory and linear methods," Ecoscience 1, 127-140.

Tipton, M. J., Schmer, F. A., Schmulbach, J. C., Ryland, D. W., Hayden, J. F., and Beaver, G. R. T. (1972). Investigation of Lake Water Quality in Eastern South Dakota with Remote Sensing Techniques. Remote Sensing Institute, South Dakota State University, Brookings, SD.

Trombulak, S.C. and C.A. Frissell (2000). Review of Ecological Effects of Roads on Terrestrial and AquaticCommunities. Conservation Biology.Volume 14 (1), pp. 18-30.

United States Department of Agriculture. (1981). "Major land resource regions and major land resource areas of the United States," USDA, Soil Conservation Service, Ag. Handbook 296, Washington, DC.

United States Department of Agriculture. (1997). "Hydrology tools for wetland determination," Part 650, Engineering Field Handbook, Natural Resources Conservation Service, Washington, DC.

United States Department of Agriculture. 2002. Field Indicators of Hydric Soils in the United States, Version 5.0. G.W. Hurt, P.M. Whited, and R.F. Pringle (eds.). Natural Resources Conservation Service in cooperation with the National Technical Committee for Hydric Soils, Fort Worth, TX.

U.S. Environmental Protection Agency. (1983). "Freshwater Wetlands for Wastewater Management: Environmental Impact Statement-Phase I Report," U.S.E.P.A. Region IV, EPA 904/9-83-107, Atlanta, GA.

U.S. Fish and Wildlife Service.(1980). Habitat Evaluation Procedures. Division of Ecological Services.ESM 102.

Van-Gestel, M., Ladd, J. N., and Amato, M. (1992). "Microbial biomass responses to seasonal change and imposed drying regimes at increasing depths of undisturbed topsoil profiles," Soil Biology and Biochemistry 24(2), 103-11. 
van der Valk, A. G., and Davis, C. B. (1978a). "The role of seed banks in the vegetation dynamics of prairie glacial marshes," Ecology 59, 322-35.

van der Valk, A. G., and Davis, C. B. (1978b). "Primary production of prairie glacial marshes." Freshwater Wetlands: Ecological Processes and Management Potential. R. E. Good and D. F. Whigham, eds., Academic Press, New York.

van der Valk, A.G. (1981). "Succession in wetlands: A Gleasonian approach," Ecology 62, 688-96.

van der Valk, A. G., ed. (1989). Northern prairie wetlands. Iowa State University Press, Ames, IA.

van Der Valk, A. G. and Pederson, R. L. (1989). "Seed banks and the management and restoration of natural vegetation." Ecology of Soil Seed Banks. M. A. Leck, V. T. Parker, and R. L. Simpson, eds., Academic Press, San Diego, CA.

van der Valk A.G.(2000). Vegetation Dynamics and Models, Chapter 7 in Prairie Wetland Ecology:the contribution of the Marsh Ecology Research Program.H.R. Murkin,A.G. van der Valk and W.R. Clark, eds.Iowa State University Press, Ames, Iowa.

Waite, D., Grover, T. R., Westcott, N. D., Sommerstad, H., and Kerr, L. A. (1992). "Pesticides in groundwater, surface water and spring runoff in a small Saskatchewan watershed," Environmental Toxicology and Chemistry $11,741-48$.

Wakeley, J. S., and Smith, R. D. (2001). "Hydrogeomorphic approach to assessing wetlands functions: Guidelines for developing regional guidebooks; Chapter 7, Verigying, field testing, and validating assessment models," ERDC/EL TR-01-31, U.S. Army Engineer Research and Development Center, Vicksburg, MS.

Walker, B. H., and Coupland, R. T. (1968). "An analysis of vegetation environment relationships in Saskatchewan sloughs," Canadian Journal of Botany 46, 509-22.

Walker, B. H. and Wehrhahn, C. F. (1971). "Relationship between derived vegetation gradients and measured environmental variables in Saskatchewan wetlands," Ecology 52, 85-95.

Wang, Shih-Chin, Jurik, T. W., and van der Valk, A. G. (1994). "Effects of sediment load on various stages in the life and death of cattail (Typha $\mathrm{x}$ Glauca),"Wetlands 14(3), 166-173.

Weller, M. W. (1978). "Management of freshwater marshes for wildlife." Freshwater wetlands. R. E. Good, D. F. Whigham, and R. L. Simpson, eds., Academic Press, New York. 
Weller, M. W. (1987). Freswater marshes, ecology and wildlfie management. Second ed., University of Minneapolis Press, Minneapolis, MN.

Weller, M. W. (1988). "Issues and approaches in assessing cumulative impacts on waterbird habitat in wetlands," Environmental Management 12(5), 695701.

Weller, M. W., and Spatcher, C. E. (1965). "Role of habitat in the distribution and abundance of marsh birds," Iowa State University Agricultural Home Economics Experiment Station Special Report 43.

Wetzel, R.G. (1975) .Limnology. W.B. Saunders, Philadelphia,743pp.

Wharton, C. H., Kitchens, W. M., Pendleton, E. C., and Sipe, T. W. (1982). "The ecology of bottomland hardwood swamps of the Southeast: A community profile," Report FWS/OBS-81/37, Office of Biological Services, U.S. Fish and Wildlife Service, Washington, DC.

Wilen ,B. O., Carter, V., and Fretwell, J. D. (1996). "Wetland mapping and inventory." National Water Summary on Wetland Resources. U.S.G.S. Water-Supply Paper 2425, U.S. Geological Survey, Reston, VA.

Wilhelm, G. S., and Ladd, D. M. (1988). "Natural area assessment in the Chicago region," Transactions of the 3rd North American Wildlife and Natural Resource Conference 3, 361-75.

Williams, R. E. (1968). "Flow of groundwater adjacent to small, closed basins in glacial till," Water Resources Research 4(4), 777-83.

Winter, T. C. (1989). "Hydrologic studies of wetlands in the northern prairie." Northern prairie wetlands. A. G. van der Valk, ed., Iowa State University Press, Ames, IA.

Winter, T. C. and Carr, M. R. (1980). "Hydrologic setting of wetlands in the Cottonwood Lake area, Stutsman County, North Dakota," Water-Resources Investigation 80-99, U.S. Geological Survey, Denver, CO.

Winter, T. C. and Rosenberry, D. O. (1995). "The interaction of groundwater with prairie pothole wetlands in the cottonwood lake area, east-central North Dakota, 1979-1990," Wetlands 15(3).

Wotten, R. S. (1990). "The classification of particulate and dissolved matter." The Biology of Particulates in Aquatic Ecosystems. R. S. Wotten, ed., CRC Press, Boca Raton, FL.

Zedler, P. H. (1987). "The ecology of southern California vernal pools: A community profile," Biological Report 85 (7.11), U.S. Fish and Wildlife Service, Washington, DC. 


\section{Appendix A Glossary}

A Horizon: A mineral soil horizon at the soil surface or below the $\mathrm{O}$ horizon characterized by accumulation of humified organic matter intricately mixed with the mineral fraction.

Assessment Model: A simple model that defines that relationship between ecosystem and landscape scale variables and functional capacity of a wetland. The model is developed and calibrated using reference wetlands from a reference domain.

Assessment Objective: The reason why an assessment of wetlands functions is being conducted. Assessment objectives normally fall into one of three categories. These include: documenting existing conditions, comparing different wetlands at the same point in time (i.e., alternatives analysis), and comparing the same wetland at different points in time (i.e., impact analysis or mitigation success).

Assessment Team (A-Team): An interdisciplinary group of regional and local scientists responsible for classification of wetlands within a region, identification of reference wetlands, construction of assessment models, definition of reference standards, and calibration of assessment models.

Direct Impacts: Project impacts that result from direct physical alteration of a wetland, such as the placement of dredge or fill.

Direct Measure: A quantitative measure of an assessment model variable.

Functional Assessment: The process by which the capacity of a wetland to perform a function is measured. The approach measures capacity using an assessment model to determine a functional capacity index.

Functional Capacity: The rate or magnitude at which a wetland ecosystem performs a function. Functional capacity is dictated by characteristics of the wetland ecosystem and the surrounding landscape, and interaction between the two.

Functional Capacity Index (FCI): An index of the capacity of a wetland to perform a function relative to other wetlands from a regional wetland subclass in 
a reference domain. Functional capacity indices are by definition scaled from 0.0 to 1.0. An index of 1.0 indicates that the wetland performs a function at the highest sustainable functional capacity, the level equivalent to a wetland under reference standard conditions in a reference domain. An index of 0.0 indicates that the wetland does not perform the function at a measurable level, and will not recover the capacity to perform the function through natural processes.

Highest Sustainable Functional Capacity: The level of functional capacity achieved across the suite of functions by a wetland under reference standard conditions in a reference domain. This approach assumes that the highest sustainable functional capacity is achieved when a wetland ecosystem and the surrounding landscape are undisturbed.

Hydrogeomorphic Wetland Class: The highest level in the hydrogeomorphic wetland classification system. There are five basic hydrogeomorphic wetland classes, including depression, fringe, slope, riverine, and flat.

Hydrogeomorphic Unit: Hydrogeomorphic units are areas within a wetland assessment area that are relatively homogenous with respect to ecosystem scale characteristics, such as micro-topography, soil type, vegetative communities, or other factors that influence function. Hydrogeomorphic units may be the result of natural or anthropogenic processes. See Partial Wetland Assessment Area.

Indicator: Indicators are observable characteristics that correspond to identifiable variable conditions in a wetland or the surrounding landscape.

Indirect Measure: A qualitative measure of an assessment model variable that corresponds to an identifiable variable condition.

Indirect Impacts: Impacts resulting from a project that occur concurrently, or at some time in the future, away from the point of direct impact. For example, indirect impacts of a project on wildlife can result from an increase in the level of activity in adjacent, newly developed areas, even though the wetland is not physically altered by direct impacts.

In-kind Mitigation: Mitigation in which lost functional capacity is replaced in a wetland of the same regional wetland subclass.

Invert: The bottom of a channel, pipe, or culvert.

Interflow: The lateral movement of water in the unsaturated zone during and immediately after a precipitation event. The water moving as interflow discharges directly into a stream or lake.

Jurisdictional Wetland: Areas that meet the soil, vegetation, and hydrologic criteria described in the "Corps of Engineers Wetlands Delineation Manual" (Environmental Laboratory 1987), or its successor. 
Mitigation: Restoration or creation of a wetland to replace functional capacity that is lost as a result of project impacts.

Mitigation Plan: A plan for replacing lost functional capacity resulting from project impacts.

Mitigation Ratio: The ratio of the FCUs lost in a Wetland Assessment Area (WAA) to the FCUs gained in a mitigation wetland.

Mitigation Wetland: A restored or created wetland that serves to replace functional capacity lost as a result of project impacts.

Model Variable: see Assessment Model Variable.

O Horizon: A layer with more than 12 to 18 percent organic $\mathrm{C}$ (by weight: 50 percent by volume). Form of the organic material may be recognizable plant parts (Oi) such as leaves, needles, twigs, moss, etc., partially decomposed plant debris (Oe), or totally decomposed organic material (Oa) such as muck.

Off-site Mitigation: Mitigation that is done at a location physically separated from the site at which the original impacts occurred, possibly in another catchment.

Out-of-kind Mitigation: Mitigation in which lost functional capacity is replaced in wetlands of a different regional wetland subclass.

Partial Wetland Assessment Area (PWAA): A portion of a WAA that is identified a priori, or while applying the assessment procedure, because it is relatively homogeneous, and different from the rest of the WAA with respect to one or more model variables. The difference may occur naturally, or as a result of anthropogenic disturbance. See Hydrogeomorphic Unit.

Project Alternatives: Different ways in which a given project can be done. Alternatives may vary in terms of project location, design, method of construction, amount of fill required, and others.

Project Area: The area that encompasses all activities related to an ongoing or proposed project.

Project Target: The level of functioning identified for a restoration or creation project. Conditions specified for the functioning are used to judge whether a project reaches the target and is developing toward site capacity.

Red Flag Features: Features of a wetland or the surrounding landscape to which special recognition or protection is assigned on the basis of objective criteria. The recognition or protection may occur at a Federal, state, regional, or local level, and may be official or unofficial. 
Reference Domain: The geographic area from which reference wetlands are selected. A reference domain may or may not include the entire geographic area in which a regional wetland subclass occurs.

Reference Standards: Conditions exhibited by a group of reference wetlands that correspond to the highest level of functional capacity (highest, sustainable level of functioning) across the suite of functions performed by the regional wetland subclass. The highest level of functional capacity is assigned an index value of 1.0 by definition.

Reference Wetlands: Wetland sites that encompass the variability of a regional wetland subclass in a reference domain. Reference wetlands are used to establish the range of conditions for construction and calibration of functional indices and to establish reference standards.

Region: A geographic area that is relatively homogenous with respect to largescale factors, such as climate and geology, which may influence how wetlands function.

Regional Wetland Subclass: Wetlands within a region that are similar, based on hydrogeomorphic classification factors. There may be more than one regional wetland subclass identified with each hydrogeomorphic wetland class, depending on the diversity of wetlands in a region and assessment objectives.

Site Potential: The highest level of functioning possible given local constraints of disturbance history, land use, or other factors. Site capacity may be equal to or less than levels of functioning established by reference standards for the reference domain, and it may be equal to or less than the functional capacity of a wetland ecosystem.

Throughflow: The lateral movement of water in an unsaturated zone during and immediately after a precipitation event. The water from through flow seeps out at the base of slopes and then flows across the ground surface as return flow, ultimately reaching a stream or lake. See Interflow for Comparison.

Variable: An attribute or characteristic of a wetland ecosystem or the surrounding landscape that influences the capacity of a wetland to perform a function.

Variable Condition: The condition of a variable as determined through quantitative or qualitative measures.

Variable Index: A measure of how an assessment model variable in a wetland compares to the reference standards of a regional wetland subclass in a reference domain.

Wetland Ecosystem: "areas that are inundated or saturated by surface or ground water at a frequency and duration sufficient to support, and that under normal circumstances do support, a prevalence of vegetation typically adapted for life in saturated soil conditions. Wetlands generally include swamps, marshes, bogs, and similar areas" (Corps Regulations 33 CFR 328.3 and 
EPA Regulations 40 CFR 230.3). In a more general sense, wetland ecosystems are three dimensional segments of the natural world where the presence of water, at or near the surface, creates conditions leading to the development of anaerobic soil conditions, and the presence of a flora and fauna adapted to the permanently or periodically flooded or saturated conditions.

Wetland Assessment Area (WAA): The wetland area to which results of an assessment are applied.

Wetland Banking: The process of creating a 'bank' of created, enhanced, or restored wetlands to serve at a future date as mitigation of project impacts.

Wetlands Functions: The normal activities or actions that occur in wetlands ecosystems, or simply the things that wetlands do. Wetland functions result directly from the characteristics of a wetland ecosystem and the surrounding landscape, and their interaction.

Wetland Creation: The process of creating a wetland in a location where a wetland did not previously exist.

Wetland Enhancement: The process of increasing the capacity of a wetland to perform one or more functions. Wetland enhancement can increase functional capacity to levels greater than the highest sustainable functional capacity achieved under reference standard conditions, but usually at the expense of sustainability, or a reduction of functional capacity of other functions.

Wetland Restoration: The process of restoring wetland function in a degraded wetland.

Wetland Values: The worth of wetland functions to an individual or society. 


\section{Appendix B}

\section{Summary of Functions, Variables and Spreadsheets}

B1: Summary of Functions

B2: Summary of variables and data forms

B3: Example Functional Capacity Index spreadsheets and calculator

\section{Appendix B-1: Summary of Functions for Prairie Pothole Depressional Wetlands}

\section{Function 1: Water Storage}

a. Definition: This function reflects the capacity of a prairie pothole wetland to collect and retain inflowing surface water, direct precipitation, and discharging ground water as standing water above the soil surface, pore water in the saturated zone, and soil moisture in the unsaturated zone. A potential independent quantitative measure of this function would be the amount of water stored in the wetland per a given time (e.g. hectare-meters/year).

\section{b. Model Variables-Symbols-Measures-Units:}

(1) Wetland Surface Outlet-V $V_{\text {OUT }}$ Elevation change of constructed or proposed (i.e., lowered) outlet to the natural outlet-ratio.

(2) Subsurface Drainage - $V_{\text {SUвOUT }}$ Effectiveness of drainage outside the wetland $O R$ sub-surface drainage beneath the wetland (i.e., tile) - unitless.

(3) Sediment Deposition in the Wetland- $V_{S E D}$-Extent of sedimentation within the wetland from culturally accelerated sources - centimeters.

(4) Change to Catchment Area - $V_{\text {SOURCE }}$ Alterations to the catchment-categorical.

(5) Land Use within the Catchment- $V_{U P U S E}$-Land use of uplands within the catchment-weighted area score. 


$$
\mathrm{FCI}=\sqrt{\left(\text { Minimum of } V_{\text {OUT }}, V_{\text {SUBOUT }}\right) \times \frac{\left[V_{\text {SED }}+\frac{\left(V_{\text {SOURCE }}+V_{\text {UPUSE }}\right)}{2}\right]}{2}}
$$

\section{Function 2: Groundwater Recharge}

a. Definition: This function is the capacity of a prairie pothole wetland to move surface water downward into local or regional groundwater flow paths. Groundwater recharge is the entry into the saturated zone of water made available at the water table surface, together with the associated flow away from the water table within the saturated zone (Freeze and Cherry 1979). A potential independent, quantitative measure of this function is the volume of water lost to groundwater per unit area per unit of time $\left(\left[\mathrm{m}^{3} / \mathrm{ha}\right] /\right.$ time $)$. Usually, this is measured or estimated on a net annual basis.

b. Model Variables-Symbols-Measures-Units:

(1) Wetland Surface Outlet-V $V_{\text {OUT }}$-Elevation change of constructed or proposed (i.e., lowered) outlet to the natural outlet-ratio.

(2) Subsurface Drainage - $V_{\text {SUBOUT }}$ - Effectiveness of drainage outside the wetland $O R$ sub-surface drainage beneath the wetland (i.e., tile) - unitless.

(3) Sediment Deposition in the Wetland- $V_{S E D}$-Extent of sedimentation within the wetland from culturally accelerated sources - centimeters.

(4) Estimated Soil Recharge Potential- $V_{\text {RECHARGE }}$-areal extent of soil types - weighted average score - unitless.

(5) Edge Index- $V_{E D G E}-$ Modified shoreline irregularity index based on perimeter to area relationship - unitless.

(6) Ratio of Catchment Area to Wetland Area- $V_{\text {CATCHWET }}$ Ratio of catchment size to wetland size-ratio. unitless.

(7) Soil Quality Index- $V_{S Q I}-$ Evaluation of physical soil properties-

c. Assessment Model:

$\mathrm{FCI}=\sqrt{\left(\text { Minimum of } V_{\text {OUT }}, V_{\text {SUBOUT }}\right) \times \frac{\left[\frac{\left(V_{\text {RECHARGE }}+V_{\text {EDGE }}+V_{\text {CATCHWET }}\right)}{3}\right]+\left[\frac{\left(V_{\text {SOI }}+V_{\text {SED }}\right)}{2}\right]}{2}}$ 


\section{Function 3: Retain Particulates}

a. Definition: The capacity of a wetland to physically remove and retain inorganic and organic particulates greater than $0.45 \mu \mathrm{m}$ (Wotten 1990) from the water column. A potential independent measure of this function is the amount of particulates retained per unit area per unit time (i.e., $\left[\mathrm{g} / \mathrm{m}^{2}\right] / \mathrm{yr}$ ).

b. Model Variables-Symbols-Measures-Units:

(1) Sediment Deposition in the Wetland $-V_{S E D}$-Extent of sedimentation within the wetland from culturally accelerated sources - centimeters.

(2) Land use within the catchment - $V_{U P U S E}$ - Land use of uplands within the catchment - weighted area score.

(3) Continuity of Grassland Adjacent to the Wetland- $V_{\text {GRASSCONT }}$ Average continuity of the grassland perimeter around the wetland-percent.

(4) Width of Grassland Perpendicular to the Wetland-V $V_{\text {GRASSWIDTH }}$ Average width of grassland around the wetland - meters.

(5) Vegetation Composition- $V_{V E G C O M P}-$ Floristic quality of all plants present — unitless index.

(6) Wetland Surface Outlet-V $V_{\text {OUT }}$-Elevation change of constructed or proposed (i.e., lowered) outlet to the natural outlet-ratio.

(7) Subsurface Drainage - $V_{\text {SUвOUT }}$-Effectiveness of drainage outside the wetland $O R$ sub-surface drainage beneath the wetland (i.e., tile) - unitless.

c. Assessment Model:

$\mathrm{FCI}=\sqrt{\mathrm{V}_{\mathrm{SED}} \times \frac{\left[\frac{\left(V_{\text {UPUSE }}+V_{\text {GRASSCONT }}+V_{\text {GRASSWDTH }}\right)}{3}\right]+\left[\frac{\left(V_{\text {VEGCOMP }}+\left(\text { Minimum of } V_{\text {OUT }}, V_{\text {SUBOUT }}\right)\right)}{2}\right]}{2}}$

\section{Function 4: Remove, Convert, and Sequester Dissolved Substances}

a. Definition: The ability of a wetland to remove and sequester imported nutrients, contaminants, and other elements and compounds. The term "removal" is used to imply permanent loss of nutrients, contaminants, or other elements and compounds through or conversion by biogeochemical reactions. The term "sequestration" implies relatively long-term accumulation of elements and compounds such as by uptake and incorporation into long-lived perennial herbaceous biomass. Elements include macronutrients essential to plant growth (e.g., nitrogen, phosphorus, potassium, etc.) and other elements such as heavy metals (e.g., zinc, chromium, etc.) that can be toxic at high concentrations. Compounds include herbicides, pesticides and other imported materials. A potential 
independent, quantitative measure of this function is the amount of one or more imported elements and compounds removed or retained per unit area during a specified period of time (e.g., $\left[\mathrm{g} / \mathrm{m}^{2}\right] / \mathrm{yr}$ ).

\section{b. Model Variables-Symbols-Measures-Units:}

(1) Wetland Surface Outlet-V $V_{\text {OUT }}$-Elevation change of constructed or proposed (i.e., lowered) outlet to the natural outlet—ratio.

(2) Subsurface Drainage - $V_{\text {SUBOUT }}$-Effectiveness of drainage outside the wetland $O R$ sub-surface drainage beneath the wetland (i.e., tile) - unitless.

(3) Continuity of Grassland Adjacent to the Wetland-V VRASSCONT Average continuity of the grassland perimeter around the wetland-percent.

(4) Width of Grassland Perpendicular to the Wetland- $V_{\text {GRASSWIDTH }}$ Average width of grassland around the wetland-meters.

(5) Change to Catchment Area- $V_{\text {SOURCE }}$-Alterations to the catchment-categorical.

(6) Land Use within the Catchment- $V_{U P U S E}$ - Land use of uplands within the catchment-weighted area score.

(7) Sediment Deposition in the Wetland $-V_{S E D}$-Extent of sedimentation within the wetland from culturally accelerated sources - centimeters.

(8) Vegetation Composition $-V_{V E G C O M P}-$ Floristic quality of all plants present - unitless index.

(9) Soil Organic Matter- $V_{S O M}-$ The amount of organic matter that is in the upper part of the soil profile-percent.

c. Assessment Model

$$
\mathrm{FCI}=\sqrt{\frac{\left(\frac{\left(V_{\text {GRASSWIDTH }}+V_{\text {GRASSCONT }}\right)}{2}\right]+\left[\frac{\left(V_{\text {SOURCE }}+V_{\text {UPUSE }}+V_{\text {SED }}\right)}{3}\right]+\left[\frac{\left(V_{\text {VEGCOMP }}+V_{\text {SOM }}\right)}{2}\right]}{3}}
$$

\section{Function 5: Plant Community Resilience and Carbon Cycling}

a. Definition: The ability of a pothole wetland to sustain native plant community patterns and rates of processes in response to the variability inherent in its natural disturbance regimes.

b. Model Variables-Symbols-Measures-Units: 
(1) Wetland Surface Outlet-V $V_{\text {OUT }}$-Elevation change of constructed or proposed (i.e., lowered) outlet to the natural outlet-ratio.

(2) Subsurface Drainage - $V_{\text {SUBOUT }}$-Effectiveness of drainage outside the wetland $O R$ sub-surface drainage beneath the wetland (i.e., tile) - unitless.

(3) Land Use Within the Catchment - $V_{U P U S E}$ - Land use of uplands within the catchment weighted area score.

(4) Continuity of Grassland Adjacent to the Wetland- $V_{\text {GRASSCONT }}$ Average continuity of the grassland perimeter around the wetland-percent.

(5) Width of Grassland Perpendicular to the Wetland- $V_{\text {GRASSWIDTH }}$ Average width of grassland around the wetland - meters.

(6) Sediment Deposition in the Wetland- $V_{S E D}$-Extent of sedimentation within the wetland from culturally accelerated sources - centimeters.

(7) Soil Organic Matter- $V_{S O M}$-The amount of organic matter that is in the upper part of the soil profile-percent.

(8) Vegetation composition- $V_{V E G C O M P}-$ Floristic quality of all plants present — unitless index.

c. Assessment Model:

$\mathrm{FCI}=\sqrt{\left(\text { Minimum of } V_{\text {OUT }}, V_{\text {SUBout }}\right) \times \frac{\left[\frac{\left(V_{\text {UPUSE }}+V_{\text {GRASSCONT }}+V_{\text {GRASSWIDTH }}\right)}{3}\right]+\left[\frac{\left(V_{\text {SED }}+V_{\text {SOM }}\right)}{2}\right]+V_{\text {VEGCOMP }}}{3}}$

\section{Function 6: Provide Faunal Habitat}

a. Definition: The ability of a prairie pothole to support aquatic and terrestrial vertebrate and invertebrate populations during some or part of their life cycle.

b. Model Variables-Symbols-Measures-Units:

(1) Wetland Surface Outlet-V $V_{O U T}$-Elevation change of constructed or proposed (i.e., lowered) outlet to the natural outlet-ratio.

(2) Subsurface Drainage - $V_{\text {SUBOUT }}$-Effectiveness of drainage outside the wetland $O R$ sub-surface drainage beneath the wetland (i.e., tile) - unitless.

(3) Land Use Within the Catchment- $V_{U P U S E}$ - Land use of uplands within the catchment-weighted area score. 
(4) Sediment Deposition in the Wetland $-V_{S E D}$-Extent of sedimentation within the wetland from culturally accelerated sources-centimeters.

(5) Continuity of Grassland Adjacent to the Wetland - $V_{\text {GRASSCONT }}$ Average continuity of the grassland perimeter around the wetland-percent.

(6) Width of Grassland Perpendicular to the Wetland - $V_{\text {GRASSWIDTH }}$ Average width of grassland around the wetland-meters.

(7) Edge Index $-V_{E D G E}-$ Modified shoreline irregularity index based on perimeter to area relationship - unitless.

(8) Proximity to Nearest Wetlands - $V_{\text {WETPROX }}$-The proximity of similar wetlands (i.e., wetlands of the same HGM class) to the wetland being assessed-meters.

(9) Vegetation Composition- $V_{V E G C O M P}-$ Floristic quality of all plants present — unitless index.

(10) Sum of the Length of Roads and Ditches in the Landscape Assessment Area- $V_{\text {HABFRAG }}$ Sum of the linear extent of roads and drainage features $(\mathrm{km})$ within the LAA; used to account for fragmentation within the wetland com$\mathrm{plex}-\mathrm{km} / \mathrm{LAA}$.

(11) Number of Basins in the Landscape Assessment Area- $V_{B A S I N S}$-The number of palustrine wetlands within the LAA - unitless.

(12) Wetland Density in the Landscape Assessment Area- $V_{\text {WETAREA }}$ The condition of the wetland complex associated with the assessment wetlandhectares.

c. Assessment Model: For projects involving evaluation at the site scale:

$$
\mathrm{FCI}=\sqrt{\frac{\left(\frac{\left(V_{\text {UPUSE }}+V_{\text {SED }}\right)}{2}\right]+\left[\frac{\left(V_{\text {GRAsScont }}+V_{\text {GRASSWITH }}+V_{\text {EDGE }}+V_{\text {WetrRox }}\right)}{4}\right]+V_{\text {veGComp }}}{3}}
$$

An Alternate Formula for projects involving evaluation of a wetland complex is:

$\mathrm{FCI}=\sqrt{\left(\text { Minimum of } V_{\text {OUT }}, V_{\text {SUBbut }}\right) \times \frac{\left[\frac{\left(V_{\text {UPUSE }}+V_{\text {SED }}\right)}{2}\right]+\sqrt{V_{\text {HABfraG }} \times\left[\frac{\left(V_{\text {BAsins }}+V_{\text {WEtAREA }}\right)}{2}\right]}+V_{\text {VEGCOMP }}}{3}}$ 


\section{Appendix B-2: Summary of Model Variables}

Each of the HGM variables used in this Guidebook is presented on the following pages. A summary of the measures and units as well as methods for collection of data is provided. Users should also note that the majority of data forms emulate the pages from electronic spreadsheet worksheets. The intent of data forms largely complementing spreadsheets is for ease of calculations and assurance that all necessary information is recorded.

\section{Vegetation variables}

\section{a. Grassland Continuity ( $\left.V_{\text {GRASSCONT }}\right)$ :}

(1) Measure/Units: The continuity of grassland expressed as a percent of the wetland perimeter.

(2) Method: This variable represents the average continuity of grassland around the perimeter of the wetland. Grassland continuity is measured by determining the perimeter (meters) of the wetland boundary that is contiguous with grassland. Divide the total distance of grassed perimeter by the total wetland perimeter to obtain the "percent of wetland boundary that has a grass edge." This variable can be measured in the field or from appropriate scale aerial photography. Any off-site measurements should be verified in the field.

(3) Data Form:

\section{GRASSCONT \\ Continuity of grassland}

Record:

a) The perimeter of the wetland (meters): USER NOTE: Multiply feet by 0.305 to convert into meters.

b) Meters of grassland (perennial cover) along perimeter:

c) Divide b) by a) and multiply by $100 \%$ to calculate percent continuity:

d) VARIABLE SUBINDEX SCORE for Vgrasscont:

\section{b. Grassland Width (V GRASSWIDTH):}

(1) Measure/Units: Average grassland width in meters perpendicular from the wetland edge.

(2) Method: Assign 12 points placed at equal intervals around the perimeter of the wetland boundary. It is recommended that the first point be located on the northern edge of the wetland and that the remaining points corre- 
spond to the hours of a clock. From each point, measure, perpendicular from the edge of the wetland, the width of the adjacent grassland from the edge of the wetland out to a distance of $15 \mathrm{~m}$. If crops, roads, or feedlots are present at the edge of the wetland, then no grassland edge is present and a score of 0 is generated for that point. The average width of grass (perennial cover) from the 12 points is then calculated. This variable can be measured in the field or from appropriate scale aerial photography. Any off-site measurements should be verified in the field.

(3) Data Form:

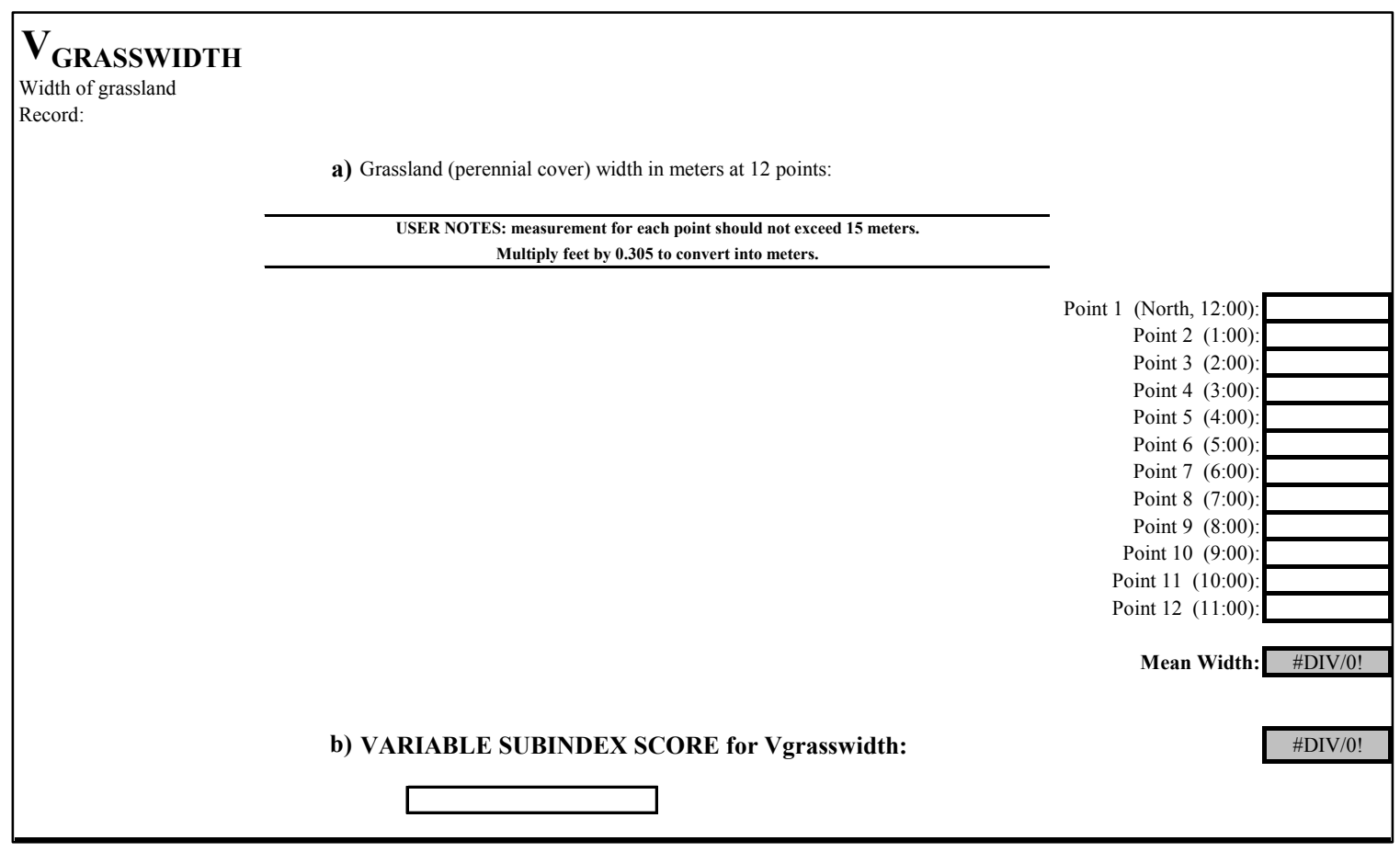

c. Vegetation Composition $\left(V_{V E G C O M P}\right)$ :

(1) Measure/Units: A modified species richness estimate measuring the degree of conservatism of the plants within the wetland.

(2) Methods:

(a) Stratify the wetland by dominant vegetation zones or plant community types, or both (i.e., low prairie, wet meadow, shallow marsh).

(b) For each zone or plant community, list all plant species. Accurate species identification is critical for this variable. Users who do not feel confident in identifying plant species should seek help with plant identification.

(c) Assign the appropriate coefficient of conservatism (C) for each plant species (see Appendix C). 
(d) Floristic quality is based on the coefficient of conservatism (C) for each species as assigned by the Northern Great Plains Floristic Quality Assessment Panel (2001).

(e) Calculate FQI as aggregated from all zones/plant communities; where, $\mathrm{FQI}=\bar{C} \times(\sqrt{N})$.

\section{(3) Data Form:}

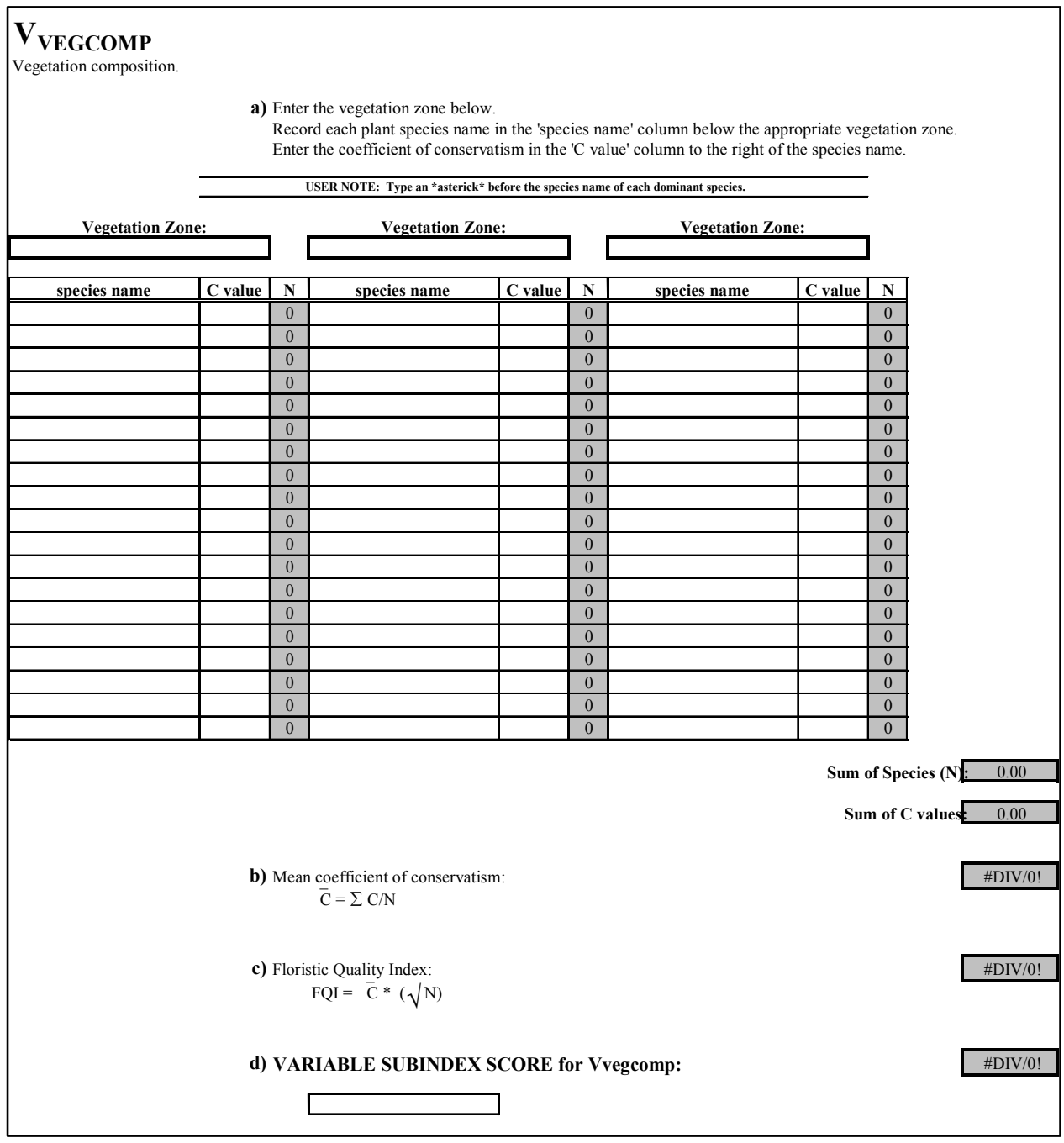

\section{Soil variables}

a. Estimated soil recharge potential ( $\left.V_{\text {RECHARGE }}\right)$ :

(1) Measure/Units: The weighted area1 score of various soil types within the wetland. Used with Appendix C-4 to generate a soil recharge rating for the WAA. 
(2) Methods: This variable is determined by the areal coverage of soil types within the WAA. Soil units are derived from custom on-site mapping, soil surveys or inferred from NWI mapping (in this order of preference). Where onsite mapping is not available, the weighted recharge potential for the WAA is then calculated using the categorical variable.

(3) Data Form:

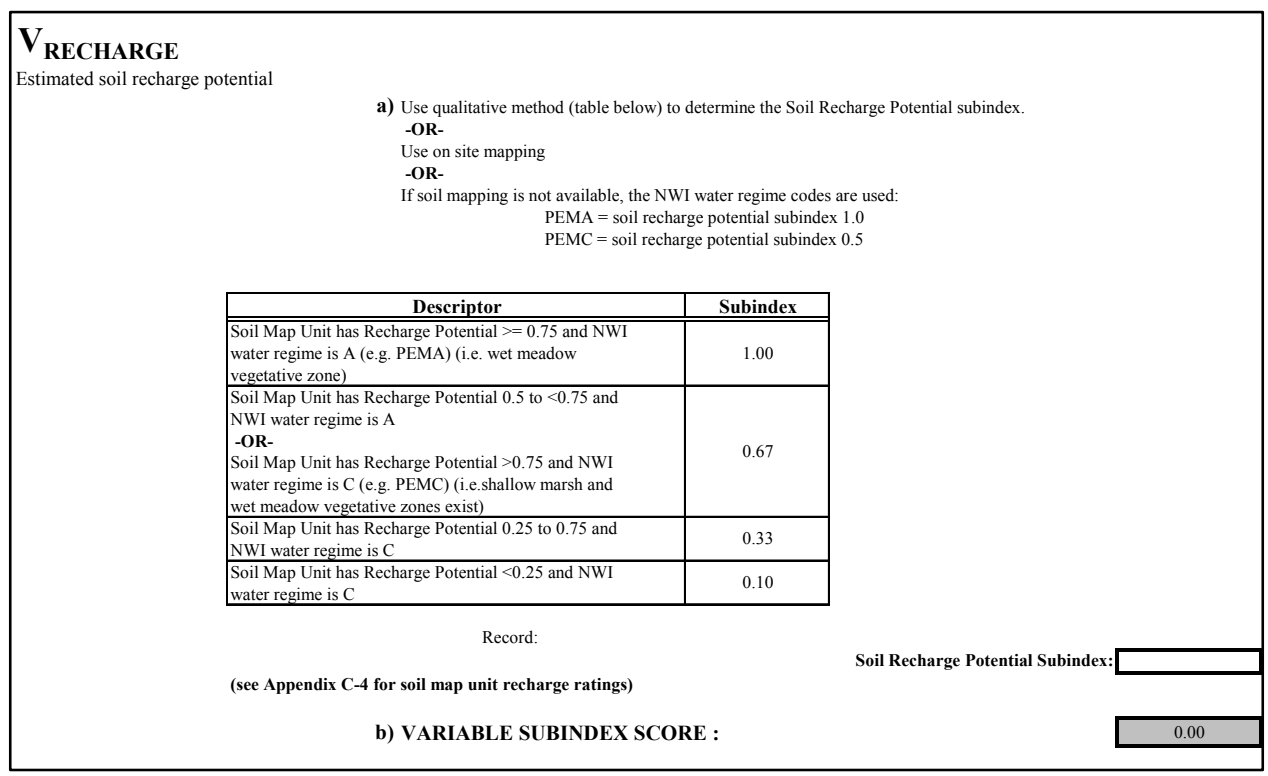

\section{b. Sediment Deposition in the Wetland $\left(V_{S E D}\right)$ :}

(1) Measure/Units: $V_{S E D}$ is the depth of sediment from natural and culturally accelerated sources as inferred from the depth to the B horizon $(\mathrm{cm})$.

(2) Methods: Dig (minimally) to the top of the B horizon in the wetland and remove a vertical slice of soil for further verification. The B horizon can be identified easily below E horizons on many sites in the Dakotas. Some sites may need deeper investigation; also note if there are any buried horizons, and at what depth. Buried layers are an indication of accelerated sedimentation and the depth to B horizon below the overwash in the "original" soil is the desired metric.

Check the soil profile in the most and least impacted areas near the outside edge of the outer depressional soil or vegetative zone. The outside edge corresponds to the hydric soil boundary of the wetland and can be checked with the soil using hydric soil indicators. Measure the depth to B horizon for the number of replicates required. The depth to $\mathrm{B}$ for the replicates should be averaged for calculation of the final subindex score. 


\section{(3) Data Form:}

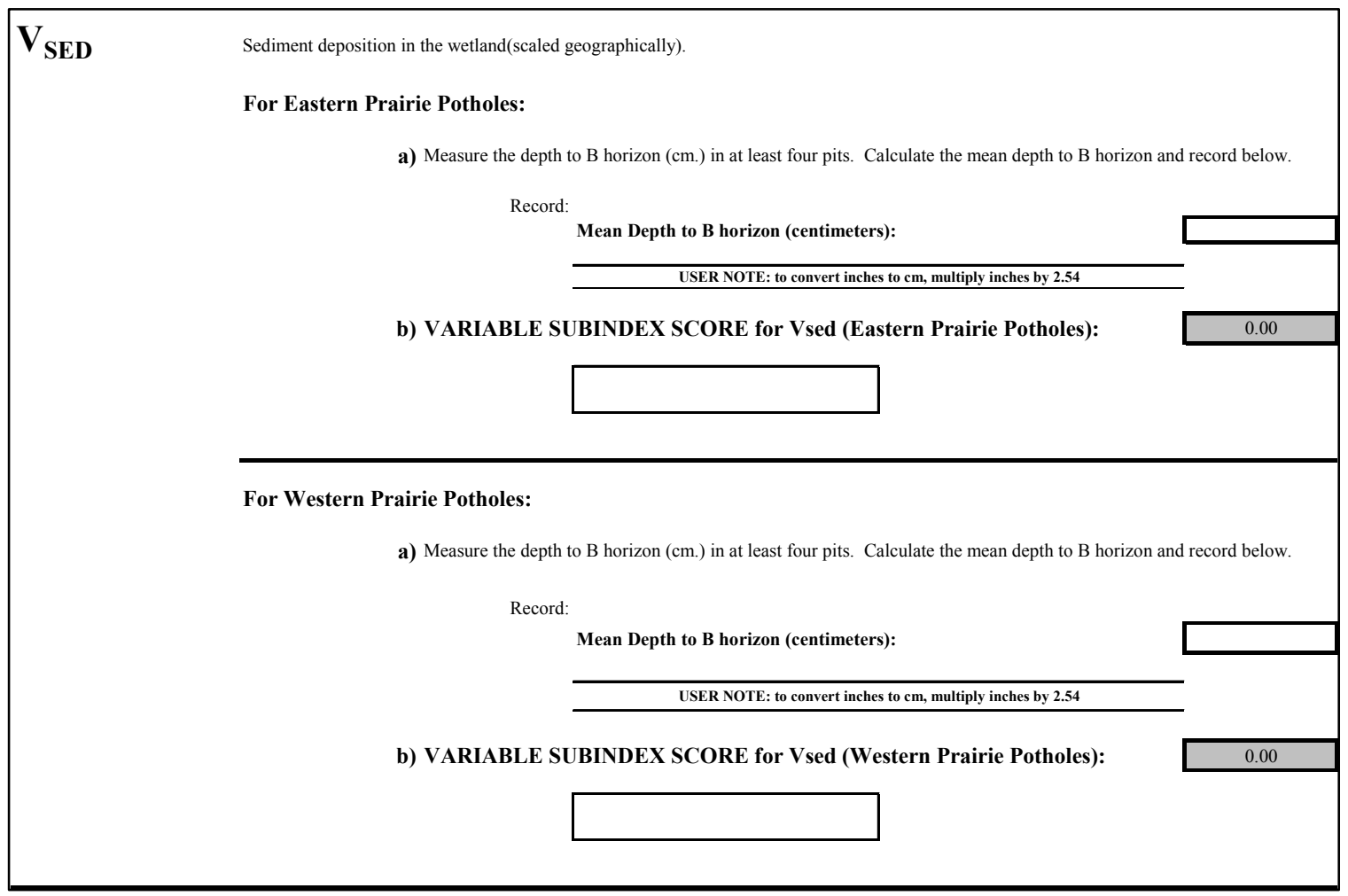

c. Soil Quality Index $\left(V_{S Q I}\right)$ :

(1) Measure/Units: $V_{S Q I}$ is the quality of the soil surface layer (A or Ap horizon) as measured by a unitless summation index based upon the description of the soils structure, rupture resistance (consistence) and pores. This variable is evaluated in the outer depressional soil-vegetation zone (usually the Tonka, Tetonka, or Endoaquoll, i.e., the wet meadow zone) of the wetland.

(2) Methods: Dig soil holes with a sharpshooter spade to a depth of at least 18 in. $(45 \mathrm{~cm})$. The soil profile should be described in accordance with delineation protocol and the appropriate documentation of characteristics necessary for computation of the SQI. The SQI is based upon a description of the upper $30 \mathrm{~cm}$ (12 in.) of the soil. With the use of a spade (sharpshooter) take a vertical slice of soil to a depth of $45 \mathrm{~cm}$. Examine in good sunlight. Apply a moderate thud to the back of the spade to help show the natural structure cleavage of the soil. Record presence or absence of an Ap horizon or evidence of past tillage.

(a) Recently tilled sites may have "fluffy" structure in the upper 15 $\mathrm{cm}$; be sure to examine the soil below the recently tilled zone for evidence of a plow pan, etc. Pay special notice to the $10-$ to $25-\mathrm{cm}$ layer, looking for horizontal layers that could be a plow layer. Look for horizontal root growth as an indicator of a highly compacted layer (plow pan). Record findings. 
(b) Examine the slice and note the size, shape and grade (distinctness) of the soil peds in the A horizon. Note if the structure parts to medium and fine granular and the size of blocks and prisms. Record the size, grade, and type of structure for the A horizon. If the sampling site is underwater, soil probe (preferably one with a 1.5 -in. diameter coring tube) could be used to obtain a sample; however, coarser structure and grade of structure may not be evident, so therefore this is not recommended. The SQI is based on observations of moist soil.

(c) Examine horizontal surfaces for tubular pores. Concentrate on the layer with the fewest pores and the most compaction if an Ap is present. Count the number of very fine and fine pores in a square centimeter and the number of medium and coarse pores in a square decimeter and record. Also examine the pores to determine their continuity. Record the number of pores and their continuity. Note: roots can be used as a surrogate for pores.

(d) To determine rupture resistance in the upper $30 \mathrm{~cm}$ of the soil, take a soil ped (about 1-in. cube) that has not been compressed or deformed in getting the slice and crush it between your forefinger and thumb, noting the strength needed to deform or rupture the ped. Note this estimation as very friable (very slight force), friable (slight force), firm (moderate force) or very firm (strong force). Then record the most resistant measurement found within the upper $45 \mathrm{~cm}$. (Hint: if tilled, this will probably be in a 10-cm-thick layer found just below the tillage zone, which may extend to $30 \mathrm{~cm}$ below the surface.)

(3) Data Form:

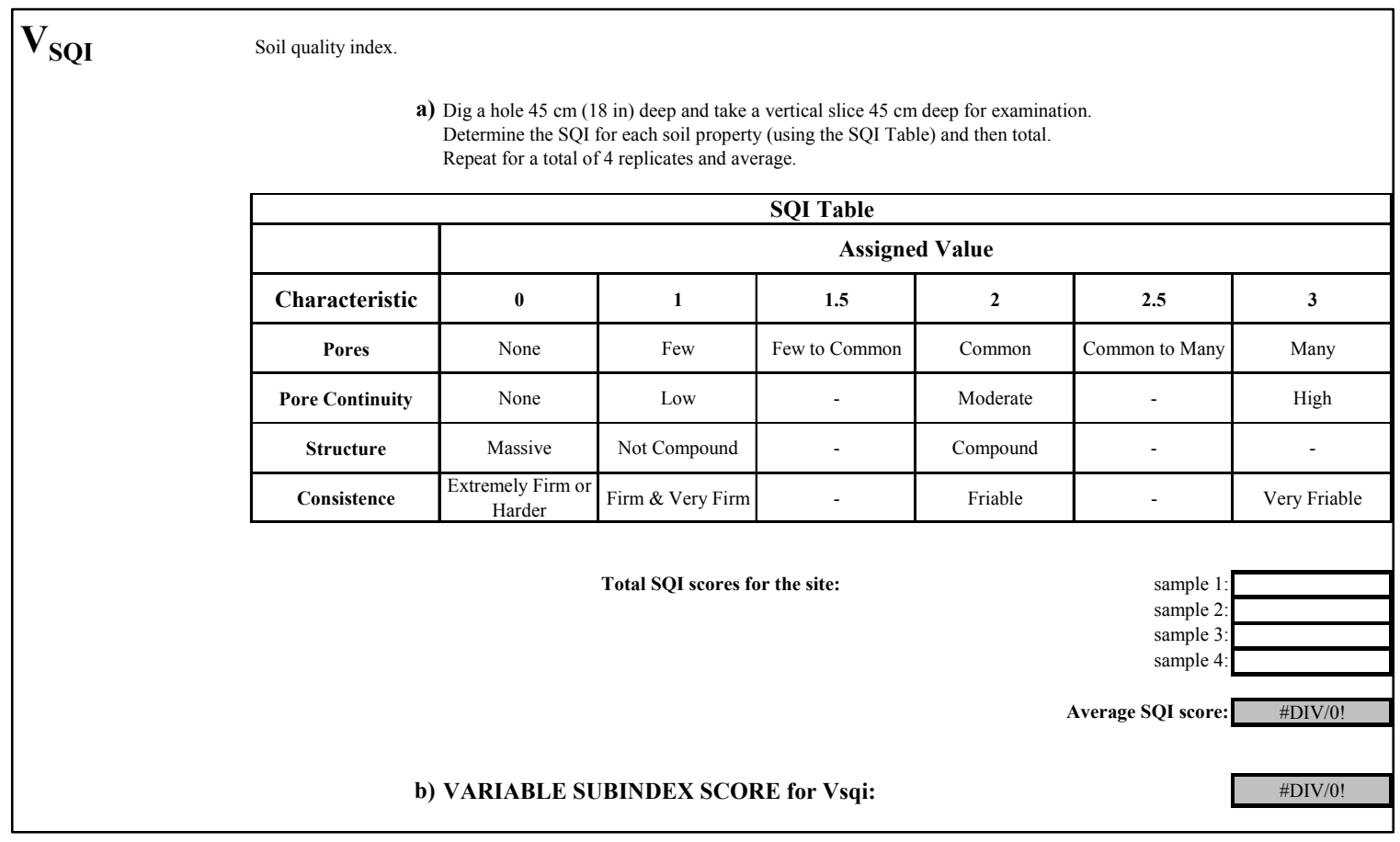




\section{d. Soil Organic Matter $\left(V_{\text {SOM }}\right)$ :}

(1) Measure/Units: Percent soil organic matter content of the upper 30 $\mathrm{cm}$ (12 in.) as per lab analysis or as estimated from a regression equation derived from litter thickness, the A horizon Darkness Index, and the Soil Quality Index. All measures are in the wet meadow zone.

(2) Methods: After the profile has been described, sample the 0- to 15and $15-$ to $30-\mathrm{cm}$ depths for lab testing. Make a composite sample for each depth from the four soil pit locations, mix, and withdraw a representative sample from each composite for lab analysis.

\section{(3) Data Forms:}

\section{Estimating \% Soil Organic Matter Through Indirect Measurements}

Method:

Measure litter depth at each sample location.

With the use of a spade (sharpshooter) take a vertical slice of soil to a depth of $45 \mathrm{~cm}$ (18 inches).

Moisten the soil and examine in good sunlight.

Using the Munsell Soil Color Chart, examine the colors of the upper 12 inches of the A horizon and determine color. *example: 10YR (hue) 3(value)/1(chroma)

Record:

Repeat for a total of 4 samples.

Litter Depth

Sample 1 Sample 2 Sample 3 Sample 4

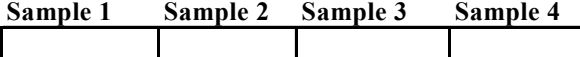

\begin{tabular}{|l|c|}
\hline Average litter depth : & 0 \\
\hline
\end{tabular}

Soil colors for A horizon Darkness Index(ADI)

USER NOTES:Enter only numbers. Letters (such as 'YR' in 10YR) can be entered next to the hue box. Enter 0 for hues of N. Enter 2 for hues or values of 2.5

\begin{tabular}{|r|r|c|r|r|c|}
\hline Sample 1 & hue: & & Sample 2 & hue: & \\
\hline & value: & & & value: & \\
\hline & chroma: & & & chroma: & \\
\hline & ADI & 0 & & ADI & 0 \\
\hline Sample 3 & hue: & & Sample 4 & hue: & \\
\hline & value: & & & value: & \\
\hline & chroma: & & & chroma: & \\
\hline & ADI & 0 & & ADI & 0 \\
\hline
\end{tabular}

\begin{tabular}{|l|c|}
\hline Average ADI: & 0 \\
\hline
\end{tabular}

Enter Soil Quality Index Value (see instructions, this Appendix)

\begin{tabular}{l|l|} 
Average SQI: & 0 \\
\hline
\end{tabular}

\section{\begin{tabular}{|l|l}
\hline$\%$ Organic Matter & 0 \\
\hline
\end{tabular}}

(Regression equation automatically calculated) 


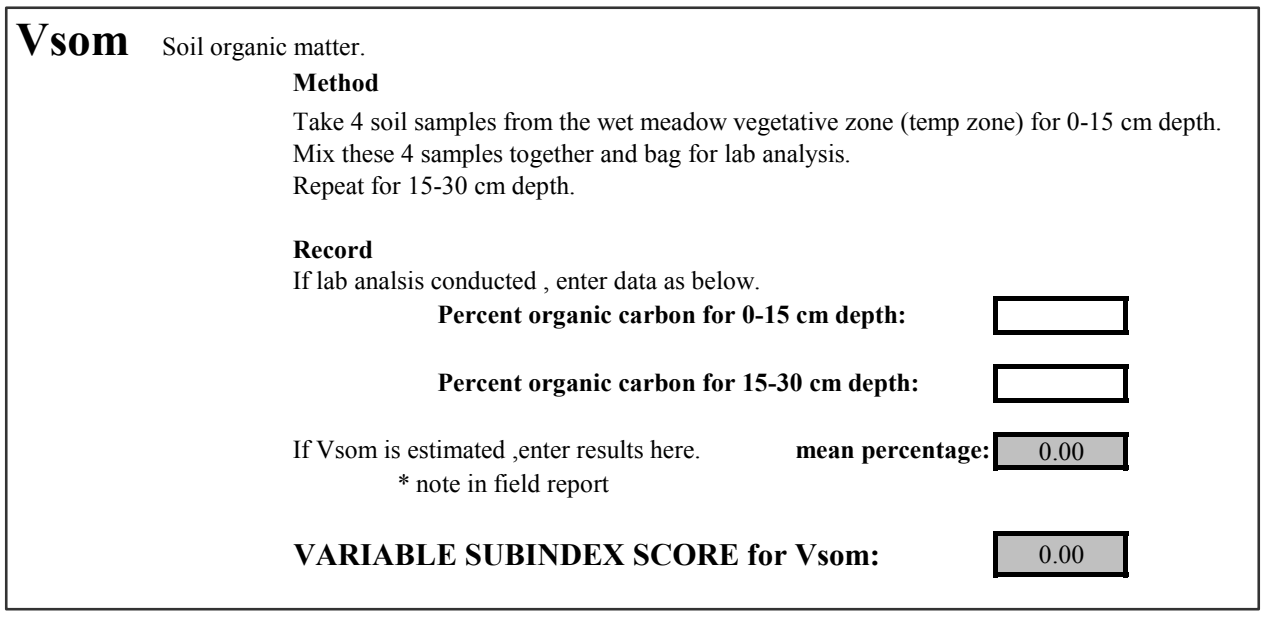

\section{Hydrogeomorphic variables}

\section{a. Wetland Surface Outlet (V $\left.V_{\text {OUT }}\right)$ :}

(1) Measure/Units: Elevation of wetland outlets, natural or constructed, in relation to edge of the wetland and hydric soils. The volume of excavations present within the hydric soil footprint of the wetland.

\section{(2) Methods:}

(a) Elevations and distances will be determined by approved surveying methods and equipment (not a hand level). Survey the elevation of the invert (the invert is the controlling elevation, or the point where overflow water exits the basin) of any surface outlets. This includes tile intakes. Survey the elevation of the outer edge of the wetland. Survey the elevation of a representative deepest part of the wetland.

(b) Record the following:

- Invert elevation, if one is present, in relation to wetland maximum depth.

- Elevation of the edge of the present-day or historic wetland (determined by soil or plants and soils).

- Elevation of a representative deepest portion of the wetland (i.e., maximum pool depth, avoiding unusual features such as animal wallows). 
(3) Data Form:

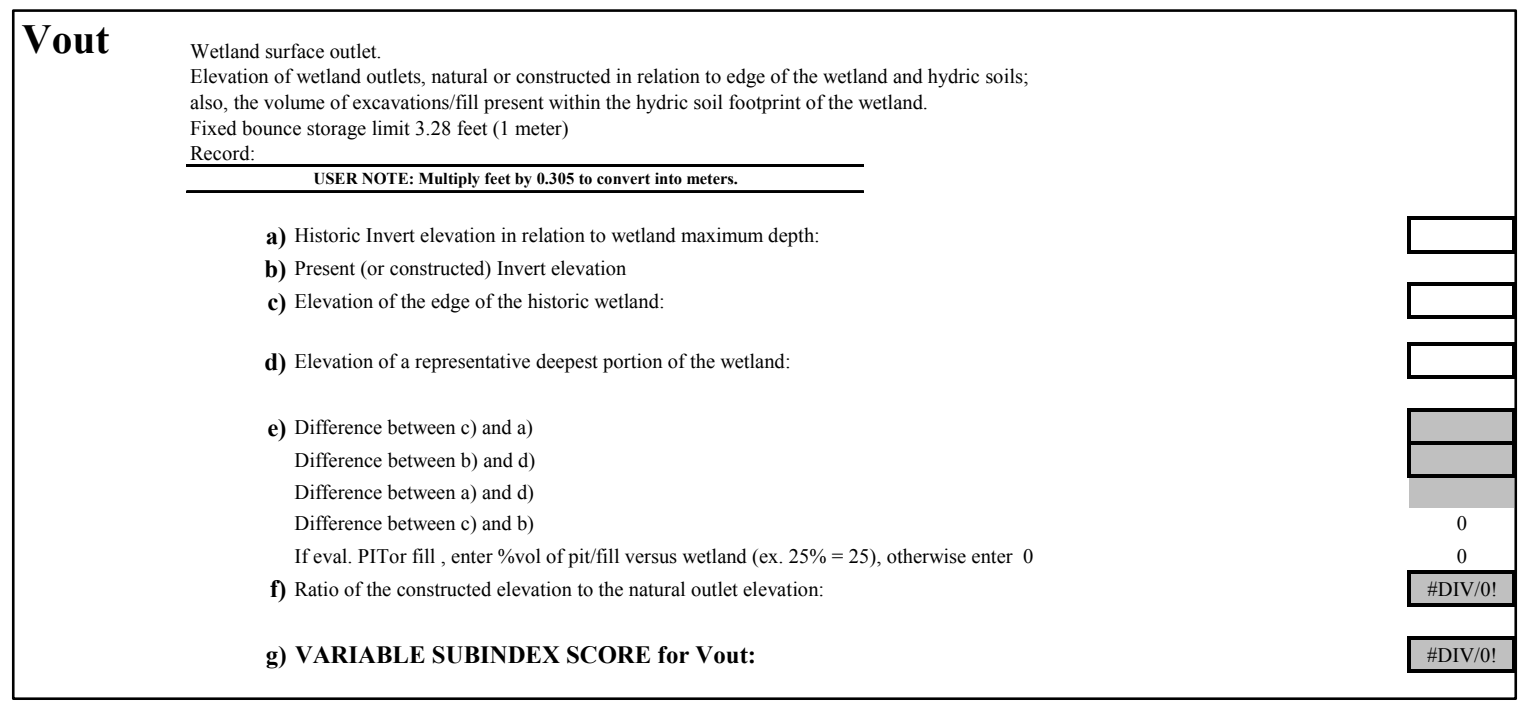

\section{b. Subsurface Drainage (VSUBOUT):}

(1) Measure/Units: Size and spacing of subsurface tile within the wetland or depth of and distance to surface drainage within $200 \mathrm{ft}$ of wetland edge.

(2) Methods:

(a) Elevations and distances will be determined by approved surveying methods and equipment (not a hand level).

(b) Record the following:

- Determine the shortest distance between the surface drainage feature and WAA. Provide the elevation of the lowest point in the surface drainage feature at this distance.

- Document location, spacing, and elevations of subsurface drainage features (tile) within the WAA.

$\diamond \quad$ Determine the tile size from scope and effect or local information.

$\diamond$ Determine the shortest distance between the tile and the wetland.

$\diamond$ Determine the depth the tile is below the ground surface with the tile probe.

$\diamond \quad$ Shoot the elevation at this location and subtract the depth to tile and the tile diameter from the ground elevation. 


\section{(3) Data Form:}

Vsubout Subsurface drainage.

a) Record:

Depth of surface drainage invert and distance from WAA edge:

depth: distance:

Location/spacing of subsurface tile within the WAA:

b) Use the following table to determine the Subindex:

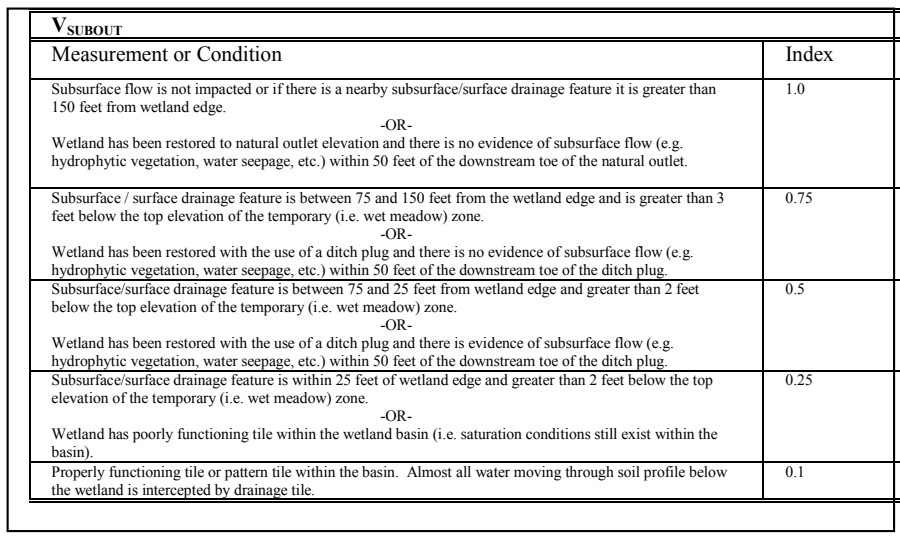

VARIABLE SUBINDEX SCORE for Vsubout:

enter subindex score

\section{c. Source Area of Flow- $\left(V_{\text {SOURCE }}\right)$}

(1) Measure/Units: The percent change (increase, decrease, or both) in the catchment area surrounding a wetland due to alterations such as tile or surface drainage, diversions, roads, land leveling, etc. This variable is scored as a condition.

(2) Method: These measurements can be taken at any time during the assessment. For efficiency they could be done in the office and checked in the field. If small wetlands on flatter topography do not show contour lines on the USGS topographic maps for delineating catchment area, sketch the catchment on an aerial photo or map in the field.

(a) Review aerial photography, USGS maps, soil maps, scope and effect maps, and NWI maps. Note and document any surface or sub-surface alterations. Note and document wetland subclass. From the USGS topographic map delineate the original catchment area or use an aerial photo in the field and sketch the catchment.

(b) Record the following:

- Type and effect of surface alterations. 
- Percent of historic catchment area still contributing runoff to the wetland.

- Additions of water to the wetland from other sources.

- Change in wetland regime class-Yes or No?

NOTE: If the office review can determine that the catchment area has been altered, determine the amount of catchment area that has been structurally altered to prevent flow to the wetland. In most cases, the index score is determined based on percent of catchment from which water is prevented from reaching the wetland. Also, note areas added to the catchment due to, for example, road and drainage ditches, tile outlets, land leveling, irrigation, etc. In the field, verify all alterations noted during the off-site review and document any additional alteration found during the field investigations.

\section{(3) Data Form:}

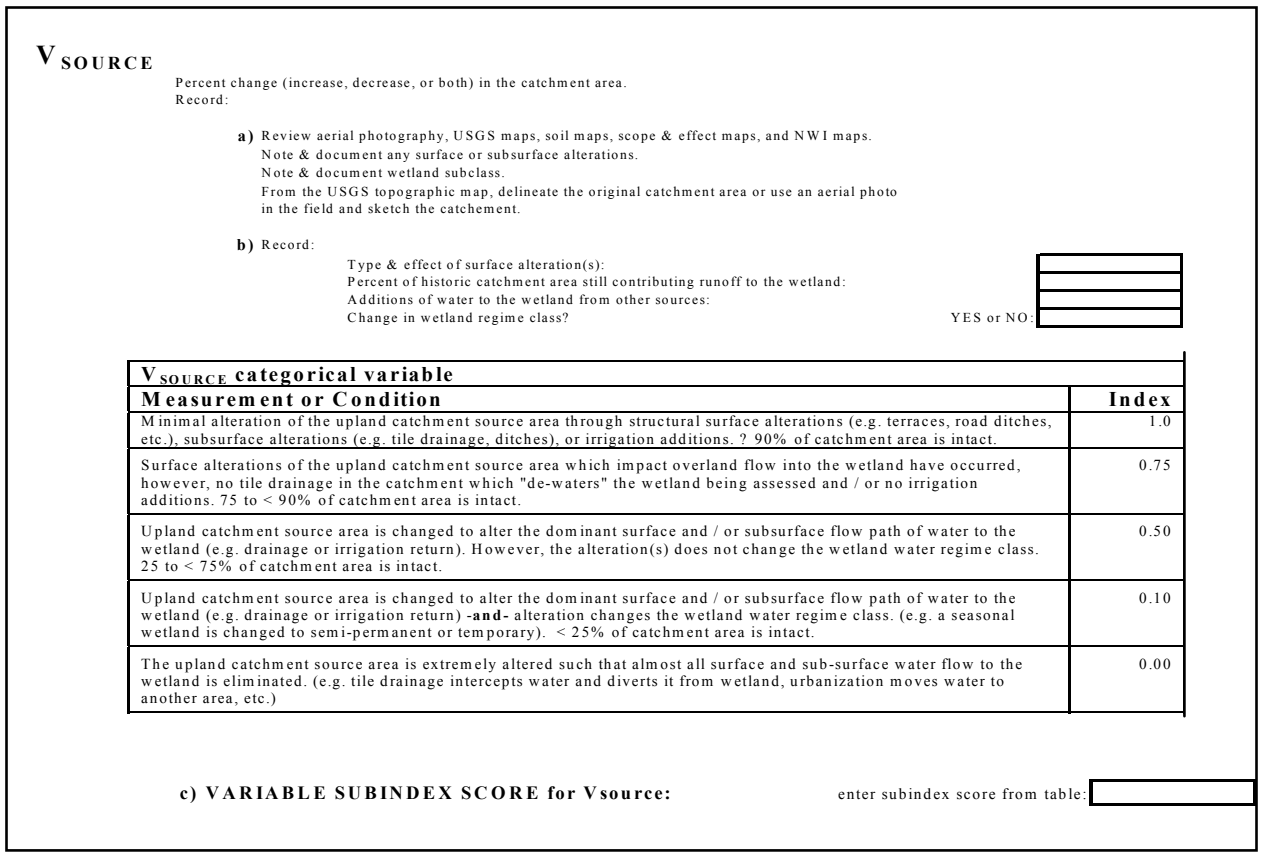

\section{d. Edge Index $\left(V_{E D G E}\right)$ :}

(1) Measure/Units: The variable is a measure of the degree of shoreline irregularity expressed as ratio of the perimeter of the WAA as compared to the perimeter of a circle of area equal to the WAA. The closer this ratio is to 1, the more circular the wetland. A larger ratio means the shoreline is more crenellated.

(2) Method: This variable can be measured in the field or from appropriate scale aerial photography. Any off-site measurements should be verified in the field. Perimeter measurements are available from previous calculation of $V_{\text {GRASSCONT. }}$. The perimeter and WAA area are inserted in the equation below for calculation of the index. The Edge Index is calculated as: 


$$
V_{\mathrm{EDGE}}=\frac{\text { wetland perimeter }}{2 \times \sqrt{\pi \times \text { wetland area }}}
$$

(3) Data Form:

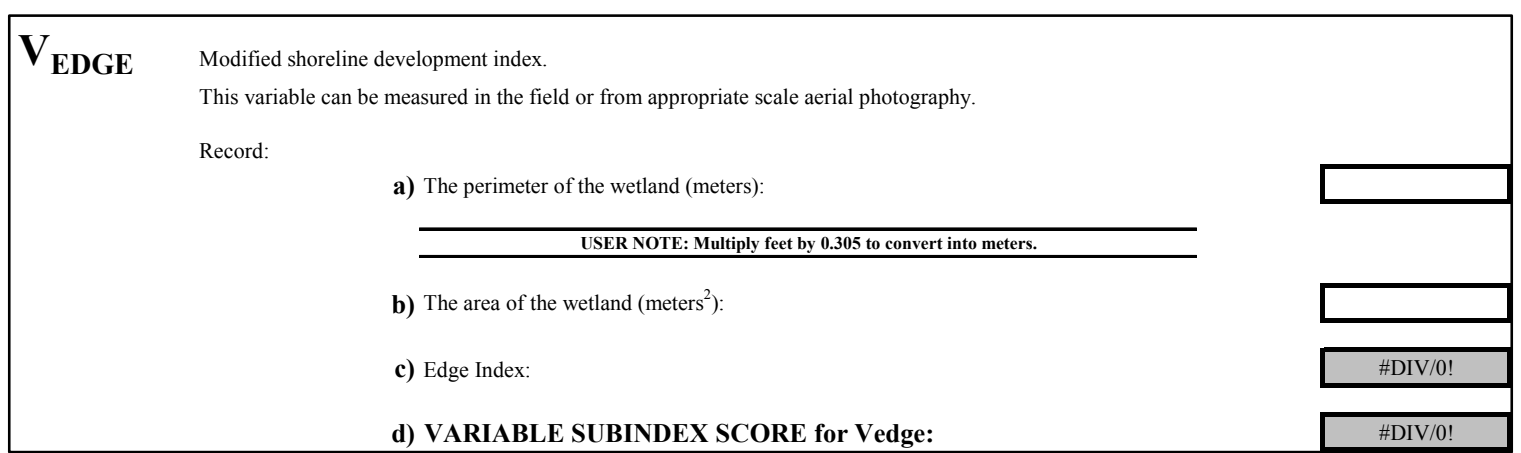

e. Ratio of catchment area to wetland area $\left(V_{C A T C H W E T}\right)$ :

(1) Measure/Units: The area of the catchment in relation to the size of the wetland. Expressed as a ratio (e.g., 5:1). Catchment area has been previously determined for $V_{\text {SOURCE. }}$. Area of the assessment site is part of the basic site description.

(2) Method: Measure the size of the historic catchment, including the wetland. Measure the size of the wetland. This variable can be measured in the field or from appropriate scale aerial photography. Any off-site measurements should be verified in the field.

(3) Data Form:

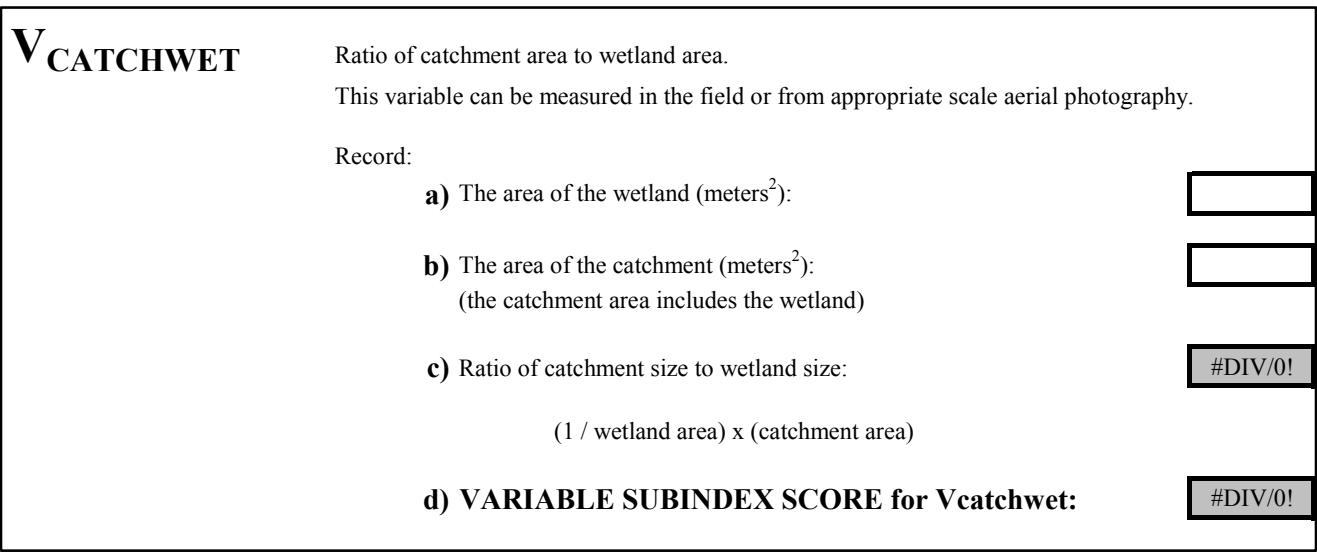

\section{Land use and landscape variables}

a. Land use within the catchment ( $\left.V_{U P U S E}\right)$ : 
(1) Measure/Units: The weighted average score of various land uses as related to runoff potential within the catchment of the wetland. Land use determinations are made from the outer edge of the wetland to the catchment boundary. Runoff curve numbers from and area of each landuse-land cover type are required.

(2) Method: A combination of off-site and on-site assessment methodology can be used for this variable.

(a) Review aerial photography and the FSA land use history for the site. From the USGS topographic map, delineate the present-day catchment area or use an aerial photo in the field and sketch the catchment. Use a dot grid, planimeter, or GIS to determine the area of the various land use categories. Then, multiply the area in each category by the curve number, add all together for a total, and divide by present-day catchment area. The weighted average score is then used to derive the sub-index score.

(b) Record the following:

- Total area of present-day catchment.

- Area of various land use within the present-day catchment by category.

- Calculate weighted average score for upland land use.

(3) Data Form:

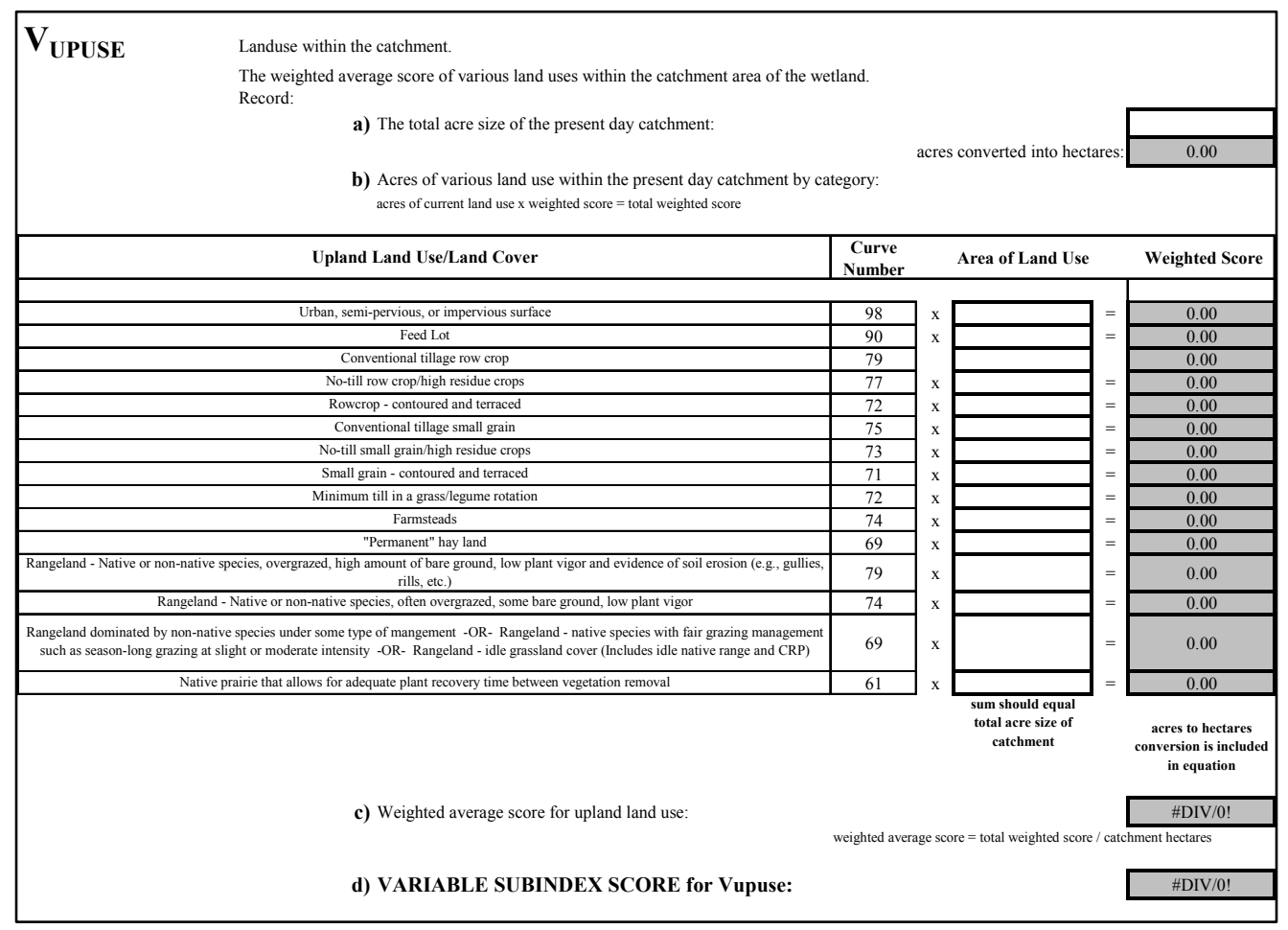




\section{b. Proximity to nearest wetlands ( $\left.V_{\text {WETPROX }}\right)$ :}

(1) Measure/Units: Distance in meters from the wetland assessment area to the nearest five wetlands of any palustrine type. The five measurements are then averaged.

(2) Method: Measure the distance in meters from the edge of the reference wetland to the edges of the nearest five wetlands. Calculate the mean distance. A preliminary measure of this can be preformed in the office using NWI or FSA mapping data; however, it should be confirmed based upon a field visit.

\section{(3) Data Form:}

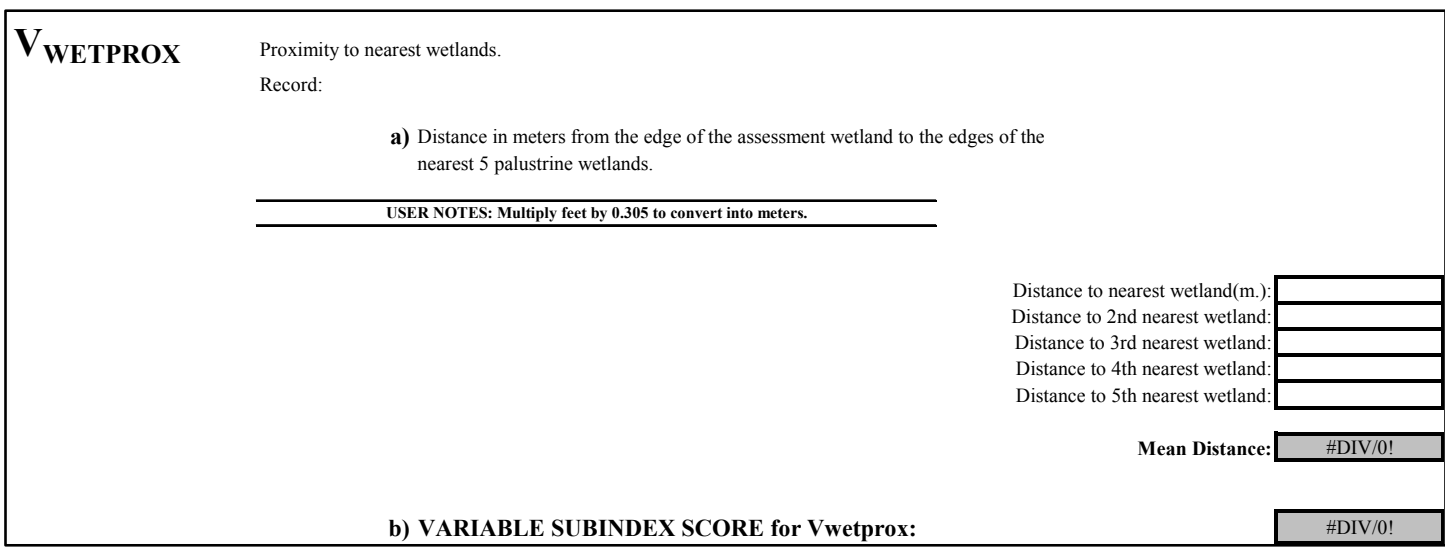

c. Wetland Density in the Landscape Assessment Area ( $\left.V_{\text {WETAREA }}\right)$ :

(1) Measure/Units: The area of palustrine wetlands within a $1.6 \mathrm{~km}$ radius from the center of the reference wetland.

(2) Method: Draw a circle with a radius of $1.6 \mathrm{~km}$ from the center of the reference wetland. Calculate the acres of palustrine wetlands within this circle, excluding the reference wetland, using recoded National Wetland Inventory (NWI) data. For wetlands bisected by the circle, only the polygons contained on the inside of the circle are included. It is recommended GIS technology be used for this variable.

\section{(3) Data Form:}

VWETAREA $\quad$ Wetland density in the landscape assessment area.
Record:
$\begin{aligned} & \text { a) The area of palustrine wetlands within a 1.6-kilometer radius from the center of the } \\ & \text { reference wetland: } \\ & \text { b) VARIABLE SUBINDEX SCORE for Vwetarea: }\end{aligned}$

d. Number of Basins in the Landscape Assessment Area ( $\left.V_{B A S I N S}\right)$ : 
(1) Measure/Units: The number of palustrine wetlands within a $1.6-\mathrm{km}$ radius from the center of the reference wetland.

(2) Method: Draw a circle with a radius of $1.6 \mathrm{~km}$ from the center of the reference wetland. Count calculates the number of palustrine wetlands within this circle, excluding the reference wetland, using recoded National Wetland Inventory (NWI) data. For wetlands bisected by the circle, only the polygons contained on the inside of the circle are included. It is recommended GIS technology be used for this variable.

(3) Data Form:

\begin{tabular}{|l}
\hline BASINS \\
$\begin{array}{l}\text { Number of basins in the landscape assessment area. } \\
\text { Record: }\end{array}$ \\
$\begin{array}{l}\text { a) The number of palustrine wetlands within a 1.6-kilometer (1-mile) radius from the center of the } \\
\text { reference wetland: } \\
\text { b) VARIABLE SUBINDEX SCORE for Vbasins: }\end{array}$
\end{tabular}

e. Sum of the length of roads and ditches in the Landscape Assessment Area $\left(V_{\text {HABFRAG }}\right)$ :

(1) Measure/Units: This variable is the sum of the linear extent of roads and drainage features $(\mathrm{km})$ within the LAA. It is used to account for fragmentation within the wetland complex.

(2) Method: Draw a circle with a radius of $1.6 \mathrm{~km}$ from the center of the reference wetland on NWI inventory maps composited with the USGS 7.5 minute quadrangles. Measure the length of all roads and Cowardin et al. (1979) linear attributes from these data. Linear attributes included from NWI mapping are the "d" or "x" modifiers. Similar information can be derived from aerial photography and USGS digital ortho quarter quads. It is recommended GIS technology be used for this variable.

(3) Data Form:

\begin{tabular}{|l|l|}
\hline HABFRAG & $\begin{array}{l}\text { Sum of the length of roads and ditches. } \\
\text { Use NWI inventory maps composited with the USGS } 7.5 \text { minute quadrangle(s) to record: } \\
\begin{array}{r}\text { a) The length (km) of all roads and linear attributes within a 1.6-kilometer (1-mile) radius from the } \\
\text { center of the reference wetland: }\end{array} \\
\text { USER NOTE: Linear attributes included from NWI mapping are the "d" or " } \mathrm{x} \text { " modifiers. } \\
\text { Multiply feet by 0.000305 to convert into kilometers. }\end{array}$ \\
\hline
\end{tabular}




\section{Appendix B-3: Functional Capacity Index Spreadsheets and Calculator (Sample)}

All variable metrics and sub-index scores are summarized on a worksheet (for illustration purposes, only a portion of this worksheet is shown).

\begin{tabular}{|c|c|c|c|c|}
\hline \multirow{23}{*}{ 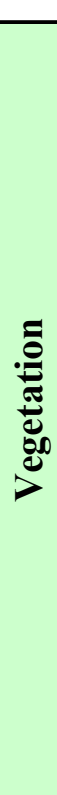 } & Variable & \multicolumn{2}{|l|}{ Data entered } & Subindex \\
\hline & \multirow{3}{*}{ Vgrasscont } & wetland perimeter: & 0.0 & \multirow{3}{*}{ \#DIV/0! } \\
\hline & & grassland meters along perimeter: & 0.0 & \\
\hline & & percent continuity: & \#DIV/0! & \\
\hline & & grassland width (meters) at 12 points: & & \\
\hline & & Point 1: & 0.0 & \\
\hline & & Point 2: & 0.0 & \\
\hline & & Point 3: & 0.0 & \\
\hline & & Point 4: & 0.0 & \\
\hline & & Point 5: & 0.0 & \\
\hline & Varasswidth & Point 6: & 0.0 & *DIVIO1 \\
\hline & & Point 7: & 0.0 & \#DIV/0! \\
\hline & & Point 8: & 0.0 & \\
\hline & & Point 9: & 0.0 & \\
\hline & & Point 10: & 0.0 & \\
\hline & & Point 11: & 0.0 & \\
\hline & & Point 12: & 0.0 & \\
\hline & & mean width: & \#DIV/0! & \\
\hline & & (see vegetation worksheet for species entered) & & \\
\hline & & sum of species: & 0.0 & \\
\hline & Vvegcomp & sum of $\mathrm{C}$ values: & 0.0 & \#DIV/0! \\
\hline & & mean coefficient of conservatism: & \#DIV/0! & \\
\hline & & \begin{tabular}{rr|} 
FQI: \\
\end{tabular} & \#DIV/0! & \\
\hline
\end{tabular}

Functional Capacity Indices are automatically populated from worksheet \#1.

\section{Function 5: Plant Community Resilience and Carbon Cycling}

Assessment model: FCI $=\sqrt{\left(\text { Minimum of Vout }, V_{\text {SUbout }}\right) \times \frac{\left[\frac{\left(\text { V UPUSE }+V_{\text {GRASSCONT }}+V_{\text {GRASSWIDTH }}\right)}{3}\right]+\left[\frac{\left(V_{\text {SED }}+V_{\text {SOM }}\right)}{2}\right]+V_{\text {VeGCOMP }}}{3}}$

Minimum of Vout \& Vsubout: 0.00

FCI derived from variable subindices calculated previously:

FCI $=\# \mathbf{D I V} / \mathbf{0}$ !

Worksheet for the variables (\#1) allows direct entry of metrics and re-calculation of the FCI's. Upon re-population of FCI worksheet above (\# 2), project scenarios are then summarized for necessary comparative analyses. 


\begin{tabular}{|c|c|c|c|c|c|}
\hline \multicolumn{6}{|l|}{ FCl/FCU Comparison worksheet } \\
\hline WAA name & \multicolumn{2}{|c|}{ Current Conditions } & \multicolumn{2}{|c|}{ Project Impacts } & \multirow[t]{2}{*}{ Mitigation target } \\
\hline Function & $\mathrm{FCl}$ & $\mathrm{FCU}$ & $\mathrm{FCl}$ & $\mathrm{FCU}$ & \\
\hline \multicolumn{6}{|l|}{ 1.Water Storage } \\
\hline \multicolumn{6}{|l|}{ 2.Ground Water Recharge } \\
\hline \multicolumn{6}{|l|}{ 3.Retain Particulates } \\
\hline \multicolumn{6}{|l|}{ 4.Remove, Convert, Seq. } \\
\hline \multicolumn{6}{|l|}{ 5.Plant Community-Carbon } \\
\hline \multicolumn{6}{|l|}{ 6a.Provide Faunal Habitat } \\
\hline 6b.Provide Faunal Habitat(complex) & & & & & \\
\hline
\end{tabular}




\section{Appendix C Reference Data and Supporting Documentation}

C-1: Reference site locations

C-2: Plant species records from reference data collection

C-3: Alternate methods for calculation of $\mathrm{V}$ vegcomp

C-4: Recharge Ratings for Soil Mapping Units

C-5: Reference data summaries

\section{Appendix C-1: Reference Site Locations}

\begin{tabular}{|c|c|c|c|c|c|c|}
\hline Site ID & $\begin{array}{l}\text { Wetland Area } \\
\text { (ha) }\end{array}$ & $\begin{array}{l}\text { Catchment Area } \\
\text { (ha) }\end{array}$ & $\begin{array}{l}\text { Physiographic } \\
\text { Region }\end{array}$ & Coordinates & County & State \\
\hline Gp01154 & 0.40 & 5.57 & Glaciated Plains & $-97.869726,47.247084$ & Steele & North Dakota \\
\hline Gp01156 & 0.73 & 1.75 & Glaciated Plains & $-98.888173,48.462823$ & Ramsey & North Dakota \\
\hline Gp01158 & 0.69 & 1.05 & Glaciated Plains & $-99.225735,48.601454$ & Towner & North Dakota \\
\hline Gp01160 & 0.98 & 2.06 & Glaciated Plains & $-99.192988,48.543605$ & Towner & North Dakota \\
\hline Gp01162 & 1 & I & Glaciated Plains & $-98.894018,48.165188$ & Ramsey & North Dakota \\
\hline Gp02173 & 0.56 & 2.51 & Glaciated Plains & $-97.659277,47.565208$ & Steele & North Dakota \\
\hline Gp02174 & 0.33 & 1.12 & Glaciated Plains & $-97.663800,47.558342$ & Steele & North Dakota \\
\hline Gp02175 & 0.60 & 0.80 & Glaciated Plains & $-97.656455,47.606315$ & Steele & North Dakota \\
\hline Gp02177 & 0.32 & 0.76 & Glaciated Plains & $-97.657525,47.606075$ & Steele & North Dakota \\
\hline Gp02179 & 1.17 & 1.53 & Glaciated Plains & $-98.124622,47.510293$ & Griggs & North Dakota \\
\hline Gp03069 & 0.59 & 0.99 & Glaciated Plains & $-97.991613,46.344491$ & Ransom & North Dakota \\
\hline Gp03070 & 0.63 & 2.59 & Glaciated Plains & $-98.093824,46.381830$ & La Moure & North Dakota \\
\hline Gp03071 & 1.01 & 1.06 & Glaciated Plains & $-98.012036,46.356369$ & Ransom & North Dakota \\
\hline Gp03107 & 0.33 & 0.42 & Glaciated Plains & $-97.697815,46.315553$ & Ransom & North Dakota \\
\hline Gp04123 & 0.22 & 0.61 & Glaciated Plains & $-98.620532,45.941250$ & Dickey & North Dakota \\
\hline Gp04125 & 0.97 & 2.63 & Glaciated Plains & $-98.374232,45.904816$ & Brown & South Dakota \\
\hline Gp04126 & 0.55 & 1.85 & Glaciated Plains & $-98.380386,45.906802$ & Brown & South Dakota \\
\hline Gp04129 & 0.53 & 2.19 & Glaciated Plains & $-98.557916,45.377180$ & Brown & South Dakota \\
\hline Gp04139 & 2.89 & 4.27 & Glaciated Plains & $-98.370227,45.727293$ & Brown & South Dakota \\
\hline Gp05089 & 1.26 & 1.03 & Glaciated Plains & $-98.367153,44.363994$ & Beadle & South Dakota \\
\hline Gp05091 & 1.05 & 1.14 & Glaciated Plains & $-98.381221,44.381285$ & Beadle & South Dakota \\
\hline Gp05092 & 0.93 & 2.78 & Glaciated Plains & $-97.952038,44.395294$ & Beadle & South Dakota \\
\hline
\end{tabular}




\begin{tabular}{|c|c|c|c|c|c|c|}
\hline Site ID & $\begin{array}{l}\text { Wetland Area } \\
\text { (ha) }\end{array}$ & $\begin{array}{l}\text { Catchment Area } \\
\text { (ha) }\end{array}$ & $\begin{array}{l}\text { Physiographic } \\
\text { Region }\end{array}$ & Coordinates & County & State \\
\hline Gp05093 & - 0.84 & 3.29 & Glaciated Plains & $-98.389190,44.373027$ & Beadle & South Dakota \\
\hline Gp05095 & 2.25 & 3.23 & Glaciated Plains & $-98.404513,44.382435$ & Beadle & South Dakota \\
\hline Gp06117 & 0.65 & 2.19 & Glaciated Plains & $-97.666019,43.820488$ & Hanson & South Dakota \\
\hline Gp06118 & 0.41 & 2.03 & Glaciated Plains & $-97.733573,43.475203$ & Hutchinson & South Dakota \\
\hline Gp06119 & 0.78 & 2.36 & Glaciated Plains & $-98.045269,43.457228$ & Hutchinson & South Dakota \\
\hline Gp06121 & 1.07 & 1.41 & Glaciated Plains & $-97.657462,43.395257$ & Hutchinson & South Dakota \\
\hline Gp06127 & 1.37 & 4.16 & Glaciated Plains & $-97.566652,43.275806$ & Hutchinson & South Dakota \\
\hline Gp07073 & 0.36 & 0.54 & Glaciated Plains & $-97.369270,46.024901$ & Sargent & North Dakota \\
\hline Gp07075 & 0.60 & 1.46 & Glaciated Plains & $-97.698443,46.320419$ & Ransom & North Dakota \\
\hline Gp07077 & 0.56 & 0.88 & Glaciated Plains & $-97.698405,46.316972$ & Ransom & North Dakota \\
\hline Gp07078 & 0.38 & 1.11 & Glaciated Plains & $-97.697079,46.329530$ & Ransom & North Dakota \\
\hline Gp08040 & 0.52 & 0.54 & Glaciated Plains & $-97.087039,45.794522$ & Roberts & South Dakota \\
\hline Gp08041 & 1.00 & 1.38 & Glaciated Plains & $-96.321347,45.335455$ & Big Stone & Minnesota \\
\hline Gp08044 & 1.09 & 1.56 & Glaciated Plains & $-96.938822,45.873293$ & Roberts & South Dakota \\
\hline Gp08045 & 1.12 & 2.00 & Glaciated Plains & $-96.386593,45.338930$ & Big Stone & Minnesota \\
\hline Gp08047 & 0.53 & 0.42 & Glaciated Plains & $-97.013236,45.858266$ & Roberts & South Dakota \\
\hline Gp09028 & 1.00 & 1.39 & Glaciated Plains & $-95.734046,45.203539$ & Swift & Minnesota \\
\hline Gp09030 & 1.26 & 0.62 & Glaciated Plains & $-95.724323,45.195915$ & Swift & Minnesota \\
\hline Gp09031 & 0.62 & 0.44 & Glaciated Plains & $-96.115864,45.582705$ & Stevens & Minnesota \\
\hline Gp09033 & 1.66 & 0.17 & Glaciated Plains & $-95.461713,45.348121$ & Swift & Minnesota \\
\hline Gp09035 & 0.64 & 0.18 & Glaciated Plains & $-96.063539,45.181967$ & Swift & Minnesota \\
\hline Gp09037 & 0.76 & 1.88 & Glaciated Plains & $-96.101270,45.281957$ & Swift & Minnesota \\
\hline Gp10019 & 0.85 & 2.28 & Glaciated Plains & $-95.755631,44.082834$ & Murray & Minnesota \\
\hline Gp10021 & 1.11 & 0.54 & Glaciated Plains & $-95.760383,44.086219$ & Murray & Minnesota \\
\hline Gp10024 & 1.15 & 1.73 & Glaciated Plains & $-94.747671,44.197464$ & Brown & Minnesota \\
\hline Gp10026 & 2.20 & 2.47 & Glaciated Plains & $-96.078340,45.190547$ & Swift & Minnesota \\
\hline Gp11006 & 1 & 1 & Glaciated Plains & $-94.058688,43.326855$ & Kossuth & lowa \\
\hline Gp11011 & 1 & 1 & Glaciated Plains & $-94.058155,43.322744$ & Kossuth & lowa \\
\hline Gp11014 & 1.08 & 0.91 & Glaciated Plains & $-95.104355,43.680174$ & Jackson & Minnesota \\
\hline Gp11015 & 0.31 & 0.93 & Glaciated Plains & $-95.094004,43.675057$ & Jackson & Minnesota \\
\hline Gp11016 & 0.92 & 1.08 & Glaciated Plains & $-95.200725,43.520696$ & Jackson & Minnesota \\
\hline Gp11017 & 0.38 & 0.57 & Glaciated Plains & $-95.079922,43.379312$ & Dickinson & lowa \\
\hline Gp12001 & 0.47 & 2.00 & Glaciated Plains & $-94.826050,43.210724$ & Palo Alto & lowa \\
\hline Gp12004 & 1.10 & 0.84 & Glaciated Plains & $-94.887889,43.172451$ & Palo Alto & lowa \\
\hline Gp12008 & 1.16 & 0.37 & Glaciated Plains & $-94.924235,43.193732$ & Clay & lowa \\
\hline Gp12009 & 1.55 & 2.31 & Glaciated Plains & $-94.830035,43.218451$ & Palo Alto & lowa \\
\hline Mc01200 & 0.48 & 3.76 & Missouri Coteau & $-104.177053,48.886492$ & Sheridan & Montana \\
\hline Mc01202 & 0.96 & 4.02 & Missouri Coteau & $-104.075730,48.878048$ & Sheridan & Montana \\
\hline Mc01204 & 0.37 & 2.77 & Missouri Coteau & $-104.301738,48.946608$ & Sheridan & Montana \\
\hline Mc01205 & 0.77 & 10.03 & Missouri Coteau & $-104.306796,48.934639$ & Sheridan & Montana \\
\hline Mc01207 & 0.80 & 2.32 & Missouri Coteau & $-104.150639,48.781164$ & Sheridan & Montana \\
\hline Mc02190 & 0.19 & 1.70 & Missouri Coteau & $-102.810720,48.727832$ & Burke & North Dakota \\
\hline Mc02192 & 0.99 & 3.37 & Missouri Coteau & $-102.905033,48.776115$ & Burke & North Dakota \\
\hline Mc02193 & 0.39 & 2.09 & Missouri Coteau & $-102.905906,48.774934$ & Burke & North Dakota \\
\hline Mc02194 & 1.39 & 3.02 & Missouri Coteau & $-102.896675,48.772313$ & Burke & North Dakota \\
\hline Mc02196 & 0.77 & 3.28 & Missouri Coteau & $-103.164098,48.651429$ & Divide & North Dakota \\
\hline Mc02198 & 0.70 & 2.50 & Missouri Coteau & $-103.216865,48.714551$ & Divide & North Dakota \\
\hline
\end{tabular}




\begin{tabular}{|c|c|c|c|c|c|c|}
\hline Site ID & $\begin{array}{l}\text { Wetland Area } \\
\text { (ha) }\end{array}$ & $\begin{array}{l}\text { Catchment Area } \\
\text { (ha) }\end{array}$ & $\begin{array}{l}\text { Physiographic } \\
\text { Region }\end{array}$ & Coordinates & County & State \\
\hline Mc03184 & 0.70 & 2.77 & Missouri Coteau & $-101.814554,48.090283$ & Ward & \begin{tabular}{|l} 
North Dakota \\
\end{tabular} \\
\hline Mc03185 & 0.52 & 4.05 & Missouri Coteau & $-101.796998,48.157245$ & Ward & North Dakota \\
\hline Mc03187 & 0.30 & 0.89 & Missouri Coteau & $-101.807216,48.148743$ & Ward & North Dakota \\
\hline Mc03189 & 0.80 & 3.10 & Missouri Coteau & $-102.039307,48.251919$ & Mountrail & North Dakota \\
\hline Mc04164 & 0.22 & 1.05 & Missouri Coteau & $-100.402225,47.691215$ & Sheridan & North Dakota \\
\hline Mc04165 & 0.92 & 3.75 & Missouri Coteau & $-100.611316,47.578242$ & Sheridan & North Dakota \\
\hline Mc04166 & 0.64 & 1.37 & Missouri Coteau & $-100.598787,47.536594$ & Sheridan & North Dakota \\
\hline Mc04169 & 0.47 & 0.70 & Missouri Coteau & $-100.813535,47.361395$ & McLean & North Dakota \\
\hline Mc04171 & 0.95 & 5.04 & Missouri Coteau & $-100.808105,47.379082$ & McLean & North Dakota \\
\hline Mc05142 & 0.39 & 0.63 & Missouri Coteau & $-99.208544,47.062157$ & Stutsman & North Dakota \\
\hline Mc05143 & 0.81 & 2.43 & Missouri Coteau & $-99.215057,47.060895$ & Stutsman & North Dakota \\
\hline Mc05144 & 0.66 & 0.99 & Missouri Coteau & $-99.294081,47.105874$ & Stutsman & North Dakota \\
\hline Mc05146 & 1.72 & 14.57 & Missouri Coteau & $-99.345495,46.955645$ & Stutsman & North Dakota \\
\hline Mc05149 & 1.68 & 7.56 & Missouri Coteau & $-99.343697,46.959457$ & Stutsman & North Dakota \\
\hline Mc06131 & 0.66 & 2.53 & Missouri Coteau & $-99.171700,45.831519$ & McPherson & South Dakota \\
\hline Mc06132 & 1.07 & 1.93 & Missouri Coteau & $-99.174055,45.830327$ & McPherson & South Dakota \\
\hline Mc06133 & 0.35 & 0.89 & Missouri Coteau & $-99.117014,45.880705$ & McPherson & South Dakota \\
\hline Mc06134 & 0.38 & 0.77 & Missouri Coteau & $-99.116665,45.879562$ & McPherson & South Dakota \\
\hline Mc06135 & 0.61 & 1.48 & Missouri Coteau & $-99.312962,45.490479$ & Edmunds & South Dakota \\
\hline Mc06136 & 0.62 & 0.74 & Missouri Coteau & $-99.308469,45.491400$ & Edmunds & South Dakota \\
\hline Mc07137 & 1.49 & 3.21 & Missouri Coteau & $-99.223572,45.493237$ & Edmunds & South Dakota \\
\hline Mc07138 & 1.04 & 3.31 & Missouri Coteau & $-99.241802,45.499276$ & Edmunds & South Dakota \\
\hline Mc08097 & 0.57 & 4.91 & Missouri Coteau & $-98.870088,44.185632$ & Jerauld & South Dakota \\
\hline Mc08098 & 0.56 & 0.87 & Missouri Coteau & $-98.753307,44.094541$ & Jerauld & South Dakota \\
\hline Mc08102 & 1.01 & 1.30 & Missouri Coteau & $-99.160210,44.387428$ & \begin{tabular}{|l|} 
Hand \\
\end{tabular} & South Dakota \\
\hline Mc08103 & 1 & 1 & Missouri Coteau & $-98.882003,44.376326$ & Hand & South Dakota \\
\hline Mc09108 & 0.77 & 2.67 & Missouri Coteau & $-98.496148,43.655741$ & Aurora & South Dakota \\
\hline Mc09110 & 1.91 & 3.69 & Missouri Coteau & $-98.524694,43.709679$ & Aurora & South Dakota \\
\hline Mc09111 & 0.31 & 2.63 & Missouri Coteau & $-98.493406,43.656305$ & Aurora & South Dakota \\
\hline Mc09113 & 2.45 & 3.43 & Missouri Coteau & $-98.541780,43.648981$ & Aurora & South Dakota \\
\hline Mc09115 & 2.39 & 5.22 & Missouri Coteau & $-98.580399,43.687035$ & Aurora & South Dakota \\
\hline Pc01049 & 0.46 & 1.33 & Prairie Coteau & $-97.475097,45.496158$ & Day & South Dakota \\
\hline Pc01052 & 1.26 & 1.88 & Prairie Coteau & $-97.505960,45.770387$ & Marshall & South Dakota \\
\hline Pc01053 & 0.55 & 0.52 & Prairie Coteau & $-97.245775,45.551641$ & Day & South Dakota \\
\hline Pc01054 & 0.50 & 1.00 & Prairie Coteau & $-97.245306,45.549824$ & Day & South Dakota \\
\hline Pc01057 & 0.43 & 0.67 & Prairie Coteau & $-97.536072,45.594863$ & Marshall & South Dakota \\
\hline Pc02059 & 0.76 & 1.19 & Prairie Coteau & $-97.680779,45.103757$ & Clark & South Dakota \\
\hline Pc02061 & 0.41 & 1.40 & Prairie Coteau & $-97.581353,45.139652$ & Clark & South Dakota \\
\hline Pc02063 & 2.52 & 1.97 & Prairie Coteau & $-97.681934,45.104976$ & Clark & South Dakota \\
\hline Pc02065 & 1.47 & 3.22 & Prairie Coteau & $-97.528109,45.098127$ & Clark & South Dakota \\
\hline Pc02067 & 0.67 & 3.04 & Prairie Coteau & $-97.496238,45.011356$ & Clark & South Dakota \\
\hline Pc03079 & 0.41 & 1.52 & Prairie Coteau & $-97.062295,44.337194$ & Brookings & South Dakota \\
\hline Pc03081 & 1.03 & 2.87 & Prairie Coteau & $-97.069529,44.350614$ & Brookings & South Dakota \\
\hline Pc03083 & 1.88 & 1.79 & Prairie Coteau & $-97.190796,44.286948$ & Kingsbury & South Dakota \\
\hline Pc03085 & 0.73 & 1.89 & Prairie Coteau & $-97.021551,44.471610$ & Brookings & South Dakota \\
\hline Pc03087 & 0.66 & 0.71 & Prairie Coteau & $-96.497926,44.717703$ & Deuel & South Dakota \\
\hline GpS501 & 0.38 & 1 & Glaciated Plains & $-98.677384,47.192244$ & Stutsman & North Dakota \\
\hline
\end{tabular}




\begin{tabular}{|c|c|c|c|c|c|c|}
\hline Site ID & $\begin{array}{l}\text { Wetland Area } \\
\text { (ha) }\end{array}$ & $\begin{array}{l}\text { Catchment Area } \\
\text { (ha) }\end{array}$ & $\begin{array}{l}\text { Physiographic } \\
\text { Region }\end{array}$ & Coordinates & County & State \\
\hline GpS502 & 0.27 & 4.80 & Glaciated Plains & $-98.677137,47.231362$ & Stutsman & North Dakota \\
\hline GpS503 & 1.26 & 11.40 & Glaciated Plains & $-98.677725,47.232832$ & Stutsman & North Dakota \\
\hline McS504 & 0.38 & 1 & Missouri Coteau & $-99.058001,47.122865$ & Stutsman & North Dakota \\
\hline McS505 & 0.91 & 1 & Missouri Coteau & $-99.058421,47.121750$ & Stutsman & North Dakota \\
\hline McS506 & 0.03 & 1 & Missouri Coteau & $-99.055956,47.121021$ & Stutsman & North Dakota \\
\hline McS507 & 0.02 & 1 & Missouri Coteau & $-99.055748,47.121386$ & Stutsman & North Dakota \\
\hline McS508 & 0.70 & 6.30 & Missouri Coteau & $-99.084231,46.978357$ & Stutsman & North Dakota \\
\hline McS509 & 0.42 & 1 & Missouri Coteau & $-99.068026,46.977423$ & Stutsman & North Dakota \\
\hline McS510 & 0.19 & 1 & Missouri Coteau & $-99.018863,46.907433$ & Stutsman & North Dakota \\
\hline McS511 & 0.60 & 1 & Missouri Coteau & $-99.018880,46.908512$ & Stutsman & North Dakota \\
\hline GpS512 & 0.18 & 2.10 & Glaciated Plains & $-98.775471,46.944998$ & Stutsman & North Dakota \\
\hline GpS513 & 0.16 & 1 & Glaciated Plains & $-98.771934,46.942469$ & Stutsman & North Dakota \\
\hline GpS514 & 0.11 & 1 & Glaciated Plains & $-98.757195,46.921435$ & Stutsman & North Dakota \\
\hline GpS515 & 1.04 & 1 & Glaciated Plains & $-98.755320,46.924408$ & Stutsman & North Dakota \\
\hline GpS516 & 0.85 & 1 & Glaciated Plains & $-98.754051,46.924128$ & Stutsman & North Dakota \\
\hline GpS517 & 1.48 & 1 & Glaciated Plains & $-98.574890,46.777377$ & Stutsman & North Dakota \\
\hline GpS518 & 0.15 & 0.90 & Glaciated Plains & $-98.947834,46.817708$ & Stutsman & North Dakota \\
\hline GpS519 & 1.91 & 10.90 & Glaciated Plains & $-98.951085,46.817602$ & Stutsman & North Dakota \\
\hline GpS520 & 0.27 & 1 & Glaciated Plains & $-98.928207,46.906024$ & Stutsman & North Dakota \\
\hline GpS521 & 0.23 & 1 & Glaciated Plains & $-98.928207,46.906024$ & Stutsman & North Dakota \\
\hline GpS522 & 0.21 & 1 & Glaciated Plains & $-98.929106,46.904174$ & Stutsman & North Dakota \\
\hline GpS523 & 0.84 & 1 & Glaciated Plains & $-98.793899,47.007395$ & Stutsman & North Dakota \\
\hline GPS524 & 0.77 & 1 & Glaciated Plains & $-98.822087,47.007235$ & Stutsman & North Dakota \\
\hline GpS525 & 0.85 & 1 & Glaciated Plains & $-98.822693,47.007235$ & Stutsman & North Dakota \\
\hline GpS526 & 0.74 & 4.00 & Glaciated Plains & $-99.011174,48.239290$ & Ramsey & North Dakota \\
\hline GpS527 & 2.98 & 10.44 & Glaciated Plains & $-99.044923,48.207361$ & Ramsey & North Dakota \\
\hline GpS528 & 0.38 & 3.98 & Glaciated Plains & $-99.050616,48.276085$ & Ramsey & North Dakota \\
\hline GpS529 & 1.46 & 3.89 & Glaciated Plains & $-99.043124,48.245247$ & Ramsey & North Dakota \\
\hline GpS530 & 2.82 & 12.20 & Glaciated Plains & $-98.990674,48.248151$ & Ramsey & North Dakota \\
\hline GpS531 & 1 & 1 & Glaciated Plains & $-99.045662,48.206308$ & Ramsey & North Dakota \\
\hline GpS532 & 1.3 & 13.00 & Glaciated Plains & $-99.035885,48.236972$ & Ramsey & North Dakota \\
\hline GpS533 & 1.66 & 7.08 & Glaciated Plains & $-99.023163,48.245585$ & Ramsey & North Dakota \\
\hline GpS534 & 0.92 & 6.80 & Glaciated Plains & $-99.033819,48.208606$ & Ramsey & North Dakota \\
\hline GpS535 & 2.16 & 7.72 & Glaciated Plains & $-99.031114,48.208931$ & Ramsey & North Dakota \\
\hline GpS536 & 0.67 & 4.28 & Glaciated Plains & $-99.006891,48.237661$ & Ramsey & North Dakota \\
\hline GpS537 & 0.17 & 1.92 & Glaciated Plains & $-99.029834,48.229740$ & Ramsey & North Dakota \\
\hline GpS538 & 0.45 & 4.25 & Glaciated Plains & $-99.021007,48.211326$ & Ramsey & North Dakota \\
\hline GpS539 & 1.3 & 13.50 & Glaciated Plains & $-99.006100,48.271255$ & Ramsey & North Dakota \\
\hline GpS540 & 3.7 & 27.00 & Glaciated Plains & $-101.094151,48.248465$ & Ward & North Dakota \\
\hline GpS541 & 1.3 & 9.50 & Glaciated Plains & $-101.067342,48.232070$ & Ward & North Dakota \\
\hline GpS542 & 0.9 & 6.00 & Glaciated Plains & $-101.096381,48.249972$ & Ward & North Dakota \\
\hline GpS543 & 1.34 & 9.40 & Glaciated Plains & $-101.061976,48.234920$ & Ward & North Dakota \\
\hline GpS544 & 0.6 & 7.70 & Glaciated Plains & $-101.063909,48.234427$ & Ward & North Dakota \\
\hline GPS545 & 0.5 & 4.90 & Glaciated Plains & $-101.118196,48.254332$ & Ward & North Dakota \\
\hline GpS546 & 3.5 & 11.40 & Glaciated Plains & $-95.828947,45.349220$ & Swift & Minnesota \\
\hline GpS547 & 0.71 & 6.96 & Glaciated Plains & $-94.769686,45.021922$ & Kandiyohi & Minnesota \\
\hline GpS548 & 0.57 & 4.18 & Glaciated Plains & $-94.790081,45.115458$ & Kandiyohi & Minnesota \\
\hline
\end{tabular}




\begin{tabular}{||l|l|l|l|l|l|l||}
\hline Site ID & $\begin{array}{l}\text { Wetland Area } \\
\text { (ha) }\end{array}$ & $\begin{array}{l}\text { Catchment Area } \\
\text { (ha) }\end{array}$ & $\begin{array}{l}\text { Physiographic } \\
\text { Region }\end{array}$ & Coordinates & County & State \\
\hline \hline GpS549 & 5.57 & 15.20 & Glaciated Plains & $-94.895430,45.002727$ & Kandiyohi & Minnesota \\
\hline McS550 & 0.65 & 4.34 & Missouri Coteau & $-107.458018,48.596399$ & Phillips & Montana \\
\hline McS551 & 0.77 & 2.39 & Missouri Coteau & $-103.596532,48.902062$ & Divide & North Dakota \\
\hline McS552 & 1.13 & 12.27 & Missouri Coteau & $-103.661490,48.819494$ & Divide & North Dakota \\
\hline GpS553 & 1.3 & 5.10 & Glaciated Plains & $-111.160051,48.667259$ & Liberty & Montana \\
\hline GpS554 & 0.69 & 7.29 & Glaciated Plains & $-111.160051,48.667259$ & Liberty & Montana \\
\hline GpS555 & 0.77 & 3.48 & Glaciated Plains & $-95.038844,43.385078$ & Dickinson & lowa \\
\hline GpS556 & 0.36 & 1.66 & Glaciated Plains & $-95.066935,43.369608$ & Dickinson & lowa \\
\hline GpS557 & 1.74 & 6.70 & Glaciated Plains & $-95.064827,43.368962$ & Dickinson & lowa \\
\hline GpS558 & 1.13 & $/$ & Glaciated Plains & $-94.992027,43.449752$ & Dickinson & lowa \\
\hline GpS559 & 2.79 & 8.14 & Glaciated Plains & $-94.986786,43.451609$ & Dickinson & lowa \\
\hline GpS560 & 0.4 & 2.70 & Glaciated Plains & $-94.873001,43.438466$ & Emmet & lowa \\
\hline GpS561 & 4.4 & 7.70 & Glaciated Plains & $-93.642704,42.695957$ & Wright & lowa \\
\hline GpS562 & 0.5 & 8.70 & Glaciated Plains & $-93.645556,42.718942$ & Wright & lowa \\
\hline GpS563 & 0.29 & 1.64 & Glaciated Plains & $-98.734183,46.840657$ & Stutsman & North Dakota \\
\hline GpS566 & 0.4 & 3.90 & Glaciated Plains & $-98.847811,47.938867$ & Benson & North Dakota \\
\hline GpS567 & 0.4 & 3.80 & Glaciated Plains & $-98.846581,47.938524$ & Benson & North Dakota \\
\hline
\end{tabular}

\section{Appendix C-2: Plant Species Records from Reference Data Collection}

\begin{tabular}{|c|c|c|c|}
\hline Scientific Name & Common Synonomy & Common Name & \begin{tabular}{|l|} 
Coefficient of \\
Conservatism
\end{tabular} \\
\hline Achillea millefolium & & Common Yarrow & 3 \\
\hline Acorus calamus & & Calamus & 0 \\
\hline Agalinis tenuifolia & & Slenderleaf False Foxglove & 8 \\
\hline Agropyron caninum & Agropyron trachycaulum & Slender Wheatgrass & 6 \\
\hline Agropyron cristatum & & Crested Wheatgrass & 0 \\
\hline Agropyron dasystachyum & & Thickspike Wheatgrass & 7 \\
\hline Agropyron elongatum & Elytrigia elongata & Tall Wheatgrass & 0 \\
\hline Agropyron intermedium & Elytrigia intermedia & Intermediate Wheatgrass & 0 \\
\hline Agropyron repens & Elytrigia repens & Quackgrass & 0 \\
\hline Agropyron smithii & Pascopyrum smithii & Western Wheatgrass & 4 \\
\hline Agropyron spicatum & & Bluebunch Wheatgrass & 9 \\
\hline Agropyron spp. & & Wheatgrass & UK \\
\hline Agrostis hyemalis & & Winter Bentgrass & 1 \\
\hline Agrostis scabra & & Rough Bentgrass & 1 \\
\hline Agrostis stolonifera & & Creeping Bentgrass & 0 \\
\hline Alisma gramineum & & Narrowleaf Water Plantain & 2 \\
\hline Alisma plantago-aquatica & Alisma subcordatum, Alisma triviale & Large-flowered Water Plantain & 2 \\
\hline Allium canadense & & Wild Onion & 8 \\
\hline Allium stellatum & & Pink Wild Onion & 7 \\
\hline Alopecurus aequalis & & Shortawn Foxtail & 2 \\
\hline Alopecurus arundinaceus & & Creeping Foxtail & 0 \\
\hline Alopecurus carolinianus & & Carolina Foxtail & 0 \\
\hline
\end{tabular}




\begin{tabular}{|c|c|c|c|}
\hline Scientific Name & Common Synonomy & Common Name & $\begin{array}{l}\text { Coefficient of } \\
\text { Conservatism }\end{array}$ \\
\hline Amaranthus retroflexus & & Rough Pigweed & 0 \\
\hline Amaranthus sp. & & Pigweed & 0 \\
\hline Ambrosia artemisiifolia & & Common Ragweed & 0 \\
\hline Ambrosia psilostachya & & Western Ragweed & 2 \\
\hline Ambrosia sp. & & Ragweed & UK \\
\hline Ambrosia trifida & & Giant Ragweed & 0 \\
\hline Ammania auriculata & & Ammania & 2 \\
\hline Amorpha canescens & & Lead Plant & 9 \\
\hline Amorpha fruticosa & & False Indigo & 4 \\
\hline Andropogon gerardii & & Big Bluestem & 5 \\
\hline Anemone canadensis & & Canadian Anemone & 4 \\
\hline Anemone cylindrica & & Candle Anemone & 7 \\
\hline Anemone patens & & Pasque Flower & 9 \\
\hline Antennaria sp. & & Pussytoes & UK \\
\hline Apocynum cannabinum & & Indian Hemp Dogbane & 4 \\
\hline Apocynum sibiricum & & Prairie Dogbane & 4 \\
\hline Aristida purpurea & & Red Three-awn & UK \\
\hline Artemisia absinthium & & Wormwood & 0 \\
\hline Artemisia biennis & & biennial wormwood & 0 \\
\hline Artemisia dracunculus & & Silky Wormwood & 4 \\
\hline Artemisia frigida & & Prairie Sagewort & 4 \\
\hline Artemisia ludoviciana & & White Sage & 3 \\
\hline Asclepias incarnata & & Swamp Milkweed & 5 \\
\hline Asclepias ovalifolia & & Ovalleaf Milkweed & 9 \\
\hline Asclepias sp. & & Milkweed & UK \\
\hline Asclepias speciosa & & Showy Milkweed & 4 \\
\hline Asclepias syriaca & & Common Milkweed & 0 \\
\hline Asclepias verticillata & & Whorled Milkweed & 3 \\
\hline Aster brachyactis & Brachyactis ciliata & Rayless Aster & 0 \\
\hline Aster ericoides & & White Aster & 2 \\
\hline Aster falcatus & & White Prairie Aster & 4 \\
\hline Aster novae-angliae & & New England aster & 8 \\
\hline Aster simplex & Aster lanceolatus & Panicled Aster & 3 \\
\hline Aster sp. & & Aster & UK \\
\hline Astragalus agrestis & & Field Milkvetch & 6 \\
\hline Astragalus canadensis & & Canadian milkvetch & 5 \\
\hline Atriplex subspicata & & Spearscale & 2 \\
\hline Avena sativa & Avena fatua var. sativa & Wild Oats & 0 \\
\hline Azolla mexicana & & Mosquito Fern & 10 \\
\hline Bacopa rotundifolia & & Water Hyssop & 3 \\
\hline Beckmannia syzigachne & & American Sloughgrass & 1 \\
\hline Bidens cernua & & Nodding Beggartick & 3 \\
\hline Bidens comosa & & Swamp Tickseed & 2 \\
\hline Bidens frondosa & & Devil's Beggartick & 1 \\
\hline Bidens sp. & & Beggar Ticks & 2 \\
\hline Boltonia asteroides & & White Boltonia & 3 \\
\hline Bouteloua curtipendula & & Sideoats Grama & 5 \\
\hline
\end{tabular}




\begin{tabular}{|c|c|c|c|}
\hline Scientific Name & Common Synonomy & Common Name & $\begin{array}{l}\text { Coefficient of } \\
\text { Conservatism }\end{array}$ \\
\hline$\overline{\text { Bouteloua gracilis }}$ & & Blue Grama & $\mid 7$ \\
\hline Brassica kaber & & Charlock & 0 \\
\hline Brassica kaber & Sinapis arvensis & Charlock & 0 \\
\hline Brassicaceae & & Mustard Family & UK \\
\hline Bromus inermis & & Smooth Brome & 0 \\
\hline Bromus japonicus & & Japanese Brome & 0 \\
\hline Bromus tectorum & & Downy Brome & 0 \\
\hline Calamagrostis canadensis & & Bluejoint & 5 \\
\hline Calamagrostis inexpansa & & Narrow Spiked Reedgrass & 5 \\
\hline Calamagrostis stricta & & Slimstem Reedgrass & 5 \\
\hline Calamovilfa Iongifolia & & Prairie Sandreed & 5 \\
\hline Calystegia sepium & & Hedge Bindweed & 0 \\
\hline Capsella bursa-pastoris & & Shepherd's Purse & 0 \\
\hline Carduus nutans & & Nodding Thistle & 0 \\
\hline Carex alopecoidea & & Foxtail Sedge & 7 \\
\hline Carex aquatilis & & Water Sedge & 10 \\
\hline Carex atherodes & & Slough Sedge & 4 \\
\hline Carex bebbii & & Bebb's Sedge & 8 \\
\hline Carex brevior & & fescue sedge & 4 \\
\hline Carex buxbaumii & & Buxbaum's sedge & 10 \\
\hline Carex eleocharis & & Needleleaf Sedge & 4 \\
\hline Carex filifolia & & Threadleaf Sedge & 7 \\
\hline Carex granularis & & Meadow Sedge & 6 \\
\hline Carex hallii & & Deer Sedge & 10 \\
\hline Carex heliophila & & Sun Sedge & 7 \\
\hline Carex hystericina & & Bottlebrush Sedge & 7 \\
\hline Carex interior & & Interior Sedge & 10 \\
\hline Carex lacustris & & Hairy Sedge & 6 \\
\hline Carex laeviconica & & Smoothcone Sedge & 6 \\
\hline Carex lanuginosa & & Woolly Sedge & 4 \\
\hline Carex praegracilis & & Clustered-field Sedge & 5 \\
\hline Carex rostrata & & Beaked Sedge & 8 \\
\hline Carex sartwellii & & Sartwell's sedge & 5 \\
\hline Carex sp. 1 & & Sedge & UK \\
\hline Carex sp.2 & & Sedge & UK \\
\hline Carex sp.3 & & Sedge & UK \\
\hline Carex spp. & & Sedge & 3 \\
\hline Carex stricta & & Tussock Sedge & 10 \\
\hline Carex sychnocephala & & Manyhead Sedge & 7 \\
\hline Carex vulpinoidea & & Fox Sedge & 2 \\
\hline Carum carvi & & Caraway & 0 \\
\hline Centaurium pulchellum & & Branched Centuary & 0 \\
\hline Cerastium brachypodum & & Nodding Chickweed & 1 \\
\hline Ceratophyllum demersum & & Coontail & 4 \\
\hline Chara spp. & & Muskgrass & UK \\
\hline Chenopodium album & & Lamb's Quarters & 0 \\
\hline Chenopodium rubrum & & Alkali Blite & 2 \\
\hline
\end{tabular}




\begin{tabular}{|c|c|c|c|}
\hline Scientific Name & Common Synonomy & Common Name & $\begin{array}{l}\text { Coefficient of } \\
\text { Conservatism }\end{array}$ \\
\hline Chenopodium sp. & & Goosefoot & UK \\
\hline Chrysopsis villosa & & Hairy False Goldenaster & 3 \\
\hline Cicuta maculata & & Common Water Hemlock & 4 \\
\hline Cirsium arvense & & Canada Thistle & 0 \\
\hline Cirsium flodmanii & & Flodman's Thistle & 5 \\
\hline Cirsium vulgare & & Bull Thistle & 0 \\
\hline Convolvulus arvensis & & Field Bindweed & 0 \\
\hline Conyza canadensis & & Canadian Horseweed & 0 \\
\hline Coreopsis tinctoria & & Plains Coreopsis & 3 \\
\hline Cornus sp. & & Dogwood & UK \\
\hline Cornus stolonifera & Cornus sericea & Red Osier Dogwood & 0 \\
\hline Crataegus rotundifolia & Crataegus chrysocarpa & Northern Hawthorn & 0 \\
\hline Crepis runcinata & & Hawksbeard & 8 \\
\hline Cyperus acuminatus & & tapertip flatsedge & 2 \\
\hline Cyperus aristatus & & Awned Cypress & 2 \\
\hline Cyperus erythrorhizos & & Redrooted Cyperus & 2 \\
\hline Cyperus esculentus & & Yellow Nutsedge & 0 \\
\hline Cyperus odoratus & & Fragrant Flatsedge & 2 \\
\hline Cyperus sp. & & Flatsedge & UK \\
\hline Cypripedium sp. & & Lady's-slipper & UK \\
\hline Dactylis glomerata & & Durango root & 0 \\
\hline Dalea candida & & White Prairieclover & 8 \\
\hline Dalea purpurea & & Purple Prairie Clover & 8 \\
\hline Descurainia sophia & & Flixweed & 0 \\
\hline Dichanthelium oligosanthes & & Scribner Rosette Grass & 6 \\
\hline Digitaria sp. & & Crabgrass & 0 \\
\hline Distichlis spicata & & Inland Saltgrass & 2 \\
\hline Echinacea angustifolia & & Purple Coneflower & 7 \\
\hline Echinochloa crusgalli & & Barnyard Grass & 0 \\
\hline Elaeagnus angustifolia & & Russian Olive & 0 \\
\hline Elaeagnus commutata & & Silverberry & 5 \\
\hline Eleocharis acicularis & & Needle Spikerush & 3 \\
\hline Eleocharis compressa & & Flatstem Spikerush & 8 \\
\hline Eleocharis erythropoda & & Bald Spikerush & 2 \\
\hline Eleocharis obtusa var. ovata & Eleocharis engelmannii & Engelmann's spikerush, blunt spikesedge & 2 \\
\hline Eleocharis palustris & Eleocharis macrostachya & Common Spikerush & 4 \\
\hline Eleocharis smallii & & Small's Spikerush & 4 \\
\hline Eleocharis sp. & & Spikerush & UK \\
\hline Eleocharis spp. & & Spikerush & UK \\
\hline Ellisia nyctelea & & Waterpod & 0 \\
\hline Elymus canadensis & & Canada wildrye & 3 \\
\hline Epilobium ciliatum & & Fringed Willowherb & 3 \\
\hline Epilobium leptophyllum & & Narrowleaf Willowherb & 6 \\
\hline Epilobium sp. & & Willowherb & UK \\
\hline Equisetum arvense & & Field Horsetail & 4 \\
\hline Equisetum hyemale & & Common Scouring Rush & 3 \\
\hline Equisetum laevigatum & & Smooth Scouring Rush & 3 \\
\hline
\end{tabular}




\begin{tabular}{|c|c|c|c|}
\hline Scientific Name & Common Synonomy & Common Name & $\begin{array}{l}\text { Coefficient of } \\
\text { Conservatism }\end{array}$ \\
\hline Equisetum sp. & & Horsetail & UK \\
\hline Equisetum spp. & & Horsetail & UK \\
\hline Erigeron canadensis & & Canada Horseweed & 3 \\
\hline Erigeron philadelphicus & & Philadelphia Fleabane & 2 \\
\hline Erigeron strigosus & & Daisy Fleabane & 3 \\
\hline Eupatorium maculatum & & Spotted Joe-pye Weed & 9 \\
\hline Euphorbia esula & & Leafy Spurge & 0 \\
\hline Euphorbia glyptosperma & Chamaesyce glyptosperma & ribseed sandmat & 0 \\
\hline Euphorbia maculata & & Spotted Spurge & 0 \\
\hline Euthamia graminifolia & & Flat-top Goldentop & 6 \\
\hline Fragaria virginiana & & Wild Strawberry & 4 \\
\hline Fraxinus pennsylvanica & & Green Ash & 0 \\
\hline Galium boreale & & Northern Bedstraw & 4 \\
\hline Galium sp. & & Bedstraw & UK \\
\hline Galium trifidum & & Small Bedstraw & 8 \\
\hline Glaux maritima & & Sea Milkwort & 4 \\
\hline Glyceria grandis & Glyceria maxima & Tall Mannagrass & 4 \\
\hline Glyceria $s p$ & & Mannagrass & UK \\
\hline Glyceria striata & & Fowl Mannagrass & 6 \\
\hline Glycine max & & Soybeans & 0 \\
\hline Glycyrrhiza lepidota & & AmericanLicorice & 2 \\
\hline Graminae & & Grass & UK \\
\hline Gratiola neglecta & & Hedge Hyssop & 0 \\
\hline Grindelia sp. & & Gumweed & 1 \\
\hline Grindelia squarrosa & & Curly-top Gumweed & 1 \\
\hline Hedeoma hispidum & & Rough False Pennyroyal & 2 \\
\hline Helenium autumnale & & Sneeze Weed & 4 \\
\hline Helianthus annuus & & Common Sunflower & 0 \\
\hline Helianthus grosseserratus & & Sawtooth Sunflower & 7 \\
\hline Helianthus maximilianii & & Maximilian Sunflower & 5 \\
\hline Helianthus nuttallii & & Nuttall's Sunflower & 8 \\
\hline Helianthus petiolaris & & Plains Sunflower & 0 \\
\hline Helianthus rigidus & Helianthus pauciflorus & Stiff Sunflower & 8 \\
\hline Helianthus sp. & & Sunflower & UK \\
\hline Heliopsis helianthoides & & False Sunflower & 5 \\
\hline Hesperis matronalis & & Dame's Rocket & 0 \\
\hline Hierochloe odorata & & Sweetgrass & 10 \\
\hline Hippuris vulgaris & & Mare's Tail & 5 \\
\hline Hordeum jubatum & & Foxtail Barley & 0 \\
\hline Hordeum vulgare & & Barley & UK \\
\hline Hypoxis hirsuta & & Yellow Stargrass & 8 \\
\hline Iris missouriensis & & Blueflag & 5 \\
\hline Iris sp. & & Iris & UK \\
\hline Iva xanthifolia & & Marsh Elder & 0 \\
\hline Juncus alpinoarticulatus & Juncus alpinus & Richardson's Rush & 7 \\
\hline Juncus articulatus & & Jointleaf Rush & 7 \\
\hline Juncus balticus & & Baltic Rush & 5 \\
\hline
\end{tabular}




\begin{tabular}{|c|c|c|c|}
\hline Scientific Name & Common Synonomy & Common Name & $\begin{array}{l}\text { Coefficient of } \\
\text { Conservatism }\end{array}$ \\
\hline Juncus bufonius & & Toad Rush & 1 \\
\hline Juncus interior & & Inland Rush & 5 \\
\hline Juncus longistylis & & Longstyle Rush & 10 \\
\hline Juncus sp. & & Rush & UK \\
\hline Juncus spp. & & Rush & UK \\
\hline Juncus tenuis & & Path Rush & 4 \\
\hline Juncus torreyi & & Torrey's Rush & 2 \\
\hline Kochia scoparia & & Kochia & 0 \\
\hline Koeleria macrantha & & Junegrass & UK \\
\hline Lactuca oblongifolia & Lactuca tatarica & Blue Lettuce & 1 \\
\hline Lactuca serriola & & Prickly Lettuce & 0 \\
\hline Lathyrus palustris & & Marsh Vetchling & 9 \\
\hline Leersia oryzoides & & Rice Cutgrass & 2 \\
\hline Lemna minor & & Common Duckweed & 9 \\
\hline Lemna trisulca & & Star Duckweed & 2 \\
\hline Lemna turionifera & & Turion Duckweed & 1 \\
\hline Lepidium densiflorum & & Peppergrass & 0 \\
\hline Leptochloa fascicularis & & Bearded Sprangletop & 0 \\
\hline Liatris ligulistylis & & Rocky Mountain Blazing Star & 10 \\
\hline Liatris punctata & & Dotted Blazing Star & 7 \\
\hline Liatris pycnostachya & & Prairie Blazing Star & 8 \\
\hline Lilium philadelphicum & & Wild Lily & 8 \\
\hline Lindernia dubia & & False Pimpernel & 2 \\
\hline Linum perenne & & Blue Flax & 6 \\
\hline Lithospermum canescens & & Hoary Puccoon & 7 \\
\hline Lobelia spicata & & Palespike Lobelia & 6 \\
\hline Lotus purshianus & Lotus unifoliolatus & Bird's-foot Trefoil & 3 \\
\hline Lycopus americanus & & American Bugleweed & 4 \\
\hline Lycopus asper & & Rough Bugleweed & 4 \\
\hline Lycopus sp. & & Bugleweed & UK \\
\hline Lygodesmia juncea & & Skeletonweed & 2 \\
\hline Lysimachia ciliata & & Fringed loosestrife & 6 \\
\hline Lysimachia hybrida & & Loosestrife & 5 \\
\hline Lysimachia thyrsiflora & & Tufted Loosestrife & 7 \\
\hline Lythrum alatum & & Winged Loosestrife & 9 \\
\hline Malva neglecta & & Common Mallow & 0 \\
\hline Malva sp. & & Mallow & 0 \\
\hline Marsilea vestita & & Western Water Clover & 2 \\
\hline Matricaria sp. & & Chamomile & UK \\
\hline Medicago lupulina & & Black Medic & 0 \\
\hline Medicago sativa & & Alfalfa & 0 \\
\hline Melilotus alba & & White Sweet Clover & 0 \\
\hline Melilotus officinalis & & Yellow Sweet Clover & 0 \\
\hline Melilotus sp. & & Sweet Clover & UK \\
\hline Mentha arvensis & & Field Mint & 3 \\
\hline Monarda fistulosa & & Wild Bergamot & 5 \\
\hline Muhlenbergia asperifolia & & Scratchgrass & 2 \\
\hline
\end{tabular}




\begin{tabular}{|c|c|c|c|}
\hline Scientific Name & Common Synonomy & Common Name & $\begin{array}{l}\text { Coefficient of } \\
\text { Conservatism }\end{array}$ \\
\hline Muhlenbergia cuspidata & & Plains Muhly & 8 \\
\hline Muhlenbergia racemosa & & Marsh Muhly & 4 \\
\hline Muhlenbergia richardsonis & & Mat Muhly & 10 \\
\hline Myriophyllum spicatum & Myriophyllum exalbescens & Watermilfoil & 3 \\
\hline Najas sp. & & Waternymph & UK \\
\hline Nepeta cataria & & Catnip & 0 \\
\hline Opuntia sp. & & Pricklypear & UK \\
\hline Oxalis stricta & & Yellow Wood Sorrel & 0 \\
\hline Oxalis violacea & & Violet Wood Sorrel & 7 \\
\hline Panicum capillare & & Common Witchgrass & 0 \\
\hline Panicum virgatum & & Switchgrass & 5 \\
\hline Parietaria pensylvanica & & Pennsylvania Pellitory & 3 \\
\hline Pedicularis canadensis & & Wood Betony & 10 \\
\hline Phalaris arundinacea & & Reed Canarygrass & 0 \\
\hline Phaseolis vulgaris & & Bean & 0 \\
\hline Phleum pratense & & Timothy & 0 \\
\hline Phragmites australis & & Common Reed & 0 \\
\hline Physalis virginiana & & Virginia Groundcherry & 4 \\
\hline Plantago major & & Common Plantain & 0 \\
\hline Poa compressa & & Canada Bluegrass & 0 \\
\hline Poa palustris & & Fowl Bluegrass & 4 \\
\hline Poa pratensis & & Kentucky Bluegrass & 0 \\
\hline Poa sandbergii & Poa secunda & Sandberg's Bluegrass & 8 \\
\hline Poa sp. & & Bluegrass & UK \\
\hline Polygonum amphibian var. emersum & & Swamp Smartweed & 0 \\
\hline Polygonum amphibium var. stipulaceum & & Water Smartweed & 6 \\
\hline Polygonum aviculare & & Knotweed & 0 \\
\hline Polygonum convolvulus & & Wild Buckwheat & 0 \\
\hline Polygonum erectum & & Erect Knotweed & 0 \\
\hline Polygonum lapathifolium & & Pale Smartweed & 1 \\
\hline Polygonum pensylvanicum & & Pennsylvania Smartweed & 0 \\
\hline Polygonum ramosissimum & & Bushy knotweed & 3 \\
\hline Polygonum sp. & & Smartweed & UK \\
\hline Polygonum spp. & & Smartweed & UK \\
\hline Polypogon monspeliensis & & Rabbitfoot Grass & UK \\
\hline Populus deltoides & & Cottonwood & 0 \\
\hline Populus tremuloides & & Quaking Aspen & 0 \\
\hline Potamogeton foliosus & & Leafy Pondweed & 2 \\
\hline Potamogeton gramineus & & Variable Pondweed & 6 \\
\hline Potamogeton natans & & Floatingleaf Pondweed & 10 \\
\hline Potamogeton nodosus & & Longleaf Pondweed & 4 \\
\hline Potamogeton pectinatus & & Sago Pondweed & 0 \\
\hline Potamogeton pusillus & & Small Pondweed & 5 \\
\hline Potamogeton richardsonii & & Richardson's Pondweed & 4 \\
\hline Potamogeton sp. & & Pondweed & UK \\
\hline Potamogeton zosteriformis & & Flatstem Pondweed & 7 \\
\hline Potentilla anserina & Argentina anserina & Silverweed & 2 \\
\hline
\end{tabular}




\begin{tabular}{|c|c|c|c|}
\hline Scientific Name & Common Synonomy & Common Name & $\begin{array}{l}\text { Coefficient of } \\
\text { Conservatism }\end{array}$ \\
\hline Potentilla arguta & & $\begin{array}{l}\text { Tall Cinquefoil } \\
\end{array}$ & 8 \\
\hline Potentilla norvegica & & Norwegian Cinquefoil & 0 \\
\hline Potentilla pensylvanica & & Pennsylvania Cinquefoil & 9 \\
\hline Psoralea argophylla & Pediomelum argrophyllum & Silverleaf Scurfpea & 4 \\
\hline Puccinellia nuttalliana & & Nuttall's Alkaligrass & 4 \\
\hline Ranunculus cymbalaria & & Shore Buttercup & 3 \\
\hline Ranunculus flabellaris & & Threadleaf Buttercup & 7 \\
\hline Ranunculus gmelinii & & Small Yellow Buttercup & 8 \\
\hline Ranunculus longirostris & Ranunculus trichophyllus & White Water Crowfoot & 7 \\
\hline Ranunculus macounii & & Macoun's Buttercup & 4 \\
\hline Ranunculus pensylvanicus & & Bristly Crowfoot & 4 \\
\hline Ranunculus sceleratus & & Cursed Crowfoot & 3 \\
\hline Ranunculus sp. & & Crowfoot & UK \\
\hline Ratibida columnifera & & Prairie Coneflower & 3 \\
\hline Rhus glabra & & Smooth Sumac & 4 \\
\hline Ribes americanum & & Wild Black Currant & 7 \\
\hline Riccia fluitans & & Liverworts & UK \\
\hline Riccia $s p$. & & Liverworts & UK \\
\hline Ricciocarpus natans & & Liverworts & UK \\
\hline Rorippa palustris & & Bog Yellowcress & 2 \\
\hline Rosa arkansana & & Prairie Wild Rose & 0 \\
\hline Rosa blanda & & Smooth Wild Rose & 0 \\
\hline Rosa sp. & & Rose & UK \\
\hline Rosa woodsii & & Western Wild Rose & 0 \\
\hline Rudbeckia hirta & & Black-eyed Susan & 5 \\
\hline Rumex altissimus & & Pale Dock & 2 \\
\hline Rumex crispus & & Curly Dock & 0 \\
\hline Rumex maritimus & & Golden Dock & 1 \\
\hline Rumex mexicanus & Rumex salicifolius & Willow-leaved Dock & 1 \\
\hline Rumex occidentalis & Rumex aquaticus & Western Dock & 7 \\
\hline Rumex orbiculatus & & Great Water Dock & 9 \\
\hline Rumex sp. & & Dock & UK \\
\hline Rumex spp. & & Dock & UK \\
\hline Rumex stenophyllus & & Eurasian Dock & 0 \\
\hline Sagittaria cuneata & & Arrowhead & 6 \\
\hline Sagittaria latifolia & & Common Arrowhead & 6 \\
\hline Sagittaria $s p$. & & Arrowhead & UK \\
\hline Sagittaria spp. & & Arrowhead & UK \\
\hline Salix amygdaloides & & Peachleaf Willow & 0 \\
\hline Salix exigua & & Sandbar Willow & 0 \\
\hline Salix nigra & & Black Willow & 0 \\
\hline Salix sp. & & Willow & UK \\
\hline Schizachyrium scoparium & Andropogon scoparius & Little Bluestem & 6 \\
\hline Scirpus acutus & Schoenoplectus acutus & Hardstem Bulrush & 5 \\
\hline Scirpus atrovirens & & Darkgreen Bulrush & 5 \\
\hline Scirpus fluviatilis & Bolboschoenus fluviatilis & River Bulrush & 2 \\
\hline Scirpus heterochaetus & Schoenoplectus heterochaetus & Slender Bulrush & 8 \\
\hline
\end{tabular}




\begin{tabular}{|c|c|c|c|}
\hline Scientific Name & Common Synonomy & Common Name & $\begin{array}{l}\text { Coefficient of } \\
\text { Conservatism }\end{array}$ \\
\hline Scirpus maritimus & Bolboschoenus maritimus & Prairie Bulrush & 4 \\
\hline Scirpus pallidus & & Cloaked Bulrush & 5 \\
\hline Scirpus pungens & Schoenoplectus pungens & Common Threesquare & 4 \\
\hline Scirpus sp. & & Bulrush & UK \\
\hline Scirpus validus & Schoenoplectus tabernaemontani & Softstem Bulrush & 3 \\
\hline Scolochloa festucacea & & Sprangletop & 6 \\
\hline Scrophularia lanceolata & & lanceleaf figwort & 5 \\
\hline Scutellaria sp. & & Skullcap & UK \\
\hline Selaginella densa & & Small Clubmoss & 6 \\
\hline Senecio congestus & & Swamp Ragwort & 2 \\
\hline Senecio pseudaureus & & Falsegold Groundsel & 5 \\
\hline Setaria glauca & Pennisetum glaucum & Yellow Foxtail & 0 \\
\hline Setaria sp. & Pennisetum sp. & Foxtail & UK \\
\hline Setaria viridis & Pennisetum viridis & Green Foxtail & 0 \\
\hline Silene $s p$ & & Catchfly & UK \\
\hline Sisyrinchium campestre & & White-eyed Grass & 10 \\
\hline Sium suave & & Water Parsnip & 3 \\
\hline Solanum sp. & & Nightshade & UK \\
\hline Solidago canadensis & & Canada Goldenrod & 1 \\
\hline Solidago gigantea & & Giant Goldenrod & 4 \\
\hline Solidago missouriensis & & Missouri Goldenrod & 5 \\
\hline Solidago mollis & & Soft Goldenrod & 6 \\
\hline Solidago rigida & Oligoneuron rigidum & Rigid Goldenrod & 4 \\
\hline Solidago sp. & & Goldenrod & UK \\
\hline Sonchus arvensis & & Field Sow Thistle & 0 \\
\hline Sonchus asper & & Prickly Sow Thistle & 0 \\
\hline Sonchus oleraceus & & Common Sow Thistle & 0 \\
\hline Sorghastrum nutans & & Indian Grass & 6 \\
\hline Sparganium eurycarpum & & Giant Burreed & 4 \\
\hline Spartina pectinata & & Prairie Cordgrass & 5 \\
\hline Sphenopholis obtusata & & Slender Wedgegrass & 7 \\
\hline Spiraea alba & & Meadow-sweet & 7 \\
\hline Spirodela polyrhiza & & Greater Duckweed & 3 \\
\hline Stachys palustris & & Marsh Hedge-nettle & 3 \\
\hline Stipa comata & Hesperostipa comata & Needle-and-thread & 6 \\
\hline Stipa curtiseta & & Needlegrass & 6 \\
\hline Stipa spartea & Hesperostipa spartea & Porcupinegrass & 8 \\
\hline Stipa viridula & Nassella viridula & Green Needlegrass & 5 \\
\hline Symphoricarpos occidentalis & & Western Snowberry & 3 \\
\hline Symphoricarpos sp. & & UK & UK \\
\hline Tanacetum vulgare & & Common Tansy & 0 \\
\hline Taraxacum officinale & & Common Dandelion & 0 \\
\hline Teucrium canadense & & Canada Germander & 3 \\
\hline Thalictrum dasycarpum & & Purple Meadow Rue & 7 \\
\hline Thalictrum venulosum & & Early Meadow Rue & 6 \\
\hline Thlaspi arvense & & Field Pennycress & 0 \\
\hline Tradescantia bracteata & & Spiderwort & 7 \\
\hline
\end{tabular}




\begin{tabular}{|c|c|c|c|}
\hline Scientific Name & Common Synonomy & Common Name & $\begin{array}{l}\text { Coefficient of } \\
\text { Conservatism }\end{array}$ \\
\hline Tragopogon dubius & & Goat's Beard & 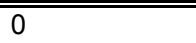 \\
\hline Trifolium hybridum & & Alsike Clover & 0 \\
\hline Trifolium pratense & & Red Clover & 0 \\
\hline Trifolium repens & & White Clover & 0 \\
\hline Triglochin maritima & & Seaside Arrowgrass & 5 \\
\hline Triticum aestivum & & Wheat & 0 \\
\hline Typha angustifolia & & Narrowleaf Cattail & 0 \\
\hline Typha latifolia & & Broadleaf Cattail & 2 \\
\hline Typha sp. & & Cattail & UK \\
\hline Typha spp. & & Cattail & UK \\
\hline Typha $X$ glauca & & Hybrid Cattail & 0 \\
\hline Ulmus pumila & & Siberian EIm & 0 \\
\hline Urtica dioica & & Stinging Nettle & 0 \\
\hline Utricularia vulgaris & Utricularia macrorhiza & Common Bladderwort & 2 \\
\hline Vallisneria americana & & American Eelgrass & 10 \\
\hline Verbena bracteata & & Prostrate Vervain & 0 \\
\hline Verbena hastata & & Blue Vervain & 5 \\
\hline Verbena sp. & & Vervain & UK \\
\hline Vernonia fasciculata & & \begin{tabular}{|l|} 
Ironweed \\
\end{tabular} & 3 \\
\hline Veronica anagallis-aquatica & & Water Speedwell & 0 \\
\hline Veronica peregrina & & Purslane Speedwell & 0 \\
\hline Vicia americana & & American Vetch & 6 \\
\hline Vicia sp. & & Vetch & UK \\
\hline Viola nuttallii & & Yellow Prairie Violet & 8 \\
\hline Viola sororia & & Downy Blue Violet & 2 \\
\hline Viola $s p$. & & Violet & UK \\
\hline Xanthium strumarium & & Cocklebur & 0 \\
\hline Zea mays & & Corn & 0 \\
\hline Zigadenus elegans & & White Camass & 8 \\
\hline Zizia aptera & & Meadow Parsnip & 8 \\
\hline Zizia aurea & & Golden Alexanders & 8 \\
\hline
\end{tabular}

\section{Appendix C-3: Alternate Methods for Calculation of $V_{\text {VEGCOMP }}$}

Two alternate methods for $V_{V E G C O M P}$ are provided below. Selection of either method in lieu of the Floristic Quality Index (FQI) as described in Chapter 4 should be so noted in the project report. Choice of method is based on user defined assessment objectives.

\section{Dominance method}

a. This method focuses only on dominant species in the herbaceous cover strata. Selection of dominant species is consistent with Routine Methods for 
Federal delineation protocol (Environmental Laboratory 1987). The following procedure is used:

(1) Identify the plant community type or types by traversing the area. Determine the number and locations of plant community types (generally defined as low prairie, wet meadow or shallow marsh). Sketch the location of each community on the base map.

(2) Select representative observation points. A representative observation point is one in which the apparent characteristics best represents the entire community.

(3) Characterize each plant community type by visually determining the dominant plant species. Dominant plant species are those that contribute more to the character of a plant community than other species present, as estimated visually.

(4) Record coefficient of conservatism ( $\mathrm{C}$ value) indicator status of dominant species in each vegetation zone or community type.

(5) Calculate percent concurrence by comparing the list of dominant species recorded to the list of dominant species found in reference standard wetlands. Reference standard dominant species are defined as those species assigned a $\mathrm{C}$ value of $\geq$ to 4 . For example, if all the dominants from the area being assessed occur on the list of dominants from reference standard wetlands, then there is 100 percent concurrence. If three out of the five dominant ground cover species from the area being assessed occur on the list, then there is 60 percent concurrence. Based on the data from reference standard sites, a variable subindex of 1.0 was assigned when percent concurrence was $\geq 80$ percent. As the percentage of concurrence decreases, a linearly decreasing variable subindex is assigned.

b. Users of this Guidebook should consult Appendix C-2 or Northern Great Plains Floristic Quality Assessment Panel (2001) for appropriate coefficient of conservatism assignments. 


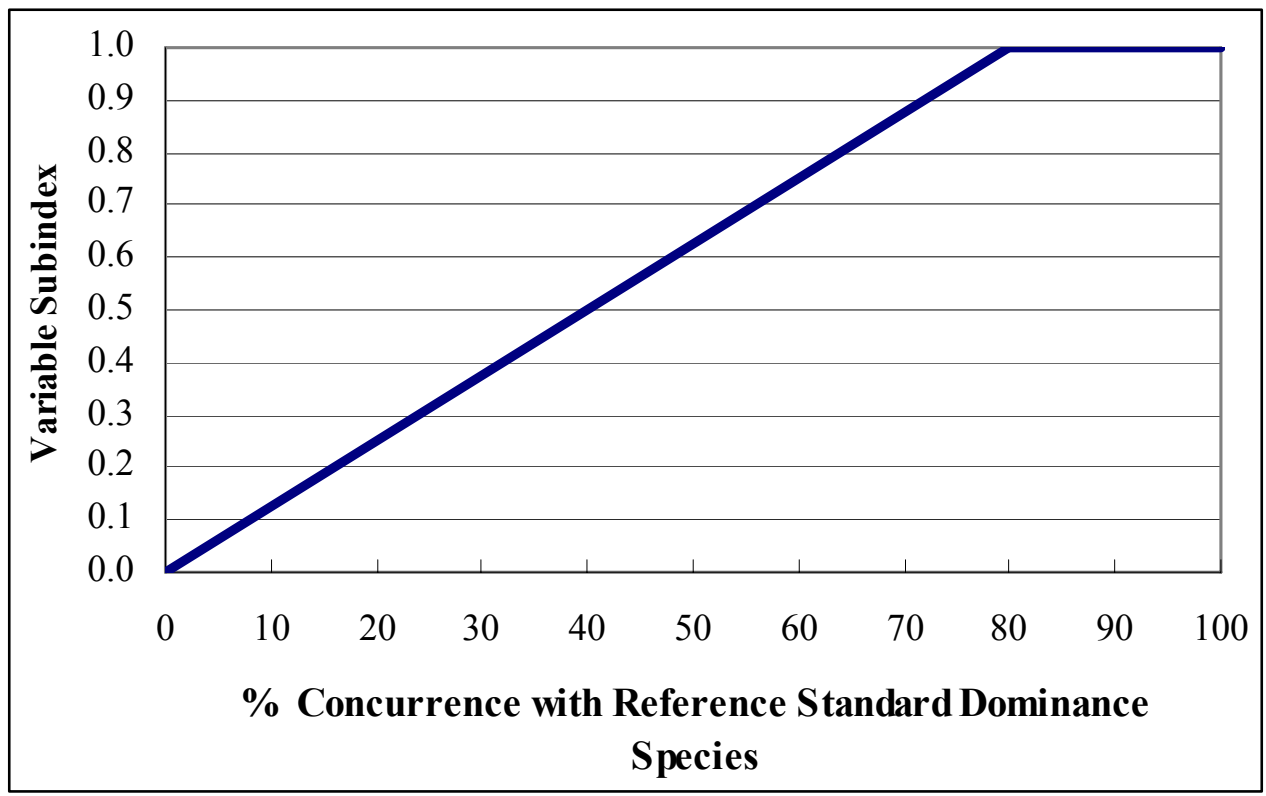

Figure C-3-1. Vegetation dominance

\section{Abundance method}

a. This method is a modification of the Floristic Quality Index for applications requiring quantitative data as part of user defined assessment objectives (e.g., monitoring). To allow greater sensitivity in interpretation of floristic integrity across the range of variation within this subclass, quantitative data may be needed. Also, given an inventory unit with species having high " $\mathrm{C}$ " values at low abundance, collection of quantitative data may be more sensitive to change detection than floristic presence data alone. This method is recommended for characterization by major zone or community type only.

$b$. The coefficient of conservatism indicator rankings is used in a weighted average ordination equation. The algorithm would be:

$$
\mathrm{FQW} A_{J}=\sum \frac{C_{i} \times A_{i J}}{\sum A_{i J}}
$$

where

$$
\begin{aligned}
\mathrm{FQW}_{J} & =\text { Floristic Quality Weighted Average for Stand }_{\mathrm{J}} \\
C_{i} & =\text { Coefficient of conservatism for species }_{\mathrm{i}} \\
A_{i J} & =\text { Abundance of species }_{\mathrm{i}} \text { in sample }_{\mathrm{J}} \\
\sum A_{i J} & =\text { Summation of all species abundance in sample }_{\mathrm{J}}
\end{aligned}
$$

c. Resultant scores could potentially range from 0 to 10 with " 0 " representing a ruderal stand, and " 10 " indicating the maximum possible score, or the highest affinity to a natural area. FQWA stand scores ranged from 0 to 8.03, mean 
value was 2.23. The reference standard condition for FQWA stand scores is $\geq$ 4.0. Reference data analyses were for 180 sites and 343 samples. The relationship of the metric to the variable sub-index is depicted below.

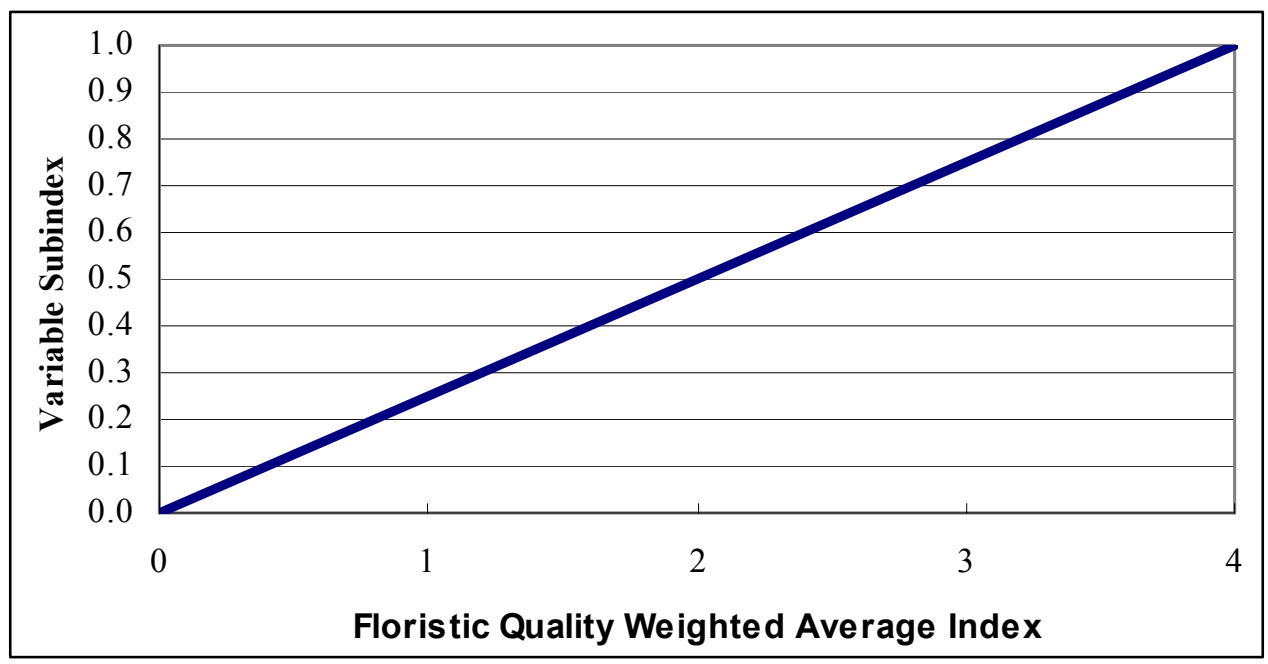

Figure C-3-2. Vegetation composition

\section{Appendix C-4: Recharge Ratings for Soil Mapping Units}

\begin{tabular}{|c|c|}
\hline Soil Name & Recharge Rating \\
\hline Badus & 0.1 \\
\hline Baltic & 0.1 \\
\hline Barbert & 1 \\
\hline Beauford & 0.5 (leached but stagno-recharge) \\
\hline Bigstone & 0.1 \\
\hline Brownton & 0.1 \\
\hline Calcousta & 0.1 \\
\hline Canisteo & 0.1 \\
\hline Colvin & 0 \\
\hline Cordova & 1 \\
\hline Corvuso & 0 \\
\hline Cosmos & 0.25 \\
\hline Crowriver & 0 \\
\hline Dovray & 0.75 (leached but stagno-recharge) \\
\hline Easby & 0 \\
\hline Enloe & 0.75 (leached but stagno-recharge) \\
\hline Fargo & 0.25 \\
\hline Flom & 0.5 \\
\hline Fulda & 0.25 (stagno-recharge) \\
\hline Glencoe & 0.75 \\
\hline Hamel & 1 \\
\hline Harps & 0 \\
\hline Harpster & 0 \\
\hline
\end{tabular}




\begin{tabular}{|c|c|}
\hline Soil Name & Recharge Rating \\
\hline Jeffers & 0.1 \\
\hline Knoke & 0.1 (stagno-recharge) \\
\hline Kossuth & 0.75 \\
\hline Lakepark & 0.5 \\
\hline Lanyon & 0.25 \\
\hline Lindaas & 0.75 \\
\hline Lura & 0.75 (leached but stagno-recharge) \\
\hline Madelia & 0.5 \\
\hline Marna & 0.5 (leached but stagno-recharge) \\
\hline Minnetonka & 1 \\
\hline Nishon & 0.1 (stagno-recharge) \\
\hline Ojata & 0 \\
\hline Okoboji & 0.75 \\
\hline Okoboji Muck & 0.25 \\
\hline Oldham & 0.1 (stagno-recharge) \\
\hline Parnell & 1 \\
\hline Perella & 0.25 \\
\hline Quam & 0.75 for $V P D$ \\
\hline Quam & 1.0 for $P D$ \\
\hline Revere & 0 \\
\hline Rolfe & 1 \\
\hline Roliss & 0.1 \\
\hline Romnell & 0.1 \\
\hline Spicer & 0.1 \\
\hline Tetonka & 1 \\
\hline Tonka & 1 \\
\hline Vallers & 0 \\
\hline Wacousta & 0.25 \\
\hline Waldorf & 0.5 (leached but stagno-recharge) \\
\hline Webster & 0.75 \\
\hline Worthing & 1 \\
\hline
\end{tabular}

\section{Appendix C-5. Reference Data}

(“/” indicates no data)

\section{a. Vegetation and soil variables}

\begin{tabular}{|l|l|l|l|l|l|l|l||}
\hline $\begin{array}{l}\text { Reference Site } \\
\text { ID }\end{array}$ & $\begin{array}{l}\text { V Grasscont, } \\
\text { \% }\end{array}$ & $\begin{array}{l}\text { V Grasswidth, } \\
\mathbf{m}\end{array}$ & $\begin{array}{l}\text { V Vegcomp, } \\
\text { FQI }\end{array}$ & $\begin{array}{l}\text { V Recharge, } \\
\text { Categorical }\end{array}$ & $\begin{array}{l}\text { V Sed, } \\
\text { cm }\end{array}$ & $\begin{array}{l}\text { V Som, } \\
\text { mean OC, \% }\end{array}$ & $\begin{array}{l}\text { V SQI, } \\
\text { SQI }\end{array}$ \\
\hline \hline Gp01154 & 100.00 & 15.00 & 5.63 & 0.67 & 35.00 & 3.42 & 9.00 \\
\hline Gp01156 & 100.00 & 15.00 & 14.92 & 0.00 & 23.00 & 2.66 & 10.00 \\
\hline Gp01158 & 100.00 & 15.00 & 12.82 & 0.55 & 24.00 & 2.63 & 9.00 \\
\hline Gp01160 & 100.00 & 15.00 & 15.12 & 0.40 & 36.00 & 3.21 & 9.00 \\
\hline Gp01162 & 100.00 & 15.00 & 17.41 & 0.84 & 28.00 & 4.26 & 10.00 \\
\hline Gp02173 & 100.00 & 15.00 & 6.46 & 1.00 & 30.00 & 3.44 & 8.00 \\
\hline
\end{tabular}




\begin{tabular}{|c|c|c|c|c|c|c|c|}
\hline $\begin{array}{l}\text { Reference Site } \\
\text { ID }\end{array}$ & $\begin{array}{l}\text { V Grasscont, } \\
\%\end{array}$ & $\begin{array}{l}\text { V Grasswidth, } \\
\text { m }\end{array}$ & $\begin{array}{l}\text { V Vegcomp, } \\
\text { FQI }\end{array}$ & $\begin{array}{l}\text { V Recharge, } \\
\text { Categorical }\end{array}$ & $\begin{array}{l}\text { V Sed, } \\
\mathrm{cm}\end{array}$ & \begin{tabular}{|l} 
V Som, \\
mean OC, \%
\end{tabular} & $\begin{array}{l}\text { V SQI, } \\
\text { SQI }\end{array}$ \\
\hline 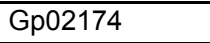 & 100.00 & 15.00 & \begin{tabular}{|l|l}
13.72 \\
\end{tabular} & 1.00 & 34.00 & 3.61 & 9.00 \\
\hline Gp02175 & 100.00 & 15.00 & 16.77 & 0.12 & 39.00 & 4.23 & 10.00 \\
\hline Gp02177 & 100.00 & 15.00 & 14.11 & 0.44 & 51.00 & 3.06 & 10.00 \\
\hline Gp02179 & 100.00 & 15.00 & 17.20 & 0.10 & 56.00 & 2.08 & 9.00 \\
\hline Gp03069 & 100.00 & 15.00 & 8.60 & 1.00 & 31.00 & 2.73 & 10.00 \\
\hline Gp03070 & 100.00 & 15.00 & 12.86 & 1.00 & 20.00 & 1.75 & 8.00 \\
\hline Gp03071 & 100.00 & 15.00 & 16.40 & 1.00 & 27.00 & 3.22 & 9.00 \\
\hline Gp03107 & 100.00 & 15.00 & 2.25 & 0.84 & 49.00 & 4.19 & 7.00 \\
\hline Gp04123 & 100.00 & 15.00 & 3.35 & 0.67 & 30.00 & 1.77 & 7.00 \\
\hline Gp04125 & 100.00 & 15.00 & 6.67 & 1.00 & 20.00 & 1.93 & 9.00 \\
\hline Gp04126 & 100.00 & 15.00 & 9.59 & 1.00 & 38.00 & 2.36 & 6.00 \\
\hline Gp04129 & 100.00 & 15.00 & 8.20 & 1.00 & 39.00 & 1.68 & \begin{tabular}{|l|}
8.00 \\
\end{tabular} \\
\hline Gp04139 & 100.00 & 15.00 & 17.84 & 1.00 & 12.00 & 3.17 & 11.00 \\
\hline Gp05089 & 100.00 & 15.00 & 4.90 & 0.84 & 35.00 & 1.57 & 6.00 \\
\hline Gp05091 & 100.00 & 15.00 & 11.73 & 0.43 & 34.00 & 2.04 & 7.00 \\
\hline Gp05092 & 100.00 & 15.00 & 8.92 & 0.56 & 38.00 & 2.76 & 6.00 \\
\hline Gp05093 & 100.00 & 15.00 & 8.18 & 0.12 & 42.00 & 1.67 & 8.00 \\
\hline Gp05095 & 100.00 & 15.00 & 16.28 & 0.61 & 19.00 & 1.82 & 111.00 \\
\hline Gp06117 & 100.00 & 15.00 & 7.84 & 0.51 & 32.00 & 2.73 & 10.00 \\
\hline Gp06118 & 100.00 & 15.00 & 11.33 & 0.50 & 0.00 & 1.44 & 7.00 \\
\hline Gp06119 & 100.00 & 15.00 & 13.15 & 0.57 & 34.00 & 2.11 & 8.00 \\
\hline Gp06121 & 100.00 & 15.00 & 18.26 & 1.00 & 30.00 & 1.80 & 10.00 \\
\hline Gp06127 & 100.00 & 15.00 & 9.86 & 1.00 & 23.00 & 1.90 & 10.00 \\
\hline Gp07073 & 100.00 & 15.00 & 8.01 & 0.53 & 24.00 & 2.71 & 7.00 \\
\hline Gp07075 & 100.00 & 15.00 & 12.05 & 1.00 & 37.00 & 2.91 & \begin{tabular}{|l|}
8.00 \\
\end{tabular} \\
\hline Gp07077 & 100.00 & 15.00 & 0.75 & 0.67 & 41.00 & 3.39 & 8.00 \\
\hline Gp07078 & 100.00 & 15.00 & 13.53 & 0.70 & 30.00 & 3.74 & 8.00 \\
\hline Gp08040 & 100.00 & 15.00 & 6.11 & 0.84 & 31.00 & 2.35 & 5.00 \\
\hline Gp08041 & 100.00 & 15.00 & 16.47 & 0.58 & 28.00 & 4.10 & 6.00 \\
\hline Gp08044 & 100.00 & 15.00 & 7.00 & 1.00 & 41.00 & 2.95 & 8.00 \\
\hline Gp08045 & 100.00 & 15.00 & 23.72 & 1.00 & 32.00 & 4.18 & 10.00 \\
\hline Gp08047 & 100.00 & 15.00 & 9.34 & 0.47 & 24.00 & 2.43 & 7.00 \\
\hline Gp09028 & 100.00 & 15.00 & 3.25 & 0.75 & 31.00 & 1.32 & 7.00 \\
\hline Gp09030 & 100.00 & 15.00 & 4.92 & 0.75 & 28.00 & 3.35 & 7.00 \\
\hline Gp09031 & 100.00 & 15.00 & 7.49 & 0.89 & 27.00 & 3.06 & 7.00 \\
\hline Gp09033 & 100.00 & 15.00 & 25.93 & 0.84 & 27.00 & 6.20 & 9.00 \\
\hline Gp09035 & 100.00 & 15.00 & 27.59 & 0.50 & 34.00 & 4.84 & 10.00 \\
\hline Gp09037 & 100.00 & 15.00 & 12.88 & 0.71 & 29.00 & \begin{tabular}{|l|l|}
4.52 \\
\end{tabular} & 10.00 \\
\hline Gp10019 & 100.00 & 15.00 & 3.75 & 0.50 & 33.00 & \begin{tabular}{|l|}
3.71 \\
\end{tabular} & 6.00 \\
\hline Gp10021 & 100.00 & 15.00 & 13.55 & 0.75 & 26.00 & 1.99 & 7.00 \\
\hline Gp10024 & 100.00 & 15.00 & 19.00 & 0.83 & 61.00 & 1.18 & 8.00 \\
\hline Gp10026 & 100.00 & 15.00 & 30.37 & 0.00 & 27.00 & 3.79 & 10.00 \\
\hline Gp11006 & 100.00 & 15.00 & 9.39 & 1.00 & 31.00 & 4.04 & 10.00 \\
\hline Gp11011 & 100.00 & 15.00 & 26.99 & 0.00 & 38.00 & 5.74 & 10.00 \\
\hline Gp11014 & 100.00 & 15.00 & 12.34 & 0.75 & 55.00 & 2.03 & 7.00 \\
\hline Gp11015 & 100.00 & 15.00 & 12.51 & 0.75 & 57.00 & 4.10 & 8.00 \\
\hline Gp11016 & 100.00 & 15.00 & 22.03 & 0.83 & 66.00 & \begin{tabular}{|l|l|}
1.41 \\
\end{tabular} & 10.00 \\
\hline
\end{tabular}




\begin{tabular}{|c|c|c|c|c|c|c|c|}
\hline $\begin{array}{l}\text { Reference Site } \\
\text { ID }\end{array}$ & $\begin{array}{l}\text { V Grasscont, } \\
\%\end{array}$ & $\begin{array}{l}\text { V Grasswidth, } \\
\text { m }\end{array}$ & $\begin{array}{l}\text { V Vegcomp, } \\
\text { FQI }\end{array}$ & $\begin{array}{l}\text { V Recharge, } \\
\text { Categorical }\end{array}$ & $\begin{array}{l}\text { V Sed, } \\
\text { cm }\end{array}$ & $\begin{array}{l}\text { V Som, } \\
\text { mean OC, \% }\end{array}$ & $\begin{array}{l}\text { V SQI, } \\
\text { SQI }\end{array}$ \\
\hline "Gp11017 & 100.00 & 15.00 & 10.40 & 0.75 & 33.00 & 2.41 & 8.00 \\
\hline Gp12001 & 100.00 & 15.00 & 3.58 & 0.92 & 34.00 & 4.22 & 10.00 \\
\hline Gp12004 & 100.00 & 15.00 & 13.88 & 0.89 & 61.00 & 1.71 & 8.00 \\
\hline Gp12008 & 100.00 & 15.00 & 29.54 & 0.30 & 37.00 & 4.70 & 11.00 \\
\hline Gp12009 & 100.00 & 15.00 & 13.86 & 0.90 & 45.00 & 2.79 & 7.00 \\
\hline Mc01200 & 100.00 & 15.00 & 9.90 & 1.00 & 14.00 & 2.77 & 11.00 \\
\hline Mc01202 & 100.00 & 15.00 & 8.05 & 0.67 & 20.00 & 3.59 & 10.00 \\
\hline Mc01204 & 100.00 & 15.00 & 6.60 & 1.00 & 48.00 & 4.71 & 8.00 \\
\hline Mc01205 & 100.00 & 15.00 & 4.82 & 1.00 & 20.00 & 3.73 & 8.00 \\
\hline Mc01207 & 100.00 & 15.00 & 7.98 & 0.50 & 27.00 & 1.59 & 10.00 \\
\hline Mc02190 & 100.00 & 15.00 & 15.87 & 0.83 & 14.00 & 6.91 & 10.00 \\
\hline Mc02192 & 100.00 & 15.00 & 6.67 & 0.67 & 33.00 & 7.29 & 10.00 \\
\hline Mc02193 & 100.00 & 15.00 & 8.98 & 1.00 & 0.00 & 5.81 & 10.00 \\
\hline Mc02194 & 100.00 & 15.00 & 10.61 & 0.89 & 28.00 & 3.08 & 8.00 \\
\hline Mc02196 & 100.00 & 15.00 & 3.10 & 0.67 & 18.00 & 2.39 & 8.00 \\
\hline Mc02198 & 100.00 & 15.00 & 19.44 & 0.91 & 54.00 & 9.20 & 10.00 \\
\hline Mc03184 & 100.00 & 15.00 & 13.88 & 0.84 & 37.00 & 5.34 & 8.00 \\
\hline Mc03185 & 100.00 & 15.00 & 16.93 & 0.48 & 42.00 & 4.59 & 8.00 \\
\hline Mc03187 & 100.00 & 15.00 & 15.91 & 0.77 & 17.00 & 7.26 & 10.00 \\
\hline Mc03189 & 100.00 & 15.00 & 10.42 & 0.25 & 62.00 & 1.91 & 7.00 \\
\hline Mc04164 & 100.00 & 15.00 & 11.47 & 0.67 & 27.00 & 4.16 & 10.00 \\
\hline Mc04165 & 100.00 & 15.00 & 13.09 & 1.00 & 0.00 & 3.54 & 7.00 \\
\hline Mc04166 & 100.00 & 15.00 & 15.43 & 1.00 & 0.00 & 2.47 & 8.00 \\
\hline Mc04169 & 100.00 & 15.00 & 12.70 & 1.00 & 15.00 & 2.59 & 10.00 \\
\hline Mc04171 & 100.00 & 15.00 & 18.60 & 1.00 & 18.00 & 4.07 & 10.00 \\
\hline Mc05142 & 100.00 & 15.00 & 17.83 & 1 & 0.00 & 2.66 & 8.00 \\
\hline Mc05143 & 100.00 & 15.00 & 12.49 & 0.82 & 38.00 & 3.96 & 8.00 \\
\hline Mc05144 & 100.00 & 15.00 & 17.76 & 0.86 & 31.00 & 4.29 & 11.00 \\
\hline Mc05146 & 100.00 & 15.00 & 6.98 & 1.00 & 43.00 & 2.14 & 9.00 \\
\hline Mc05149 & 100.00 & 15.00 & 12.00 & 0.93 & 38.00 & 3.39 & 6.00 \\
\hline Mc06131 & 100.00 & 15.00 & 14.93 & 1.00 & 61.00 & 3.13 & 8.00 \\
\hline Mc06132 & 100.00 & 15.00 & 18.56 & 1.00 & 26.00 & 3.53 & 10.00 \\
\hline Mc06133 & 100.00 & 15.00 & 14.91 & 1.00 & 18.00 & 2.34 & 11.00 \\
\hline Mc06134 & 100.00 & 15.00 & 20.50 & 0.61 & 25.00 & 2.68 & 11.00 \\
\hline Mc06135 & 100.00 & 15.00 & 5.81 & 0.51 & 39.00 & 2.24 & 7.00 \\
\hline Mc06136 & 100.00 & 15.00 & 7.04 & 0.67 & 20.00 & 2.61 & 8.00 \\
\hline Mc07137 & 100.00 & 15.00 & 11.68 & 0.65 & 30.00 & 2.04 & 10.00 \\
\hline Mc07138 & 100.00 & 15.00 & 9.10 & 1.00 & 19.00 & 2.85 & 10.00 \\
\hline Mc08097 & 100.00 & 15.00 & 7.60 & 1.00 & 26.00 & 2.40 & 8.00 \\
\hline Mc08098 & 100.00 & 15.00 & 15.04 & 1.00 & 40.00 & 3.31 & 8.00 \\
\hline Mc08102 & 100.00 & 15.00 & 11.08 & 0.97 & 19.00 & 3.52 & 10.00 \\
\hline Mc08103 & 100.00 & 15.00 & 9.70 & 0.67 & 33.00 & 2.11 & 10.00 \\
\hline Mc09108 & 100.00 & 15.00 & 10.04 & 1.00 & 58.00 & 3.02 & 7.00 \\
\hline Mc09110 & 100.00 & 15.00 & 11.85 & 0.43 & 43.00 & 2.32 & 8.00 \\
\hline Mc09111 & 100.00 & 15.00 & 10.46 & 0.65 & 27.00 & 2.54 & 8.00 \\
\hline Mc09113 & 100.00 & 15.00 & 17.64 & 0.92 & 17.00 & 1.75 & 9.00 \\
\hline Mc09115 & 100.00 & 15.00 & 15.97 & 0.48 & 24.00 & 2.93 & 10.00 \\
\hline
\end{tabular}




\begin{tabular}{|c|c|c|c|c|c|c|c|}
\hline $\begin{array}{l}\text { Reference Site } \\
\text { ID }\end{array}$ & $\begin{array}{l}\text { V Grasscont, } \\
\%\end{array}$ & $\begin{array}{l}\text { V Grasswidth, } \\
\text { m }\end{array}$ & $\begin{array}{l}\text { V Vegcomp, } \\
\text { FQI }\end{array}$ & $\begin{array}{l}\text { V Recharge, } \\
\text { Categorical } \\
\end{array}$ & $\begin{array}{l}\text { V Sed, } \\
\text { cm }\end{array}$ & $\begin{array}{l}\text { V Som, } \\
\text { mean OC, \% }\end{array}$ & $\begin{array}{l}\text { V SQI, } \\
\text { SQI } \\
\end{array}$ \\
\hline $\begin{array}{l}\text { Pc01049 } \\
\end{array}$ & 100.00 & 15.00 & 14.10 & 0.93 & 0.00 & 3.26 & 6.00 \\
\hline Pc01052 & 100.00 & 15.00 & 6.36 & 0.50 & 46.00 & 3.96 & 7.00 \\
\hline Pc01053 & 100.00 & 15.00 & 11.14 & 0.90 & 38.00 & 3.50 & 8.00 \\
\hline Pc01054 & 100.00 & 15.00 & 13.86 & 0.42 & 33.00 & 3.21 & 8.00 \\
\hline Pc01057 & 100.00 & 15.00 & 19.56 & 0.88 & 23.00 & 4.78 & 10.00 \\
\hline Pc02059 & 100.00 & 15.00 & 10.79 & 0.92 & 31.00 & 4.08 & 8.00 \\
\hline Pc02061 & 100.00 & 15.00 & 16.28 & 0.15 & 28.00 & 3.04 & 7.00 \\
\hline Pc02063 & 100.00 & 15.00 & 13.95 & 0.75 & 41.00 & 2.59 & 8.00 \\
\hline Pc02065 & 100.00 & 15.00 & 10.80 & 0.80 & 28.00 & 3.58 & 8.00 \\
\hline Pc02067 & 100.00 & 15.00 & 16.23 & 1.00 & 41.00 & 6.43 & 9.00 \\
\hline Pc03079 & 100.00 & 15.00 & 6.26 & 0.92 & 61.00 & 3.37 & 9.00 \\
\hline Pc03081 & 100.00 & 15.00 & 11.67 & 0.95 & 41.00 & 3.51 & 6.00 \\
\hline Pc03083 & 100.00 & 15.00 & 9.22 & 1.00 & 37.00 & 3.41 & 10.00 \\
\hline Pc03085 & 100.00 & 15.00 & 9.62 & 0.60 & 53.00 & 2.96 & 8.00 \\
\hline Pc03087 & 100.00 & 15.00 & 22.46 & 0.64 & 28.00 & 5.28 & 11.00 \\
\hline GpS501 & 100.00 & 13.72 & 12.49 & 0.87 & 45.00 & 4.16 & 10.00 \\
\hline GpS502 & 100.00 & 15.24 & 3.40 & 1.00 & 65.00 & 3.40 & 8.00 \\
\hline GpS503 & 44.00 & 15.24 & 6.35 & 1.00 & 46.00 & 3.67 & 8.00 \\
\hline McS504 & 100.00 & 15.24 & 15.72 & 1.00 & 35.00 & 4.33 & 11.00 \\
\hline McS505 & 100.00 & 15.24 & 19.84 & 1.00 & 20.00 & 4.33 & 11.00 \\
\hline McS506 & 100.00 & 15.24 & 9.55 & 1.00 & 23.00 & 4.25 & 11.00 \\
\hline McS507 & 100.00 & 15.24 & 9.00 & 1.00 & 24.00 & 4.25 & 11.00 \\
\hline McS508 & 100.00 & 15.24 & 8.25 & 1.00 & 25.00 & 3.27 & 9.00 \\
\hline McS509 & 85.00 & 14.02 & 7.24 & 1.00 & 20.00 & 3.19 & 9.00 \\
\hline McS510 & 0.00 & 0.00 & 0.33 & 1.00 & 30.00 & 2.33 & 6.00 \\
\hline McS511 & 60.00 & 1.52 & 8.74 & 1.00 & 25.00 & 3.18 & 8.00 \\
\hline GpS512 & 0.00 & 0.00 & 5.67 & 1.00 & 43.00 & 1.86 & 3.00 \\
\hline GpS513 & 0.00 & 0.00 & 3.67 & 1.00 & 38.00 & 2.05 & 3.00 \\
\hline GpS514 & 14.00 & 0.91 & 2.67 & 1.00 & 66.00 & 2.04 & 5.00 \\
\hline GpS515 & 0.00 & 0.00 & 6.63 & 1.00 & 40.00 & 1.45 & 7.00 \\
\hline GpS516 & 100.00 & 10.36 & 6.33 & 1.00 & 38.00 & 3.29 & 7.00 \\
\hline GpS517 & 0.00 & 0.00 & 3.89 & 1.00 & 35.00 & 2.66 & 3.00 \\
\hline GpS518 & 85.00 & 13.72 & 12.48 & 1.00 & 18.00 & 4.25 & 11.00 \\
\hline GpS519 & 90.00 & 14.33 & 13.57 & 1.00 & 15.00 & 4.25 & 11.00 \\
\hline GpS520 & 100.00 & 15.24 & 14.18 & 1.00 & 32.00 & 4.64 & 11.00 \\
\hline GpS521 & 100.00 & 15.24 & 12.83 & 1.00 & 29.00 & 4.55 & 11.00 \\
\hline GpS522 & 100.00 & 15.24 & 11.40 & 1.00 & 32.00 & 4.42 & 11.00 \\
\hline GpS523 & 80.00 & 8.84 & 6.67 & 1.00 & 36.00 & 1.67 & 8.00 \\
\hline GPS524 & 0.00 & 0.00 & 8.54 & 1.00 & 42.00 & 2.08 & \begin{tabular}{|l|}
8.00 \\
\end{tabular} \\
\hline GpS525 & 0.00 & 0.00 & 6.67 & 1.00 & 43.00 & 1.70 & 8.00 \\
\hline GpS526 & 0 & 0.00 & 2.96 & 1.00 & 46.00 & 3.13 & \begin{tabular}{|l|}
8.00 \\
\end{tabular} \\
\hline GpS527 & 0 & 0.00 & 6.41 & 1.00 & 23.00 & 2.08 & 3.00 \\
\hline GpS528 & 0 & 0.00 & 3.42 & 0.75 & 31.00 & 2.77 & 6.00 \\
\hline GpS529 & 75 & 11.25 & 6.46 & 0.92 & 18.00 & 3.58 & 8.00 \\
\hline GpS530 & 100 & 15.00 & 4.99 & 1.00 & 36.00 & 3.16 & 7.00 \\
\hline GpS531 & 0 & 0.00 & 3.07 & 0.41 & 36.00 & 2.08 & 3.00 \\
\hline GpS532 & 0 & 0.00 & 1.50 & 0.75 & 36.00 & 2.08 & 3.00 \\
\hline
\end{tabular}




\begin{tabular}{|c|c|c|c|c|c|c|c|}
\hline $\begin{array}{l}\text { Reference Site } \\
\text { ID }\end{array}$ & $\begin{array}{l}\text { V Grasscont, } \\
\%\end{array}$ & \begin{tabular}{|l} 
V Grasswidth, \\
m
\end{tabular} & $\begin{array}{l}\text { V Vegcomp, } \\
\text { FQI }\end{array}$ & $\begin{array}{l}\text { V Recharge, } \\
\text { Categorical }\end{array}$ & $\begin{array}{l}\text { V Sed, } \\
\text { cm }\end{array}$ & \begin{tabular}{|l|} 
V Som, \\
mean OC, \%
\end{tabular} & $\begin{array}{l}\text { V SQI, } \\
\text { SQI }\end{array}$ \\
\hline GpS533 & 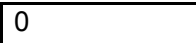 & 0.00 & $\overline{1.23}$ & \begin{tabular}{|l|l}
1.00 \\
\end{tabular} & 34.00 & 3.00 & \begin{tabular}{l|l}
7.00 \\
\end{tabular} \\
\hline GpS534 & 0 & 0.00 & 2.12 & 0.88 & 46.00 & 3.00 & 7.00 \\
\hline GpS535 & 0 & 0.00 & 6.55 & 1.00 & 48.00 & 3.67 & 8.00 \\
\hline GpS536 & 0 & 0.00 & 1.34 & 1.00 & 46.00 & 3.00 & 7.00 \\
\hline GpS537 & 100 & 15.00 & 0.87 & 1.00 & 51.00 & 3.89 & 10.00 \\
\hline GpS538 & 0 & 0.00 & 2.58 & 1.00 & 41.00 & 2.54 & 5.00 \\
\hline GpS539 & 90 & 13.50 & 6.26 & 0.58 & 41.00 & 3.26 & 7.00 \\
\hline GpS540 & 0 & 0.00 & 2.32 & 1.00 & 41.00 & 2.56 & 7.00 \\
\hline GpS541 & 0 & 0.00 & 7.05 & 1.00 & 30.00 & 2.70 & 5.00 \\
\hline GpS542 & 0 & 0.00 & 4.25 & 1.00 & 36.00 & 2.84 & 6.00 \\
\hline GpS543 & 0 & 0.00 & 1.50 & 1.00 & 31.00 & 3.23 & 8.00 \\
\hline GpS544 & 0 & 0.00 & 1.73 & 1.00 & 38.00 & 3.02 & 9.00 \\
\hline GPS545 & 0 & 0.00 & 3.33 & 0.90 & 56.00 & 3.26 & 7.00 \\
\hline GpS546 & 0 & 0.00 & 7.29 & 0.25 & 46.00 & 2.30 & 3.00 \\
\hline GpS547 & 100 & 15.00 & 18.63 & 0.75 & 66.00 & 4.86 & 11.00 \\
\hline GpS548 & 0 & 0.00 & 3.91 & 0.75 & 61.00 & 3.26 & 7.00 \\
\hline GpS549 & 0 & 0.00 & 5.86 & 0.75 & 66.00 & 3.21 & 7.00 \\
\hline McS550 & 100 & 15.00 & 6.95 & 0.10 & 15.00 & 3.39 & 11.00 \\
\hline McS551 & 100 & 15.00 & 5.67 & 0.10 & 5.00 & 2.76 & 11.00 \\
\hline McS552 & 0 & 0.00 & 2.28 & 0.17 & 36.00 & 2.34 & 7.00 \\
\hline GpS553 & 100 & 15.00 & 6.74 & 0.10 & 8.00 & 3.34 & 11.00 \\
\hline GpS554 & 0 & 0.00 & 4.03 & 0.10 & 23.00 & 2.34 & 7.00 \\
\hline GpS555 & 100 & 15.00 & 12.01 & 0.34 & 41.00 & 4.79 & 11.00 \\
\hline GpS556 & 100 & 15.00 & 4.81 & 0.75 & 74.00 & 3.23 & 8.00 \\
\hline GpS557 & 100 & 15.00 & 12.57 & 0.75 & 71.00 & 4.79 & 11.00 \\
\hline GpS558 & 0 & 0.00 & 4.53 & 0.53 & 91.00 & 2.20 & 4.00 \\
\hline GpS559 & 0 & 0.00 & 4.32 & 0.75 & 112.00 & 3.00 & 7.00 \\
\hline GpS560 & 100 & 15.00 & 4.48 & 0.75 & 74.00 & 4.68 & 11.00 \\
\hline GpS561 & 0 & 0.00 & 2.69 & 0.32 & 66.00 & 2.08 & 3.00 \\
\hline GpS562 & 0 & 0.00 & 2.12 & 0.50 & 89.00 & 2.08 & 3.00 \\
\hline GpS563 & 100 & 15.00 & 1.50 & 0.92 & 40.00 & 3.33 & 7.00 \\
\hline GpS566 & 100 & 15.00 & 14.21 & 1.00 & 35.00 & 2.03 & 4.00 \\
\hline GpS567 & 100 & 15.00 & 9.22 & 1.00 & 36.00 & 3.56 & 8.00 \\
\hline
\end{tabular}

\section{b. Hydrogeomorphic, land use and landscape variables}

\begin{tabular}{|c|c|c|c|c|c|c|c|c|c|c|}
\hline $\begin{array}{l}\text { Reference } \\
\text { Site ID }\end{array}$ & $\begin{array}{l}V_{\text {out }} \text {, ratio } \\
\text { of } \\
\text { elevations }\end{array}$ & $\begin{array}{l}V_{\text {SUBout }} \\
\text { Categorical }\end{array}$ & $\begin{array}{l}V_{\text {SOURCE }} \\
\text { Categorical }\end{array}$ & $\begin{array}{l}V_{\text {EDGE, }} \\
\text { Edge } \\
\text { Index }\end{array}$ & $\begin{array}{l}V_{\text {CATCHWET, }} \\
\text { Unitless } \\
\text { ratio }\end{array}$ & $\begin{array}{l}V_{\text {UPUSE, }} \\
\text { wt } \\
\text { score }\end{array}$ & $\begin{array}{l}V_{\text {WETPROX, }} \\
\mathrm{m}\end{array}$ & $\begin{array}{l}V_{\text {WETAREA }} \\
\text { ha/LAA }\end{array}$ & $\begin{array}{l}V_{\text {BASINS }} \\
\text { \#Basins/LAA }\end{array}$ & $\begin{array}{l}V_{\text {HABFRAG, }} \\
\text { km/LAA }\end{array}$ \\
\hline Gp01154 & 0.00 & 1.00 & 1.00 & 1.35 & 15.00 & 70.80 & 412.73 & 157.17 & 106.00 & 7.89 \\
\hline Gp01156 & 1.00 & 1.00 & 1.00 & 1.23 & 3.52 & 69.00 & 254.16 & 65.95 & 130.00 & 18.90 \\
\hline Gp01158 & 1.00 & 1.00 & 1.00 & 1.29 & 2.61 & 69.00 & 115.72 & 55.47 & 246.00 & 9.65 \\
\hline Gp01160 & 1.00 & 1.00 & 1.00 & 1.16 & 3.13 & 69.00 & 144.91 & 152.18 & 160.00 & 10.94 \\
\hline Gp01162 & 1.00 & 1.00 & 1.00 & 1 & 1 & 69.00 & 139.86 & 133.83 & 108.00 & 4.63 \\
\hline Gp02173 & 0.05 & 1.00 & 1.00 & 1.56 & 5.93 & 69.00 & 375.54 & 201.29 & 32.00 & 12.34 \\
\hline Gp02174 & 1.00 & 1.00 & 1.00 & 1.09 & 4.45 & 69.00 & 179.24 & 131.23 & 30.00 & 9.59 \\
\hline Gp02175 & 1.00 & 1.00 & 1.00 & 1.22 & 2.28 & 61.00 & 147.30 & 135.85 & 65.00 & 9.44 \\
\hline
\end{tabular}




\begin{tabular}{|c|c|c|c|c|c|c|c|c|c|c|}
\hline $\begin{array}{l}\text { Reference } \\
\text { Site ID }\end{array}$ & $\begin{array}{l}V_{\text {out }} \text {, ratio } \\
\text { of } \\
\text { elevations }\end{array}$ & \begin{tabular}{|l} 
V SuBout, \\
Categorical
\end{tabular} & $\begin{array}{l}\text { V SouRCE, } \\
\text { Categorical }\end{array}$ & \begin{tabular}{|l}
$V_{E D G E}$ \\
Edge \\
Index
\end{tabular} & \begin{tabular}{|l}
$V_{\text {CATCHWET, }}$ \\
Unitless \\
ratio
\end{tabular} & \begin{tabular}{|l|}
$V_{\text {UPUSE, }}$ \\
wt \\
score
\end{tabular} & $\begin{array}{l}V_{\text {WETPROX, }} \\
\mathrm{m}\end{array}$ & $\begin{array}{l}V_{\text {WETAREA, }} \\
\text { ha/LAA }\end{array}$ & $\begin{array}{l}V_{\text {BASINS, }} \\
\text { \#Basins/LAA }\end{array}$ & $\begin{array}{l}V_{\text {HABFRAG, }} \\
\mathrm{km} / \mathrm{LAA}\end{array}$ \\
\hline Gp02177 & 1.00 & 1.00 & 1.00 & 1.20 & $\begin{array}{ll}3.75 \\
\end{array}$ & 61.00 & \begin{tabular}{|l|l}
126.75 \\
\end{tabular} & 136.03 & 65.00 & 9.41 \\
\hline Gp02179 & 1.00 & 1.00 & 1.00 & 1.08 & 2.39 & 69.00 & 173.58 & 70.91 & 37.00 & 9.13 \\
\hline Gp03069 & 1.00 & 1.00 & 1.00 & 1.23 & 2.92 & 69.00 & 109.99 & 148.99 & 188.00 & 10.81 \\
\hline Gp03070 & 1.00 & 1.00 & 1.00 & 1.20 & 4.95 & 69.00 & 216.73 & 134.46 & 145.00 & 13.35 \\
\hline Gp03071 & 1.00 & 1.00 & 1.00 & 1.21 & 1.98 & 69.00 & 143.76 & 141.49 & 178.00 & 10.79 \\
\hline Gp03107 & 0.00 & 1.00 & 1.00 & 1.17 & 3.24 & 69.00 & 119.25 & 150.29 & 318.00 & 11.95 \\
\hline Gp04123 & 0.64 & 1.00 & 1.00 & 1.61 & 3.14 & 69.00 & 150.92 & 66.75 & \begin{tabular}{|l|}
174.00 \\
\end{tabular} & 12.25 \\
\hline Gp04125 & 1.00 & 1.00 & 1.00 & 1.44 & 3.96 & 69.00 & 181.53 & 67.34 & 262.00 & 12.30 \\
\hline Gp04126 & 1.00 & 1.00 & 1.00 & 1.17 & 4.31 & 72.00 & 135.09 & 68.27 & 251.00 & 12.57 \\
\hline Gp04129 & 1.00 & 1.00 & 1.00 & 1.29 & 5.53 & 69.00 & 114.51 & 192.71 & 89.00 & 12.82 \\
\hline Gp04139 & 1.00 & 1.00 & 1.00 & 1.91 & 2.53 & 68.70 & 215.42 & 65.64 & 249.00 & 14.11 \\
\hline Gp05089 & 0.00 & 1.00 & 1.00 & 1.30 & 1.93 & 69.80 & 181.44 & 185.07 & 139.00 & 12.74 \\
\hline Gp05091 & 1.00 & 1.00 & 1.00 & 0.00 & 1.86 & 69.00 & 103.12 & 172.24 & 132.00 & 7.28 \\
\hline Gp05092 & 1.00 & 1.00 & 1.00 & 1.53 & 4.03 & 69.00 & 208.36 & 104.88 & 159.00 & 9.28 \\
\hline Gp05093 & 1.00 & 1.00 & 1.00 & 1.14 & 4.88 & 69.00 & 95.65 & 230.36 & 136.00 & 7.11 \\
\hline Gp05095 & 1.00 & 1.00 & 1.00 & 1.17 & 2.65 & 69.00 & 122.97 & 161.92 & 132.00 & 6.30 \\
\hline Gp06117 & 1.00 & 1.00 & 1.00 & 1.09 & 4.57 & 69.00 & 370.07 & 111.88 & 115.00 & 12.01 \\
\hline Gp06118 & 0.00 & 1.00 & 1.00 & 1.14 & 6.17 & 69.00 & 129.54 & \begin{tabular}{|l|l|}
73.56 \\
\end{tabular} & 106.00 & 12.24 \\
\hline Gp06119 & 1.00 & 1.00 & 1.00 & 1.12 & 4.09 & 69.00 & 195.19 & 41.94 & 43.00 & 12.73 \\
\hline Gp06121 & 1.00 & 1.00 & 1.00 & 1.19 & 2.52 & 69.00 & 157.89 & 86.71 & 102.00 & 13.39 \\
\hline Gp06127 & 1.00 & 1.00 & 1.00 & 1.46 & 4.54 & 69.00 & 93.62 & 32.33 & 113.00 & 13.40 \\
\hline Gp07073 & 1.00 & 1.00 & 1.00 & 1.12 & 2.72 & 69.00 & 107.02 & 130.98 & 190.00 & 13.27 \\
\hline Gp07075 & 1.00 & 1.00 & 1.00 & 1.23 & 3.62 & 69.00 & 132.60 & \begin{tabular}{|l|}
158.77 \\
\end{tabular} & 331.00 & 12.62 \\
\hline Gp07077 & 0.23 & 1.00 & 1.00 & 1.37 & 2.98 & 69.00 & 122.85 & 154.87 & 321.00 & 12.02 \\
\hline Gp07078 & 1.00 & 1.00 & 1.00 & 1.18 & 4.18 & 69.00 & 62.31 & 169.38 & 365.00 & 12.84 \\
\hline Gp08040 & 0.35 & 1.00 & 1.00 & 1.44 & 2.85 & 69.00 & 83.39 & \begin{tabular}{|l|}
91.03 \\
\end{tabular} & 355.00 & 13.43 \\
\hline Gp08041 & 1.00 & 1.00 & 1.00 & 1.10 & 2.55 & 69.00 & 222.81 & \begin{tabular}{|l|}
104.49 \\
\end{tabular} & 109.00 & 13.23 \\
\hline Gp08044 & 1.00 & 1.00 & 1.00 & 1.12 & 3.02 & 68.80 & 197.04 & 139.05 & 90.00 & 6.46 \\
\hline Gp08045 & 1.00 & 1.00 & 1.00 & 1.20 & 3.09 & 69.00 & 140.87 & 143.95 & 83.00 & 9.36 \\
\hline Gp08047 & 1.00 & 1.00 & 1.00 & 1.13 & 1.94 & 61.00 & 84.18 & 113.83 & 218.00 & 16.02 \\
\hline Gp09028 & 0.80 & 1.00 & 1.00 & 1.14 & 2.44 & 69.00 & 4771.71 & 4.07 & 8.00 & 111.51 \\
\hline Gp09030 & 1.00 & 1.00 & 1.00 & 1.17 & 1.72 & 69.00 & 628.83 & 4.89 & 9.00 & 10.53 \\
\hline Gp09031 & 1.00 & 1.00 & 1.00 & 1.11 & 1.81 & 69.00 & 475.91 & 11.13 & 65.00 & 12.63 \\
\hline Gp09033 & 1.00 & 1.00 & 1.00 & 1.04 & 1.07 & 69.00 & 291.59 & 112.44 & 38.00 & 9.31 \\
\hline Gp09035 & 1.00 & 1.00 & 1.00 & 1.10 & 1.34 & 69.00 & 224.26 & 162.45 & 88.00 & 10.91 \\
\hline Gp09037 & 1.00 & 1.00 & 1.00 & 1.24 & 3.42 & 69.00 & 862.37 & 62.04 & 15.00 & 14.96 \\
\hline Gp10019 & 0.51 & 1.00 & 1.00 & 1.28 & 3.92 & 69.00 & 169.62 & 27.58 & 23.00 & 13.05 \\
\hline Gp10021 & 1.00 & 1.00 & 1.00 & 1.10 & 1.32 & 70.00 & 145.12 & 28.40 & 25.00 & 9.22 \\
\hline Gp10024 & 1.00 & 1.00 & 1.00 & 1.21 & 2.45 & 69.00 & 121.49 & 85.15 & 37.00 & 8.46 \\
\hline Gp10026 & 1.00 & 1.00 & 1.00 & 1.54 & 2.51 & 69.00 & 217.33 & 156.91 & 62.00 & 12.64 \\
\hline Gp11006 & 1.00 & 1.00 & 1.00 & 1 & 1 & 69.00 & 113.56 & \begin{tabular}{|l|}
37.82 \\
\end{tabular} & 15.00 & 15.43 \\
\hline Gp11011 & 1.00 & 1.00 & 1.00 & 1 & 1 & 69.00 & 113.56 & 38.05 & 17.00 & 17.54 \\
\hline Gp11014 & 1.00 & 1.00 & 1.00 & 1.25 & 1.92 & 69.00 & 737.47 & 10.20 & 6.00 & 11.37 \\
\hline Gp11015 & 1 & 1.00 & 1.00 & 1.45 & 3.48 & 69.00 & 662.84 & 45.23 & 11.00 & 9.59 \\
\hline Gp11016 & 1.00 & 1.00 & 1.00 & 1.43 & 1.72 & 69.00 & 295.12 & 142.63 & 69.00 & 10.55 \\
\hline Gp11017 & 1.00 & 1.00 & 1.00 & 1.23 & 2.26 & 69.00 & 486.28 & \begin{tabular}{|l|}
108.48 \\
\end{tabular} & 59.00 & 17.31 \\
\hline Gp12001 & 1 & 1.00 & 1.00 & 1.08 & 5.79 & 69.00 & 266.31 & 17.02 & 55.00 & 11.19 \\
\hline
\end{tabular}




\begin{tabular}{|c|c|c|c|c|c|c|c|c|c|c|}
\hline $\begin{array}{l}\text { Reference } \\
\text { Site ID }\end{array}$ & $\begin{array}{l}V_{\text {out }} \text {, ratio } \\
\text { of } \\
\text { elevations }\end{array}$ & $\begin{array}{l}V_{\text {subout }} \\
\text { Categorical }\end{array}$ & $\begin{array}{l}\text { V } \text { SOURCE, } \\
\text { Categorical }\end{array}$ & \begin{tabular}{|l}
$V_{E D G E}$, \\
Edge \\
Index
\end{tabular} & $\begin{array}{l}V_{\text {CATCHWET, }} \\
\text { Unitless } \\
\text { ratio }\end{array}$ & $\begin{array}{l}V_{\text {UPUSE, }} \\
\text { wt } \\
\text { score }\end{array}$ & $\begin{array}{l}V_{\text {WETPROX, }} \\
\mathrm{m}\end{array}$ & $\begin{array}{l}V_{\text {WETAREA }} \\
\text { ha/LAA }\end{array}$ & $\begin{array}{l}V_{\text {BASINS, }} \\
\text { \#Basins/LAA }\end{array}$ & $\begin{array}{l}V_{\text {HABFRAG, }} \\
\text { km/LAA }\end{array}$ \\
\hline Gp12004 & 1.00 & 1.00 & 1.00 & 1.28 & $\mid 1.58$ & 69.00 & 691.76 & 337.53 & 24.00 & $\mid 11.47$ \\
\hline Gp12008 & 1.00 & 1.00 & 1.00 & 1.27 & 1.03 & 69.00 & 57.60 & 351.72 & 39.00 & 12.23 \\
\hline Gp12009 & 1.00 & 1.00 & 1.00 & 1.18 & 2.52 & 69.00 & 321.14 & 11.64 & 58.00 & 11.81 \\
\hline Mc01200 & 1.00 & 1.00 & 1.00 & 1.20 & 9.04 & 69.00 & 162.13 & 46.40 & 151.00 & 6.32 \\
\hline Mc01202 & 0.44 & 1.00 & 1.00 & 1.23 & 5.27 & 69.00 & 282.34 & 110.20 & 78.00 & 7.99 \\
\hline Mc01204 & 1.00 & 1.00 & 1.00 & 1.27 & 8.22 & 69.00 & 162.57 & 55.94 & 90.00 & 2.48 \\
\hline Mc01205 & 1.00 & 1.00 & 1.00 & 1.12 & 13.71 & 69.00 & 318.24 & 54.27 & 88.00 & 1.85 \\
\hline Mc01207 & 1.00 & 1.00 & 1.00 & 1.28 & 3.79 & 69.00 & 455.49 & 25.41 & 20.00 & 6.82 \\
\hline Mc02190 & 1.00 & 1.00 & 1.00 & 1.47 & 10.05 & 62.20 & 109.54 & 109.72 & 236.00 & 6.72 \\
\hline Mc02192 & 0.00 & 1.00 & 1.00 & 1.40 & 4.47 & 69.00 & 101.96 & 120.34 & 190.00 & 9.33 \\
\hline Mc02193 & 1.00 & 1.00 & 1.00 & 1.25 & 6.69 & 67.40 & 89.25 & 119.58 & 193.00 & 9.71 \\
\hline Mc02194 & 1.00 & 1.00 & 1.00 & 1.16 & 3.05 & 62.20 & 179.12 & 115.15 & 222.00 & 8.90 \\
\hline Mc02196 & 0.29 & 1.00 & 1.00 & 1.19 & 5.27 & 69.00 & 273.20 & 243.56 & 30.00 & 4.60 \\
\hline Mc02198 & 1.00 & 1.00 & 1.00 & 1.33 & 4.74 & 69.00 & 125.33 & 73.34 & 109.00 & 11.42 \\
\hline Mc03184 & 1.00 & 1.00 & 1.00 & 1.30 & 5.19 & 69.00 & 117.86 & 92.35 & 219.00 & 9.07 \\
\hline Mc03185 & 1.00 & 1.00 & 1.00 & 1.14 & 8.96 & 69.00 & 169.05 & 75.57 & 153.00 & 5.36 \\
\hline Mc03187 & 1.00 & 1.00 & 1.00 & 1.18 & 4.00 & 69.00 & 139.15 & 71.24 & 194.00 & 6.97 \\
\hline Mc03189 & 1.00 & 1.00 & 1.00 & 1.08 & 4.96 & 69.00 & 267.42 & 63.29 & 57.00 & 7.66 \\
\hline Mc04164 & 0.22 & 1.00 & 1.00 & 1.06 & 5.50 & 69.00 & 281.40 & 48.09 & 106.00 & 11.69 \\
\hline Mc04165 & 1.00 & 1.00 & 1.00 & 1.24 & 5.15 & 69.00 & 73.24 & 73.90 & 162.00 & 8.85 \\
\hline Mc04166 & 1.00 & 1.00 & 1.00 & 1.12 & 3.19 & 69.00 & 251.93 & 79.26 & 104.00 & 13.14 \\
\hline Mc04169 & 1.00 & 1.00 & 1.00 & 1.17 & 2.55 & 69.00 & 201.51 & 101.78 & 107.00 & 15.62 \\
\hline Mc04171 & 1.00 & 1.00 & 1.00 & 1.29 & 6.39 & 69.00 & 143.91 & 125.24 & 134.00 & 20.25 \\
\hline Mc05142 & 1.00 & 1.00 & 1.00 & 1.43 & 2.67 & 69.00 & 305.51 & 50.40 & 137.00 & 3.28 \\
\hline Mc05143 & 1.00 & 1.00 & 1.00 & 1.20 & 4.36 & 69.00 & 148.13 & 54.23 & 156.00 & 3.35 \\
\hline Mc05144 & 1.00 & 1.00 & 1.00 & 1.58 & 2.56 & 69.00 & 166.42 & 93.24 & 179.00 & 5.30 \\
\hline Mc05146 & 0.00 & 1.00 & 1.00 & 1.39 & 9.03 & 69.00 & 230.38 & 90.82 & 166.00 & 6.51 \\
\hline Mc05149 & 1.00 & 1.00 & 1.00 & 1.12 & 5.66 & 69.00 & 239.45 & 85.73 & 166.00 & 6.19 \\
\hline Mc06131 & 1.00 & 1.00 & 1.00 & 1.20 & 5.08 & 69.00 & 129.51 & 108.26 & 100.00 & 2.76 \\
\hline Mc06132 & 1.00 & 1.00 & 1.00 & 1.42 & 2.82 & 69.00 & 113.73 & 107.12 & 100.00 & 2.59 \\
\hline Mc06133 & 1.00 & 1.00 & 1.00 & 1.09 & 3.51 & 69.00 & 140.15 & 107.24 & 214.00 & 2.94 \\
\hline Mc06134 & 1.00 & 1.00 & 1.00 & 1.04 & 2.79 & 69.00 & 133.52 & 105.17 & 217.00 & 3.37 \\
\hline Mc06135 & 1.00 & 1.00 & 1.00 & 1.23 & 3.33 & 69.00 & 290.27 & 55.25 & 90.00 & 8.90 \\
\hline Mc06136 & 1.00 & 1.00 & 1.00 & 1.59 & 2.31 & 69.50 & 308.78 & 43.01 & 93.00 & 8.70 \\
\hline Mc07137 & 1.00 & 1.00 & 1.00 & 1.11 & 3.12 & 69.00 & 152.68 & 55.05 & 162.00 & 2.74 \\
\hline Mc07138 & 1.00 & 1.00 & 1.00 & 1.46 & 4.00 & 69.00 & 295.98 & 82.86 & 162.00 & 1.11 \\
\hline Mc08097 & 0.00 & 1.00 & 1.00 & 1.23 & 9.96 & 69.00 & 273.90 & 111.50 & 92.00 & 13.33 \\
\hline Mc08098 & 1.00 & 1.00 & 1.00 & 1.10 & 2.93 & 70.00 & 149.06 & 39.96 & 44.00 & 4.58 \\
\hline Mc08102 & 1.00 & 1.00 & 1.00 & 1.14 & 2.20 & 69.00 & 210.69 & 81.79 & 52.00 & 3.04 \\
\hline Mc08103 & 1.00 & 1.00 & 1.00 & 1 & 1 & 69.00 & 68.58 & 194.55 & 212.00 & 7.20 \\
\hline Mc09108 & 0.00 & 1.00 & 1.00 & 1.20 & 4.70 & 69.00 & 208.25 & 57.34 & 97.00 & 17.61 \\
\hline Mc09110 & 1.00 & 1.00 & 1.00 & 1.24 & 2.87 & 69.00 & 271.60 & 50.13 & 81.00 & 19.55 \\
\hline Mc09111 & 1.00 & 1.00 & 1.00 & 1.41 & 9.52 & 69.00 & 163.39 & 53.66 & 104.00 & 18.10 \\
\hline Mc09113 & 1.00 & 1.00 & 1.00 & 1.52 & 2.55 & 69.00 & 352.13 & 107.39 & 69.00 & 12.48 \\
\hline Mc09115 & 1.00 & 1.00 & 1.00 & 1.50 & 3.12 & 69.00 & 142.03 & 138.13 & 94.00 & 3.10 \\
\hline Pc01049 & 1.00 & 1.00 & 1.00 & 1.35 & 3.74 & 72.00 & 260.13 & 89.51 & 69.00 & 15.89 \\
\hline Pc01052 & 0.00 & 1.00 & 1.00 & 1.13 & 2.56 & 72.00 & 242.73 & 147.30 & 99.00 & 8.14 \\
\hline
\end{tabular}




\begin{tabular}{|c|c|c|c|c|c|c|c|c|c|c|}
\hline $\begin{array}{l}\text { Reference } \\
\text { Site ID }\end{array}$ & $\begin{array}{l}V_{\text {out }} \text {, ratio } \\
\text { of } \\
\text { elevations }\end{array}$ & $\begin{array}{l}\text { V suBout, } \\
\text { Categorical }\end{array}$ & $\begin{array}{l}\text { V souRcE, } \\
\text { Categorical }\end{array}$ & \begin{tabular}{|l}
$V_{E D G E}$ \\
Edge \\
Index \\
\end{tabular} & \begin{tabular}{|l}
$V_{\text {CATCHWET, }}$ \\
Unitless \\
ratio
\end{tabular} & \begin{tabular}{|l}
$V_{\text {UPUSE, }}$ \\
wt \\
score
\end{tabular} & $\begin{array}{l}V_{\text {WETPROX }} \\
\mathbf{m}\end{array}$ & $\begin{array}{l}V_{\text {WETAREA, }} \\
\text { ha/LAA }\end{array}$ & $\begin{array}{l}V_{\text {BASINS, }} \\
\text { \#Basins/LAA }\end{array}$ & $\begin{array}{l}V_{\text {HABFRAG, }} \\
\text { km/LAA }\end{array}$ \\
\hline Pc01053 & $\overline{1.00}$ & 1.00 & 11.00 & $\overline{c 1.17}$ & 2.02 & 69.00 & \begin{tabular}{|l|l}
142.40 \\
\end{tabular} & 56.70 & 331.00 & 7.60 \\
\hline Pc01054 & 1.00 & 1.00 & 1.00 & 1.69 & $\begin{array}{ll}3.08 \\
\end{array}$ & 69.00 & 184.92 & 51.71 & 293.00 & 7.77 \\
\hline Pc01057 & 1.00 & 1.00 & 1.00 & 1.21 & 2.74 & 69.00 & 92.81 & 200.95 & 129.00 & 2.33 \\
\hline Pc02059 & 0.00 & 1.00 & 1.00 & 1.18 & 3.03 & 69.00 & 244.87 & \begin{tabular}{|l|}
68.72 \\
\end{tabular} & 95.00 & 10.73 \\
\hline Pc02061 & 1.00 & 1.00 & 1.00 & 1.07 & 4.88 & 69.00 & 183.83 & \begin{tabular}{|l|l}
104.34 \\
\end{tabular} & 60.00 & 10.99 \\
\hline Pc02063 & 1.00 & 1.00 & 1.00 & 1.23 & 1.75 & 69.00 & 280.52 & 67.86 & 97.00 & 10.73 \\
\hline Pc02065 & 1.00 & \begin{tabular}{|l|}
1.00 \\
\end{tabular} & \begin{tabular}{|l|}
1.00 \\
\end{tabular} & 1.07 & 2.97 & 63.80 & 164.92 & \begin{tabular}{|l|}
95.63 \\
\end{tabular} & 108.00 & \begin{tabular}{|l|}
10.56 \\
\end{tabular} \\
\hline Pc02067 & 1.00 & 1.00 & 1.00 & 1.18 & 5.37 & 69.00 & \begin{tabular}{|l|}
198.09 \\
\end{tabular} & 242.74 & 54.00 & 3.77 \\
\hline Pc03079 & 0.00 & 1.00 & 1.00 & 1.44 & 4.39 & 69.00 & 293.14 & 85.21 & 38.00 & 14.70 \\
\hline Pc03081 & 1.00 & 1.00 & 1.00 & 1.10 & 4.21 & 69.00 & 204.01 & 38.61 & 32.00 & 10.07 \\
\hline Pc03083 & 1.00 & 1.00 & 1.00 & 1.37 & 2.15 & 61.00 & \begin{tabular}{|l|}
273.39 \\
\end{tabular} & 139.04 & 54.00 & \begin{tabular}{|l|}
11.58 \\
\end{tabular} \\
\hline Pc03085 & 1.00 & 1.00 & 1.00 & 1.08 & 3.42 & 69.00 & 180.06 & 190.34 & 47.00 & 13.57 \\
\hline Pc03087 & 1.00 & 1.00 & 1.00 & 1.32 & 2.09 & 69.00 & 69.87 & 147.66 & \begin{tabular}{|l|}
173.00 \\
\end{tabular} & 6.87 \\
\hline GpS501 & 1.00 & 1.00 & 0.75 & 1.36 & 1 & 65.40 & 154.45 & 59.10 & 89.00 & 12.27 \\
\hline GpS502 & 1.00 & 1.00 & 0.50 & 1.12 & 17.70 & 71.86 & 155.37 & \begin{tabular}{|l|}
94.59 \\
\end{tabular} & 109.00 & 14.31 \\
\hline GpS503 & 1.00 & 1.00 & 0.75 & 1.12 & 9.03 & 75.18 & 179.41 & 91.34 & \begin{tabular}{|l|l}
103.00 \\
\end{tabular} & 14.32 \\
\hline McS504 & 1.00 & 1.00 & 0.75 & 1.21 & 1 & 60.96 & 134.13 & 129.85 & 125.00 & 5.35 \\
\hline McS505 & 1.00 & 1.00 & 1.00 & 1.14 & 1 & 60.85 & 90.80 & 124.76 & 125.00 & 6.16 \\
\hline McS506 & 1.00 & 1.00 & 1.00 & 1.08 & 1 & 60.77 & 106.06 & 115.97 & 135.00 & 6.15 \\
\hline McS507 & 1.00 & \begin{tabular}{|l|}
1.00 \\
\end{tabular} & \begin{tabular}{|l|}
1.00 \\
\end{tabular} & 1.19 & 1 & 61.19 & 124.40 & \begin{tabular}{|l}
115.13 \\
\end{tabular} & 137.00 & 5.97 \\
\hline McS508 & 1.00 & 1.00 & 1.00 & 1.21 & 8.95 & 72.46 & 155.22 & 140.33 & 151.00 & 4.48 \\
\hline McS509 & 0.47 & \begin{tabular}{|l|}
0.25 \\
\end{tabular} & \begin{tabular}{|l|}
0.10 \\
\end{tabular} & 1.11 & 1 & 74.11 & \begin{tabular}{|l|}
97.12 \\
\end{tabular} & 153.80 & 136.00 & 7.28 \\
\hline McS510 & 0.00 & 0.10 & \begin{tabular}{|l|}
0.10 \\
\end{tabular} & 1.07 & 1 & \begin{tabular}{|l|}
78.07 \\
\end{tabular} & 195.69 & \begin{tabular}{|l|}
95.03 \\
\end{tabular} & 116.00 & $\begin{array}{l}7.65 \\
\end{array}$ \\
\hline McS511 & 0.61 & \begin{tabular}{|l|}
0.25 \\
\end{tabular} & \begin{tabular}{|l|}
0.50 \\
\end{tabular} & 1.07 & 1 & \begin{tabular}{|l|l|}
77.93 \\
\end{tabular} & 148.77 & \begin{tabular}{|l|}
90.67 \\
\end{tabular} & 119.00 & 8.24 \\
\hline GpS512 & 1.00 & 1.00 & 0.10 & 1.13 & \begin{tabular}{|l|}
11.79 \\
\end{tabular} & 75.38 & \begin{tabular}{|l|}
83.14 \\
\end{tabular} & 30.46 & 75.00 & 12.58 \\
\hline GpS513 & 1.00 & 0.25 & 0.10 & 1.18 & 1 & 78.22 & 121.58 & 29.66 & \begin{tabular}{|l|}
70.00 \\
\end{tabular} & 111.96 \\
\hline GpS514 & 0.60 & 0.25 & 0.10 & 1.12 & 1 & 77.61 & \begin{tabular}{|l|l}
197.53 \\
\end{tabular} & 19.99 & 49.00 & 6.30 \\
\hline GpS515 & 1.00 & \begin{tabular}{|l|}
1.00 \\
\end{tabular} & 0.50 & 0.59 & 1 & \begin{tabular}{|l|}
76.18 \\
\end{tabular} & 146.44 & \begin{tabular}{|l|}
17.96 \\
\end{tabular} & \begin{tabular}{|l|}
47.00 \\
\end{tabular} & 6.23 \\
\hline GpS516 & 1.00 & 0.50 & 0.50 & 0.98 & 1 & 78.82 & 107.47 & 15.95 & 41.00 & 7.03 \\
\hline GpS517 & 1.00 & 0.75 & 0.50 & 1.59 & 1 & 74.98 & 306.60 & 15.60 & 72.00 & 19.90 \\
\hline GpS518 & 1.00 & 1.00 & 1.00 & 1.32 & 6.18 & 61.02 & 267.73 & 57.06 & 131.00 & 1.47 \\
\hline GpS519 & 1.00 & 1.00 & 1.00 & 1.44 & 5.69 & 61.05 & 150.77 & 61.03 & 142.00 & 1.22 \\
\hline GpS520 & 1.00 & 1.00 & 1.00 & 0.46 & 1 & 61.14 & 134.48 & 36.62 & 124.00 & 14.05 \\
\hline GpS521 & 1.00 & 1.00 & 1.00 & 1.00 & 1 & 61.14 & 134.48 & 36.62 & 124.00 & 14.05 \\
\hline GpS522 & 1.00 & \begin{tabular}{|l|}
1.00 \\
\end{tabular} & \begin{tabular}{|l|}
1.00 \\
\end{tabular} & 0.57 & 1 & 61.34 & \begin{tabular}{|l|}
95.50 \\
\end{tabular} & \begin{tabular}{|l|}
38.58 \\
\end{tabular} & 128.00 & 17.66 \\
\hline GpS523 & 0.67 & 1.00 & 1.00 & 1.15 & 1 & 78.14 & 217.86 & 46.32 & 76.00 & 18.92 \\
\hline GPS524 & 1.00 & \begin{tabular}{|l|}
1.00 \\
\end{tabular} & $\begin{array}{ll}1.00 \\
\end{array}$ & 1.09 & 1 & 76.38 & 225.43 & \begin{tabular}{|l|l|}
47.56 \\
\end{tabular} & 46.00 & 14.54 \\
\hline GpS525 & 0.05 & 1 & 1.00 & 1.06 & 1 & 78.51 & \begin{tabular}{|l|}
162.98 \\
\end{tabular} & \begin{tabular}{|l|}
47.74 \\
\end{tabular} & 46.00 & 14.49 \\
\hline GpS526 & 1.00 & 1.00 & 0.75 & 1 & 5.40 & 76.00 & \begin{tabular}{|l|}
115.11 \\
\end{tabular} & \begin{tabular}{|l|}
143.32 \\
\end{tabular} & 215.00 & 13.90 \\
\hline GpS527 & 0.05 & 1 & 1 & I & 9.40 & 75.00 & 231.47 & \begin{tabular}{|l|}
104.07 \\
\end{tabular} & 194.00 & 13.84 \\
\hline GpS528 & 1.00 & \begin{tabular}{|l|}
1.00 \\
\end{tabular} & 1.00 & 1 & 9.21 & 75.00 & \begin{tabular}{|l|}
92.35 \\
\end{tabular} & 108.50 & 233.00 & 20.19 \\
\hline GpS529 & 1.00 & 1.00 & 0.87 & 1 & 2.66 & 70.50 & 90.69 & \begin{tabular}{|l|}
169.07 \\
\end{tabular} & 217.00 & 14.07 \\
\hline GpS530 & 0.38 & 0.50 & 1.00 & 1 & 4.30 & 69.00 & 272.48 & \begin{tabular}{|l|}
384.61 \\
\end{tabular} & 88.00 & 5.65 \\
\hline GpS531 & 0.07 & 0.00 & 1.00 & 1 & 1 & 75.00 & 188.00 & \begin{tabular}{|l|}
103.49 \\
\end{tabular} & 198.00 & 14.21 \\
\hline GpS532 & 1.00 & 1.00 & 0.75 & 1 & 9.94 & 75.00 & 120.30 & 207.99 & 220.00 & 17.71 \\
\hline GpS533 & 0.00 & 0.00 & 1.00 & 1 & 4.28 & 76.00 & 149.53 & 160.00 & 208.00 & 16.17 \\
\hline GpS534 & 0.27 & 1.00 & 1.00 & 1 & 7.43 & 76.00 & \begin{tabular}{|l|}
124.22 \\
\end{tabular} & 98.20 & 195.00 & 8.63 \\
\hline
\end{tabular}




\begin{tabular}{|c|c|c|c|c|c|c|c|c|c|c|}
\hline $\begin{array}{l}\text { Reference } \\
\text { Site ID }\end{array}$ & $\begin{array}{l}V_{\text {out }} \text {, ratio } \\
\text { of } \\
\text { elevations }\end{array}$ & $\begin{array}{l}V_{\text {SUвоUт, }} \\
\text { Categorical }\end{array}$ & \begin{tabular}{|l}
$V_{\text {SOURCE, }}$ \\
Categorical
\end{tabular} & \begin{tabular}{|l}
$V_{E D G E}$, \\
Edge \\
Index \\
\end{tabular} & \begin{tabular}{|l}
$V_{\text {CATCHWET, }}$ \\
Unitless \\
ratio \\
\end{tabular} & \begin{tabular}{|l}
$V_{\text {UPUSE, }}$ \\
wt \\
score \\
\end{tabular} & $\begin{array}{l}V_{\text {WETPROX }} \\
\mathbf{m}\end{array}$ & $\begin{array}{l}V_{\text {WETAREA }} \\
\text { ha/LAA }\end{array}$ & $\begin{array}{l}V_{\text {BASINS, }} \\
\text { \#Basins/LAA }\end{array}$ & $\begin{array}{l}V_{\text {HABFRAG }} \\
\text { km/LAA }\end{array}$ \\
\hline GpS535 & 1.00 & 1.00 & 1.00 & 1 & 3.60 & 77.00 & 171.18 & 91.33 & 205.00 & 7.19 \\
\hline GpS536 & 0.00 & 0.00 & 1.00 & 1 & 6.41 & 75.00 & 115.70 & 133.06 & 210.00 & 11.85 \\
\hline GpS537 & 1.00 & 1.00 & 1.00 & 1 & 11.14 & 70.50 & 72.99 & 214.73 & 217.00 & 16.75 \\
\hline GpS538 & 0.41 & 0.10 & 1.00 & I & 9.56 & 75.00 & 131.19 & 82.62 & 197.00 & 9.98 \\
\hline GpS539 & 0.11 & 0.10 & 1.00 & I & 10.32 & 72.00 & 171.95 & 199.42 & 123.00 & 9.47 \\
\hline GpS540 & 0.04 & 0.10 & 0.75 & 1 & 7.29 & 75.40 & 251.09 & 40.37 & 144.00 & 17.93 \\
\hline GpS541 & 1.00 & 1.00 & 0.71 & I & 7.26 & 75.00 & 317.56 & 36.76 & 152.00 & 16.28 \\
\hline GpS542 & 0.50 & 0.10 & 1.00 & 1 & 6.75 & 75.40 & 367.23 & 43.57 & 132.00 & 16.97 \\
\hline GpS543 & 0.08 & 1 & 1 & 1 & 7.06 & 75.00 & 466.81 & 36.83 & 161.00 & 17.01 \\
\hline GpS544 & 0.12 & 0.10 & 1.00 & 1 & 13.00 & 75.00 & 421.73 & 37.73 & 155.00 & 16.97 \\
\hline GPS545 & 1.00 & 1.00 & 1.00 & 1 & 9.90 & 75.00 & 190.41 & 40.02 & 117.00 & 12.69 \\
\hline GpS546 & 1.00 & 0.10 & 0.75 & 1 & 3.25 & 79.00 & 377.23 & 42.88 & 15.00 & 12.94 \\
\hline GpS547 & 1.00 & 1.00 & 0.87 & 1 & 9.72 & 69.00 & 282.19 & 30.61 & 32.00 & 22.07 \\
\hline GpS548 & 1.00 & 1.00 & 1.00 & 1 & 7.35 & 79.00 & 378.49 & 35.81 & 53.00 & 18.06 \\
\hline GpS549 & 0.33 & 0.10 & 0.50 & 1 & 2.73 & 79.00 & 321.56 & 219.69 & 44.00 & 20.13 \\
\hline McS550 & 1.00 & 1.00 & 1.00 & 1 & 6.68 & 61.00 & 148.57 & 28.06 & 72.00 & 7.38 \\
\hline McS551 & 1.00 & 1.00 & 1.00 & 1 & 3.10 & 61.00 & 186.25 & 71.53 & 142.00 & 8.44 \\
\hline McS552 & 1.00 & 1.00 & 1.00 & 1 & 10.86 & 75.00 & 176.85 & 68.84 & 165.00 & 4.21 \\
\hline GpS553 & 1.00 & 1.00 & 1.00 & 1 & 3.92 & 72.60 & 235.26 & 32.17 & 42.00 & 6.03 \\
\hline GpS554 & 1.00 & 1.00 & 1.00 & 1 & 10.57 & 75.00 & 235.26 & 32.17 & 42.00 & 6.03 \\
\hline GpS555 & 1.00 & 1.00 & 0.75 & 1 & 4.52 & 69.00 & 118.75 & 142.74 & 50.00 & 13.48 \\
\hline GpS556 & 1.00 & 1.00 & 1.00 & 1 & 4.61 & 70.00 & 190.80 & 135.96 & 76.00 & 15.77 \\
\hline GpS557 & 1.00 & 1.00 & 1.00 & 1 & 3.85 & 72.00 & 126.46 & 141.41 & 78.00 & 16.20 \\
\hline GpS558 & 0.18 & 0.10 & 0.60 & 1 & 1 & 79.00 & 189.27 & 18.82 & 30.00 & 13.41 \\
\hline GpS559 & 0.34 & 0.25 & 1.00 & 1 & 2.92 & 79.00 & 318.86 & 19.36 & 31.00 & 14.27 \\
\hline GpS560 & 1.00 & 1.00 & 1.00 & 1 & 6.81 & 67.60 & 347.25 & 41.59 & 49.00 & 9.01 \\
\hline GpS561 & 1.00 & 0.24 & 1.00 & 1 & 1.75 & 75.10 & 130.52 & 5.04 & 31.00 & 16.95 \\
\hline GpS562 & 0.29 & 0.00 & 1.00 & 1 & 17.60 & 79.00 & 590.06 & 3.64 & 20.00 & 12.97 \\
\hline GpS563 & 1.00 & 1.00 & 1.00 & 1 & 5.50 & 69.00 & 146.55 & 162.59 & 90.00 & 10.38 \\
\hline GpS566 & 1.00 & 1.00 & 1.00 & 1 & 9.88 & 61.00 & 92.60 & 80.53 & 235.00 & 6.97 \\
\hline GpS567 & 1.00 & 1.00 & 1.00 & 1 & 9.63 & 61.00 & 101.06 & 84.49 & 231.00 & 6.96 \\
\hline
\end{tabular}




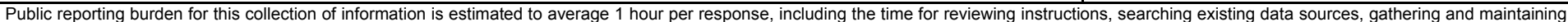

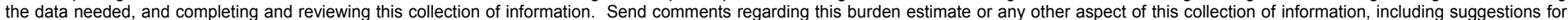

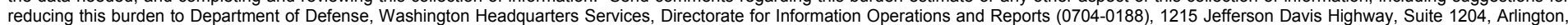

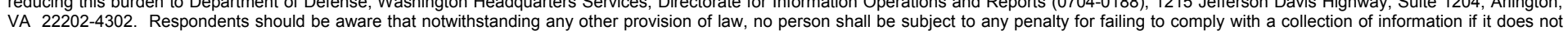
VA 22202-4302. Respondents should be aware that notwithstanding any other provision of law, no person shall be sube
display a currently valid OMB control number. PLEASE DO NOT RETURN YOUR FORM TO THE ABOVE ADDRESS.

\begin{tabular}{l|c}
$\begin{array}{l}\text { 1. REPORT DATE (DD-MM-YYYY) } \\
\text { May } 2006\end{array}$ & $\begin{array}{c}\text { 2. REPORT TYPE } \\
\text { Final report }\end{array}$ \\
\hline
\end{tabular}

\section{TITLE AND SUBTITLE}

A Regional Guidebook for Applying the Hydrogeomorphic Approach to Assessing

Wetland Functions of Prairie Potholes

\section{DATES COVERED (From - To)}

\section{5a. CONTRACT NUMBER}

5b. GRANT NUMBER

5c. PROGRAM ELEMENT NUMBER

\section{AUTHOR(S)}

Michael C. Gilbert, P. Michael Whited, Ellis J. Clairain, Jr., and R. Daniel Smith

\section{5d. PROJECT NUMBER}

5e. TASK NUMBER

\section{5f. WORK UNIT NUMBER}

\section{PERFORMING ORGANIZATION NAME(S) AND ADDRESS(ES)}

Environmental Laboratory, U.S. Army Engineer Research and Development Center, 3909 Halls Ferry Road, Vicksburg, MS 39180-6199;

U.S. Army Engineer District, Omaha, 106 S. 15th Street, Omaha, NE 68102;

National Resource Conservation Service, U.S. Department of Agriculture, 52 Boyden Road, Holden, MA 01520

\section{SPONSORING / MONITORING AGENCY NAME(S) AND ADDRESS(ES)}

U.S. Army Corps of Engineers

Washington, DC 20314-1000

\section{DISTRIBUTION / AVAILABILITY STATEMENT}

Approved for public release; distribution is unlimited.

\section{SUPPLEMENTARY NOTES}

\section{ABSTRACT}

The Hydrogeomorphic (HGM) Approach is a method for developing functional indices and the protocols used to apply these indices to the assessment of wetland functions at a site-specific scale. The HGM Approach was initially designed to be used in the context of the Clean Water Act, Section 404 Regulatory Program, permit review to analyze project alternatives, minimize impacts, assess unavoidable impacts, determine mitigation requirements, and monitor the success of compensatory mitigation. However, a variety of other potential uses have been identified, including the determination of minimal effects under the Food Security Act, design of wetland restoration projects, and management of wetlands.

This report uses the HGM Approach to develop a Regional Guidebook to (a) characterize ponded, herbaceous marshes of the glaciated Prairie Pothole Region, (b) provide the rationale used to select functions of the ponded, herbaceous depressional marsh subclass, (c) provide the rationale used to select model variables and metrics, (d) provide the rationale used to develop assessment models, (e) provide data from reference wetlands and document its use in calibrating model variables and assessment models, and (f) outline the necessary protocols for applying the functional indices to the assessment of wetland functions.

\section{SUBJECT TERMS}

See reverse.

16. SECURITY CLASSIFICATION OF:

\section{a. REPORT}

UNCLASSIFIED

b. ABSTRACT
UNCLASSIFIED

c. THIS PAGE UNCLASSIFIED

\begin{tabular}{l|c|} 
17. LIMITATION & $\begin{array}{c}\text { 18. NUMBER } \\
\text { OF ABSTRACT }\end{array}$ \\
OF PAGES \\
170
\end{tabular}

19a. NAME OF RESPONSIBLE PERSON

19b. TELEPHONE NUMBER (include area code) 


\section{SUBJECT TERMS}

404 Regulatory Program

Assessment

Classification

Clean Water Act

Depression

Ecosystem

Evaluation

Function
Functional assessment

Functional profile

Geomorphology

Hydrogeomorphic (HGM) Approach

Hydrology

Impact analysis

Index

Indicators
Landscape

Mitigation

Model

Prairie Pothole

Reference wetlands

Restoration

Value

Wetland 